\title{
Effects of impaired vitamin K-dependent protein carboxylation
}

Citation for published version (APA):

Spronk, H. M. H. (2003). Effects of impaired vitamin K-dependent protein carboxylation. [Doctoral Thesis, Maastricht University]. Universiteit Maastricht. https://doi.org/10.26481/dis.20030620hs

Document status and date:

Published: 01/01/2003

DOI:

10.26481/dis.20030620hs

Document Version:

Publisher's PDF, also known as Version of record

\section{Please check the document version of this publication:}

- A submitted manuscript is the version of the article upon submission and before peer-review. There can be important differences between the submitted version and the official published version of record.

People interested in the research are advised to contact the author for the final version of the publication, or visit the DOI to the publisher's website.

- The final author version and the galley proof are versions of the publication after peer review.

- The final published version features the final layout of the paper including the volume, issue and page numbers.

Link to publication

\footnotetext{
General rights rights.

- You may freely distribute the URL identifying the publication in the public portal. please follow below link for the End User Agreement:

www.umlib.nl/taverne-license

Take down policy

If you believe that this document breaches copyright please contact us at:

repository@maastrichtuniversity.nl

providing details and we will investigate your claim.
}

Copyright and moral rights for the publications made accessible in the public portal are retained by the authors and/or other copyright owners and it is a condition of accessing publications that users recognise and abide by the legal requirements associated with these

- Users may download and print one copy of any publication from the public portal for the purpose of private study or research.

- You may not further distribute the material or use it for any profit-making activity or commercial gain

If the publication is distributed under the terms of Article $25 \mathrm{fa}$ of the Dutch Copyright Act, indicated by the "Taverne" license above, 


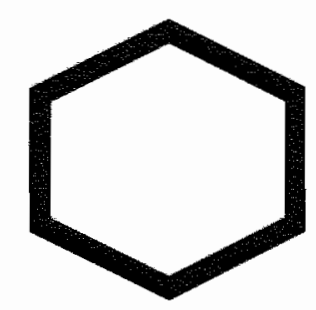

effects of impaired vitamin

K-dependent protein carboxylation 
Printed by: Drukkerij Bakker VOF, Merkelbeek

Lay-out: $\quad$ Esther Ginczinger / Drukkerij Bakker VoF, Merkelbeek

ISBN: $\quad$ 90-9016838-9

(6) Henri M.H. Spronk, Heerlen 2003

Thesis University Maastricht - with a summary in Dutch

No part of this book my be reproduced, stored in a retrieval system or transmitted in any form or by any means, without permission of the author, or, when appropriate, of the publishers of the publications. 


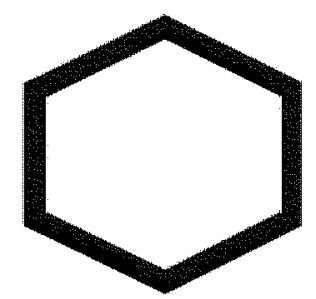

effects of impaired vitamin

K-dependent protein carboxylation

\section{PROEFSCHRIFT}

ter verkijging van de graad van doctor aan de Universiteit Maastricht, op gezag van de Rector Magnificus, Prof. Dr. A.C. Nieuwenhuijzen Kruseman volgens het besluit van het college van Decamen, in het openbaar te verdedigen op vrijdag 20 juni 2003 om 12:00 uur

door

Henrdrikus Maria Hubertus Spronk geboren 7 juni 1970 te Margraten 
Promotor:

Prof. Dr. J.G.R. De Mey

Co-promotores:

Dr. C. Vermeer

Dr. H.H.W. Thijssen

Beoardelingscommissie:

Prof. Dr. J.F.M. Smits (woorzitter)

Prof. Dr. H. ten Cate

Prof. Or. M.J.A.P. Daemen

Prof. Dr. FC.S. Ramaekers

Prof. Dr. L. Rosing

Financial support by the Netherlands Heart Foundation for the publication of this thesis is gratefully acknowledged 
Tact is the knack of making a point without making an enemy.

Isaac Newton 


\section{Contents}

\section{Introduction}

1.1 General Intraduction

$\gamma$-Glutamyl carboxylase

Vitamin $\mathrm{K}$

Vitamin $K$ antagonists

Substrates for $\gamma$ glutamyl carboxylase

Matrix Gla protein: Molecular background

Matrix Gla protein: Function

Clinical significance of vascular calcification

Vitamin K, MGP, and vascular calcification

1.2 Introduction to this thesis

Naturally occurring mutation(s) of the $\gamma$-glutamyl carboxylase

2.1 A novel mutation in the $\gamma$-glutamyl carboxylase gene resulting in congenital combined deficiency of all vitamin K-dependent blood coagulation factors

2.2 Congental combined deficiencies of all vitamin K-dependent coagulation factors

3 Characteristics of recombinant W5015 mutated human $\gamma$-glutamyl carboxylase. 
Preparation and evaluation of tools for in vivo and in vitro studies

4 Matrix Gla protein accumulates between tissue and calcium deposits in the arterial vessel wall

5 Total chemical synthesis of human matrix Gla protein

Induced impaired $\gamma$-glutamyl carboxylation and the role of MGP in calcification

6 Tissue-specific utilization of menaquinone-4 results in prevention of arterial calcification in warfarin-treated rats

7 Regulation of human VSMC calcification by matrix Gla protein

8 Possible role for apoptotic bodies in the cellular release of matrix Gla protein

\section{General discussion}

9.1. Discussion and summary

9.2 Discussie en samenvatting

Curriculum vitae

Publications

Abstracts

Dankwoord

References 




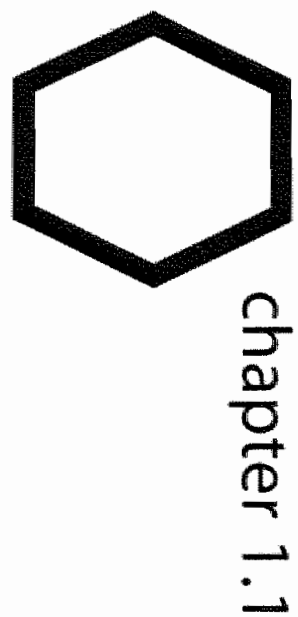

general introduction 



\section{Introduction}

Matrix Gla protein (MGP) plays a key role in arterial calcification. Gla stands for Y-carboxy glutamic acid (Figure 1), an unusual amino acid formed during posttranslational modification by the action of the vitamin $k$-dependent enzyme g-glutamyl carboxylase in the rough endoplasmic reticulum $[144,218\}$. In this introduction, the general properties of MGP and its role in the vessel wall are discussed with reference to (1.) other vitamin K-dependent proteins and (2.) the roles of MGP in the calcification of bone. Finally, MGP is evaluated as a potential target for prevention and pharmacological intervention of arterial calcification.

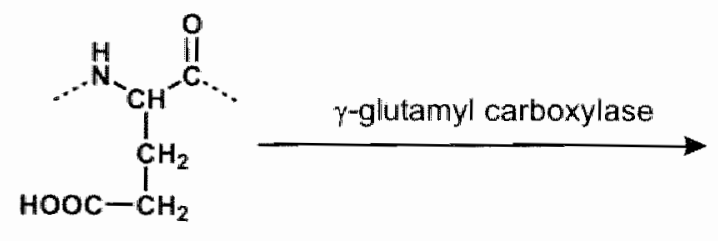

glutamic acid (Glu)<smiles>CN[C@@H](CC(C(C)=O)C(=O)O)C(=O)O</smiles>

$\gamma$-Carboxy glutamic acid (Gla)

Figure 1

Structures of glutamic acid (Clu) and y-carboxy glutamic achd (Gla)..

\section{$\gamma$-Glutamyl Carboxylase}

The enzyme $\gamma$ glutamyl carboxylase is an integral membrane protein and is located at the luminal side of the rough endoplasmic reticulum (RER) and the Golgi complex. The absence of undercarboxylated proprothrombin in the Golgi complex suggests that the majority of carboxylation occurs in the RER. Although the genomic sequences are known for bovine $[182,264$, sheep $[1321$, rat [187], mouse [271], whale, toadfish 164, and drosophila carboxylase 1120, 243], this introduction will focus on the human enzyme. The enzyme occurs in a

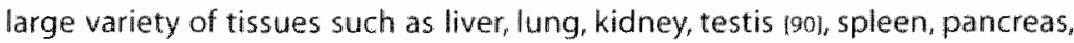
thyroid, arterial vessel wall, bone 125, 241], tumor cells [42], and skin [43]. It is generally accepted that in humans the carboxylase from various tissues is the product of the same gene, located on chromosome 2 at position p12 11121. The gene is $13 \mathrm{~kb}$ long, has one transcriptional start site and the 15 exons encode for a mRNA with an open reading frame of 2277 nucleotides 1260 . The protein consists of 758 amino acids with a molecular weight of $94 \mathrm{kDa}_{\mathrm{A}} \mathrm{A}$ hydrophilic region $(1-51)$ is followed by a hydrophobic region $(51-314)$ and a carboxy-terminal hydrophilic region (3.15 - 758). There are three to seven putative transmembrane regions. It was shown that the enzyme spans the ER 
membrane at least 5 times, with its $\mathrm{N}$-terminus in the cytoplasim and its C-terminus in the lumen of the RER (Figure 2) [2291. The protein contains nine potential N-linked glycosylation sites of which eight are located in the carboxy-terminal hydrophilic region [260].

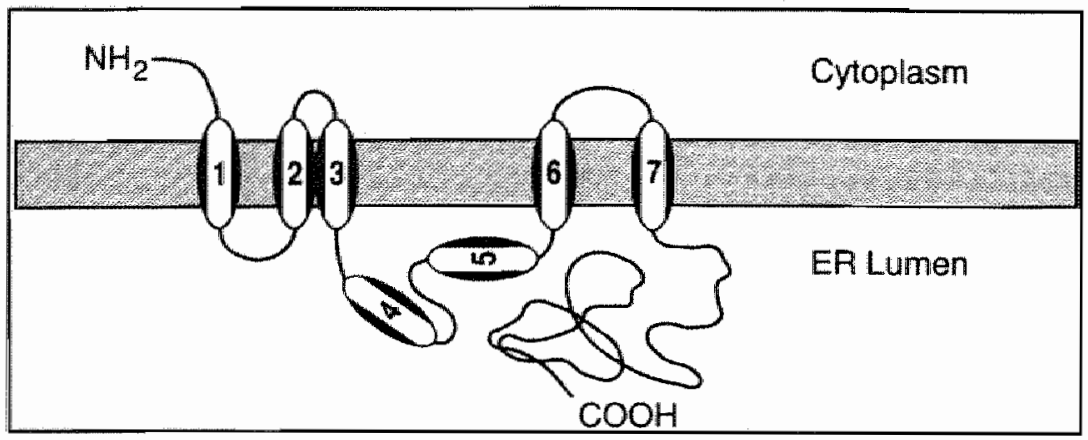

Figure 2

Hypothetical transmembrane structure of human -glutamyl carboxylase. Adapted from Tie et a. $\llbracket 229\rfloor$

At least two regions of $\gamma$-glutamyl carboxylase are important for the $\gamma$-glutamyl carboxylation reaction: l. the active and vitamin $K$ binding site, and II. the substrate (propeptide) binding site. Two reactions are catalysed by the $\gamma$-glutamy\| carboxylase enzyme at its active site 1137,247$]$. The first reaction is the addition of carbon dioxide to a glutamate residue resulting in a Gla-residue and the second one is the oxygenation of vitamin $\mathrm{K}$ hydroquinone $\left(\mathrm{KH}_{2}\right)$ to vitamin $\mathrm{K} 2,3$-epoxide $(\mathrm{KO})$. Both reactions are catalysed by the carboxylase with a $1: 1$ stoichiometry $[115,259]$. From studies with purified bovine liver enzyme it has been demonstrated that the epoxidase activity is part of the carboxylase enzyme [137]. The model of base strength amplification is a generally accepted hypothetical molecular mechanism [47]. An active site thiol (weak base: (y5-5) in the carboxylase initiates the chain of reactions by deprotonating vitamin $\mathrm{KH}_{2}$, leading to vitamin $\mathrm{K}$ alkoxide, which in its own light is a strong base in a hydrophobic environment. The strong base, in turn, deprotonates a Glu residue which in turn will be carboxylated. Oxidation of $\mathrm{KH}_{3}$ into $\mathrm{KO}$ by molecular oxygen provides the energy required for the $\mathrm{CO}_{2}$-fixation at the $y$-position of a glutamate residue. Carboxylation may proceed by the removal of the $\gamma$-proton of the Glu-residue followed by a $\mathrm{CO}_{2}$-attack at the same position.

The exact amino acids involved in formation of the active site within carboxylase are not known yet. However, site-directed mutagenesis analyses showed major roles for residues 218,359, and 394 in the catalytic activity of the enzyme $[140,22 \pi]$. Furthermore, a vitamin $\mathrm{K}$-dependent protein site of interaction comprising amino acids 343-355 was identified through an immobilized peptide showing that residues 343 and 345 within this peptide 
are important in formation of the active site [177]. For identification of the propeptide binding site different methods have been used. These suggest several potentiall locations (Table 1).

\section{Table 1}

Proposed propeptide and active sites in raglutamyl carboxylase

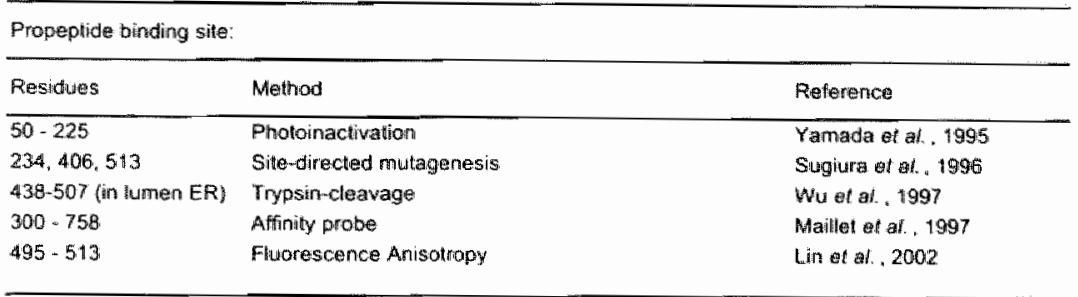

Actwe Site f epoxidation Site:

\begin{tabular}{|c|c|c|}
\hline Residues & Method & Reference \\
\hline $217 / 218,359$ & Sitte-directed mutagenesis & Sugivara of al. 1990 \\
\hline $50-314$ & Unactivation with preptide sibustrate & Kulopulos of al. , 1994 \\
\hline 394 & Site-directed mutagenesis & Multucumarania eit at, 2000 \\
\hline 99.450 & Amino acid analysis of ${ }^{2} \mathrm{C}-\mathrm{NE}$ H modified carboxyalse & Pudoia at al. , 2000 \\
\hline $34,3,3.5$ & Site-diracted nuth genesis & Pudola ef al. „2091 \\
\hline
\end{tabular}

\section{Vitamin $\mathrm{K}$}

Vitamin $K$ is a generic name for a group of fat-soluble compounds called vitamin $\mathrm{K} 1$ (or phylloquinone) and vitamin $\mathrm{K} 2$ (menaquinones, Figure 3.1), which both can act as cofactor for $\gamma$-glutamyl carboxylase. All K-vitamers have a 2-methyl-1,4-naphthoquinone ring structure in common but differ in the length and degree of saturation of an aliphatic side chain at the 3-position. Vitamin $\mathrm{K} 2$ is a group name for structurally related compounds, containing a side chain built of repeating unsaturated 5-carbon (prenyly units; these isomers are designated menaquinone-n (MK-n) according to the number ( $n$ ) of prenyl units. For example: menaquinone- 4 (MK-4) consists of a naphthoquinone ring structure with a side chain of 4 prenyl units at the 3 -position (Figure 3.1). The hydrophobicity of menaquinones increases proportionally with increasing side chain length. A third form of vitamin $K$, menadione ( $K 3$ ), is a synthetic product. It is the 2-methyl-1,4-naphthoquinone ring structure without a side chain.

Phylloquinone is mainly found in green leafy vegetables like spinach, kale, sprouts and broccoli $[11,13$. These green leafy vegetables contain approximately 1000-8000 $\mathrm{kg}$ phylloquinone per $\mathrm{kg}$. Other minor sources of phylloquinone are fruit, dairy produce and grains. Menaquinones are synthesised by a selected number of bacteria and mostly occur in fermented foods and explains why the daily requirement for vitamin $k$ is low and why vitamin $K$ 
A.<smiles>CC1=C(C/C=C(\C)CCCC(C)CCCC(C)CCCC(C)C)C(=O)c2ccccc2C1=O</smiles>

B.<smiles>CC(C)=CCC/C(C)=C/CC/C(C)=C/CC/C(C)=C/CC1=C(C)C(=O)c2ccccc2C1=O</smiles>

C.<smiles>CC1=CC(=O)c2ccccc2C1=O</smiles>

Figure 3.1

Structures of vitamin $K . A$ : vitamin $K \mathbb{1}$ or phylloquinone. $B$ : menaquinone-4 (MK-4) $C$ : vitarmin K3 or menadione.

Glu
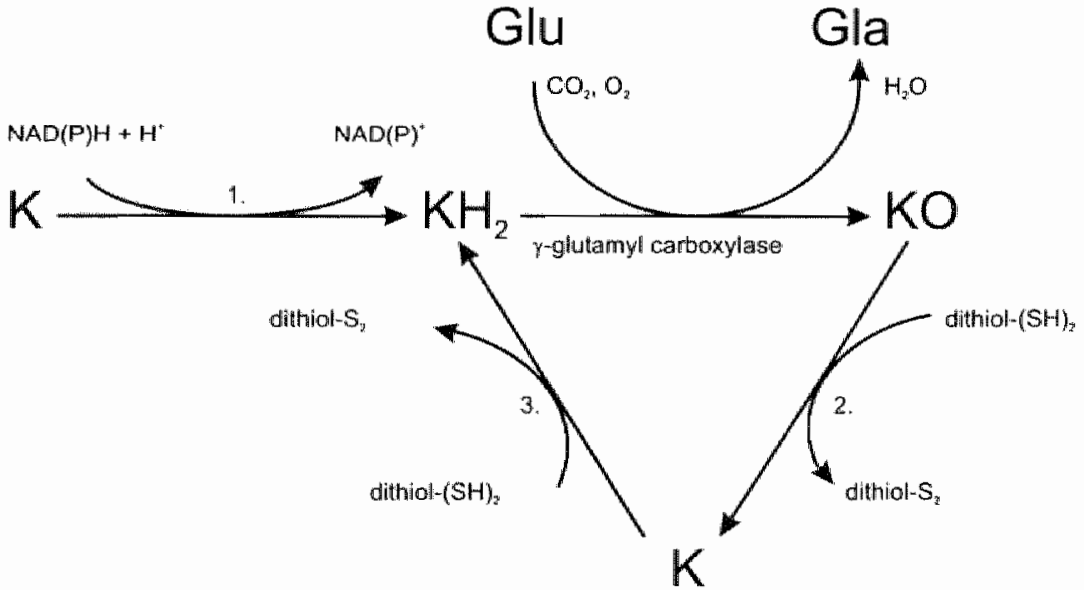

Figure 3.2

The witamin $K$-cycle. Vitamin $K$-quinone $(K)$ is first reduced to vitamin $K$-hydroquinone (KH. and then oxidized to vitamin $K$ epoxide $(K O)$. During the oxidation step glutamic acid (Giu) is reduced to warboxy glutamic acid (Cla). Finally $K O$ is reduced to $K$. 1 . NAOP(P)H-dependent $K$ reductase (DT-diaphorasel. 2. dithiol-dependent KO-reductase. 3. dithiol-dependent Kreductase. 
deficiency is rarely seen in healthy subjects 1150,226$]$. Besides in the dithioldependent pathway, vitamin $K$ (and not $K O$ ) may also be reduced by DTdiaphorase, an NAD(P)H dependent dehydrogenase. Although the DTdiaphorase is highly expressed in the liver, the dithiol-dependent pathway is the most active one for $\mathrm{KH}_{2}$ generation [249]. like cheeses and other dairy produces [198]. A large pool of menaquinones is synthesised by the intestinal microflora: MK-10 and 11 by bacteroides, MK-8 by enterobacteria, MK-7 by veillonella species, and MK-6 by Eubacterium lentum. Very high concentrations of $M K-7$ (ranging from 9 to $12 \mathrm{mg} / \mathrm{kg}$ ) are found in fermented soy beans (natto) [1981. MK-4 is not produced by the intestinal microflora, but relatively high concentrations of it are found in egg yolk, dairy and meats [198. Besides these dairy sources, MK-4 is also synthesised by the conversion of menadione into MK- 4 by a number of tissues and by the conversion of vitamin $\mathrm{K} 1$ into $M K-4(8 B 8)$.

The degree to which vitamin $K$ is absorbed in the intestine depends on the side chain, the composition of the food matrix and on the efficiency of liberation from the food matrix. Compared to MK-4 through MK-7, the menaquinones with longer side chains (i.e. MK-B to MK-13) are not efficiently absorbed $[2,199]$. Fat-solubilised vitamin $K$ in for example a meal of spinach with butter has a higher absorption rate than vitamin $\mathrm{K}$ from spinach alone $[69,235]$.

Vitamin $K$ is taken up in the digestive tract by the absorptive enterocytes of the small-intestine and packed with cholesterol, lipids, and lipoproteins into chylomicrons. After exocytosis these chylomicrons enter the blood circulation via the lymphatic system and are rapidly degraded into chylomicron remnants. In this way, most of the absorbed vitamin $\mathrm{K} 1$ is. delivered to the liver by chylomicron remnants which are cleared from the circulation via apolipoprotein E (ApoE) receptor mediated uptake 1126.2051 . The clearance rate is dependent on the ApoE genotype. Three regularly encountered Apo E genotypes are E2, E3, and E4, which promote chylomicron remnant clearance in the order $E 2<E 3<E 4$ [255]. As a result, subjects with an ApoE2/2 or ApoE2/3 genotype tend to have higher plasma vitamin $K 1$ concentrations compared to those with the genotypes ApoE3/3, ApoE3/4, or ApoE4/4 [107]. Very little is known about the vitamin $K$ transport to and uptake by extra-hepatic tissues like the arterial vessel wall and bone. It has been shown that vitamin $K 1$ is predominantly carried by the triacylglycerolrich lipoprotein fraction (TGRLP) (114) and that cultured osteoblasts can internalise vitamin $\mathrm{K} 1$ from $\mathrm{LDL}$, chylomicron remnants. $\mathrm{VLL}$, and $\mathrm{HDL}$ by an ApoE dependent mechanism [14G]. In contrast, besides the TGRLP fraction MK-4 is also carried by the LDL and HDL fraction [200]. Another source for extra-hepatic MK-4 is provided by the conversion of vitamin K1 into MK-4 
Not the form in which it occurs in food (vitamin K-quinone), but the reduced form vitamin $K$ hydroquinone $\left(\mathrm{KH}_{3}\right)$ is the active cofactor used by the enzyme Yalutamyl carboxylase. $\mathrm{KH}_{2}$ is converted into vitamin $\mathrm{K}$ epoxide $(\mathrm{KO})$, and $\mathrm{KO}$ is subsequently reduced into vitamin $\mathrm{K}$ and witamin $\mathrm{KH}_{3}$ in two reactions by the action of one or more dithiol dependent witamin $K$ epoxide reductases (VKOR, Figure 3.2) (223). This recycling mechanism is called the vitamin $K$-cycle and explains why the daily requirement for vitamin $K$ is low and why vitamin $K$ deficiency is rarely seen in healthy subject5 1150,226]. Besides in the dithioldependent pathway, vitamin $K$ (and not $\mathrm{KO}$ ) may also be reduced by DTdiaphorase, an NAD(P)H-dependent dehydrogenase. Although the DTdiaphorase is highly expressed in the liver the dithiol-dependent pathway is the most active one for $\mathrm{KH}$, generation [249].

Cofactor activities of $\mathrm{KI}$ and $\mathrm{MK}-4$ in in vitro carboxylase studies are comparable as indicated by almost equal concentrations for half-maximal reaction velocity in specific assays for carboxylase and VKOR 261 . For the in vivo biological activity vitamin K-deficient rats were used to test the potency of various forms of vitamin $K$ to counteract hypoprothrombinaemia. Two studies suggested respectively a 2-5 [73) and a 8 fold higher activity of $K 1[131]$. In other words, vitamin KI thas a higher biological $\gamma$-glutamyl carboxylase cofactor activity in the liver than has MK-4. Since both vitamins have comparable in witro cofactor activity, differences in biological activity may be explained by different tissue distribution. Supportive for this theory is the abserved 10-fold higher hepatic accumulation of $K 1$ than of MK-4 whereas MK-4 was preferentially taken up by a number of extra-hepatic tissues [169].

\section{Vitamin $\mathrm{K}$ antagonists}

The VKOR is extremely sensitive to the action of 4-hydroxycoumarin derivatives such as warfarin [59. Oral anticaagulant is another name for the 4hydroxycoumarin derivatives since these drugs are frequently used for the treatment and prophylaxis of thrombo-embolic diseases and as rodenticides. linhibition of VKOR by oral anticoagulants results in blockade of KO recycling and thus in inhibition of $\gamma$-glutamyl carboxylation of the vitamin $K$. dependent proteins. DT-diaphorase is relatively insensitive to warfarin and is able to bypass the inhibited dithiol-dependent enzyme during warfarin anticoagultation 12481. During an overdose of anticoagulant the NADH-dependent pathway is therefore the only route by which $\mathrm{KH}_{2}$ can be made to act as a cofactor in the $\gamma$ glutamyl carboxylation[244].

\section{Substrates for $\gamma$-glutamyl carboxylase}

Since vitamin $K$ is used as a cofactor in the $\gamma$ glutamyl carboxylation the products of carboxylase action are called vitamin $K$-dependent proteins. 
Vitamin K-dependent proteins are involved in several physiological processes such as haemostasis, bone and soft tissue mineralization, and cellular proliferation. The coagulation factors $1: 1$ (prothrombin), VII, $\mid X_{t}$ and $X$, have pro-coagulant activity, whereas proteins $C$ and $S$ inhibit blood coagulation (see review: [39]). Protein $Z$ is involved in fixation of thrombin via binding to a phospholipid surface [86:. MGP and osteocalcin (or bone Gla protein) are regulators of tissue mineralization, whereas Gas 6 is involved in the regulation of cell growth (reviews: $[135,234]$. The mRNA sequences of four new putative vitamin K-dependent proteins were recently reported. Two of the proteins are rich in prolines and are therefore called proline-rich Gla proteins (PRGP1 and PRGP2) [109]. Together with the two transmembrane Gla proteins. TMG3 and TMG4 [110), these putative proteins form a new class of vitamin $K$ dependent proteins the functions of which are not known yet. Also, the enzyme $\gamma$-glutamyl carboxylase itself was reported to contain three Gla residues per molecule enzyme 191. In all these proteins the presence of Gla residues is a prerequisite for the $\mathrm{Ca}^{2+}$-binding and/or $\mathrm{Ca}^{2+}$-dependent interaction with negatively charged surfaces.

For correct $\gamma$-glutamy carboxylation all substrates for the $\gamma$-glutamyl carbaxyllase enzyme, are synthesised in a precursor form. This precursor peptide contains a pre-sequence for translocation across the RER membrane, and a propeptide-sequence for recognition by and binding to the $\gamma$-glutamyl carboxylase enzyme [96]. As a result of the pre-sequence removal, the immature protein is released into the lumen of the RER and binds to $\gamma$-glutamyl carboxylase via its propeptide sequence. Binding of the propeptide to carboxylase is thought to provide the majority of the binding energy required for anchoring a substrate to the enzyme [214]. Except for MGP, all known vitamin $\mathrm{K}$-dependent proteins contain a $\mathrm{N}$-terminal propeptide sequence consisting of residues -18 to -1 . The protein sequence of MGP revealed that it contains a sequence segment (residues 15 through 30 ) that is homologous to the propeptide of other vitamin K-dependent proteins and probably has a comparable role in $\gamma$-glutamyl carboxylase recognition [164]. In Figure 4 the sequence alignments of the propeptides from all known human vitamin K-dependent proteins are listed.

Amino acid residues at positions $-16,-10$, and -6 are highly conserved among the human vitamin $K$-dependent proteins. From the sequence alignment a $X-Z-F-Z-X-X-X-X-X-A-X-X-Z-Z$ motif from residues -18 to -6 can be dleduced, with $Z$ being an alliphatic hydrophobic residue (lle, $V a l$, Leu), $F$ phenylalanine, A alanine, and $X$ stands for any amino acid. Except for human Gas6, all human vitamin K-dependent proteins possess Phe at position -16. The amino acids between position -15 and -8 have either polar or charged side chains. Point mutations of the highly conserved hydrophobic residues at $-16,-10$, and -6 within the propeptide resulted in a dramatic reduction of carboxyllation of 


\begin{tabular}{|c|c|c|c|c|c|c|c|c|c|c|c|c|c|c|c|c|c|c|c|c|}
\hline & & & * & & & & & $*$ & & & & 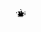 & & & & & & & & 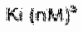 \\
\hline Facior 泪 & is & 18 & 4 & P & $\mathrm{E}$ & 5 & 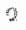 & 4 & F & $\Leftrightarrow$ & \pm & 9 & 8 & - & $\sim$ & m & $v$ & $\mathrm{R}$ & \% & \\
\hline Fator will & $\mathrm{n}$ & y & \% & * & 0 & 3 & $\bar{E}$ & H & 星 & 6 & $y$ & $1 \%$ & ? & - & n & $-\frac{}{4}$ & i & i & 4 & \\
\hline Fralctar ar & 7 & \% & 1/y & : & $H$ & 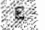 & 荮 & \% & 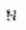 & $x$ & 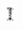 & Wh & $\frac{a y}{y}$ & m & + & -4 & $\mathrm{~F}$ & $x$ & ? & \\
\hline Factor $x$ & $\approx$ & 5 & 7 & 和 & $\mathrm{FH}$ & 8 & in & $\%$ & $M$ & s & I & $\%$ & A & . & - & -6 & $y$ & $r$ & 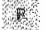 & \\
\hline Prothen 6 & 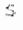 & $\%$ & 48 & 5 & $a$ & 6 & 踏 & $1 \%$ & $H$ & 0 & $y$ & $\%$ & P & "' & - & $\quad I$ & at & $k$ & $1 \%$ & \\
\hline Prolón S & s & $\mu$ & $6 \%$ & 5 & $\psi$ & 0 & 0 & 1 & $s$ & 2 & $y$ & 1 & $y$ & - & - & $-3 \%$ & K & 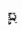 & $\mathrm{p}$ & \\
\hline Finstein $Z$ & $s$ & 1 & $18 \%$ & $y$ & A & 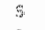 & $\%$ & y & $n$ & 0 & $y$ & x & $y$ & - & $\cdots$ & $\cdots$ & 积 & 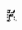 & 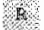 & \\
\hline Wop & 㳔 & iv & 2 & $H$ & s. & f & 嘖 & \% & 4 & $\mathrm{I}$ & 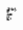 & I & 5 & - & - & 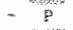 & 9 & 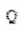 & M & \\
\hline Oglesurcalciri & t & 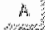 & by & $s$ & $r$ & 0 & $E$ & 5 & 8 & E. & $y$ & $y$ & $\mathrm{~s}$ & - & - & $-1 x$ & $\ddot{z}$ & R & \% & $500 \cdot 10^{2}$ \\
\hline 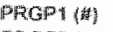 & 悀 & 8 & (1) & $\mathrm{T}$ & $\therefore$ & \% & $x$ & \% & 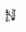 & $\$$ & it & \% & 4 & 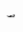 & $\cdot$ & - औ. & Y & F & th & -13 \\
\hline $\mathrm{PPOP}$ ( $(1)$ & : & W & 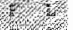 & 5 & 5 & 9 & 蛋 & x & 3 & $s$ & $\mathbb{P}$ & $\%$ & $s$ & $s_{3}$ & 4 & T 1 & $\check{i}$ & P & 1 & \\
\hline $7 a_{4}(03)$ & 今 & W & \% & $E$ & $A_{3}$ & $k$ & D & 1 & the & 3 & $y$ & $2 \%$ & 20 & $\therefore$ & - & $-\sqrt{10}$ & $F$ & $\%$ & 15 & \\
\hline TMASA & E & \% & 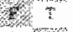 & 5 & H & 26 & $E$ & 8 & 的 & 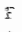 & 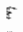 & I & H & $\cdots$ & - & $=-$ & - & 瓷 & \% & \\
\hline 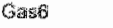 & s & $A$ & H & p & 战 & $\mathrm{F}$ & $\overline{\mathrm{E}}$ & $8 x$ & $\ddot{i}$ & 0 & 5 & 4 & p & $F$ & $\sim$ & $-y^{2}$ & in & st & W & \\
\hline
\end{tabular}

\section{Fligure 4}

Amino acid sequence alignment in one letter code of the propeptides of human vitamin $k$. dependent proteins. The highly conserved amino acid residues are boxed in grey. w: Predicted peptide sequence from mRNA. *: Residues implicated in the recognition by the $\gamma$ glutamyl carboxylase. SInhibition constants toward FixprociLA carboxylation [213].

the attached substrate. The less conserved residues at $-18,-17$, and -15 contribute to a lesser extend to the affinity towards the carboxylase [80,92]. Further evidence for the propeptide recognition by carboxylase was provided by carboxylation of substrates in which covalently attached propeptides directed carboxylation of the attached Glu-rich regions $165,90,214)$. The affinities of propeptides towards carboxylase vary by more than 100,000fold, despite the homology between propeptides [213]. The propeptide of factor $X$ has the highest affinity for carboxylase, followed by MGP, factor VII, Protein S, PRGP 1, Factor IX, Protein C, and factor II. By far the lowest affinity has the propeptide of osteocalcin. Changing only two residues $(-6$ and -10$)$ of the osteocalcin propeptide to those of the conserved sequence improved its affinity to the level of the other propeptides $\{214\}$

Except for MGP, all precursor proteins contain an arginine at -1 and an arginine-rich region at positions -2 to -5 . The importance of paired basic residues at position -1 and -2 for proper cleavage of the propeptide was shown by point mutations in blood coagulation factor IX [231. The cleavage of the propeptide takes place in the trans Golgi compartment [24] and a role for PACE/Furin has been suggested [252]. Although MGP contains an arginine at position +15 , the propeptide is not removed due to lack of the arginine-rich region.

Besides the sequence similarity in the propeptide of all mammalian Glaproteins, there is another similarity in the mature proteins. Price et al. found the sequence Gla-X-X-X-Gla-X-Cys at positions +17 to +23 in all mammalian Gla-proteins [164). In witro carboxylation experiments revealed a possible role for this sequence in substrate recognition by carboxylase. Descarboxylated osteocalcin and descarboxyprothrombin fragment 13-19, both without the 
Glu-X-X-X-Glu-X-Cys sequence, are carboxylated with $K_{4,}$ values in the fumolar range $[44,236]$. In contrast, Glu-containing peptide substrates lacking the Glu-X-X-X-Glu-X-Cys motive had $K_{\mathrm{s}}$ values in the millimolar range, indicating a possible role for the internal sequence in substrate recognition by the carboxylase. On the other hand, a 59 amino acid peptide consisting of factor IX's propeptide and Gla domain was found to be a better substrate compared to a peptide of the free Gla domain alone, which turned out to be a relativelly poor substrate [214].

\section{Matrix Gla Protein: Molecular Background}

The mature Matrix Gla protein (MGP) is an 84 amino acid protein which contains five Gla-residues at positions $2,37,41,48$, and 52 [167!. Besides the posttranslational $\gamma$-glutamyl carboxylation the protein can be phosphorylated at serine residues 3,6, and 9 [165]. A truncated 77-residue of MGP lacking the COOH-terminal residues Arg-Lys-Arg-Arg-Gly-Thr-Lys is present in human bone [78].

MGP was first isolated from bovine bone [167] and since then the corre* sponding human, rat [164], mouse [931, avian [256], soupfin shark (Galeorhinus galeus) [1831, and Xenopus laevis 29] proteins or MRNAs were identified. Comparisons of the MGP and osteocalcin gene and protein sequences of several vertebrate and invertebrate species suggest a common ancestor for these two genes $[29,31,159,183]$. MGP expression (mRNA or protein) has been detected in various tissues and cell cultures like bone, kidney, spleen, lung, cartilage [61], the arterial vessel wall [201], and arterial smooth muscle cells [203]. The human MGP gene (Figure 5). chromosome locus 12p13.1-p12.3, spans $3.9 \mathrm{~kb}$ and consists of 4 exons and 3 large introns, which cover almost $80 \%$ of the gene (27). Besides the presence of a consensus TATA sequence and two CAT boxes in the genomic sequence flanking the $5^{\prime}$ end of the gene, putative binding sites for transcription factors AP1 and AP2, CAMP-dependent transcription factors, metal responsive elements, and retinoilc acid and vitamin $D$ were identified in the promoter region. Indeed, MGP gene expression has been shown to be strongly induced by retinoic acid and 1,25-dihydroxyvitamin $D_{3}$ in a number of human cell lines including osteoblasts, articular cartilage chondrocytes, and fibroblasts 130 ) as well as in rat chondrocytes, osteoblasts, and osteosarcoma cells $14,60,621$. On the other hand, down regulation of MGP gene expression by retinoic acid was observed in several human breast carcinoma cells and in a rat kidney cell line [104, 205]. This repression of MGP gene expression in human breast carcinoma cells correlated with high estrogen receptor levels, whereas high MGP expression levels were associated with low estrogen receptor expression [2061. Kirfel et al. showed binding of a retinoic acid receptor / retinoid $X$ receptor heterodimer to a negative response element between -138 and -102 [57] within the MGP 
promoter leading to decreased MGP expression [104]. Another pathway for increasing the MGP expression is via high levels of extracellular calcium. Using cell cultures of human vascular smooth musicle cells (VSMCs), Farzaneh.Far et al showed that this effect is mediated by a yet unknown $G$ protein mediated cation-sensing mechanism [56]. The effect of transforming growth factor $\beta$ (TGFB) is also contradictory. MGP MRNA expression increases in cultured embryonic lung cells after treatment with TGFB [270], whereas transient transfection of MGP promoter-luciferase constructs into rat VSMCs suggested down regulation by TGF $\beta$ [57]. Several polymorphisms of the human MGP gene are known (Figure 5). A dinucleotide-repeat (CA) polymorphism ranging from 13 to 18 repeats has been identified at the MGP locus 12533. Six polymorphisms are known to occur in the promoter of the human MGP' gene: -7 ( $G$ or $A),-138$ ( $T$ or $C),-514(C$ or $T),-2447$ ( $G$ or $A)[55],-814$ (A or $G$ ), and -2682 ( $C$ or T), and two in the coding region: Lys $34 G$ lu and Thr $83 \mathrm{Ala}$ [85]. Two of these promoter polymorphisms (-7 (G or A), -138 (T or C) have an important impact on in vitro promoter activity: the $-7 \mathrm{~A}$ and $-138 \mathrm{C}$ variants. had higher promoter activity compared to the corresponding $-7 \mathrm{G}$ and $-138 \mathrm{~T}$ variants. Also, patients with the $C C$ variant at -138 had significantly higher serum MGP levels compared to subjects with the IT variant probably due to decreased binding of the AP1 complex to the promoter [55].

\section{Matrix Gla Protein: Function}

Although the molecular mechanism of MGP action is not known, data from various studies demonstrate that it plays a major role in the inhibition of softtissue calcification. Most importantly, MGP-deficient mice showed two phenotypes: impaired bone growth and extensive medial calcification of the aorta, leading to death within eight weeks after birth due to ruptures of the thoracic or abdominal aorta [123]. During normal endochondral bone formation MGP is expressed in the epiphyseal growth plate by resting, proliferating. and late hypertrophic chondrocytes in the calcifying zone, but not in the early hypertrophic chondrocytes (124). In the MGP-deficient mice, however, hypertrophic chondrocytes are absent and the proliferative zone is calcified, which resulted in a disorganization of chondrocyte columns [123]. in line with this finding is the reported induction of apoptosis of proliferative and hypertrophic chondro-cytes after expression of antisense MGP CDNA in a cultured mouse chrondrogenic cell line (145). Overexpression of MGP in the maturing chondrocytes of the same cell line also induced apoptosis, whereas higher MGP levels during the hypertrophic phase had an inhibitory effect on calcification and no effect on cell viability [145]. Constitutive overexpression of MGP in chicken embryo limb resulted in in vivo inhibition of cartilage mineralization, delayed chondrocyte maturation and termination of endochondral and intramembranous ossification [2661. All together these data suggest a role for MGP in survival of proliferative and hypertrophic chondrocytes. 

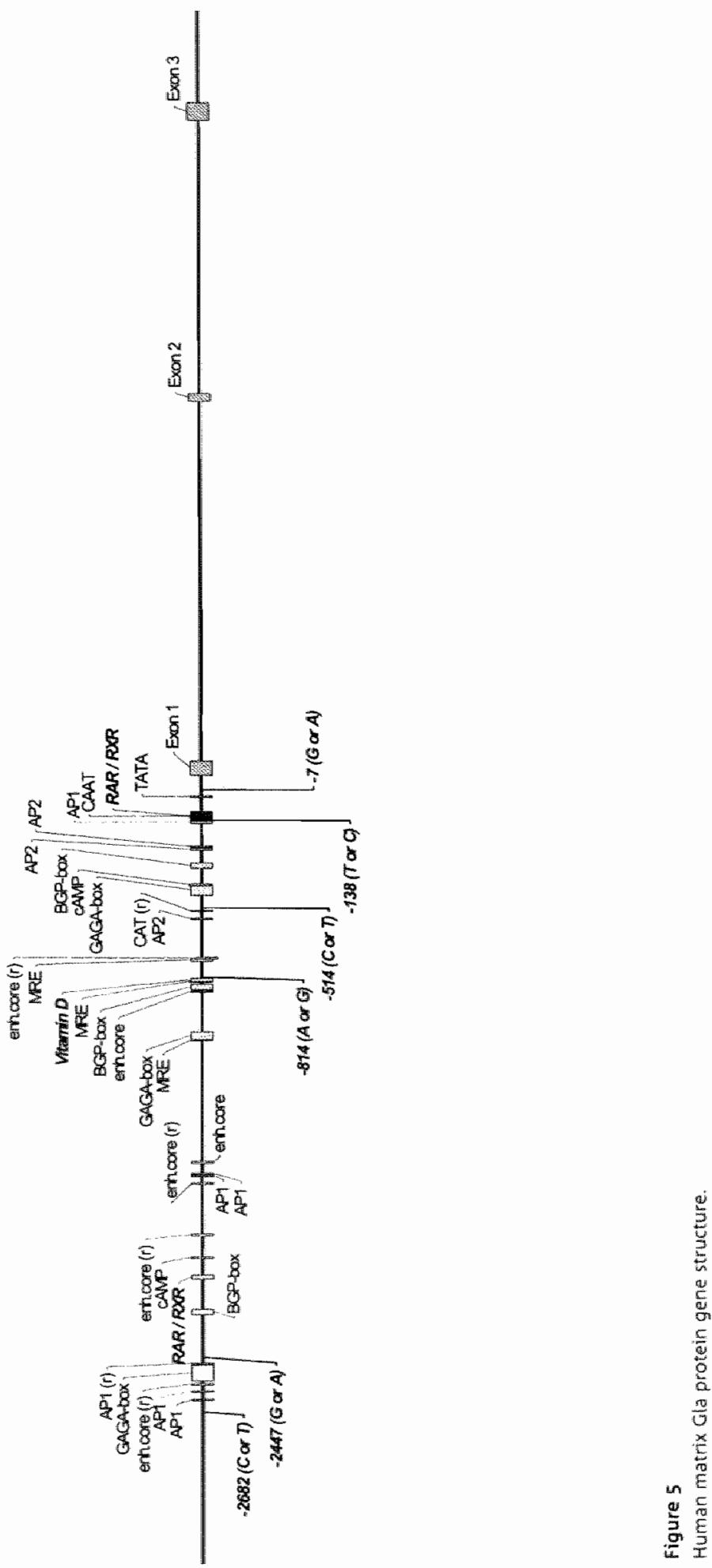
The association between MGP and vascular calcification was initially suggested by the detection of high levels of the corresponding MRNA in proliferating rat VSMCS 12031, and the presence of both the MRNA and protein in the arterial vessel wall where it is synthesised by medial and intimal VSMCs and macrophages 2011. Expression of MGP by intimal smooth muscle cells (SMCS) starts already in the intimal xanthoma lesions, increases in the fibrous cap atheroma were it is also present in the foam cells of the lipid core, and extends further in the fibrocalcific plaque [45]. In the fibrocalcific plaques expression of MGP is localised to CD68-positive macrophages surrounding the necrotic core, intimal smooth muscle cells, and around calcium deposits. In all these atherosclerotic plaque stages, MGP is also expressed by the underlying medial VSMC5. Compared to normal arteries, total MGP MRNA. expression is lower in peripheral arteries with calcification of the media (Mönckeberg's sclerosis) (2021. However, the expression is increased in a small subset of VSMCs adjacent to the medial calcification. A possible explanation for the increase in MGP MRNA expression around both medial and intimal calcifications may be the proposed $G$ protein mediated cation-sensing mechanism $[56$.

Despite the observed medial calcification in the MGP deficient mice model and the increased expression of MGP around the site of mineralization in both intimal and medial calcification only little is known about the molecular mechanism of MGP function. As mentioned before, Gla-residues are involved in the $\mathrm{Ca}^{2+}$-binding and/or $\mathrm{Ca}^{2+}$-dependent interaction with negatively charged surfaces. Therefore, it is likely that the Gla-residues within MGP are involved in the inhibition of calcification. Indeed, this was demonstrated in a number of experiments in rats by inhibition of $\gamma \mathrm{glutamyl}$ carboxylation with warfarin $[161,162]$. Rats were treated with both vitamin $K$ and warfarin in such a way that $y$ glutamyl carboxylation could proceed in the liver, but was inhibited in extra-hepatic tissues such as the aortic vessel wall resulting in undercarboxylation of MGP. Using this protocol, arterial calcification around the elastic lamellae of the media was found within 3 to 4 weeks of treatment [161. Treatment of hypertrophic chondrocyte cultures with the vitamin $K$-antagonist warfarin triggered in vitro calcification, whereas this calcification was counteracted by MGP overexpression in the

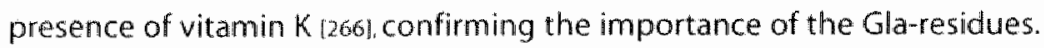

It is hard to envisage that MGP would prevent the precipitation of calcium phosphate simply by binding all calcium in the extracellular space. The remarkable observation of cartilage-producing chondrocytes in the tunica media of the MGP-deficient mice 1123l and the above suggested role for MGP in chondrocyte differentiation are supportive for a imore complex process of calcification inhibition by MGP. In recent years it has been generally accepted that arterial calcification and inhibition thereof are actively regulated 
processes that may be similar to bone formation and in which besides MGP several other proteins are involved. For example, the bone-associated proteins bone morphogenetic protein 2 and 4 [15, 45], bone sialoprotein [45], collagen type | [98], osteocalcin [19], osteonectin [179], and osteopontin [68] are present in calcified human atherosclerotic plaques. Several of these proteins are also found in association with medial calcification. In addition, the calcium crystal deposits are hydroxyapatite, which is the type of crystal normally found in bone $[195]$

In medial calcification the bone-associated proteins are exclusively expressed in VSMCS, whereas in case of intimal calcification these proteins are synthesised by macrophages, multipotent mesenchymal cells, pericytes, or VSMCs. Cell cultures from isolated human aortic medial VSMC [176), bovine and human pericyte-like aortic cells (CVC) (15], bovine aortic SMCs (BASMCs) [207], and human placenta pericytes [176] are frequently used to study the molecular mechanisms involved in arterial calcification. All these cells can differentiate in culture to form osteoblast-like cells and form multicellular nodules preceding calcification $115,22,176,207,2541$. It is not known whether the calcification is the result of differentiation into osteoblast-like cells or the other way around. The cultured cells synthesise proteins characteristic for osteoblasts, including alkaline phosphatase, collagen type I, osteocalcin, and osteonectin. Furthermore, increased MGP MRNA expression in VSMC nodules is associated with in witro calcification of these nodules (176). Together with the transition to an osteoblastic phenotype and calcification, the expression of smooth muscle markers SM22 $\alpha$ and SM $\alpha$ actin is reduced [176, 217l, a phenomenon also found in atherosclerotic intimal VSMCS 12011 and in the calcified arteries of MGP-deficient mice [217]. Differentiation of CVCS into an osteoblast-like cell can be induced by 25-hydroxycholesterol and TGF- $\beta 1$ [254]. as well as by an increase in intracellular CAMP levels 1,230]. Macrophages/ monocytes activated by lipopolysaccharide in vitro, produce tumor necrosis. factor- $\alpha$ (TNF- $\alpha$ ) and treatment of CVC cultures with this conditioned medium or with TNF- $\alpha$ stimulated osteoblastic differentiation and calcification of CVC through an increase in CAMP $[231,232]$. Also, in vitro calcification of CVCs is enhanced upon treatment with oxidized-LDL stimulated macrophages/monocytes [232]. However, this mechanism probably involves cell-cell interaction between the vascular cells and activated macrophages/monocytes.

Bone morphogenetic protein 2 (BMP-2), a potent inducer of bone and cartilage formation 11851, has also been suggested as a factor capable of inducing osteoblastic differentiation. Using ligand-blotting, Wallin et $a$. demonstrated binding between MGP and BMP-2 1245. Osteogenic and chondrogenic differentiation is inhibited in pluripotent mouse rnesenchymal cells overexpres sing human MGP and treated with BMP-2 14. Furthermore, 
recombinant human BMP-2 induced osteogenic and chondrogenic differentiation of cultured VSMCs isolated from MGP-deficient mice aortas [14]. Based on these results Böstrom et al. hypothesized that the presence of chondrocyte-like cells in MGP-deficient mice aortas are the result of free (not bound to MGP) BMP-2, synthesised by endothelial cells, which induces a chondrogenic differentiation of cells intended for smooth-muscle differentiation. Whether MGP must be carboxylated in order to bind BMP-2 is not known yet.

Both intimal and medial calcification involves the deposition of calcium containing crystals and it is thought that matrix vesicles initiate bone minralization by serving as nucleation sites [3]. Matrix vesicles are small extracellular remnants produced by budding from the outer cell membranes of chondrocytes, osteoblasts, and odontoblasts. Calcification of the matrix vesicles starts with formation of the first crystals within the vesicles followed by subsequent crystal penetration of the matrix vesicle membrane. Structures similar to matrix vesicles have been identified in calcified arteries [101]. It has been suggested that matrix vesicles are formed as a result of apoptosis. 13L and chondrocyte-derived apoptotic bodies have similarities with matrix vesicles [B3]. Matrix vesicle-like structures derived from SMCs within human fatty streaks contain BAX protein, a proapoptotic member of the bcl-2 family [106]. The link between matrix vesicle-like structures and apoptotic bodies is supported by the fact that apoptosis precedes in vitro VSMC nodule calcification and that these VSMC derived apoptotic bodies can act as nucleation sites for hydroxyapatite formation [175]. Compared to confluent VSMC cultures the VSMC derived apoptotic bodies contain relative high levels of MGP [171]. Together with the before mentioned observation that overexpression of MGP in maturing chondrocytes induced apoptosis [145]. this suggest a role for MGP in apoptosis and subsequent vascular medial calcification.

\section{Clinical significance of vascular calcification}

Vascular calcification occurs in two distinct forms: intimal calcification, which always occurs in the context of atheroselerosis and medial calcification, which can occur in its absence. Intimal caleification begins as early as the second decade of life, soon after fatty streak formation [215] and increases with age and lesion progression [46, 215]. Intimal calcification only occurs within atherosclerotic plaques and moreover, coronary artery calcification occurs exclusively in atherosclerotic arteries [208]. Plaque rupture is believed to be responsible for many acute coronary disease everits, including myocardial infarction $[40,53,66]$. Whether intimal calcification stabilizes atherosclerotic plaques or promotes plaque rupture is still a matter of debate. Calcified lesions and fibrotic hypocellular lesions are much stiffer than cellular lesions [116]. Furthermore, biomechanical data suggests that 
calcification reduces the "stresses" in a plaque and does not cause ruptures [34, 91]. Ut has been suggested that when the entire fibrous cap covering a lesion is calcified the underlying plaque is encapsulated and protected from rupture [46]. Plaques with a heavily calcified cap are about five times stiffer than cellular lesions or normal vessel wall and very resistant to rupture 1117 184]. On the other hand, coronary artery calcification has been linked with atherosclerotic plaque rupture 154 ! and coronary artery and aortic calcifica tion are closely associated with increased risk for cardiovascular events 1257 2581. Calcium crystals have been shown to aggravate inflammation [38], if this is the case in an atherosclerotic plaque, enhanced inflammation would be expected to indirectly cause plaque instability [173]. These contradictory data have lead to the hypothesis that only when extensive calcification has occurred, the atherosclerotic plaque is resistant to rupture, and early or intermediate stagles of calcification may actually enhance plaque vulnerability to rupture $[46,173]$.

Tunica media calcification is an age dependent process, which occurs independentliy of atherosclerosis. Medial calcification is associated with uraemia [953], type II diabetes mellitus $[48,51]$ and diabetic neuropathy [48]. It appears to be a strong independent predictor of cardiovascular and coronary heart disease mortality $[48,51,118]$. Calcification of the arterial media leads to stiffening of the arterial tone [10]. Stiffening of the arterial tone may lead to an increase in cardiac work and systolic blood pressure, which is a highly significant predictor of myocardial infarction and vascular death [125].

\section{Vitamin K, MGP and vascular calcification}

Given the proposed role of MGP and its Gla-residues in the prevention of calcium deposition, two factors influencing arterial calcification can be deduced: (1) the level of MGP expression and (2) the vitamin K-status. Low MGP expression might be a risk factor for vascular calcification. In this light it is of interest to investigate whether patients with the TT variant of the -138 (T or C) promotor polymorphism are more sensitive to vascular calcification compared to patients with the $\mathrm{CC}$ variant [55]. For both vitamin $\mathrm{K} 1$ and $\mathrm{K} 2$, inverse correlations between dietary intake and arterial calcification have been shown $[67,94\}$. The inverse correlation found was strongest for the menaquinones. In hypercholesterolemic rabbits, high menaquinone intake suppressed the progression of atherosclerotic plaques, intimal thickening and pulmonary atherosclerosis 195. Local vitamin K-deficiency in the arterial vessel wall therefore might lead to undercarboxylated MGP and thus to increased calcification. Present RDA values for vitamin $\mathrm{K}(1.5 \mu \mathrm{g} / \mathrm{day} / \mathrm{kg}$ body weight) are solely based on the hepatic requirement for clotting factor synthesis. It is known, however, that the ratio in which $\mathrm{K} 1$ and $\mathrm{K} 2$ accumulate is tissue dependent, with relatively high $K 2$ accumulation in the pancreas, 
testis and arterial vessel wall [r 89 . Furthermore, only in extreme cases low dietary vitamin $K$ intake leads to the hepatic synthesis of undercarboxylated clotting factors [226]. For the arterial vessel wall new RDA values need to be defined for vitamin $K 1$ and $K 2$ separately. Patients and subjects at risk for cardiovascular diseases may not optimally be protected against arterial calcification because of a dietary inadequacy of vitamin $K$. Supplements containing $K 1$ and $k 2$ may contribute to optimal vascular health. Oral anticoagulants such as warfarin have more pronounced effects than vitamin Kafdiciency, most notably at young age. This was discovered in women who were anticoagulated during the first trimester of pregnancy, and who gave birth to babies with serious bone defects in $30 \%$ of the cases (the "foetal warfarin syndrome ${ }^{a r}(15,7)$. A regimen of vitamin $K+$ warfarin caused similar bone defects in young animals $[170]$ and calcification of the arterial vessel wall in aduilt animals [161. At later age, the effects of oral anticoagulants on arterial calcification are less severe (162). No data have been published about the effects of oral anticoagulants on the human arterial vessel wall. It may be expected, however, that oral anticoagulant treatment is a risk factor for arterial calcification, especially in combination with the $T T$ variant of the MGP -138 (T or Cl promotor polymorphism. 




$$
\text { วิ่ }
$$

introduction to this thesis 



\section{Introduction to this thesis}

In the first part of this thesis we investigate a novel mutation in the human $\gamma$-glutamyl carboxylase gene. The identification of this mutation is described in Chapter 2, followed by the characterisation of the purified mutated human $\gamma$-glutamyl carboxylase enzyme (Chapter 3). For this purpose, the mutation was introduced into the human gene, expressed in insect cells, and purified for further enzyme analysis. Next, we developed and characterised antibodies against human MGP (Chapter 4) and synthesised full-length MGP (Chapter 5). These tools were used in the last part of this thesis, which focuses on induced impairment of $\gamma$-glutamyl carboxylation and the role of MGP in vascular calcification. In Chapter 6 we describe the inhibition of $\gamma$-glutamyl carboxylation in the arterial vessel wall. The results from this study form the basis for our hypothesis that MK-4 serves not only as a cofactor for $\gamma$-glutamyl carboxylase, but has a second yet unknown function. This hypothesis is supported by the results from Chapter 7. In this Chapter the effects of MGP and induced impairment of $\gamma$-glutamyl carboxylation on VSMC calcification are described. The cellular distribution of MGP in cell cultures is described in Chapter 8. Finally, the findings of these studies and future directions are discussed in Chapter 9. 



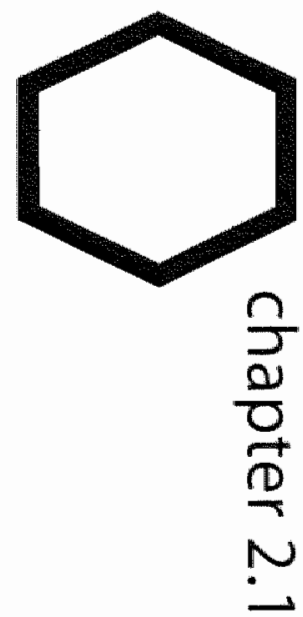

a novel mutation in the $\gamma$-glutamyl

carboxylase gene resulting in congenital

combined deficiency of all vitamin

k-dependent blood coagulation factors

h.m.h.spronk $\bigcirc$ r.a. farah $\bigcirc$ g.r.buchanan $\bigcirc$ c.vermeer $\bigcirc$ b.a.m.soute 



\section{Abstract}

A mutation in the $\gamma$ glutamyl carboxylase gene leading to a combined congenital deficiency of all vitamin $K$-dependent coagulation factors was identified in a Lebanese boy. He is the first offspring of consanguineous parents and was homozygous for a unique point mutation in exon 11 resulting in the conversion of a tryptophan codon (TGG) to a serine codon (TCG) at amino acid residue 501. The reported mutation affects $\gamma$-glutamyl carboxylation of both hepatic and extra-hepatic Gla-proteins, suggesting the presence of only one type of enzyme in all tissues. Oral vitamin $\mathrm{Kl}$ administration resulted in resolution of the clinical symptoms. Screening of several family members on this mutation with a RFLP technique based on the presence of 3 BstNI sites in the unaffected allele and 2 BstNI sites in the affected allele revealed 10 asymptomatic members who were heterozygous for the mutation, confirming the autosomal recessive pattern of inheritance of this disease. In 50 non-related normal individuals the mutation was not found. This is the second time that a missense mutation in the $\gamma$-glutamyl carboxylase gene is described which has serious impact on normal haemostasis. 


\section{Introduction}

In mammals vitamin $K$ functions as a cofactor for the endoplasmic enzyme y-glutamyl carboxylase, which catalyses the posttranslational modification of glutamate residues (Glu) into $\gamma$-carboxy glutamate residues (Gla) 225]. The only known function of these Gla-residues is to bind calcium which is essential for their biological activity [14.21. The blood coagulation factors II (prothrombin), VII, IX and $X$ were the first vitamin K-dependent proteins in which Gla-residues were discovered (223). Other Gla-containing proteins are: the anticoagulant proteins $C$ and $S$ 150,219l, protein $Z$ [156», and the extra hepatic Gla-proteins osteocalcin (OC) 74 ) matrix Gla protein (MGP) 1163 and the product of the growth-arrest-specific gene 6 (Gas6) (130).

The enzyme $\gamma$ glutamyl carboxylase is an integral membrane protein located at the luminal site of the rough endoplasmic reticulum in a wide variety of tissues, including liver, kidney, bone and aorta. Recently Stafford et al. succeeded in cloning the human $\gamma$ glutamyl carboxylase gene and in the purification of the corresponding recombinant protein [260]. The enzyme consists of 758 amino acids and has a molecular weight of $94 \mathrm{kDa}$. The cDNA has an open reading frame of 2277 nucleotides and is encoded by the 15 exons of the carboxylase gene [112]. For the conversion of Glu into Gla residues the enzyme is strictly dependent on the reduced form of vitamin $K$ $\left(\mathrm{KH}_{2}\right)$ which is the cofactor in this reaction. The energy for the Glu-Gla conversion is delivered by the simultaneous oxidation of $\mathrm{KH}_{2}$ into $\mathrm{K}$ epoxide $(\mathrm{KO})$. Recycling of $\mathrm{KO}$ by the enzymes $\mathrm{KO}$ - and $\mathrm{K}$-reductase ensures that vitamin $K$ is efficiently used [240]. Vitamin $K$ deficiency may lead to undercarboxylation of all Gla-containing proteins. Several other reasons may underlie the occurrence of undercarboxylated Gla-proteins, however. First, the recycling of vitamin $K$ may be impaired by a blockade of $\mathrm{KO}$-reductase as a result of coumarin ingestion, which may lead to an exhaustion of the available vitamin $K$ stores. Second, a malfunction of the precursor protein caused by mutation(s) in the propeptide region may result in either poor substrate recognition by carboxylase 799 or in impairment of cleavage of the propeptide from the mature Gla-protein [251. A third reason stems from a genetic disorder in the $\gamma$ glutamyl carboxylase gene.

We have previously reported on a defective $\gamma$-glutamyl carboxylase in Devon Rex cats leading to a deficiency of all vitamin K-dependent coagulation factors and shown that the low procoagulant activity in these cats was likely to be caused by a mutation in the $\gamma$-glutamyl carboxylase gene resulting in a decreased affinity for $\mathrm{KH}_{2} \mid 2091$. Hereditary combined deficiency of all vitamin $K$-dependent procoagulants and anticoagulants is a rare bleeding disorder reported only by a few authors $[12,13,37,95,154)$. Until now, in only ane report the hereditary deficiency of all vitamin K-dependent proteins was linked to a 
defective $\gamma$ glutamyl carboxylase [19]. These authors showed a missense mutation in exon 9 of the $\gamma$-glutamyl carboxylase gene leading to the conversion of an arginine into a leucine at residue 394 in the $\gamma$-glutamyl carboxylase enzyme (L394R).

In the present communication, we report a missense mutation in the yglutamyl carboxylase gene from a $G$ to $C$ that results in the substitution of a tryptophan for a serine leading to a deficiency of all vitamin $K$-dependent proteins. The mutation is held responsible for the associated bleeding symptoms.

\section{Materials and Methods}

\section{Case report}

Patient no. 4 (Figure 1) is a full-term breast-fed boy from Baalbeck, Lebanon who presented in 1996 to the emergency room at age 7 days with severe bleeding from the umbilicus. There was no history of circumcision. He was the first offspring of consanguineous asymptomatic parents (patients no. 30 and 2) from the Bekaa valley in Lebanon. There was no family history of bleeding disorders and no history of drug intake during pregnancy. On arrival at the emergency room, he was pale with poor peripheral perfusion. actively bleeding from the umbilicus. He required sutures, blood transfusion and close observation in the intensive care unit. Laboratory evaluation showed markedly prolonged PT and PTT values (both $>100 \mathrm{sec}$ ). Renal and liver functions were normal. There was no evidence of fat malabsorption or skeletal abnormalities. He received transfusilons of fresh frozen plasma as well as parenteral vitamin $K 1$ which controlled his bleeding and he was discharged from the hospital. Data from further laboratory investigations are summarized in Table 1. Since then, he has had spontaneous bruising, several episodes of oral mucosal bleeding and three episodes of rectall bleeding requiring hospitalisation and infusion of vitamin $\mathrm{K} 1$ and fresh frozen plasma. He has no evidence of skeletal abnormalities by $X$-ray imaging. After diagnosis of deficiency of all vitamin- $K$ dependent factors, he was given 5 mg/day of vitamin $\mathrm{K} 1$ orally (phytomenadione, Roche, Basel, Switzerland) resulting in marked improvement of his bleeding tendency. Because the numerous bleeding episodes had resulted in iron deficiency anaemia, he also received iron in therapeutically doses. His vitamin $K 1$ dose was decreased to $2.5 \mathrm{mg} / \mathrm{day}$, and he remained stable with no evidence of bleeding.

\section{Blood collection}

After informed consent from his parents. EDTA blood samples were obtained on the patient, his parents and several family members for DNA analysis and citrated samples for coagulation assays. 


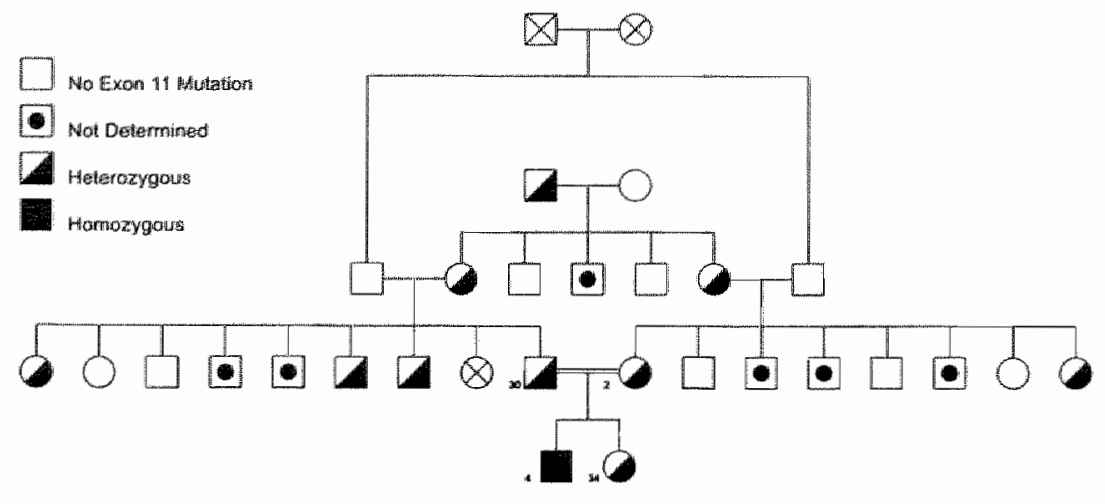

Figure 1

Pedigree of W5015 mutation. Pedigree of the Lebanese family showing the segregation of the W5015 mutation in the roglutamyl carboxylase gene.

\begin{tabular}{|c|c|c|c|c|c|}
\hline \multirow[t]{2}{*}{ Patient: } & \multirow[t]{2}{*}{30} & 2 & \multicolumn{2}{|l|}{4} & \\
\hline & & Age: & 7 Days & 18 Months & 20 Months ${ }^{*}$ \\
\hline PT & $12^{* \prime}$ & $12^{\prime \prime}$ & $>100^{\prime \prime}$ & $>100^{\prime \prime}$ & $20.2^{11}$ \\
\hline PTT & $30^{\prime \prime}$ & $32^{\prime \prime}$ & $>100^{\prime \prime}$ & $>100^{\prime \prime}$ & $36^{\mathrm{tR}}$ \\
\hline Fibrinogen & $3.9 \mathrm{~g} / \mathrm{L}$ & $2.8 \mathrm{~g} / \mathrm{L}$ & $2.8 \mathrm{~g} / \mathrm{L}$ & $2.8 \mathrm{~g} / \mathrm{L}$ & $2.8 \mathrm{~g} / \mathrm{L}$ \\
\hline Bleeding Time & $2^{\prime \prime} 00^{* \prime}$ & $2^{*} 30^{* \prime}$ & $1^{\prime \prime} 30 "$ & - & - \\
\hline Platelets & 296,000 & 273,000 & 154,000 & 448,000 & 301,000 \\
\hline Factor $\|^{* *}$ & 100 & 116 & - & 4.8 & 36 \\
\hline Factor V & 85 & 88 & 76.5 & 100 & - \\
\hline Factor VIII & 62 & 90 & $<1$ & $<1$ & 30 \\
\hline Factor VIII & 100 & 80 & 100 & 100 & 100 \\
\hline Factor IX & 100 & 60 & 9 & 6.4 & 40 \\
\hline Factor $X$ & 100 & 100 & 26 & $<1$ & 66 \\
\hline Protein $\mathrm{C}$ & 90 & 110 & - & - & 40 \\
\hline Protein $S$ & 84 & 107 & - & - & 35 \\
\hline $\mathrm{UCOC}^{*-* * * *}$ & 100 & 100 & & & $>200$ \\
\hline Vitamin $K 1$ & - & - & - & - & . $>1 \mathrm{ng} / \mathrm{mL}$ \\
\hline Vitamin $K 1 \% O$ & - & - & - & - & $0.38 \mathrm{ng} / \mathrm{mL}$ \\
\hline
\end{tabular}

Table 1

Summary of patient"s laboratory data of blood coagulation and vitamin Kudependent proteins. plasma levels. (*): After 2 months oral vitamin $k 1$ therapy $(5 \mathrm{mg} / \mathrm{day})$. (**): All vitamin $\mathrm{K}$ dependent proteins plasima tevels are in percentage of nomal. (**): ucoC stands for undercarboxylated osteocalcin.

\section{Undercarboxylated osteocalcin}

The serum concentration of undercarboxylated osteocalcin was measured with the commercially available Takara Kit (Takara Shuzo, Tokyo, Japan) according to the manufacturer's instructions. 
Coagulation assays

Prothrombin, factor $\mathrm{V}, \mathrm{VII}, \mathrm{X}$ and $\mathrm{X}$ were determined by one stage coagulation assays using immuno-depleted plasma according to the manufacturer's protocol (Stago, Asnieres-sur-Seine, France). Protein C was determined with a clotting assay after activation with Agkistrodon c. contortrix venom and protein 5 by clotting assay based on the cofactor activity of protein $S$ which enhances the anticoagulant action of activated protein C (5taclot, Asnieres-sur-Seine, France).

\section{Genomic DNA samples}

Genomic DNA was extracted from leukocytes by means of the QIAamp Blood Kit (Qiagen GmbH, Hilden, Germany) according to the manufacturer's instructions.

\section{Polymerase chain reaction}

The 15 exons of the $\gamma$-glutamyl carboxylase gene were screened for mutations by PCR amplification and subsequent sequencing of both strands. A typical PCR reaction contained: $50 \mathrm{mM} \mathrm{KCl}, 10 \mathrm{mM}$ Tris- $\mathrm{HCl}$ pH $9.0,1.5 \mathrm{mM}$ $\mathrm{MgCl}_{2 n} 100 \mu \mathrm{M}$ dNTP's (Amersham Pharmacia Biotech, Roosendaal, The Netherlands), $500 \mathrm{ng}$ forward primer and $500 \mathrm{ng}$ reverse primer (Table 2), 1.5 U Taq DNA Polymerase (Amersham Pharmacia Biotech, Roosendaal, The Netherlands), $10 \%(v / v)$ dimethyl sulfoxide (DMSO) and $300 \mathrm{ng}$ human genomic DNA in a total volume of $50 \mu \mathrm{L}$. All PCR amplifications were performed in a DNA Thermal Cycler 480 (PE Biosystems, Nieuwerkerk a/d $\|$ Issel, The Netherlands). All amplifications first underwent an initial denaturation of 5 minutes at $95^{\circ} \mathrm{C}$ followed by 33 cycles of denaturation for 1 minute at $95^{\circ} \mathrm{C}$, primer annealing for 1 minute at temperatures as indicated in Table 2 and primer extension at $72{ }^{\circ} \mathrm{C}$ for 2 minutes. A final 5 minute extension at $72{ }^{\circ} \mathrm{C}$ was performed before cooling the reactions to $4^{\circ} \mathrm{C}$. After PCR amplification, products were purified using the commercial "High Pure PCR product purification" kit according to the manufactures instructions (Roche, Basel, Switzerland). Sequence analysis of all purified PCR amplification products were performed by means of the BigDyeTM Terminator Cycle Sequencing Kit according to the manufactures instructions (PE Biosystems, Nieuwerkerk a/d Ussiel, The Netherlands) and analysed on the ABI Prism 310 Genetic Analyzer (PE Biosystems, Nieuwerkerk a/d IIssel, The Netherlands).

\section{Analysis of exon 11 mutation (W5015)}

For simple analysis of the W5015 mutation, a 246 bp fragment including exon 11 was amplified using primers Carb-E-X|-5 and Carb-E-XI-3. PCR amplification conditions were the same as described above. After purification, $15 \mu \mathrm{L}$ PCR product was digested with $10 \mathrm{U}$ BstNI (New England Biolabs, Beverly, MA) at $37^{\circ} \mathrm{C}$ for 3 hours. Restriction enzyme fragments were analysed by gel 
electrophoresis on a $4.0 \%(\mathrm{w} / \mathrm{v})$ MetaPhor Agarose gel (FMC BioProducts, Rockland, ME).

Exon No. Elongation Primer Sequence $\left(5^{\circ}>3^{\circ}\right)$
Temperature
$\left({ }^{\circ} \mathrm{C}\right)$

1

47

Carb-E-1-5

CTAGGGAAGCAAATTCTCCTG Carb-E-1-3

ACCGGGAGACACTGGGCGTC

2

60

Carb-E-4I-5

Cuarb-E-11-3

GAGCTGTTGGTGCAGTGATITC AGAGATTGTCATTCTICCACTCT

3

57

Carb-E-111-5 Carb-E-111-3

GTACTGTGCAGAGTAGGCACTO TTCACCAGCATGCTICTAITTC

4

57

Carb-E-IV-5

Carb-E-IV-3

CTGGGCCTGTGGTGATCTCTTG TGATAACCATCCTGACCCAGCCA

5

57

Carb-E-V-5

Carb-E-V-3

GCTCCCCCCTCCAATGTTTACCT GTGGGATGGCCATGCTGACCAC

6

60

Carb-E-VI-5

TGTAACTCAGGAGCATGGATTC Carb-E-WI-3

CATTACTGAGAGAGATGAGTCAC

Carb-E-VII-5

Carb-E-VII-3

TTCGTGCTGTGAATGTGCITTGA GCTAGTCCCTTCCTGCAAAACTG

$8 \& 9$

57

Carb-E-VIII-5

GAGGCCCAGCCAAACTCCT Carb-E-HXX-3

CAAAGCACAAGGGGGCTCTG

10

57

Carb-E-X-5

Carb-E $\times \times-3$

GGCAGTGCATGACATGTCTTGG AAGCAAGGGCTGTTCATCTTGG

11

57

Carb-E-XI-5

Carb-E-XI-3

GGTGGCTGTGATGTCCTTAGAA AAGACAGAAAAGCCTCTCCTCA

12

Carb-E-XXll-5

Carb-E-XII-3

GCCATGGGGTGGGATGATGAAC TGCACTCAGTICTITCTGCTGTTG

13 57

Carb-E-XIII-5 Carb-E-X X H -3

GGAGGCCATAAGCTGGCTAGAG GGCTAGAACATCATTCATAACC

14

57

Carb-EM XIV-5

CTAGCTGGCAGAAGAGGAGTTC Carb-E-XIV-3 TATGATGGCAATGACAAATATTG

15 57

Carb-E-XV-5 Carb-E-XW-3

GGAGGAGTGAGGACCAGGTGC TGTCCATTGCATAGAATGGGTC

Table 2

PCR ellongation temperatures and direct sequencing of palutamyl carboxylase gene. 


\section{Results}

Repeated tests showed that all blood coagulation factors were normal except for the vitamin K-dependent factors $\|(4.8 \%)$, VII $(<1 \%), 1 X(6.4 \%)$ and $X(<1 \%)$ (Table 1$)$. It was established that these low concentrations were not caused by vitamin K-deficiency due to mallabsorption, liver disease or accidental anticoagulant ingestion. A missense mutation in exon 9 as reported by Brenner et al. [19] was initially thought to be the reason for the coagulation problems found in the patient. However, screening with a specific PCR approach based on the introduction of an Alu I site in the amplified PCR product of exon 9, as described by these authors, failed to show the L394R mutation in the carboxylase gene of the patient. Screening of all exons including intron/exon borders was necessary to identify a potential new mutation in the $\gamma$-glutamyl carboxylase gene. Primers that were used for the PCR amplification are listed in Table 2, and the amplified products were subsequently cycle sequenced using either the corresponding forward or reversed primer.

A

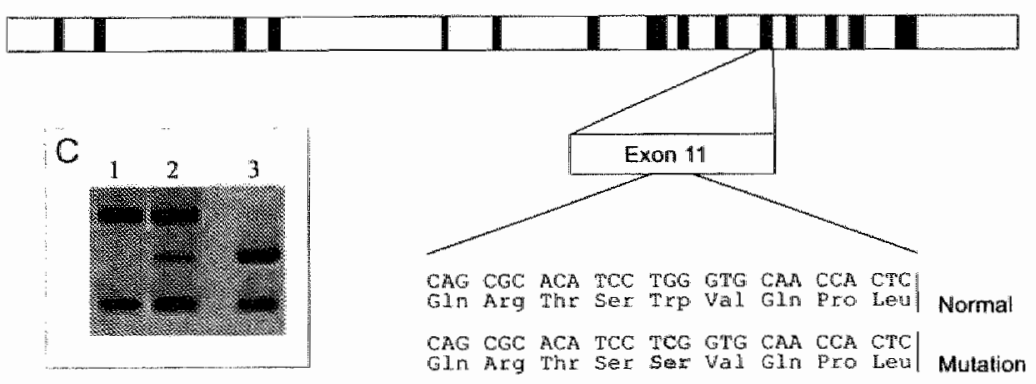

B

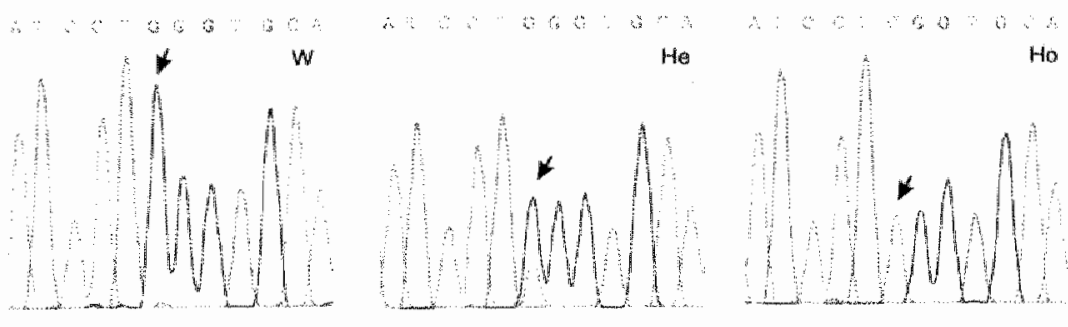

Figure 2

Identification of W5015 mutation. A: Schematic representation of the humar rylutamyl carboxylase gene structure. The 15 exons are indicated in black and in detail the $G$ to $C$ transition in exor 11 at codon 501 . This nucleotide substitution results in a Tryptophan to serine replacement in the protein. B: Sequence analysis of genomic DNA from a nomal control person (W), a heterozygous patierv (He), and the homozygous patient (Ho). C: RFLP analysis of the W5015 mutation, which results in loss of a BstNll site in the amplitied exon 1 il DNA. Lane 1: patient's DNA homozygous for the mutation; Lane 2: Heterozygous pattern; lane 3. normal, control. 
Sequence analysis of the 15 exons in the carboxylase gene revealed that the patient was homozygous for a unique point mutation in exon 11 resulting in the conversion of a tryptophan codon (TGG) to a serine codon (TCG) att residue 501 (W5015, Figure 2A). Other mutations were found neither in the exons nor in the intron/exon regions. The asymptomatic parents had normal coagulation patterns and were both heterozygous for the W5015 mutation (Figure 2A and Figure 1 patients no. 30 and 2). We designed a simple RFLP technique for the detection of the mutation based on the presence of 3 BstNI sites in the unaffected allele and 2 BstNI sites in the affected allele (Figure $2 C$ ). Using this technique we analysed 50 normal Caucasian individuals and most members of the pedigree. In none of the Caucasian individuals the mutation was found (data not shown), whereas in the related individuals eight heterozygous members were demonstrated (Figure 1). In none of the heterozygous members procoagulant activities were affected, confirming the autosomal recessive pattern of inheritance of this disease.

\section{Discussion}

Here we report a combined congenital deficiency of all vitamin K-dependent blood coagulation factors that is associated with a mutation in the $\gamma$ glutamyl carboxylase gene resulting in the conversion of tryptophan into serine at amino acid residue 501 (W5015). Although combined deficiencies of vitamin K-dependent procoagulants have been reported in the literature on several occasions, the $\mathbb{L 3 9 4 R}$ mutation in the $\gamma$ glutamyl carboxylase gene as described by Brenner et al. [19] is the first case in which a naturally occurring mutation is responsible for such a deficiency. The impact of this mutation on the procoagulant activity is explained by these authors as a decreased affinity of substrates for the carboxylase propeptide binding site leading to impaired carboxylation. The fact that this defect could partly be corrected by the administration of a high dose of vitamin $K$ indicated that the L394R mutation does not result in a complete inactivation of $\gamma$-gllutamyll carboxylase. However, the mechanistic properties resulting in this combined deficiency have not yet been characterized.

In this paper we describe a second case in which a missense mutation in the $\gamma$-glutamyl carboxylase gene is responsible for low procoagulant activity. It was confirmed that the L394R mutation was not the reason for the defect. Vitamin $K$ deficiency due to malabsorption, liver disease or anticoagulant ingestion was excluded and because the patient had undetectable vitamin $K$ epoxide serum levells, abnormality of vitamin $K$ epoxide reductase levels could also be ruled out. Interestingly, orally administered vitamin $\mathrm{K} 1$ resulted in the resolution of the clinical symptoms, just as was the case in the patient described in the Brenner report. Theoretically, the mutation might affect either the vitamin $\mathrm{K}$ binding site or the propeptide binding site. In both cases 
the efficacy of orally given vitamin $K 1$ could be explained by the fact that under physiological conditions the concentration of the cofactor is near or below its $K_{w}$. The effect of vitamin $K$ administration, the only parameter which can be varied, may be explained by an increase of the rate of carboxylation. resulting in a partial correction of the deficiency. In preliminary expression studies W501A (tryptophan changed into alanine) mutated recombinant Y-glutamyl carboxylase was expressed in High five insect cells. With this mutant carboxylase it was demonstrated in in vitro experiments that a serious decrease in $\gamma$-glutamyl carboxylase activity had been induced $(D$. Stafford, personal communication). This suggests that the Trp501 is critical for carboxylase activity, and it is to be expected that the W5015 $\mathrm{\gamma}$-glutamyl carboxylase mutation as found in the present report has the same impact on the carboxylase activity. This would explain the observed low activity of all vitamin K-dependent coagulation factors. Sugiura et al. already described that point mutations at the charged residues $513 / 515$ resulted in a $\gamma$-glutamyl carboxylase enzyme with reduced affinity for the propeptide [222]. Earlier, we reported a diefective $\psi$-glutamyl carboxylase in Devon Rex cats resulting in a bleeding tendency. We have identified the nature of this abnormality as a mutation in the $\gamma$-glutamyl carboxylase substrate binding site leading to an increased dissociation constant for reduced vitamin $\mathrm{K} 1$ and consequently to an increased requirement for vitamin $\mathrm{K} 1$. The clinical phenotype in the Devon Rex cats is similar to the phenotype found in the r-glutamyl carboxylase W5015 mutant of the patient, which suggests that both mutations are located in a corresponding sequence of the $\gamma$-glutamyl carboxylase gene. In the patient's plasma, descarboxy-osteocalcin was also demonstrated in high concentrations, which indicates that not only hepatic proteins but also extra-hepatic proteins are affected by the mutation in the $\gamma$ glutamyl carboxylase. This is consistent with the present view that only one gene encodes the $\gamma$-glutamyl carboxylase in all tissues where it is found. Since Gla-proteins are not only involved in blood coagulation but also in preventing (soft) tissue calcification, the reported mutation may potentially lead to bone malformations and/or increased risk for arterial calcification.

In summary, this is the second time that a naturally occurring mutation is found in human $\gamma$ glutamyl carboxylase, which has serious haemorrhagic consequences. The rapid diagnosis of the W5015 mutation makes it possible to identify the defect in the $\gamma$-glutamyl carboxylase gene in these and further families and to predict associated bleeding disorders in the future. However, to examine the impact of the W5015 mutation on the enzymatic aspects of $\gamma$-glutamyl carboxylase it is necessary to obtain the recombinant W5015 mutant form. 


\section{Acknowledgments}

We thank Drs. Rony Sayad, Myrna Germanos and Mrs. Amale Richa for their contribution. We are grateful to Dr. Darrel Stafford for sharing with us unpublished data, to Dr. Gulltaume van Eys for helpful discussion and to Mrs. Kitty Linssen for excellent technical assistance. 




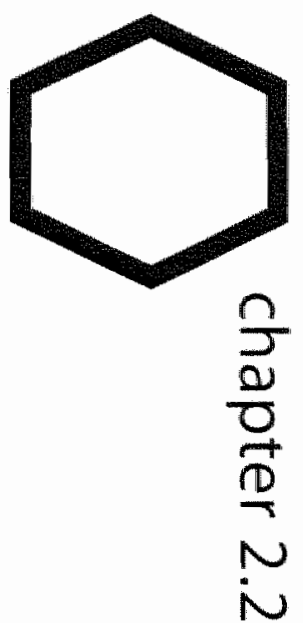

congenital combined deficiencies of all

vitamin K-dependent coagulation factors 

Congenital combined deficiencies of all vitamin $K$-dependent coagulation factors are a rare bleeding disorder. Recently, we reported a missense mutation of the $\gamma$ glutamyl carboxylase gene, resulting in a serine codon (TCG) instead of a tryptophan codon (TGG) at amino acid residue 501 of the $\gamma$-glutamyl carboxylase enzyme [2.10]. The carboxylase gene is located on chromosome 2 and has 15 exons which encode a MRNA with an open reading frame of $2277 \mathrm{nt}$. The $\gamma$ glutamyl carboxylase enzyme consists of 758 amino acids and has a molecular weight of $94 \mathrm{kDa}[260$. Vitamin $k$ is a necessary cofactor in the $\gamma$-glutamyl carboxylation reaction in which specific glutamic acid residues (Glu) in a number of proteins are modified into $\gamma$-carboxy glutamic acid residues (Gla) including the procoagulant factors $\|_{\text {, }}$ VII, IX, and $X$, the anticoagulant proteins $C$ and $S$, and the extra-hepatic proteins osteocalcin and matrix Gla protein. These Gla residues serve as binding sites for calcium and are a prerequisite for normal haemostasis [63].

Here we describe a second patient with a congenital deficiency of all vitamin $K$-dlependent coagulation factors which is caused by a defective $\gamma$-gllutamyl carboxylase consistent with the conversion of a tryptophan codon (TGG) to a serine codon (TCG) at amino acid residue 501. The older sister, parents, grandparents and great grandmother were all asymptomatic and heterozygous for this mutation, indicative for the autosomal recessive patterin of inheritance. The patient was a full term, breast fed female infant adrnitted at her 3 rd day of life for multiple bruises and glastrointestinal haemorrhage. Symptoms resolved after administration of vitamin $\mathrm{K}(5 \mathrm{mg} / \mathrm{day}$ for $3 \mathrm{days}$ ) and she was discharged from the hospital. At 3 months she suffered from a spontaneous intracerebral haemorrhage with a $2 \mathrm{~cm}$ haematoma in the right frontal lobe and a subarachnoidal haemorrhage. A 3 year old sister was in good health. Parents were first degree consanguineous. There was no other known family history of abnormal bleeding. Physical examination showed a welldeveloped and nourished infant. There was no evidence of malabsorption, liver disease or medicine intake. Blood urea nitrogen (BUN), creatinin, electrolytes, liver enzymes, and lipoprotein electrophoresis were all normal. On serial testing the patient showed prolonged prothrombin time at $21 \%$ "NR: 3.8 ) and prolonged partial thromboplastin time (aPTT) at $41^{\prime \prime}$ (control $\left.28^{*}\right)$, that both improved after vitamin $\mathrm{K}$ administration $(5 \mathrm{mg} /$ day twice) but returned to baseline levels 72 hours after. Fibrinagen and bleeding time were normal. Dosage of coagulation factors showed: factor $11: C 9 \%$ factor VII:C $35 \%$, factor $X: C \quad 30 \%$, factor $\| X: C \quad 13 \%$, and factors $V: C$ and $X \| 1 \mathrm{C}$ 100\%. Activity of vitamin $K$-dependent factors slightly improved after vitamin $K$ administration (Table 1). Serum levels of vitamin K estimated 15 days after administration were still elevated ( $4134 \mathrm{ng} / \mathrm{mL}$ ). Vitamin K epoxide levels were undetectable. Descarboxy factor 11 was elevated at $2100 \mathrm{ng} / \mathrm{mL}$ (normal < 2). The patient received intramuscularly $5 \mathrm{mg}$ vitamin $k$ twice weekly for two weeks and then $5 \mathrm{mg}$ once a week (for four weeks) and then $5 \mathrm{mg}$ once a month with 
significant clinical improvement. Vitamin $K$ administration was stopped after 16 months and a follow up examination at three and a half years showed no abnormalities. Since then the prothrombin time spontaneously returned to $31 \%$ (INR: 2.5$)$.

Before Vitamin $K$

After Vitamin $\mathrm{K}$

PT

$21 \%$

$40 \%$

INR

3.8

aPTT

$41^{11} / 28^{\prime \prime}$

$36^{\prime \prime} / 28^{\prime \prime}$

Factor II

$9 \%$

$13 \%$

Factor VII

$35 \%$

$69 \%$

Factor IX

not determined

$13 \%$

Factor $X$

$30 \%$

$38 \%$

Protein $\mathrm{C}$

not determined

$38 \%$

Factor $\mathrm{V}$

$100 \%$

Factor XIII

$100 \%$

\section{Table 1}

Summary of patient's laboratory data of blood coagulation and vitamin K-dependent proteins plasma levels. (PT, prothrombin time; INR, international nomalised ratios; $A P T T_{n}$ activated partial thromboplastin time)

Genomic DNA extraction from leucocytes, PCR amplification and subsequent sequencing of both strands of all 15 exons were performed according to Spronk et al. 1210 Except for the W5015 mutation as described by Spronk et al. no abnomalities in other exons were found. The patient was found to be homozygous for the W50IS mutation in contrast to both parents and the asymptomatic sister who were found to be heterozygous (Figure 1). Analysis of seven related individuats showed that five of them were heterozygous (Figure 1) and that none of the procoagulant activities were decreased. confirming the autosomal recessive pattern of inheritance of this disease.

There are several reasons by which impaired $\gamma$-glutamyl carboxylation, leading to a decreased activity of the vitamin $k$-dependent proteins, can be induced. Vitamin K-deficiency and ingestion of coumarin derivatives are the two common ones. Bleeding disorders caused by inherited deficiency of vitamin K-dependent procoagulants have only been reported in a few cases. Diagnosis of the W5015 mutation as described by Spronk et al explained the clinical phenotype of the patient. Recognition of the witamin K-dependent 
coagulation factors by Yglutamyl carboxylase is dependent on the propeptide sequence at the $\mathrm{N}$-terminus of the immature protein. Regions around amino acid residues $234,406,513$ of the $\gamma$ glutamyl carboxylase are involved in propeptide binding $[222]$. The W5015 mutation in proximity to one of these propeptide binding sites on $\gamma$-glutamyl carboxylase might influence this binding. Assuming that under physiological conditions the cofactor concentration is marginal, the observed increase in active coagulation factor levels after vitamin $\mathrm{K}$ administration may be explained by an increased carboxylation rate. The segreglation pattern of the W5015 mutation confirms the autosomal recessive pattern of inheritance for combined deficiency of the vitamin K-dependent coagulation factors in this family. In all reported cases until now the clinical presentation and evolution is different $118,19,37,71$. $95,133,154,155,2421$. Whether this is caused by other genetic factors or by a different availability of vitamin $K$ remains to be investigated.

This is the second patient in which the W5015 mutation in the $\gamma$-glutamyl carboxylase gene is described. Identification of the mutation on the carboxylase gene allows diagnosis of potential calriers as well as prenatal diagnosis for this hereditary bleeding disorder.

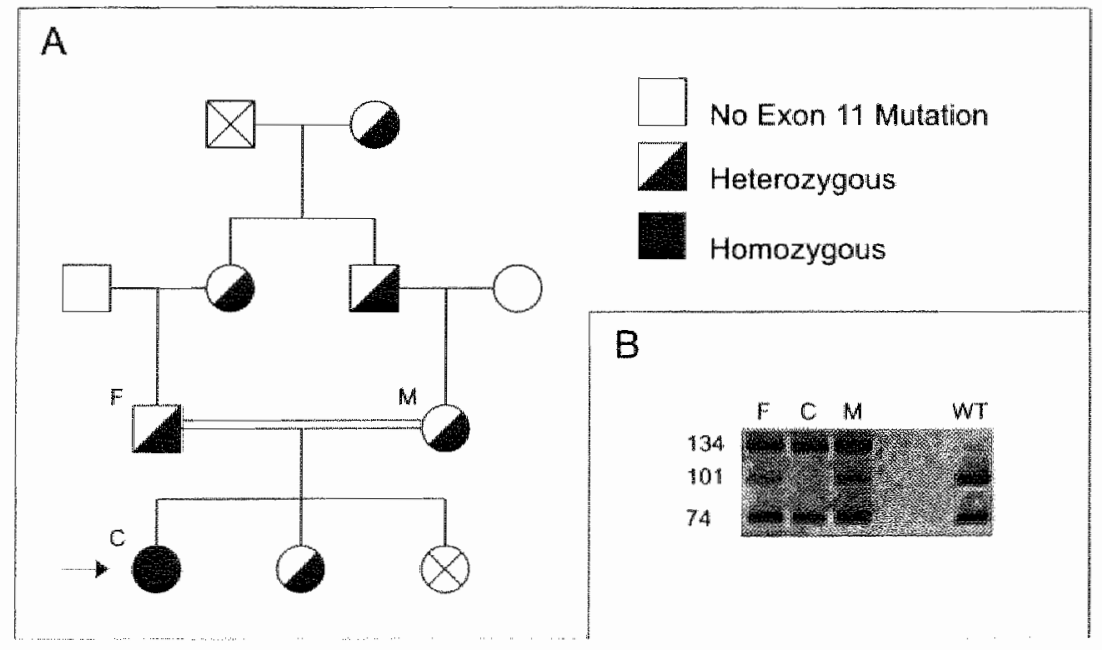

\section{Figure 1}

A. Pedigree of the family showing the segregation of the W5015 mutation in the frolutamyl carboxylase gene. Only members of the family available tor the study are shown. Afrectad subjects, carrier subjects, and unaffected subjects are indicated by solid symbolls, half solid symbols, and open symbols respectively. The member indicated with died of bleding. The member indicated by the $\rightarrow$ is our proband.

B. RFLP analysis of the W501S mutation, which results in loss of a Bstwits ste in the amplified exon 11 DNA. F: Heterozygous father, $C$ homozygous affected child. M: heterozygous. mother, WT: wild-type control. 



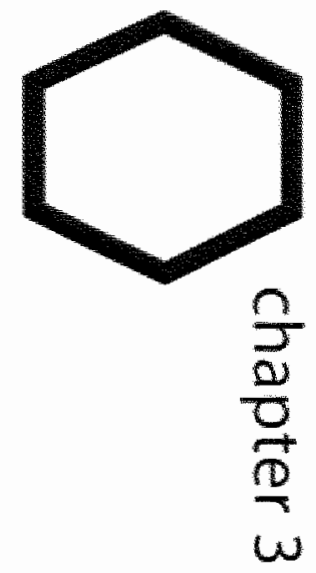

characteristics of recombinant w501s

mutated human $\gamma-g$ lutamyl carboxylase

b.a.m.soute $\bigcirc$ d.y.jin $\bigcirc$ h.m.h spronk $\bigcirc$ v.p.mutucumarana $\bigcirc$ p.j.lin

t.m. hacking $O$ d.w. stafford $\bigcirc$ c.vermeer

submitted 



\begin{abstract}
A mutation (W5015) in the vitamin K-dependent $\gamma$-glutamyl carboxylase (VKC) that leads to a congenital bleeding disorder was recently discovered in two patients. To characterize the enzyme defect, recombinant VKC-W5015 was expressed in and purified from insect cells. The major effect of the mutation appears to be to decrease the affinity of the carboxylase for the propeptide of its substrates. This observation agrees with recent data of Lin et al. [121] that places part of the propeptide binding site within residues 495513 of VKC. Additionally, we demonstrate that the affinity between descarboxy osteocalcin (d-OC) and VKC remains unaffected by the W501S mutation. This confirms earlier data that the high affinity site for $\mathrm{d}-\mathrm{OC}$ is not located on the propeptide binding domain of VKC. Two properties of the enzyme suggest an explanation for the observation that vitamin $K$ supplementation ameliorates the effects of the mutation: 1 , since full carboxylation requires the propeptide to remain bound to the enzyme sufficiently long for full carboxylation, a reduced affinity can cause its premature release before carboxylation is complete; 2 , propeptide binding results in a decrease of the $K_{m}$ for vitamin $K$ hydroquinone in wild type, but not in mutant carboxylase resulting in increased vitamin $K$ requirement of affected subjects.
\end{abstract}




\section{Introduction}

The vitamin K-dependent post-translational modification of glutamate residues (Glu) into $y$-carboxyglutamate residues $(G / a)$ is a specific process performed in all mammalian species [223]. Although originally only some bload clotting proteins were thought to require this madification it is now recognized that a number of proteins involved in bone metabolism and calcium homeostasis also require Gla residues for function $[64,161,193]$. Except for matrix Gla protein, all known Gla proteins are syruthesized in a precursor form in which a propeptide sequence serves as a high affinity recognition site for VKC $(96,214)$. The conserved propeptide sequence is not only essential for directing $\gamma$ glutamyl carboxylation of most of these proteins, but also modulates the $K_{w 4}$ for the cofactor vitamin $K$ hydroquinone $\left(K_{2} H_{2}\right)(35,209]$. During the carboxylation reaction, $\mathrm{KH}_{2}$ is converted into vitamin $\mathrm{K} \mathrm{2}$,3epoxide (KO). Recycling of KO via the quinone into the hydroquinone form is mediated by vitamin $K$ epoxide reductase (VKOR). Obviously, undercarboxylation of all vitamin $K$-dependent proteins may result from a malfunction of either the enzymes involved in this process, VKC or VKOR, from malabsorbtion of vitamin $K_{\text {, }}$ or vitamin $K$ deficiency.

Congenital combined deficiency of all vitamin $\mathbb{K}$-dependent blood coagulation factors is rare and only a few cases are reported in the literature $[12,20,37,95,154]$. To date, the deficiency could only be related unequivocally to a molecular defect of VKC in three patients $119,138,210]$, whereas evidence for a mutation in VKOR has been reported in two families $[149,154]$. In all these reports the deficiency resulted in a diversity of phenotypes varying from hemorrhagic diathesis (which in some cases could be corrected by oral administration of vitamin $k$ ). to skeletal abnormalities suggesting poor vitamin $\mathrm{K}$ status of both the liver and extra-hepatic tissues [12). Brenner et al. [19] showed that a L394R mutation in VKC caused a severe bleeding disorder, which Mutucumarana et al. (140) found to be mainly the result of a defective glutamate-binding site.

Recently we reported that a bleeding disorder in two patients with combined deficiency of all vitamin K-dependent proteins was the result of a missense mutation in exon 11 (Trp 501 to Ser: W5015) of the human VKC gene $1138,2101$. In both patients the deficiency could be correcied by administration of vitamin $K$. The W5015 mutation is located in a region where several authors reported a possible propeptide binding site. Wu et al. [262] described a propeptide binding site near residues $438-507$, a region reported to reside in the lumen of the endoplasmic reticulum (ER) 12291. A propeptidelike sequence within VKC (residues 495-513) was suggested by Price and Willliamson to function as an intra-molecular inhibitory domain preventing the carboxylation of substrates lacking a propeptide [169]. However, recently 
Lin et al. (n21) characterized this region as a part of the enzyme directly involved in propeptide binding. Here we report on the expression, purification and characterization of recombinant W5015 mutant carboxylase from insect cells.

\section{Materials and Methods}

\section{Materials}

All chemicals were of analytical grade or better. Vitamin $\mathrm{K} 1$ was purchased from Abbott (Abbott Park, IL), $\mathrm{NaH}^{14} \mathrm{CO}_{3}$ with a specific activity of 56 $\mathrm{mCi} / \mathrm{mmol}$ was from ICN Pharmaceuticals (Costa Mesa, CA), CHAPS (3-[13cholamidopropyl) dimethylammoniol-1-propane sulfonate\}, L- $\alpha$-Phosphatidylcholine (type $X-E$ ) and pepstatin were from Sigma (St. Louis, MO). Leupeptin, aprotinin, and phenylmethylsulfonyl fluoride were from Roche Applied Science (Indianapolis, $N$ N). FLEEL was purchased from Bachem (Philadelphia, PA). ECL Western blotting detection reagents were from Amersham Pharmacia Biotech (Piscataway, NJ). The peptide proflX19, containing the sequence AVFLDHENANKILNRPKRY, was synthesized by Dr. Frank Church (University of North Carolina, Chapel Hill, NC) and FIXproGla, a 59-residue recombinant peptide containing the propeptide and first 41 esidues of the Gla domain of human factor IX, was prepared as described previously [263]. Synthetic descarboxy osteocalcin (d-OC) was synthesized by

Dr. Paull Proost (The Rega Institute, Department of Molecular Immunology Catholic University of Leuven, Belgium), according to Wuyts et al. [265]. The consensus propeptide, AVFLSREQANQVLQRRRR, was synthesized by manual solid phase peptide synthesis using tBoc chemistry protocols [196]. The pSK vector was from Stratagene (La Jolla, CA) and the insect cell expression wector (PVL1392) was purchased from Pharmingen (San Diego, CA). The baculovirus viral DNA (BacVector 3000) was purchased from Novagen (Madison, W). The Sf9 cells (Spodoptera frugiperda) were obtained from the Lineberger Cancer Center (University of North Carolina,Chapel Hill, NC), and the High Five cells (Tricholusia ni) were a gift from Dr. Thomas Kost of Glaxo-Welcome Inc. (Research Triangle Park, NC). The HPC4 antibody affinity resin was provided by Dr. Charles Esmon (Oklahoma Medical Research Foundation, OKlahoma (City, OK) and the anti-FLAG M2 monoclonal antibody and MET-FLAG bacterial alkaline phosphatase were from Sigma. Peroxidaseconjugated goat anti-mouse immunoglobulin was from Jackson ImmunoResearch (West Grove, PA).

\section{Expression of Recombinant Wild-type and W5015 Mutant Carboxylase}

The CDNA encoding the human $\gamma$ glutamyl carboxylase [260] was cloned into the pSK-vector either as such or after modification by site-specific mutagenesis [1:1] to give the w5015 mutant. Both constructs contained 
amino terminal the sequence encoding the FLAG epitope (DYKDDDDK) and C-terminal the HPC4 tag containing the sequence EDQVDPRLIDGK 216 . The engineered DNA constructs were subcloned into the pVL1392 vector and both wild-type and mutant carboxylase were expressed in baculovirusinfected High Five cells as described previously [213). Preparation of microsomes from High-Five insect cells followed by solubilization and purification of the microsomel pellet were performed as described previously [140].

\section{SDS-Polyacrylamide Gel Electrophoresis and Western Blot Analysis}

Purified wild-type and mutant carboxylase were analyzed by silver-stained SDS-polyacrylamide gel electrophoresis (10\% gels, Bio-Rad) and by Western blot analysis as described [140].

\section{Carboxylase assay}

Standard reaction mixtures $(125 \mu \mathrm{l})$ contained: $40 \mathrm{nM}$ of purified proteins, 25 mM MOPS pH 7.4, $500 \mathrm{mM} \mathrm{NaCl,} \mathrm{0.16 \%} \mathrm{CHAPS,} 0.16 \%$ phosphatidyl choline, $1.4 \mathrm{mM} \mathrm{NaH}^{\prime 4} \mathrm{CO}_{3}(10 \mu \mathrm{Ci}), 222 \mu \mathrm{M}$ of vitamin $\mathrm{K}$ trydroquinone $\left(\mathrm{KH}_{2}\right), 6 \mathrm{mM}$ DTT, and various concentrations of FLEEL or FIXproGla. The mixture was incubated at $20^{\circ} \mathrm{C}$ in sealed tubes, during 30 minutes in case of FLEEL and 60 minutes in case of propeptide containing substrates. Kinetic analysis was performed on equal aliquots. substracted from the incubation mixture at $t=0$, $t=15$, and $t=30$ or $t=60 \mathrm{~min}$ if applicable. Inhibition experiments were done under the same reaction conditions and incubation times as above. All reactions were stopped by adding $0.8 \mathrm{~mL}$ of $5 \%$ trichloroacetic acid to $100 \mu \mathrm{L}$ of reaction mixture and unbound ${ }^{14} \mathrm{CO}_{2}$ was removed by boiling for 3 minutes. Total incorporation was determined using a Wallac 1414 Winspectrall iquid scintillation counter (EG\&G Wallac, Turku, Finland). Data are expressed as pmol " $\mathrm{CO}_{2}$ incorporated per minute. Kinetic parameters were determined by fitting to the Michaelis-Menten equation by non linear regression 1220

\section{Results}

Expression and purification of W5015 and wild-type human Y-glutamy/carboxylase The expression of both W5015 mutant and wild-type carboxylase in insect cells was performed as described [213]. The propeptide sequence is present in all vitamin $K$-dependent proteins and is important for recognition of the substrate by VKC [96]. In previous studies the purification of both bovine and recombinant $V K C$ was performed in the presence of the propeptide of human coagulation factor IX [261]. Purifications performed in the absence of the propeptide always resulted in less active carboxylase preps. Nowadays, purification of carboxylase is facilitated by the presence of a FLAG tag at the amino terminus and a HPC4 tag at the carboxyl terminus of the recombinant protein. Affinity purification to apparent homogeneity on an HPC4 antibody 
column was possible with the wild-type carboxylase (Figure 1). However, mutant carboxylase W5015 was less stable than wild type and lower molecular weight bands were visible in all preparations. Recently Stanley et al. showed that a consensus propeptide sequence had considerably higher affinity towards VKC than any known propeptide [212]. This consensus propeptide was derived by aligning all known propeptides followed by choosing the most prevalent amino acid at each position. Because the propeptide is known to stabilize $V K C$, we investigated whether including the propeptide during purification would allow the isolation of a larger fraction of active enzyme. Therefore, we added $5 \mu \mathrm{M}$ consensus propeptide into the cultured cells before they were distupted and included it in every purification step. A control was done in the absence of propeptide. Inclusion of the consensus propeptide resulted in only marginally increased stability on gel and in about 5 times more enzymatic activity (data not shown).

In order to properly characterize the enzyme defect of the W5015, it was necessary to purify the enzyme in the absence of the propeptide and therefore such preparations contained some degraded material.

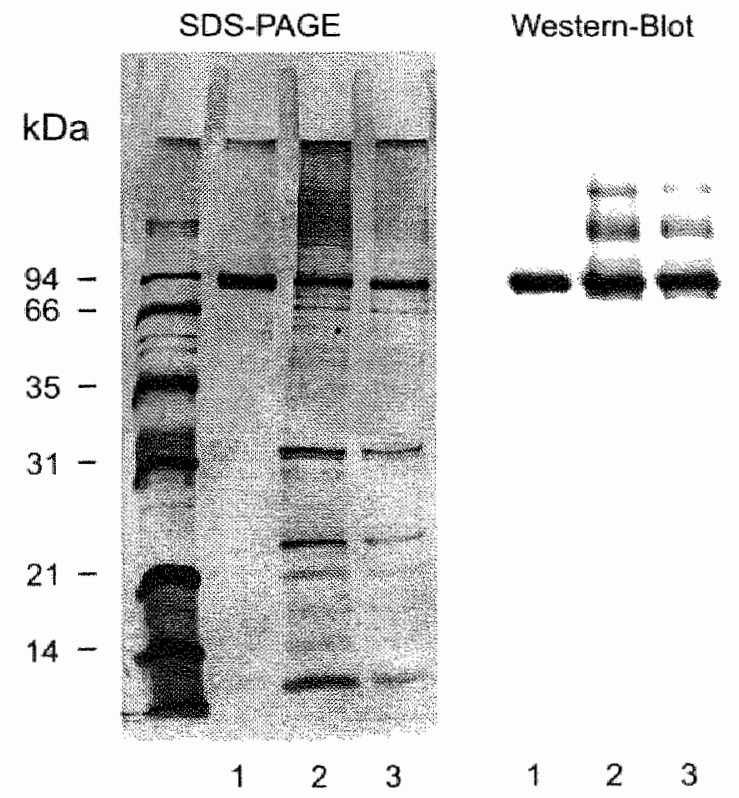

Figure 1

5DS-polyacrylamide gel alectrophoresis and Whestern blot analysis of widdype and W50HS carboxylase. Purified proteins were electrophorased on a $10 \%$ reduced polyacrylanide gel and sillwer stained fleft panel). For Western blot proteins were transferred onto prollywinylidene difluoride membrane and probed with the antif FLAG M2 monoclonal antibody and detacted WSing ECL reagents (right panel) SDS-PAGE: Lane 1, wild-type carboxylase; lane 2, mulant W5015; lane 3, mutant W5015 * 5 fM consensus propeptide. Western-Blot: Lane 1, wildwype carboxylase; lane 2. mutant W5015; lane 3. mutant W5015 + 5 uM consensus propeptide. Molecular mass standards are on the left lane of the SDS PACE panel. 


\section{FixproGla carboxylation}

To test the influence of the W5015 mutation on the carboxylation of propeptidemcontaining substrates we used FIXproGla, a recombinant substrate derived from human blood coagulation factor $\mathrm{XX}$. The $K_{\mathrm{m}}$ for FIXproGla found in wild-type and mutant carboxylase was 0.26 and $21.1 \mu \mathrm{M}$, respectively (Table 1. Figure 2A). The 80 fold difference in $K_{\text {s }}$ provides evidence that the mutation is located in a region in the VKC molecule which is important for binding of the substrate via its propeptide sequence.

\begin{tabular}{llcr}
\hline Parameter & Condition & WT & W501s \\
& & $K_{\mathrm{MM}}(\mu \mathrm{M})$ & $K_{\mathrm{M}}(\mu \mathrm{M})$ \\
\hline prolX50 & & $0.26 \pm 0.05$ & $21.1 \pm 3.4$ \\
prolX19 & + FLEEL & $0.07 \pm 0.008$ & $2.93 \pm 0.43$ \\
KH2 & + prolX19 & $6.8 \pm 0.95$ & $22.1 \pm 3.9$ \\
FLEEL & & $3,934 \pm 485$ & $4.372 \pm 602$ \\
& + conserisus & $821 \pm 54$ & $944 \pm 145$ \\
& + prolX19 & $956 \pm 102$ & $3564 \pm 485$ \\
dOC & & $3.3 \pm 0.58$ & $1.7 \pm 0.22$ \\
& + consensus & $1.32 \pm 0.17$ & $0.83 \pm 0.09$ \\
\hline
\end{tabular}

Table 1

Michaelis Menten constants for various reaction components using wild-type (WT) and W501S mutant carboxylase.

Walues were determined as described under "Materials and Methods".

a Determined at $10 \mathrm{mM}$ FLEEL

betermined at 2 and 50 HM FKXproGia in wild-type and mutant enzyme reactions, respectively

C Dettermined at 10 HM proflX 19

Influence of profIX19 on FLEEL carboxylation

It is known from literature that the propeptide of vitamin K-dependent proteins, in addition to directing carboxylation of these proteins, also functions as a stimulator of carboxylase actiwity [35, 105]. To investigate this stimulatory effect, we examined the influence of proFlX19 an the carboxylation of FLEEL. The half-maximal stimulation of FLEEL. with proFIX19 was at $0.07 \mu \mathrm{M}$ in the wild-type carboxylase and at $2.93 \mu \mathrm{M}$ in the W5015 mutant form (Table 1, Figure 2B). The almost 40 -fold difference in half-maximal stimulation indicates a decreased affinity for proF $X 19$ towards VKC caused by the W501S mutation.

Influence of FIXproGla on the $K_{\mathrm{st}}$ for witarmin $\mathrm{KH}_{2}$

The propeptide sequence is not anly important for recognition of the sub- 
strate, when covalently linked to the Gla domain it also decreases the $K_{\text {wh }}$ for the cofactor $\mathrm{KH}_{2}$ by 7-20 fold [209]. In contrast, propeptide alone does not decrease the $\mathrm{K}_{\mathrm{M}}$ for vitamin $\mathrm{KH}_{2}$ in a small substrate like FLEEL [35]. As can be seen in Table 1, the $\mathrm{K}_{\mathrm{m}}$ for $\mathrm{KH}_{2}$ in wild-type and W501S mutant carboxylase was found to be 6.8 and $22.1 \mu \mathrm{M}$, respectively. This suggests that the mutated propeptide binding region in W501S results in a lower affinity for $\mathrm{KH}_{2}$.

\section{FLEEL carboxylation}

The kinetics of FLEEL carboxylation were determined for wild-type and W5015 mutant carboxylase molecules. In the absence of prof $1 \times 19$ the observed $K_{1}$ values of the wild-type carboxylase and the mutant form were comparable (3934 and $4372 \mu \mathrm{M}$ respectively, Table 1), indicating that the catalytic domain of the enzyme is not affected by the mutation. However, in the presence of $10 \mu \mathrm{M}$ proFIX19 only the $K_{M}$ value of the will-type form decreased whereas the $K_{M}$ value of the W501S mutant form only slightly changed (Table 1. Figure $2 \mathrm{C}$ ). This is consistent with a mutation which has a negative impact on the enzyme-propeptide interaction.

\section{Carboxylation of osteocalcin}

The propeptide of osteocalcin (OC) is the only propeptide that has essentially unmeasurable affinity for the carboxylase. This lack of affinity is due to two substitutions in the propeptide: an alanine at -10 and valine instead of lleucine at -6 . In spite of the low affinity of the osteocalcin propeptide for carboxylase, osteocalcin itself is a low $K_{p M}$ substrate $[7,49,88]$ for VKC. Recently we showed that there is another high affinity binding site on $V K C$ for $d-O C 188$, 89. The $K_{\text {im }}$ values determined for $d-O C$ in wild-type and W5015 mutant carboxylase were 3.3 and $1.7 \mu \mathrm{M}$ (Table 1, Figure 2D), respectively, and were in good agreement with previous reports, suggesting that the W5015 mutation does not influence the binding of d.OC.

\section{Discussion}

Patients with hereditary combined deficiency of all vitamin K-dependent procoagulants and anticoagulants are rare and only a few calses have been reported. In the only previous case for which the defect is known it was found to be a mutation in $\mathrm{VKC}$ [19]. We recently reported a second case from two patients from Lebanon and determined that the W501S mutation in the VKC gene was the reason for the severe hemorrhagic diathesis $\{138,210\}$. In this paper we investigated the molecular mechanism behind this deficiency. To accomplish this goal, recombinant W5015 mutant VKC was expressed in insect cells and purified by affinity chromatography. The propeptides of all vitamin Kdependent precursor proteins show substantial sequence similarity; notably the amino acid residues at $-16,-10,-6,-4$ and -1 are highly conserved. The propeptide of the substrate functions as a recognition- and binding element 

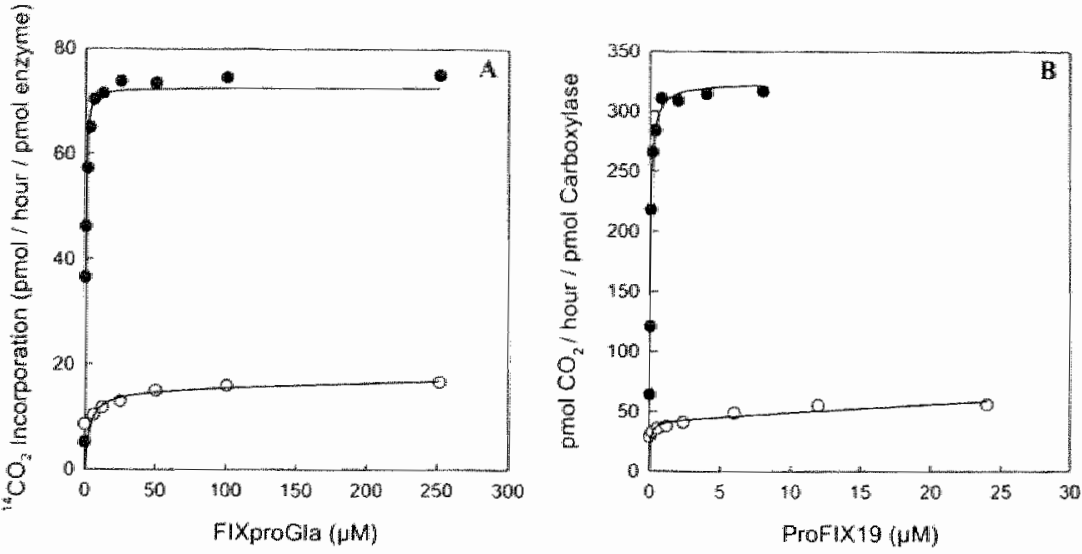

64
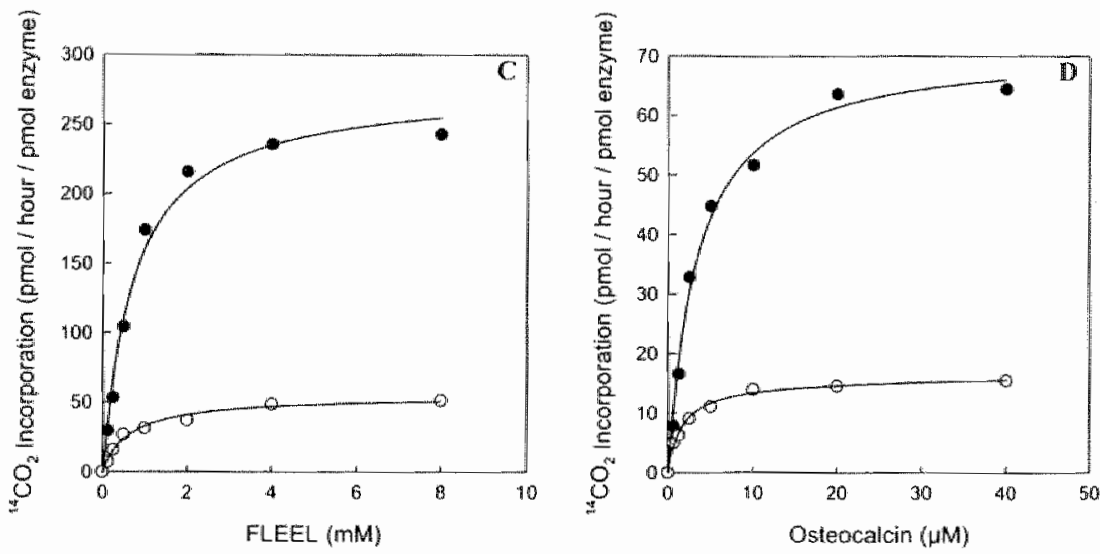

Filgure 2

A: Carboxylation of FIXproGita. Carboxylation of Fixprocila was measured by ascos incorporation. FxproGla concentrations between a and $25.2 \mu \mathrm{M}$ were used for wild type carboxylase (filled circles) and for mutant W5015 (open circles). The $K_{w}$ is $0.26 \pm 0.05 \mu \mathrm{M}$ for the wild-type carboxylase and $21.1 \pm 3.4$ for mutant W5o1s.

B: Stimulation of FLEL carboxylation by profXX19. Carboxylation of FLEEL was measired by ${ }^{4} \mathrm{CO}_{2}$ incorporation and peactions were performed in the presence of $10 \mathrm{mM}$ FLEEL. Concentrations of profix 19 between $D$ and 8 HM were used for wild-type carboxylase (filled circles) and between o and $24 \mu \mathrm{M}$ for mutant W501S (open circles). The halfm maximal stimulation concentration of proflX19 was $0.07 \pm 0.008$ and $2.93 \pm 0.43 \mu$ w for the wild-type and mutant W5015, respectively.

C: FLEL carboxylation: Carboxylation of FLEEL was measured by ${ }^{2} \mathrm{CO}_{2}$ incorporation and in the presence of $10 \mu \mathrm{M}$ profixig. Concentrations of FLEEL between 0 and $8 \mathrm{mM}$ were used for both the wild type carboxylase (filled circles) and mutant W501S (open circles). The $K_{\text {m }}$ is $956 \pm 102 \mu \mathrm{M}$ for the wild-type carboxylase and $3564 \pm 485$ for mutant W5015.

D: Osteacalcin carboxylation: Carboxylation of osteocalcin $(\mathrm{d}-\mathrm{OC})$ was measured by "CO, incorporation. Concentrations of osteocalcin between 0 and $A 0$ wh were used for both the wild-type carboxylase (filled circles) and mutant W5025 (open circles). The $K_{\text {sf }}$ is $3.3 \pm 0.58$ HM for the wild -type carboxylase and $1.7 \pm 0.22$ for mutant W5015. 
for VKC and is removed from the substrate after completion of the carboxylation process. The propeptide itself is used for purification of VKC in most purification protocols [261]. In the propeptide purification procedure an enzyme-propeptide complex is formed and after an extensive washing step the enzyme is eluted by free propeptide. In the present protocols an HPC4 antibody tag at the carboxyl terminal end of recombinant VKC facilitates purification and also makes it possible to obtain the enzyme in a propeptidefree form. However, it is known that the stability of VKC is very sensitive to temperature and high concentrations of CHAPS, especially in the absence of propeptide [35]. Recently, Presnell et al, [160! showed that a carefully prepared carboxylase preparation still contained about 50\% inactive VKC. In our experiments we noticed that purification in the absence of the consensus propeptide resulted in W5015 mutant VKC preparations that had approximately $20 \%$ of the normal activity. The purified W5015 mutant VKC obtained in this way always showed minor protein bands on SDS-page smaller than the $96 \mathrm{kD}$ band normally found in the wild-type preparations (Figure 11). These bands are probably the result of proteolysis of the W5015 mutant VKC molecule because of a more relaxed structure that makes the enzyme less stable. Allthough we presume that these degradation products do not have catalytic activity and that they do not have propeptide binding capacity, we can not exclude that these fragments might impact on the data analysis. Therefore, presentation of values on $V_{\text {max }}$ should be regarded with great care.

At least three regions in the VKC molecule are important in the carboxylation process: a) the substrate (propeptide) binding site, b) the active (glutamate binding site) and c) the vitamin K-binding site. There is significant evidence that small peptide substrates lacking a propeptide sequence directly diffuse into the active site and therefore can be used for measurement of the catalytic apparatus of the VKC molecule i.e. the activity of the glutamate binding site. From our experiments we conclude that the active site is not affected by the W501S mutation, since the kinetics for carboxylation of the non-physiological substrate FLEEL are almost identical in both wild-type and mutant VKC. Interestingly, docking of the free propeptide to VKC induces a conformational change that renders the carboxylase a better enzyme for the substrate FLEEL in wild-type VKC. Obviously, this characteristic is lost in W5015 mutant VKC since the affinity for FLEEL is not increased by proFIX19.

All data obtained in our experiments are consistent with the W5015 mutation playing a role in propeptide binding. For instance, the W501S mutation caused a decrease in the kinetics of the carboxylation of FIX proGla. The 80fold higher $K_{\mathrm{m}}$ value as found in the W501S mutant form is an indication that the mutation is located in a region that plays a role in substrate recognition. Moreover, the concentration of proflX19 necessary for half-maximal stimulation FLEEL decreased almost 40 times in the mutant form. For 
identification of the propeptide binding site several methods have been used leading to different potential locations (Table 2). The reason for these differences may be wariations in the used techniques or that non-contiguous regions of the enzyme are involved in the propeptide binding site. The previously reported binding site near residues $438-507$ by Wu et al. [262] and the region around residue 513 by Sugiura et al. (221) are in agreement with the results as found in our experiments with FIXproGla having a lower affinity in the W5015 mutant carboxylase than in the wild type enzyme. Recently Lin et al. $121 j$ confirmed Wu's data by showing that mutations, made in the 495-513 region of human carboxylase, specifically affect propeptide binding by decreasing the apparent affinity of carboxylase for the propeptide. Although a mutation of residue W501 was not investigated by these authors, it is likely to expect a dlecreased apparent affinity also in this W5015 mutant form. A consequence of this altered propeptide binding might be an increased turnover rate of propeptide-containing substrates leading to incomplete carboxylation. In addition, several authors showed that a propeptide covalently attached to the Gla domain induces a substantial decrease in the $K_{\mathrm{M}}$ for vitamin $\mathrm{KH}_{2}[68,209]$. It is possible that a decreased affinity for the propeptide caused by the W5015 mutation, on its turn, also negatively affects the $K_{M}$ for its cofactor $\mathrm{KH}_{2}$ which results in a decreased affinity for $\mathrm{KH}_{2}$ as found in the W5015 mutant carboxylase. Taking also into account that in newborns vitamin $K$ nutrition is at risk because (1) the placenta transport of fat-soluble vitamins is poor: (2) the neonatal liver is immature with respect to coagulation factors synthesis; (3) breast milk is low in vitamin $k_{r}$ it is understandable that in these patients the clinical symptoms improve on the administration of vitamin $K$.

Propeptlde binding sile:

\begin{tabular}{|c|c|c|}
\hline Reridus & Mathod: & Reterence \\
\hline $50-225$ & Plhotoinactivation & Yamada of ai , 1995 \\
\hline $234,406,513$ & Sile-directed mutagenesis & Sughura of al. 1996 \\
\hline 438-507 (in tumen ERT) & Trypsin-cleatage & Wu et al. "1997 \\
\hline $300-758$ & Affinily probe & Mallet of al. . 199? \\
\hline $495-513$ & Fluorescence Anisotropy & Lin et al. 2002 \\
\hline
\end{tabular}

Active Site tepoxidiation Silte:

\begin{tabular}{|c|c|c|}
\hline Residues. & Mentrod & Reference \\
\hline $217 / 218,359$ & Silemdirected mulagenesis & Sugina et af., 1996 \\
\hline $50-314$ & Inachivation wath peptide substraten & Kultiopulos et al, 1994 \\
\hline 394 & Sile-directed nuthagenesis & Mutucumarana et as, 2000 \\
\hline 99.450 & Amino acid analysis of ${ }^{14} \mathrm{C}$-NEM modified cathoxyalse & Pudota el al. . 2000 \\
\hline 343,345 & Silendirected mutagenesis & Pludota el all. 2004 \\
\hline
\end{tabular}

Table 2

Proposed propeptide- and active sites on $\gamma$-glutamyl carboxylase 
Whereas the role of the propeptides in almost all vitamin K-dependent proteins is well defined, this role remains uncertain in case of OC. Stanley et al. [213] observed that the affinities of the propetides varied over a broad range and that especially the propeptide of $O C$ showed impaired binding to carboxylase. Nevertheless, several authors found that $O C_{\text {, }}$ after thermal decarboxylation, could serve as a low $K_{\Delta}$ substrate for $\gamma$-glutamyl carboxylase in the absence of a covalently attached propeptide $[49,236]$. Recently we postulated the presence of a second high affinity binding site on carbaxylase capable of specifically binding $d-O C$. Our results in this paper indicate that in spite of an affected propeptide binding site, the affinity of W5015 mutant carboxylase for d-OC did slightly improve, which confirms that $d-O C$ does not utilize the propeptide binding site on VKC.

When comparing carboxylase sequences in different species (Table 3 ) it is obvious that amino acid 501 is a highly conserved residue in the carboxylase molecule and it is very well possible that specific recognition interactions between carboxylase and its polypeptide substrates are mediated by this region of the molecule. Price and Williamson observed a homology over 24 residues (495-518) between the carboxylase molecule and the integral $\gamma$-glutamyl carboxylation recognition site of the matrix Gla protein, suggesting that this region might play a regulatory role in the prevention of non specific carboxylation [169]. However, here we demonstrate that amino acid 501 is directly involved in propeptide binding supporting the theory of Lin et al. [121] that residues $495-513$ in human carboxylase are part of the propeptide binding site.

Homo sapiens bos tautus Ovis aries Ratefu norvegicus Mus muscuthis Dephinapherus leucas Oparamus lani Drosoplivilat malanogastier

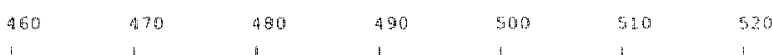

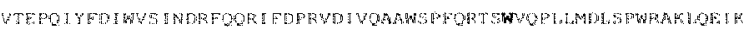

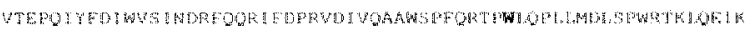

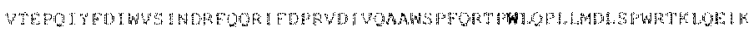

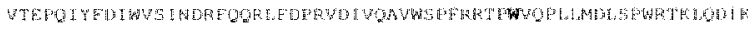

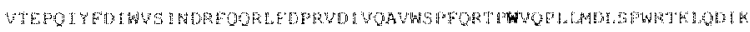

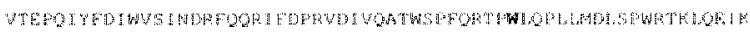

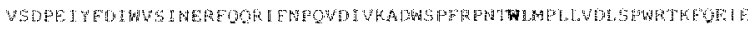

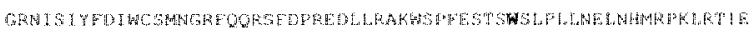

Table 3

Alignment sequences of y-glutamyl carboxylase in different species

"* indicates positions which have a single, fully conserved residue

\section{Acknowledgement}

We thank Drs. D.L. Straight and G. Tans for helpful discussions on enzyme kinetics. 



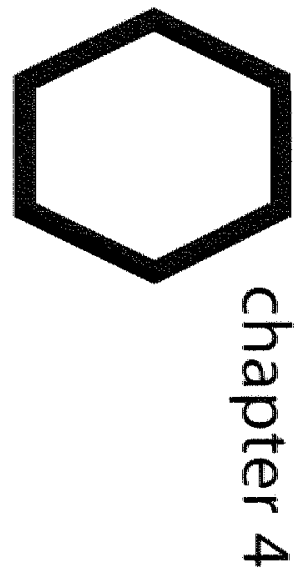

matrix gla protein accumulates at the border of regions of calcification and normal tissue in the media of the arterial vessel wall

h.m.h. s.pronk $\bigcirc$ b.a.m.soute $\bigcirc$ l.j.schürgiers $\bigcirc$ j.p.m.cleutjens $\bigcirc$ h.h.w.thijssen j.g.r. de mey $\bigcirc$ c.vermeer based on: biochem bilophys res commun (2001] 289:485-490 



\section{Abstract}

Vitamin K-dependent Matrix Gla-Protein (MGP) has been suggested to play a role in the inhibition of soft-tissue calcification. Here we report the expression of recombinant prokaryotic MGP as part of a fusion protein and the preparation of two antibodies that specifically recognize MGP. Monoclonal antibodies were raised against synthetic peptides homologous to the sequences 3-15, and 63-75 of human MGP. Both antibodies recognize recombinant and synthetic human MGP. Immunohistochemical analysis showed that MGP was associated with the extracellular matrix of noncalcified bone and with chondrocytes in cartilage. In the healthy human arterial vessel wall, MGP antigen was demonstrated in association with smooth muscle cells and elastic laminae of the tunica media, and with the extracellular matrix of the adventitia. The co-localization with the elastic llaminae was lost at sites of medial calcification: in both human and rat arteries, high amounts of MGP were found in the extracellular matrix at borders of intimal and medial calcification. Our data demonstrate the close association between MGP and calcification. It is suggested that undercarboxylated MGP is biologically inactive and that poor vascular vitamin $\mathrm{K}$ status may form a risk factor for vascular calcification. 


\section{Introduction}

In mammals, vitamin $K$ functions as a cofactor for the endoplasmic reticulum enzyme $\gamma$ glutamyl carboxylase, which catalyses the posttranslational modification of glutamate residues (Glu) into y-carboxy glutamate (Gla) !63, 240! In all Gla-containing proteins known, the Gla-residues are essential for stabilizing the tertiary structure and for the function of these proteins. Mammalian Gla-proteins are involved in at least three physiological processes: haemostasis, bone metabolism, and vascular biology. Matrix Gla protein (MGP) is a $10 \mathrm{kDa}$ protein containing five Gla residues and is synthesised in bone, cartilage, and soft tissues such as lung, heart and kidney [61, 167]. It has also been shown that MGP is expressed by human medial vascular smooth muscle cells (VSMCs) and that MGP mRNA synthesis is upregulated in calcified atherosclerotic plaques [201]. The molecular mechanism of MGP function is not known, but recent data demonstrate that it plays a major role in the inhibition of soft-tissue calcification. First, MGPdeficient mice showed extensive medial calcification of the aorta, leading to death within eight weeks after birth due to ruptures of the thoracic or abdominal aorta [123]. Second, in the same MGP-deficient mice cartilageproducing chondrocytes were detected in the tunica media of the calcified arteries. Third, a relation between MGP and chondrocyte function was recently suggested by Yagami et al., who showed that in hypertrophic chondrocyte cultures in vitro calcification was triggered by treatment with the vitamin $K$-antagonist warfarin, whereas calcification was counteracted by MGP overexpression in the presence of vitamin $K$ [266]. In the same study constitutive MGP overexpression in chicken limb resulted in in vivo inhibition of cartilage mineralization, delayed chondrocyte maturation and termination of endochondral and intramembranous ossification.

The importance of Gla-residues in the prevention of vascular calcification was shown in rats by inhibition of $\gamma$-glutamyl carboxylation with warfarin [161). Rats were treated with both vitamin $\mathrm{K}$ and warfarin, in such a way that $\gamma$-glutamyl carboxylation could proceed in the liver, but was inhibited in extra-hepatic tissues such as the aortic vessel wall resulting in undercarboxylated MGP. Using this protocol, arterial calcification around the elastic lamellae of the media was found within 3 to 4 weeks of treatment. All data presently available suggest that MGP is a potent inhibitor of tissue calcification, and that vitamin $K$ is necessary for its $\gamma$-glutamyl carboxylation and thus for rendering MGP its biological activity. To investigate MGP expression and accumulation in healthy and pathological tissues, we have developed antibodies against two different sequences of human MGP and used these to localize the antigen in bone, trachea and vessel wall. 


\section{Materials and Methods}

\section{Chemicals and Reagents}

All solutions were prepared using reagents of analytical or HPLC grade. Synthetic peptides homologous to the sequences 3-15 and 63-75 of human MGP were synthesised and purified by Pepscan Systems Lelystad, The Netherlands), peptides homologous to sequences $1-53$, and 54-84, and 1-84 (full length) human MGP were synthesised and purified by Dr. T. Hacking as described previously [76]. These peptides will be referred to as $M_{G} P^{3-45}$,

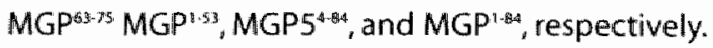

\section{Construction of recombinant plasmids}

Total RNA was extracted from isolated human osteoblasts cultured in RPMI 1640 medium (ICN Pharmaceuticals, $(\mathrm{A})$, supplemented with $1,25(\mathrm{OH})_{2}$ vitamin $D_{3}$ (Life Technologies, Breda, The Netherlands). Reverse transcription was performed according to standard procedures with M-MLV reverse transcriptase (Life Technologies). After synthesis of total CDNA, MGP and proosteocalcin (proOC) specific DNAs were amplified by PCR. MGP CDNA was equipped with a 5'-5phl and factor $X_{a}$ digestion site, and with a $3^{\prime}-H i n d l l l$ site (primers: 5"-GCA TGC ATT GAA GGT CGT TAT GAA TCA CAT GAA AGC and 5'-TAT AAG CTT GGC CCC TCG GCG CTT CCT), whereas 5'-5phl and 3'-HindIII digestion sites were introduced in the proOC CDNA (primer s: 5'-GCA TGC GCA GCC ITT GTG TCC AAG and 5'-AAG CTT GAC CGG GCC GTA GAA GCG CCG). The sticky-end inserts were ligated in Sphl and HindIII digested prokaryotic expression vector $\mathrm{pQE} 40$ (Qiagen, Hilden, Germany) for in-frame fusion with the $6 \mathrm{His}$-DHFR fusion protein. The recombinant plasmids were transformed into E.coli M15[REP4]-strain (Nal' Str' rif "lac ara gal mtl $\mathrm{F}$ recA* uvr") and the resulting vectors were confirmed by restriction enzyme digestion and nucleotide sequencing. All molecular biology protocols were according to Sambrook et al. n191].

\section{Large-scale synthesis of recombinant proteins}

For the production of recombinant proteins $6 \mathrm{His}-\mathrm{DHFR}-\mathrm{Xa}-\mathrm{MGP}$ and 6 His-DHFR-proOC, bacteria (1 L cultures) were grown to a density of $A 600=$ 0.7 in LB medium. Next, the expression of the recombinamt genes was induced by adding isopropyl-b-D-thiogalactopyranoside (IPTG, MB\| Fermentas $\mathrm{GmbH}$, St. Leon-Rot, Germany) to a final concentration of $2 \mathrm{mM}$ and growth was continued for another $4 \mathrm{~h}$. Protein samples were analysed by SDS-PAGE and subsequent Coomassie blue staining. The recombinant proteins 6His-DHFR-Xa-MGP and 6His-DHFR-proOC were characterized by immunoblotting using an anti-6His IgG antibody (Qiagen). 
Qiagen) affinity chelation chromatography. Bacteria from $1 \mathrm{~L}$ cullture were harvested by centrifugation $(30 \mathrm{~min}$ at $3,000 \times \mathrm{g})$ and proteins were extracted by dissolving the pellet in buffer $A(8 \mathrm{M}$ urea, $300 \mathrm{mM} \mathrm{NaCl}, 50 \mathrm{mM}$ Tris- $\mathrm{HCl}, \mathrm{pH} 8.0)$. After centrifugation of the lysate $(30 \mathrm{~min}$ at $10,000 \times \mathrm{g})$, the supernatant was fittered over a Ni-NTA agarose column in buffer A. After several washes with buffer $A$, the recombinant $6 \mathrm{His}$-tagged protein was eluted with buffer $\mathrm{B}(8 \mathrm{M}$ urea, $0.5 \mathrm{M}$ imidazole, $50 \mathrm{mM}$ Tris- $\mathrm{HCl}, \mathrm{pH} \mathrm{8.0)}$ ).

\section{Production of monoclonal antibodies}

Antibodies were produced against synthetic peptides, according to generally accepted procedures and tested as described by Braam et al. [1].

\section{SDS-PAGE and Western blot analysis}

Protein samples in SDS sample buffer (40 mM Tris-HCl, $\mathrm{pH} 6.7,4 \%(\mathrm{w} / \mathrm{v})$ SDS, $10 \%(\mathrm{w} / \mathrm{v})$ glycerol, $2 \%(\mathrm{v} / \mathrm{v})$ 2-mercaptoethanol, $0.01 \%(\mathrm{w} / \mathrm{v})$ bromophenol blue) were boiled for 5 min. Polyacrylamide gels $12.5 \%(w / v)$ in SDS were run under denaturing conditions 1131. After electrophoresis, the gels were either stained with Coomassie blue R-250 or transferred to an Immobilon-P PVDF membrane (Millipore, Bedford, MA) [2331. After washing the membranes in PBS for 15 min, non specific binding sites were blocked with blocking buffer for 1 $h$ at room temperature and incubated at $4^{\circ} \mathrm{C}$ overnight with the appropriate antibody in blocking buffer. After washing with PBS-Tween, the membrane was incubated for $1 \mathrm{~h}$ at room temperature with biotin-conjugated antichicken IgG (Dako) diluted in PBS-Tween. Membranes were washed three times with PBS-Tween, followed by a final wash step of $15 \mathrm{~min}$ with PBS and development with $E C L$ Western blotting detection reagents. (Amersham Pharmacia). Finally, protein bands were visualized on Hyperfilm $\mathrm{ECL}$ (Amersham Pharmacia).

Aortic calcifications in rats

Vascular media calcification was induced in male Lewis rats ( 8 weeks old) using a modification of the protocol described by Price et al., who injected vitamin $K 1$ and warfarin daily [161] In our model both $K 1$ and warfarin were given orally and in lower doses $(10 \mathrm{mg} \mathrm{K} 1$ and $15 \mathrm{mg}$ warfarin per day). After maintaining the animals on this treatment for four weeks, media calcification that had developed in the aortic arch was visualized by Von Kossa staining. The experimental protocols were performed in accordance with local institutional guidelines and approved by the Experimental Animal Ethics Committee of the University of Maastricht.

\section{Histology and immunahistochemistry}

Paraffin-embedded human tissues were obtained from the archives of the Department of Pathology of the University Hospital of Maastricht. Rat tissues were from male rats of the Lewis strain. Tissues were collected, fixed by 
immersion in $4 \%$ formaldehyde in PBS for $12 \mathrm{~h}$ at room temperature, and embedded in paraffin. Sections ( $4 \mu \mathrm{m}$ ) were stained with haematoxylin and eosin for general histological evaluation and calcification was demonstrated by Von Kossa staining. Immunohistochemistry was performed by using either the monoclonal $\alpha 3-15 \mathrm{lgG}$ or $\alpha 63-75 \mathrm{lg} G$ as a first antibody and biotinylated anti-mouse lgG (Dako) as the second antibody. Staining was performed with the avidin-biotin immuno alkaline phosphatase kit from Dako. Negative controls were performed by substituting the primary antibody by either PBS, an irrelevant antibody, and by adding competitive amounts of synthetic MGP peptides.

\section{Results}

Expression of recombinant MGP and osteocalcin

Initial attempts to express human MGP (10 kDa) and proOC $(6 \mathrm{kDa})$ in a prokaryotic expression system were not successful. This is not unusual with small proteins ( $<15 \mathrm{kDa}$ ) and has been attributed to improper folding and a high rate of proteolytic degradation. Therefore, both CDNAs were cloned into the commercially available pQE40 QIAexpress system, with DHFR as a fusion protein. To be able to enzymatically split recombinant MGP from the chimeric product, a cleavage site specific for blood coagulation factor $X a$ was introduced between DHFR and MGP. Extracts from induced bacterial cultures containing either expression vector pQE40 Xa-MGP or pQE40 proOC were analysed by SDS-PAGE and subsequent Western-blot analysis. Depending on the plasmid construct used, recombinant 6His-DHFR-Xa-MGP (pQE40 XaMGP), or 6His-DHFR-proOC (pQE40 proOC) were found in the bacterial lysates. On Western-blots, the corresponding protein bands ( 36 and $32 \mathrm{kDa}$ respectively) could be visualized using antibodies against the $6 \mathrm{His}$ epitope (Figure 1). The molecular weights of the observed recombinant proteins are in accordance with the theoretical molecular weights "calculated from their amino acid sequences. For 6His-DHF-proOC a second band at lower molecular weight was observed, which is probably a preliminary termination product generated by rare codion use in the host Escherichia coli.

During Ni-NTA affinity chromatography of the 6His-DHFR-Xa-MGP protein from the crude bacterial lysate it became clear that the recombinant fusion protein was only soluble under extreme $\mathrm{pH}$ conditions $(<2$ or $>10)$ or in $8 \mathrm{M}$ urea. Its solubility was not improved by ionic conditions, varilous detergents, or reducing agents such as dithiothreitol. The theoretical pl of the 6His-DHFRXa-MGP protein is 9.8. In an attempt to increase the solubility of the fusion protein, the DHFR moiety was replaced by the much larger maltose binding protein (MBP). Despite its lower theoretical pl of 7.7, however, the solubility of the resulting MBP-MGP construct was not better than that of the DHFRcontaining product. Since better yields were obtained with 
6His-DHFR-Xa-MGP, the latter protein was used for further experiments. Unfortunately, the non physiological buffer in which the recombinant proteins were dissolved, did not allow its digestion with factor $X_{a}$.

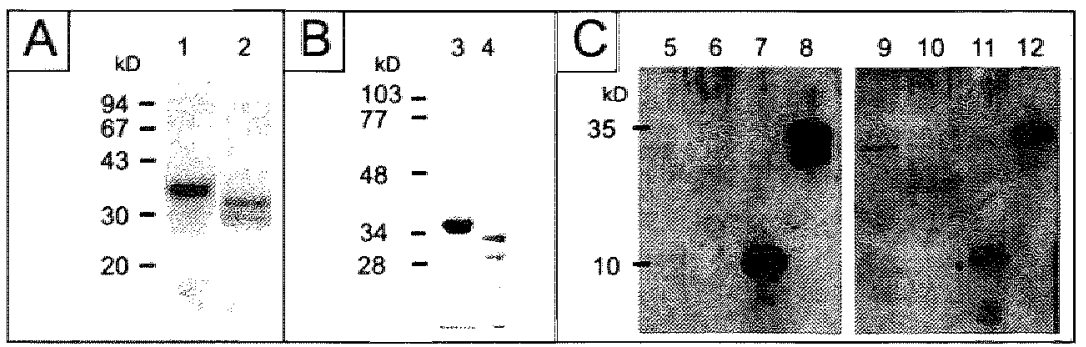

Figure $\mathbb{1}$

Characterization of recombinant products.

A. SDS-PAGE of Ni-NTA purified 6His-DHFR-Xa-MGP (lane 1) and 6His-DHFR-proOC (lane 2).

B. Western-blat analysis of crude bacterial lysates from 6His-DHFR-Xa-MGP expression culture (lane 3) and 6His-DHFR-proac flane 4), using antibodies against the 6His epitope. C. Recognition of synthetic and recombinant MGP by two antibodies against MCP. Westermblot analysis of prokaryotic recombinant 6His-DHFR-Xa-MGP (lanes 8 and 12), full length synthetic MCP (MGPis, lanes 7 and 11 ), synthetic osteocalcin (lanes 6 and 10), and prokaryotic recombinant 6His-DHFR-proOC [lanes 5 and 9). Lanes 5 through 8 are stained with mouse monoclonal antibody $\alpha 3-15 \mathrm{MCP}$, and lanes 9 through 12 are stained with mouse monoclonal antibody $0663-75$ MGP.

\section{Screening of antibadies}

Clonal hybridoma cell lines producing antibody against MGP were selected with an indirect ELISA by comparing antibody reactivity against $6 \mathrm{His}-\mathrm{DHFR}-$ $X a-M G P$ and 6 His-DHFR-proOC (negative control). The purified antibodies ( $\alpha 3$-15 MGP mAb and $\alpha 63-75$ MGP mAb) were found to be of subclass $\mathrm{IgG}_{1}$ and on Western blots the $\alpha 3-15$ MGP mAb recognized synthetic MGP ${ }^{1: 44}$, the 6His-DHFR-Xa-MGP prokaryotic expression product (Figure 1C), as well as the synthetic MGP ${ }^{1.53}$ (data not shown). In a simillar way, the purified $\alpha 63-75$ MGP mAb was tested for recognition of the various MGP-related products. The antibody proved to be specific for synthetic MGP:s4, and recombinant 6His-DHFR-Xa-MGP, but did not recognize MGP'-53 (dlata not shown). Neither $\alpha$ 3-15 MGP mAb nor $\alpha 63-75$ MGP mAb recognized the $6 \mathrm{His}$-DHFR-proOC construct, or synthetic $\mathrm{OC}^{1.49}$ (Figure $1 \mathrm{C}$ ).

\section{Immunohistochemical localization of MGP}

Both anti-MGP antibodies were used for immunolocalisation of MGP in human foetal bone, trachea, healthy arterial vessel wall, and blood vessells with medial calcification (Figure 2). In human bone, a weak signal was associated with the extracellular matrix at sites of non-calcified bone (Figure $2 A$ and $B$ ), whereas no MGP immunoreactivity was detected at calcified sites (data not shown). In tracheal cartilage, MGP was found mainly intra- and pericellularly in association with a subset of hypertrophic chondrocytes ( $2 \mathrm{C}$ and 
D). In the healthy human arterial vessel wall low levels of MGP immunoreactivity were found in the intima, media, and adventitia (Figure $2 E$ and $F$ ). In the adventitia, MGP was mostly associated with the extracellular matrix, in the media with vascular smooth muscle cells and in a striped pattern which co-localized with the elastic laminae. This pattern was lost at sites of medial calcification where protein levels of MGP seem to be strongly increalsed at sittes of calcification. Accumulation of MGP antigen was most pronounced in the extracellular matrix at the borders of intimal (data not shown) and medial calcification (Figure $2 \mathrm{G}$ and $\mathrm{H}$ ).

Both antibodies showed cross reactivity with rat MGP as indicated by the localization of MGP in rat bone, trachea, and vessel wall. The localization of rat MGP antigen was comparable to that in the corresponding human tissues: pericellularly in hypertrophic chondrocytes and vascular smooth muscle cells, and extracellular in the vascular tunica media. To be able to compare MGP accumulation at sites of vascular calcification in human and rat tissues we have subjected rats to the vitamin $K+$ warfarin regïmen which is known to result in arterial calcifications after 4 weeks. Like in human calcified arte-ries, high concentrations of MGP antigen were found at the border of the mineralised areas (figure $2 \mathrm{H}$ ).

\section{Discussion}

Accumulating evidence suggests that MGP plays an important role in the prevention of arterial calcification $[123,161]$. Since the availability of fresh human bone is limited and because its poor solubility complicates the purification of native MGP, we have synthesised prokaryotic recombinant MGP. Attempts to express MGP in bacteria as such were unsuccessful, but high yields were obtained if MGP was expressed as part of a fusion protein. Although the insoluble MGP moiety formed only a relatively small part in the total constructs, the chimeric proteins containing either DHFR or MBP protein as water-soluble components were found to be insoluble under physiological conditions. Nevertheless, the recombinant MGP construct was successfully used as an antigen in an indirect ELISA to select positive hybridomas and for screening of antibodies by Western blot analysis. With both monoclonal antibodies (against the MGP $N$ - and C-terminus) we have demonstrated the occurrence of MGP protein at low concentrations in healthy thuman arterial vessel wall. This is in accordance with a previous study of Shanahan et al, in which MGP mRNA was detected throughout the media and an association of the protein with the ellastic lamina was suggested [202] Substantial accumulation of MGP was found at sites of wascular calcification. Both antibodies demonstrated similar MGP antigen localisation patterns in all tested human and rat tissues. 

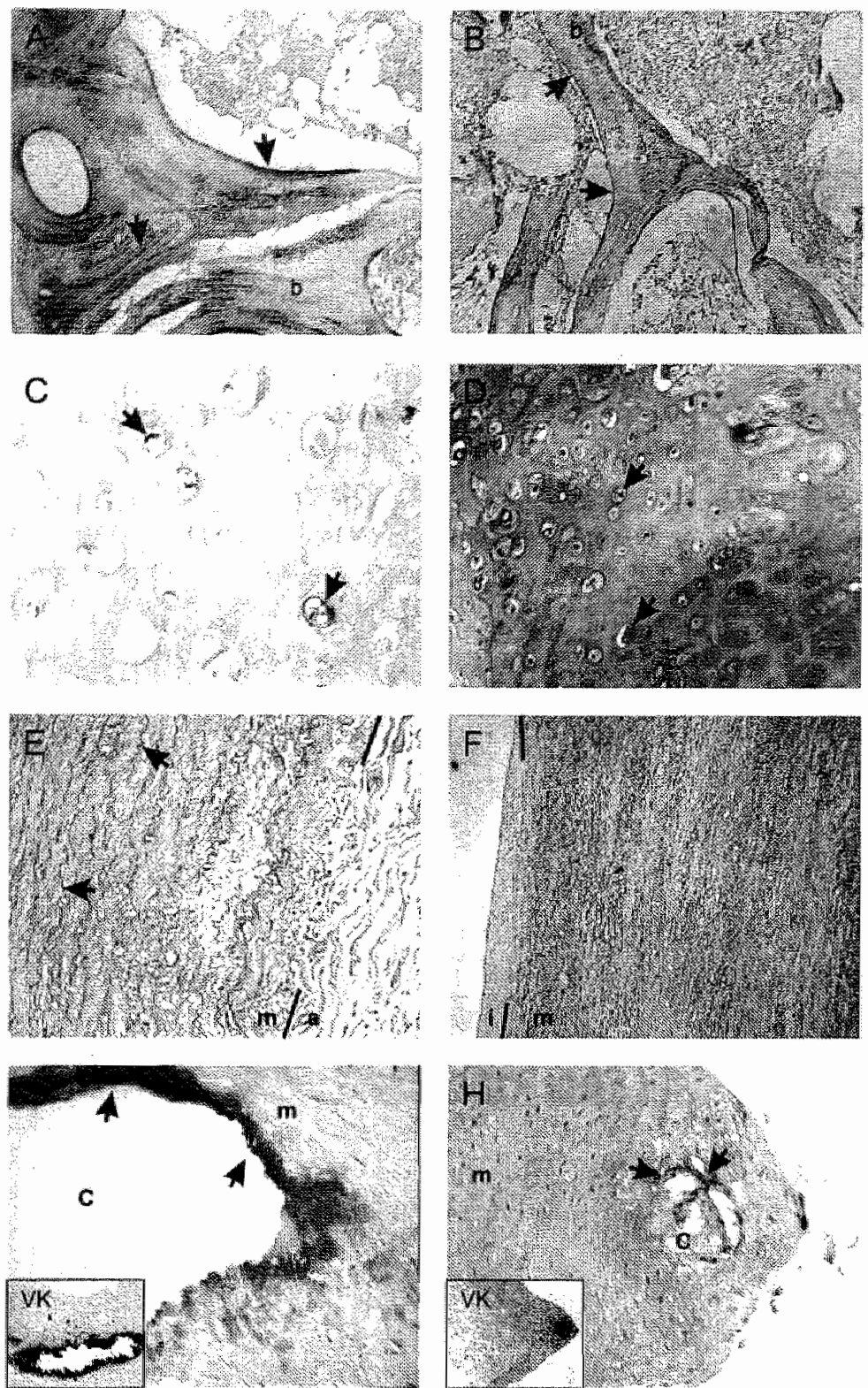

\section{Figure 2}

Ammunohistochemistry of thuman and rat tissues for MGP with mouse monoclonal antibody Q3-15 MGP ( $A, C, E$, and $G$ ) and mouse monodonal antibody $\alpha 63-75$ MGP (B, D, F, and $H$ ). Positive MGP staining is indicated by a pink/red colour (see arrows). Panel $A$ and $B$ : Human foetal non-calcified bone (b indicates bone). $C$ and $D$ : Human tracheal cartilager. $E$ and $F$ : Healthy thuman arterial vessel wall, i indicates intima. $m$ indicates media, a stands for adventitia. G: Human cononary artery with medial calcification, m indicates media, c indicates the calcified areat: inserts: VK stands for Von Kassa staining with calcified areas in black. H: Medial calcitication in the aorta of a warfarin-treated rat (m: media, c: calcified area, VK: insert of Won Kossa staining with calcification in black). 
Because of its poor solubility, it is difficult to understand how MGP can perform its function in vivo and in which way the protein is transported in blood. Although we were not able to make a soluble fusion protein, one possible explanation for the apparent solubility in plasma is the formation of a complex between MGP and a soluble carrier protein or the association with lipoproteins. Association between MGP and bone morphogenetic proteins has been suggested in this respect [2:37]. Alternatively, the data available in the literature do not exclude the possibility that reported data on circulating MGP reflect water-soluble degradation products. Our histological findings indicate that extracellular MGP is mainly complexed with or precipitated on the extracellular matrix at areas of calcification.

The proposed function of MGP as inhibitor of calcification is supported by several studies including excessive arterial calcification in MGP-deficient mice [123] and prevention of calcification by MGP over-expression in avian chondrocytes [266]. Available data suggest that inhibition of extra-thepatic $\gamma$-glutamyl carboxylation may result in undercarboxylation of vascular MGP and subsequent calcification of the tunica media [161, 162]. It seems plausible, therefore, that carboxylated MGP is, the active form which acts as an inhibitor of tissue calcification. Unfortunately, neither of the antibodies described in this paper discriminate between carboxylated and undercarboxylated MGP. When used for immunohistochemical analysis of calcified arteries, MGP was found to be localized at the border between tissue and calcium deposits. This is consistent with in situ hybridisation data showing upregulation of MGP MRNA synthesis at sites of calcification $[161,174)$. These data may be explained by assuming a feed-back mechanism of increased MGP production, possibly to prevent or minimize further mineral deposition. In case of local vitamin K-deficiency or inhibition of Gla-formation by coumarin anticoagulants, the impaired biological activity of the undercarboxylated MGP produced would give rise to increased calcification and further amplification of undercarboxylated MGP synthesis. Thus, both prolonged vitamin K-deficiency and the use of vitamin K-antagonists (coumarins) may form independent risk factors for vascular calcification. Evidence for this assumption was provided in a population-based study, in which an inverse correlation between dietary vitamin $k$ intake and the occurrence of aortic calcification in elderly subjects was demonstrated [04]. It is still unclear how MGP fulfils its calcification inhibitory activity. An attractive hypothesis was recently postulated by Bostrom, who proposed that MGP may act as an inhibitor of a cartillage and bone inducing factor 161. The author further suggests that MGP may occur complexed to BMP. In this concept extracellular transport of the virtually insoluble MGP would take place as a soluble complex with BMP in which BMP function is strongly reduced. Recently, it was shown that in vitro MGP can form a complex with BMP-2 [245], and that in cell culture BMP activity is possibly modulated by MGP [14]. Here we like to put forward the hypothesis 
that undercarboxylated MGP, synthesised during vitamin K-deficiency or coumarin treatment, has lower affinity for BMP than has carboxylated MGP. This would explain the strong accumulation of MGP-related antigen which was found at all sites of vascular calcification that we have investigated thus far. Obviously, conformation-specific antibodies discriminating between carboxylated and undercarboxylated MGP are required to test this hypothesils. 




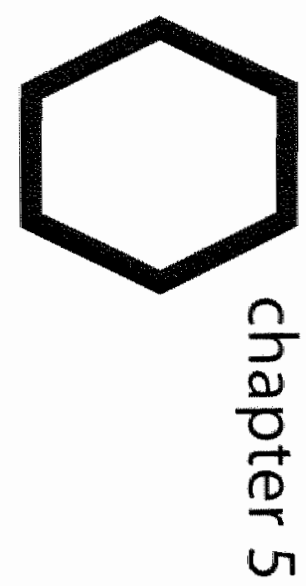

total chemical synthesis of human matrix gla protein 



\section{Abstract}

Human matrix Gla protein (MGP) is a vitamin K-dependent extracellular matrix protein that binds $\mathrm{Ca}^{2+}$-ions and that is involved in the prevention of vascular calcification. MGP is a $10.6 \mathrm{kD}$ protein ( 84 amino acids) containing five $\gamma$-carboxy glutamic acid (Gla) residues and one disulfide bond. Studies of the mechanism by which MGP prevents calcification of the arterial media are hampered by the low solubility of the protein $(<10 \mu \mathrm{g} / \mathrm{mL})$. Because of solubility problems, processing of a recombinant expressed MGP.fusion protein chimera to obtain MGP was unsuccessful. Here we describe the total chemical synthesis of MGP by tBoc solid-phase peptide synthesis (SPPS) and native chemical ligation. Peptide Tyr $-\mathrm{Ala}^{53}$ was synthesised on a derivatised resin yielding a C-terminal thioester group. Peptide Cys ${ }^{34}-$ Lys $^{1 / 4}$ was synthesised on Lys-PAM resin yielding a C-terminal carbaxylic acid. Subsequent native chemical ligation of the two peptides resulted in the formation of a native peptide bond between $\mathrm{Ala}^{53}$ and $\mathrm{Cy} \mathrm{s}^{53}$. Folding of the 1-84-polypeptide chain in $3 \mathrm{M}$ guanidine ( $\mathrm{pH}$ 8) resulted in a decrease of molecular mass from 10,605 to 10,603 (ESI-MS), representing the loss of two protons because of the formation of the $\mathrm{Cys}^{54}-\mathrm{Cys}^{\mathrm{sin}}$ internal disulfide bond. Like native MGP, synthetic MGP had the same low solubility when brought into aqueous buffer solutions with physiological salt concentrations, confirming its native like structure. However, the solubility of MGP markedly increased in borate buffer at $\mathrm{pH} 7.4$ in the absence of sodium chloride. $\mathrm{Ca}^{2+}$-binding to MGP was confirmed by analytical HPLC, on which the retention time of MGP was reduced in the presence of $\mathrm{CaCl}_{2}$.

Circular dichroism studies revealed a sharp increase in a-helicity at $0.2 \mathrm{mM}$

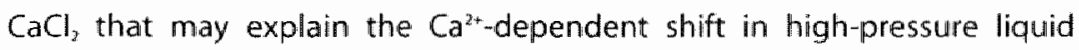
chromatography (HPLC)-retention time of MGP. In conclusion, facile and efficient chemical synthesis in combination with native chemical ligation yielded MGP preparations that can aid in unravelling the mechanism by which MGP prevents vascular calcification. 
Matrix $\gamma$-carboxy glutamic acid (Gla) protein (MGP) is an 84-amino-acid protein that was first described in an extract from bovine bone $\| 167$. Following this report, MGP was detected in rats [152], humans [100], mice [931, sharks [183]. and chickens [256] either as a protein or as MRNA. MGP is found in high concentrations in the extracellular matrix of bone and cartilage $[77,167]$ but is also synthesised in a wide variety of other tissues such as lung, heart, kidney, and arterial vessel wall [611. MGP contains five posttranslationally modified $\gamma$-carboxy glutamic acids [167] and, therefore, belongs to the vitamin $K$ dependent family of proteins (Figure 1).

It was reported that deficiencies in MGP caused impaired bone growth and, more importantly, massive calcification of the arterial wessel wall in mice [123]. To study the molecular mechanisms by which MGP protects against calcification and bone deformation, sufficient amounts of MGP are required. However, the low solubility of MGP limited recombinant production of MGP because an Escherichia coli-expressed dihydrofolate reductase-MGP chimera could not be processed further because of insolubility of the fusion protein under physiological conditions [17]. Moreover, conventional purification from bone is also hindered by the insolubility of the protein.
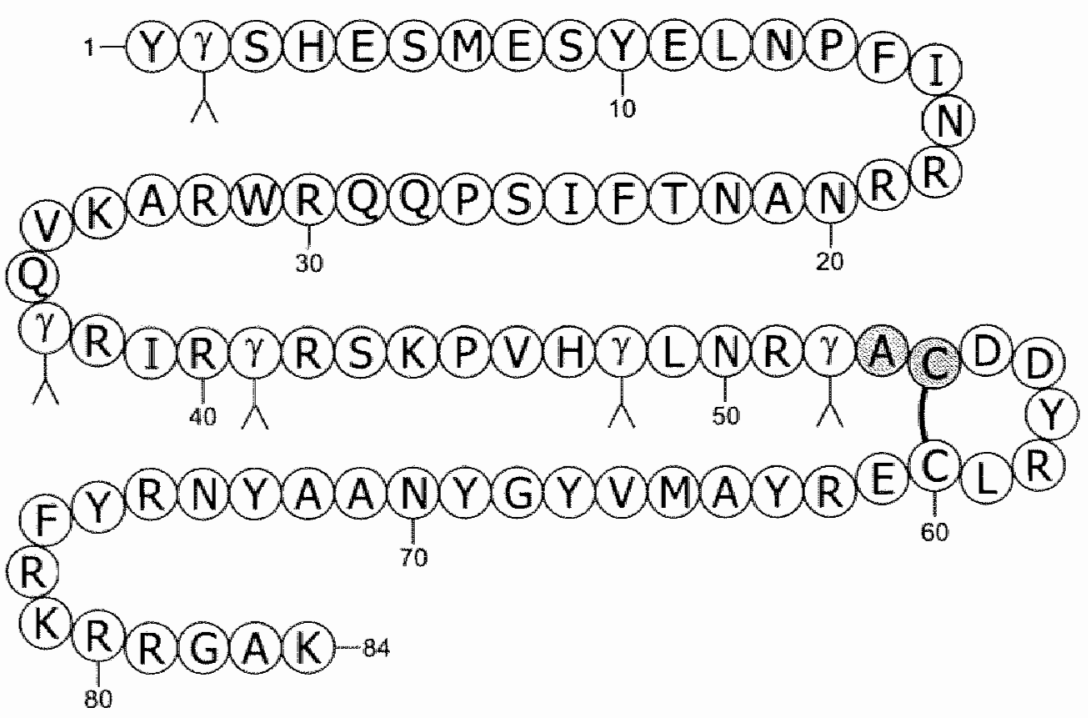

Figure 1

Amino acid sequence of matrix cha protein. The grey residues at position 53 -54 represent the alamine-cysteine native chemical ligation site. The solid line represents the disulfide-bond. $y$ denotes ycarboxy glutamic acid. Sequence from nucleotide analysis. $[32,100]$. 
When biologically active proteins cannot be generated by recombinant expression techniques because of insolubility or misfolding, chemical protein synthesis is an excellent alternative that, because of its versatility, can greatly add to structure-function analysis of the protein of interest. Because polypeptide chains of 40-60 amino acids realistically represent the efficiency limit of solid-phase peptide synthesis, native chemica! ligation was.

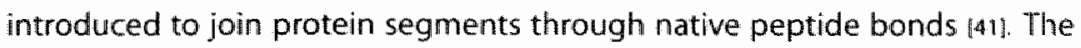
native chemical ligation technique uses the principle of a chemoselective reaction between two unprotected peptides in aqueous solution in which a carboxyterminal thioester undergoes a thiol-exchange with an amino terminal cysteine sulfhydryl side chain. A subsequent, rapid, intramolecular rearrangement yields a native peptide bond at the site of ligation (Figure 2). Here we report the total chemical synthesis of MGP by solid-phase peptide synthesis and native chemical ligation, yielding highly pure MGP with a full amide backbone and native biochemical features.
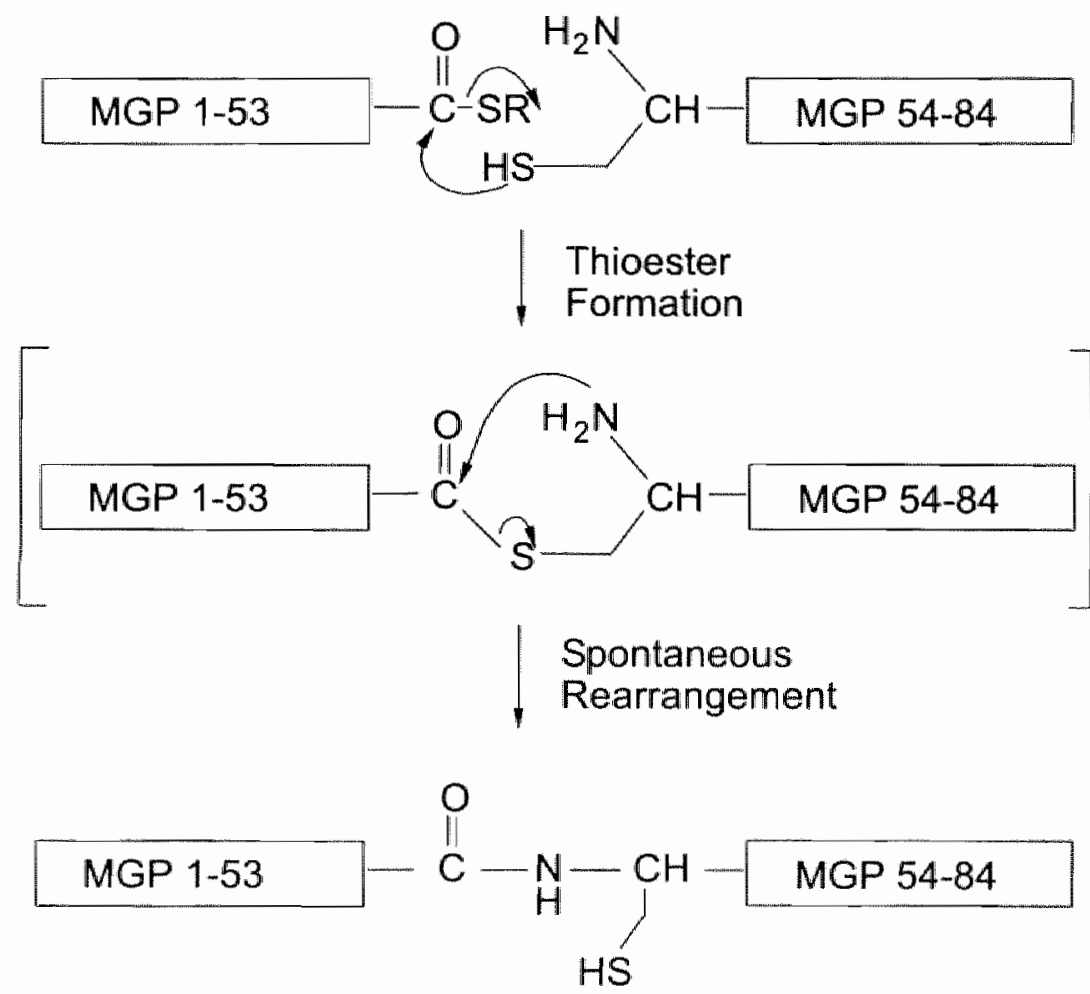

Figure 2

Native chemical ligation strategy for the total chemical synthesis of human matrix Gla protenth. The 53-residue N-terminal peptide-thioester (COSR) fragment and the 30-tesidue C-terminat fragment of MGP were synthesised by stepwise SPPS techniques using Boc chemistry protocols. The two fragments are initially joined by thioester formation (not observed as: a discrete intermediate), and a subsequent spontaneous, rapid rearrangement results in the formation of a native peptide bond at the site of ligation. 


\section{Materials and methods}

\section{Materials}

Most Boc-amino acids and 2-(1H-benzotriazol-1-yl) 1,1,3,3-tetramethyluronium hexafluorophosphate (HBTU) were from Nova-Biochem. Boc-Lys(ClZ)-OH was obtained from Bachem Bioscience; $B o c-A r g(p$-toluenesulfonyl)$\mathrm{OH}$ and Boc-Asn (xanthyl)-OH were from Midwest Bio-Tech. S-trityl-mercaptopropionic acid was obtained from Peptides International. Boc-Lys-OCH2Pamresin and Boc-Leu-OCH2Pam-resin were obtained from Applied Biosystems. $N, N$,-disopropylethylamine (DIEA), p-cresol, thiophenol, and benzylmercaptan were obtained from Aldrich. N,N-Dimethylformamide (DMF) and HPLC-grade acetonitrile were purchased from Fischer. Trifluoroacetic acid (TFA) was obtained from Halocarbon, and HF was purchased from Matheson Gas.

Na.Boc- $\gamma, \gamma$-di-cyclohexyl-L- - carboxy glutamic acid-OH synthesis $\mathrm{N}^{*}$-Boc- $\gamma$, $\gamma$ di-cyclohexyl-L- $\gamma$ carboxy glutamic acid-OH (Boc-Gla[dcHx]-OH) was synthesised as described (148).

\section{Peptide synthesis}

The sequence of MGP to be synthesised $[32,100]$ is shown in Figure 1.Peptides were prepared by manual solid-phase peptide synthesis (SPPS) on a 0.3 mmol scale (MGP 1-53) and $0.35 \mathrm{mmol}$ scale (MGP 54-84) using the in situ neutralization/HBTU activation procedure for Boc chemistry essentially as previously described [196]. Each synthetic cycle consisted of $\mathrm{Na}-\mathrm{BoC}$ removal by a 1-2-min treatment with neat TFA, a 1 min DMF-flow wash, and a $10 \mathrm{~min}$ coupling (Arg, Asn: $20 \mathrm{~min}$ ) with $1.0 \mathrm{mmol}$ preactivated Boc amino acid in the presence of excess DIEA, followed by a second DMF-flow wash. For $3 \mathrm{~min}, 1.1$ mmol Boc amino acids (except Boc -Gla[dcHx]-OH) were preactivated with 1.0 mmol HBTU (0.5 M in DMF)in the presence of $3 \mathrm{mmol}$ DIEA. For $3 \mathrm{~min}, 0.44$ mmol Na-Boc Gla(deHx)-OH was preactivated with $0.4 \mathrm{mmol} H B T U$ in the presence of $1.5 \mathrm{mmol}$ DIEA. After each coupling step, yields were determined by measuring residual free amine with the quantitative ninhydrin assay [i92]. After coupling of GIn residues, a DCM flow wash was used before and after deprotection using TFA to prevent possible high-temperature (TFA/DMF)catalysed pyrrolidonecarboxylic acid formation [1966). Side-chain-protected amino acids were Boc-Arg (p-toluenesulfonyl)-OH, Boc-Asn(xanthyl)-OH, BocAsp(O-cyclohexyl)-OH, Boc-Cys(4-methylbenzyl)-OH, Boc-Gla(di-O-cyclohexyl)-OH, Boc-Glu(O-cyclohexyl)-OH, Boc-His(dinitrophenyl)-OH, Boc-Lys(2(C-Z)-OH, Boc-Ser(benzyl)-OH, Boc-Thr(benzyl)-OH, and Boc-Tyr(2-Br-Z)-OH. Other amino acids were used without side-chain protection. After chain assembly was completed, the peptides were deprotected and cleaved from the resin by treatment with anhydrous $\mathrm{HF}$ for $1 \mathrm{~h}$ at $0{ }^{\circ} \mathrm{C}$ using $4 \%$ anisole (MGP 1-53) or p-cresol(MGP 54-84) as a scavenger. The imidazole side chain- 
dinitrophenyl (Dnp)-protecting groups remained on His residues on peptide MGP 1-53 because the Dnp-removal procedure is incompatible with $C$ terminal thioester groups. However, Dnp is gradually remowed by thiols during the ligation reaction yielding unprotected His. After cleavage, both peptides were precipitated and washed with ice-cold diethylether. Subsequently, the precipitate was dissolved in aqueous acetonitrile and lyophillised.

\section{TAMPAL resin}

$0.6 \mathrm{mmol}$ S-trityl mercaptopropionic acid was activated with $0.54 \mathrm{mmol}$ HBTU in the presence of 2 mmol DIEA and coupled for 10 min to Boc-LeuOCH2Pam-resin ( $99.61 \%$ coupling). The resulting TAMPAL resin was used as a starting resin for polypeptide chain assembly following removal of the trityl protecting group and formation of the thioester bond with any desired amino acid using standard peptide coupling protocols. Treatment of the final peptide with anhydrous HF yielded the C-terminal activated mercaptopropionic acid-lleucine (MPAL) thioester peptide that can directly participate in native chemical ligation [75]. Trityldeprotection was achieved by $2 \times 1 \mathrm{~min}$ treatment with a solution of $1.25 \%$ triisopropylsilane and $1.25 \% \mathrm{H}_{2} \mathrm{O}$ in TFA.

HPLC

Analytical reversed-phase HPLC was performed on a Hewlett Packard HPLC 1050 system using Vydac $C-18$ columns $\left(5 \mu \mathrm{m}_{s} 0.46 \times 5 \mathrm{~cm}\right)$. Semipreparative reversed-phase HPLC was performed on a Rainin HPLC system using a Vydac C-18 column $(10 \mu \mathrm{m}, 2.5 \times 25 \mathrm{~cm})$. Linear gradients of acetonitrile in water $/ 0.1 \%$ TFA were used to elute bound peptides. The flow rates used were 1: $\mathrm{mL} / \mathrm{min}$ (analytical) and $15 \mathrm{~mL} / \mathrm{min}$ (semipreparative).

\section{Mass spectrometry}

ESI-MS was performed on an API-III triple quadrupolle mass spectrometer (PESciex). Peptide masses were calculated from the experimental $\mathrm{m} / \mathrm{z} \mathrm{ratios}$ from all the observed protonation states of a peptide using Mac5pec software (Sciex). Theoretical masses of peptides and proteins were calculated using MacProMass software (Beckman Research Institute).

\section{Native chemical ligation}

The ligation of unprotected synthetic peptide segments was performed as described earlier [75]. In short, peptides were dissolved in $0.1 \mathrm{M}$ phosphate buffer containing $6 \mathrm{M}$ guanidine, $\| \%(\mathrm{v} / \mathrm{v})$ benzy/mercaptan, and $1 \%(\mathrm{v} / \mathrm{v})$ thiophenol ( $\mathrm{pH} 7)$. The ligation reaction was performed at $37^{\circ} \mathrm{C}$ under frequent vortexing, and the reaction was monitored by HPLC and ESI-MS until completion. 


\section{CD spectroscopy}

CD spectra were recorded on an AVIV stopped-flow CD spectrometer Model $2025 \mathrm{~S}$ at $25^{\circ} \mathrm{C}$. MGP was dissolved in $25 \mathrm{mM}$ boric acid at $\mathrm{pH} 7.4$, and the concentration was determined by quantitative amino acid analysils. $C D$ spectra are presented as the molar ellipticity versus wavelength in $0.5-\mathrm{nm}$ increments. The mean residual welight ellipticity was calculated using Equation (1).

$[\theta]_{\text {HAFi }}=(\theta \times 100 \times \mathrm{Mr}) /(\mathrm{c} \times \mathrm{d} \times \mathrm{n})$

where $[\theta]_{\text {M }}$ is the mean residue ellipticity (deg $\mathrm{cm}^{2} \mathrm{dmol}$ ), $\theta$ the observed ellipticity at $222 \mathrm{~nm}, \mathrm{Mr}$ the molecular weight of MGP $c$ the concentration in $\mathrm{mg} / \mathrm{mL}$, $\mathrm{d}$ the path length in centimetres, and $\mathrm{n}$ the number of residues [194]. The ellipticity of MGP at $222 \mathrm{~nm}$ was recorded as a function of the $\mathrm{CaCl}_{2}$ concentration. To a volume of $250 \mu \mathrm{L}$ of $\mathrm{MGP}\left(3.4 \mathrm{mM}, \mathrm{CaCl}_{2}\right.$ was added to a final concentration of $20,40,79,157,311,618,1225$, and 2411 HM. MGP concentrations were corrected for dilution of the sample by $\mathrm{CaCl}_{2}(20 \mu \mathrm{L}$ maximal addition). For the calculation of $\alpha$ helical content of MGP, the averages of the mean residual weight ellipticities at $223,222.5,222,221.5$, and $221 \mathrm{~nm}$ were used. The percentage of $\alpha$-helix in MGP was determined as the ratio of the mean residual weight ellipticity at $222 \mathrm{~nm}$ and the maximal theoretical mean residual weight ellipticity at $222 \mathrm{~nm}([0] \mathrm{max} ;$ [33]) using Equation (2).

$[\theta]_{\max }=-39500(1-(2.57 / \mathrm{n}))$

\section{SDS-PAGE and Western blot analysis}

Protein samples in SDS sample buffer (40 mM Tris-HCl at pH 6.7,4\%(w/v) SDS, $10 \%(v / v)$ glycerol, $2 \%(v / v)$ 2-mercaptoethanol, $0.01 \%(w / v)$ bromophenol blue) were applied to polyacrylamide gels $20 \%(\mathrm{w} / \mathrm{w})$ in SDS under denaturing conditions. After electrophoresis, the gels were transferred to Immobilon-P PVDF membranes (Millipore). After washing the membranes in PBS for 15 min, non-specific binding sites were blocked with blocking buffer ( $3 \%$ w/v non-fat dry milk in PBS) for $1 \mathrm{~h}$ at room temperature and incubated at $4{ }^{\circ} \mathrm{C}$ overnight with an $03-15 \mathrm{MGP}$ antibody in blocking buffer [17]. After washing three times with $0.3 \%(v / v)$ Tween-20 in phosphate-buffered saline (PBS-Tween), the membrane was incubated for 1 h at room temperature with HRP-conjugated rabbit anti-mouse IgG in PB5-Tween. The membrane was washed with PBS-Tween, followed by a fimall wash step of $15 \mathrm{~min}$ with PBS and development with ECL Western blotting detection reagents (Amersham Pharmacia). Finally, protein bands were visualized on Hyperfilm $\mathbb{E C L}$ (Amersham Pharmacia). 


\section{Results}

\section{Synthesis of matrix Gla protein peptides}

To establish chemical access to the 84-residue human matrix Gla protein a two-fragment synthesis was chosen with a suitablle ligation site at $\mathrm{Ala}{ }^{53}-\mathrm{Cy} \mathrm{s}^{54}$, conducted by the need for an $\mathrm{N}$-terminal cysteine on the C-terminal peptide at the site of ligation (Figure 1). The synthesis of the 84-residue MGP therefore required synthesis of two polypeptides: $\mathrm{NH}_{2}-\mathrm{Tyr}^{\mathrm{i}}-\mathrm{Ala} \mathrm{a}^{5 \mathrm{*}} \mathrm{COSR}$ (MGP 1-53) and $\mathrm{NH}_{2}-\mathrm{Cys}^{54}-\mathrm{L}_{2} \mathrm{~s}^{\mathrm{s} 4}-\mathrm{COOH}$ (MGP 54-84). MGP 1-53 was synthesised on C-terminal thioester generating resin (TAMPAL) to yield the cuterminal mercaptopropionic acid-Leu (MPAL)-activated thioester. MGP 54-84 was synthesised on Lys-PAM resin to yield an $\mathrm{N}$-terminal free cysteine and a $\mathrm{C}$ terminal carboxylic acid group after cleavage of the peptide from the resin. The synthesis $(0.3 \mathrm{mmol})$ of MGP $1-53$ on TAMPAL resin yielded $2.08 \mathrm{~g}$ peptide resin (theoretical yield: $2.27 \mathrm{~g}$ corrected for resin sampling), with an average coupling efficiency of $99.56 \%$ (range $99.33 \%-99.96 \%$ ) based on ninhydrin assays after each coupling step. After the $\mathrm{N}^{*}$-Boc group was removed, $330 \mathrm{mg}$ peptide-resin was cleaved with anhydrous HF, yielding 216 mg dry crude peptide that was further purified on preparative high-pressure liquid chromatography (HPLC; Figure 3A). From preparative HPLC, $29 \mathrm{mg}$ of pure MGP 1-53 was obtained. ESI-MS revealed a molecular mass of $7282.3 \pm$ $0.3 \mathrm{D}$ (Figure $3 \mathrm{~B}$ ), which agreed well with the theoreticall average mass of

7282.6 D of MGP 1-53-MPAL, with dinitrophenyl (Dnp) groups attached to $\mathrm{His}^{4}$ and $\mathrm{His}^{47}$ (Figure $3 \mathrm{~B}$ ).

The synthesis of MGP $54-84(0.35 \mathrm{mmol})$ on Lys-PAM resin yielded $2.06 \mathrm{~g}$ peptide-resin (theoretical yield: $2.11 \mathrm{~g}$ ) with an average coupling efficiency of $99.52 \%$ (range $99.23 \%-99.83 \%$ ). Yielding $185 \mathrm{mg}$ dry crude peptide, $300 \mathrm{mg}$ peptide resin was cleaved with anhydrous HF. From a preparative HPLC run of $80 \mathrm{mg}$ of crude MGP 54-84, $21 \mathrm{mg}$ of pure MGP 54-84 was obtained (Figure 3A).ESI-MS showed an apparent molecular mass of $3872.8 \pm 0.7 \mathrm{D}$ (Figure $3 \mathrm{C}$ ), which fitted well with the calculated average isotopic mass of $3873.4 \mathrm{D}$.

\section{Synthesis of matrix Gla protein by native chemical ligation}

Native chemical ligation of MGP peptides was performed with $27.8 \mathrm{mg}$ (3.8 4mol) MGP 1-53 and 17.1 $\mathrm{mg}(4.4 \mu \mathrm{mol}) \mathrm{MGP}$ 54-84. The peptides were dissolved in $2 \mathrm{~mL}$ ligation buffer with $2 \%$ thiophenol and $2 \%$ benzylmercaptan, resulting in a final peptide concentration of $1.9 \mathrm{mM}$ MGP 1-53 and $2.2 \mathrm{mM}$ MGP 54-84 at $\mathrm{pH} \approx 7$. After $1 \mathrm{~h}$ at $37^{\circ} \mathrm{C}$, multiple peaks could be observed on analytical HPLC (Figure $3 D$ ). In addition to the starting materials (54-84 and 1-53-MPAL[2 Dnpl), the following fragments were identified: a +26-D derivative of 54-84 (peak 1); 1-53-MPAL without Dnp (peak 2); 1-53MPAL with 1 His-Dnp (peak 3); MGP 1-53-benzylmercaptan thioester exchange (peak 4); 1-53-MPAL with 1 His-Dnp (peak 5); and the ligated 

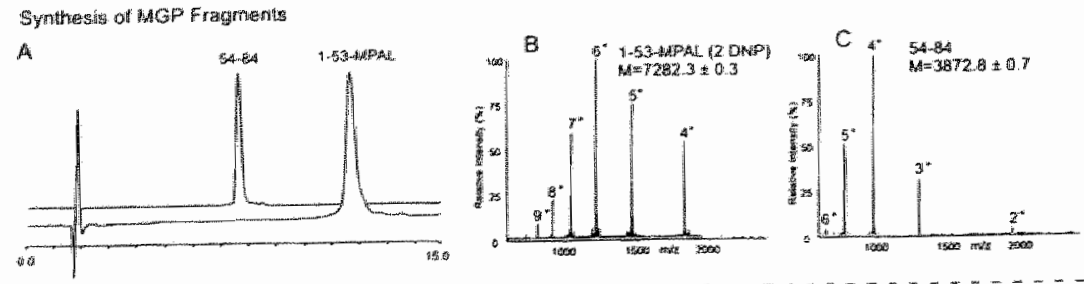

Natwe Chemical Lighation of MGP Fragments
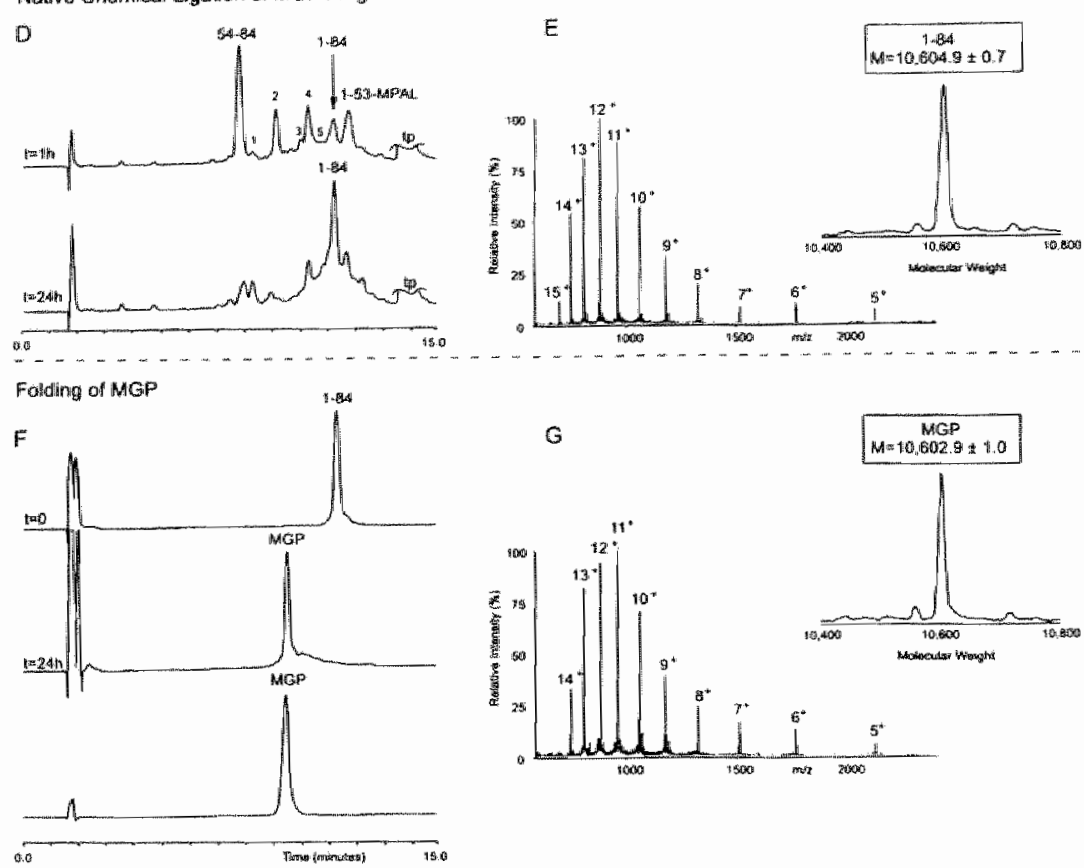

Figure 3

Total synthesis of human matrix Gla protein by native chemical ligation. Synthesis of MGP fragments: (A) HPLC chromatogram $(6.18,22.5 \%$. $1 \%$ acetonitrile, $1.23 \% / \mathrm{min})$ of the silarting synthetc peptidle segments MGP 54-84 and MGP 1-53. (B) EST-MI5 spectrum of MCP 1-53 shows the $\mathrm{m} / 2$ ratios (fourth through nirith ionised states) with an calculated mass of $7282.3 \pm 0.3 \mathrm{D}$ (theoretical average mass of 7282.61. (C) ESI-MS spectrum of MGP $54-84$ shows the m/2 ratios (second through sixth ionised states) with an calculated mass of $3872.8 \pm 0.7 \mathrm{D}$ (theoretical average mass: 3873 D). Native chemical ligation of MGP fragments: (O) HPLC rhromatograms of the ligation reaction. started by the addition of $2 \%(w / v)$ thiophenol and $2 \%$ benzylmercaptan to the peptide mixture MGP $1-53$ and MGP 54-84. At $t=1$ h, ligated product (12-84) Is shown as well as the C-terminal segment starting material. The unreacted N-terminal material can be accounted for as multiple intermediates eluting between 7 and 13 min (see (ext). At $t=24 \mathrm{~h}$, ligation was almost complete. (E) ESI-MS spectrum shows the $\mathrm{m} / z$ pattern of the ligated material (fifth through fifteenth ionised states) with a calculated mass of 10,504,9 40.7 D (theoretical awerage mass of the reduced 84-residue MGP: 10,604.8 D) "Folding and disulfide formation of MCP: (F) HPLC chromatograms of the purfied, reduced MCP polypeptide $(t=0)$, the crude, folded material $(t=24 \mathrm{~h})$, and the purified final product (MGP). (G) ESIMS spectrum shows the $\mathrm{m} / \mathrm{z}$ pattern (fifth through fourteenth ionised state) with a calculated molecular mass of $10,602.9 \pm 1.0 \mathrm{D}$ theoretical average inass of MGP containing one disulfide: $10,602.8 \mathrm{D}$ ). 
84-residue polypeptide (1-84; Figure 3D). The difference in retention time of peaks 3 and 5 can be explained by Dnp groups that are attached to different His residues in fragment 1-53. ESI-MS revealed a mass for the 1-84 MGP polypeptide of $10,604.9 \mathrm{D}$, which fitted well with the theoretical average isotopic malss of $10,604.8 \mathrm{D}$ (Figure 3E). After $24 \mathrm{~h}$, ligation was almost complete, and the mixture was applied to preparative HPLC (C18:22.5\%-41\% acetonitrile, $0.31 \% / \mathrm{min}$ ) to isolate the 1-84-polypeptide chain, yielding $17 \mathrm{mg}$ (42\% yield) dry peptide after lyophilisation.

\section{Folding of matrix Gla protein}

The 84-residue polypeptide chain of MGP (16 mg) was folded in $3 \mathrm{M}$ guanidine $(\mathrm{pH} 8.0)$ at a final concentration of $0.2 \mathrm{mg} / \mathrm{mL}$ polypeptide. Overnight stirring exposed to air at $4^{\circ} \mathrm{C}$ resulted in a quantitative shift of the peptide peak on analytical HPLC from 11.36 to $9.55 \mathrm{~min}$ (Figure $3 \mathrm{~F}$ ). This shift was likely because of a conformationall change caused by the formation of

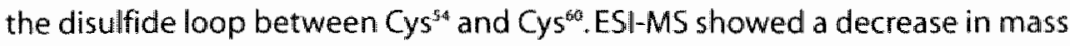
of the folded polypeptide from $10,604.9 \mathrm{D}$ to $10,602.9 \mathrm{D}$, the loss of $2.0 \mathrm{D}$ representing the loss of two hydrogen atoms from the free sulfhydryl groups on formation of the disulfide bond (Figure 3G). After purification on preparative HPLC (C18: 22.5\%- 41\% acetonitrile, $0.31 \% / \mathrm{min}), 6 \mathrm{mg}$ of MGP containing five Gla residues and an internal disulfide were isolated (35\% yield). When MGP was brought into Tris buffer $(50 \mathrm{mM}$ Tris, $100 \mathrm{mM} \mathrm{NaCl}$ at

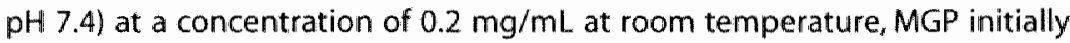
dissolved, but it precipitated within minutes after addition of buffer (data not shown). Addition of guanidine to the Tris buffer prevented precipitation at guanidine concentrations $>2.5 \mathrm{M}$. The insolubility of synthetic MGP resembles that of native, purified MGP, which precipitates at concentrations $>10 \mu \mathrm{g} / \mathrm{mL}[154]$. However, when MGP was brought into Boric acid buffer (25 $\mathrm{mM}$ boric acid at $\mathrm{pH} 7.4$ ) at $0.2 \mathrm{mg} / \mathrm{mL}$, no precipitation was observed, and peak area analysis by analytical HPLC showed that $>90 \%$ of MGP was still in solution after overnight incubation (data not shown).

\section{Ca binding to matrix Gla protein}

Evidence of $\mathrm{Ca}^{2+}$-binding to MGP was obtained by analytical HPLC in the absence or presence of $5 \mathrm{mM} \mathrm{CaCl}$. The retention time of $M G P$ decreased from $9.6 \mathrm{~min}$ in the absence of $\mathrm{CaCl}_{2}$ to $8.8 \mathrm{~min}$ in the presence of $5 \mathrm{mMCaCl}$ (Figure 4). This shift in retention time was either caused by a charge effect or by a conformational change of MGP on binding of $\mathrm{Ca}^{24}$-ions. The two additional peaks that elute before and after the main peak may represent MGP molecules that have bound a different number of $\mathrm{Ca}^{2+}$-ions (Figure 4).

To investigate a possible change in secondary structure contents of MGP on binding of $\mathrm{Ca}^{2 *}$-ions, folded MGP was subjected to circular dichroism (CD) studies. In the absence of $\mathrm{CaCl}_{2}, \mathrm{CD}$ spectroscopy showed a typical protein 


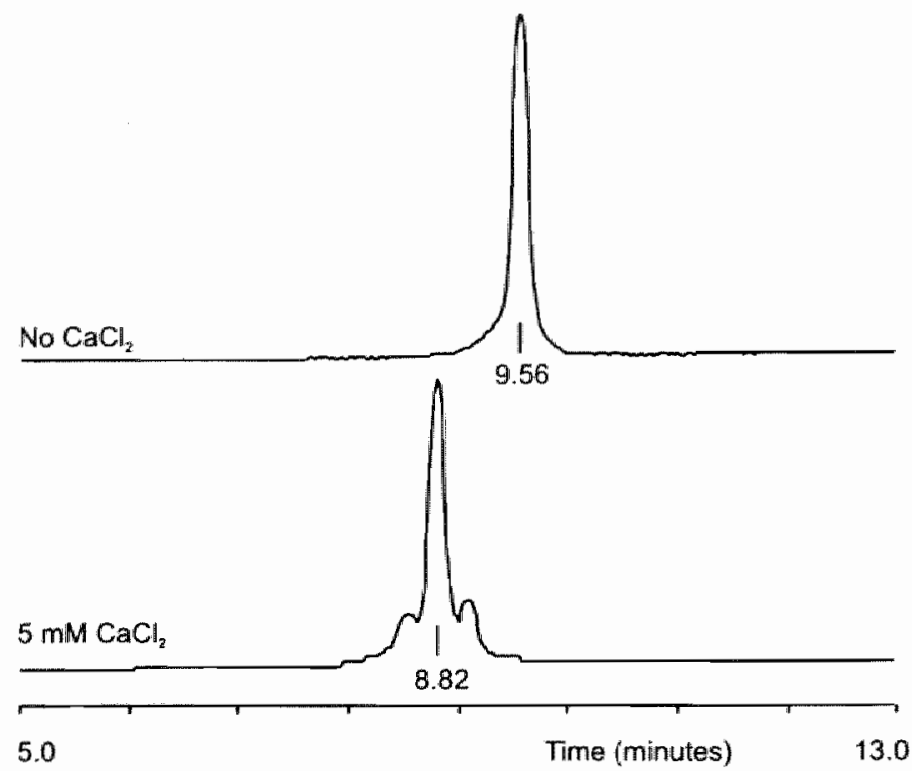

Figure 4

$\mathrm{Ca}^{*}$-binding to synthetic MGP. HPLC chromatograms $(\mathrm{C} 28: 22.5 \%-41 \%$ acetonitrile, $1.23 \% / \mathrm{min})$ of synthetic MGP in the absence or in the presence of $5 \mathrm{mM} \mathrm{CaCl}$.

94

structure spectrum composed of a mixture of $\alpha$-helix, $\beta$-structure, and random coil (Figure 5). From the mean residual weight rotation at $222 \mathrm{~nm}$, it was estimated that MGP contained $21 \% \alpha$-helix in the absence of $\mathrm{CaCl}_{2}$. However, addition of varying amounts of $\mathrm{CaCl}_{2}(20 \mu \mathrm{M}-2.4 \mathrm{mM})$ to $\mathrm{MGP}$ resulted in a sharp increase in mean residual weight rotation at $222 \mathrm{~nm}$ at $-0.2 \mathrm{mM} \mathrm{CaCl}_{2}$ (Figure 5B). This effective concentration of $\mathrm{CaCl}_{2}$ lies in the range of Glamdependent $\mathrm{Ca}^{2 *}$ binding to bone Gla protein [84] and to Gla* containing coagulation factors ([143), and references therein), which occurs between 0.1 and $1 \mathrm{mM} \mathrm{CaCl}$. It was calculated that MGP contained $21 \%$ $\alpha$-helix in the absence of $\mathrm{CaCl}_{2}$, which increased to $26 \%$ at $0.3 \mathrm{mM} \mathrm{CaCl}$, representing an increase in $\alpha$-helicity of $\approx 25 \%$.

To compare synthetic MGP with native MGP, SDS-PAGE was performed under denaturing conditions. After Western blotting, MGP was detected with monoclonal antibodies against a synthetic peptide 3-15 from MGP [17]. Figure 6 shows MGP isolated from human bone (kindly donated by Dr. Reidar Wallin from Wake Forest University) in comparison with synthetic MGP (Mr: 10.6 $\mathrm{kDa}$ ) and the fragments from which MGP was synthesised. As can be observed, the synthetic MGP in lane 1 comigrates with a purified sample of human MGP in lane 2 (barely visible) and a crude preparation of human MGP in lane 4. The MGP fragment $1-53$ with a mass of $7.3 \mathrm{kDa}$ in lane 3 has increased mobility compared to full-length MGP, and because of the single 

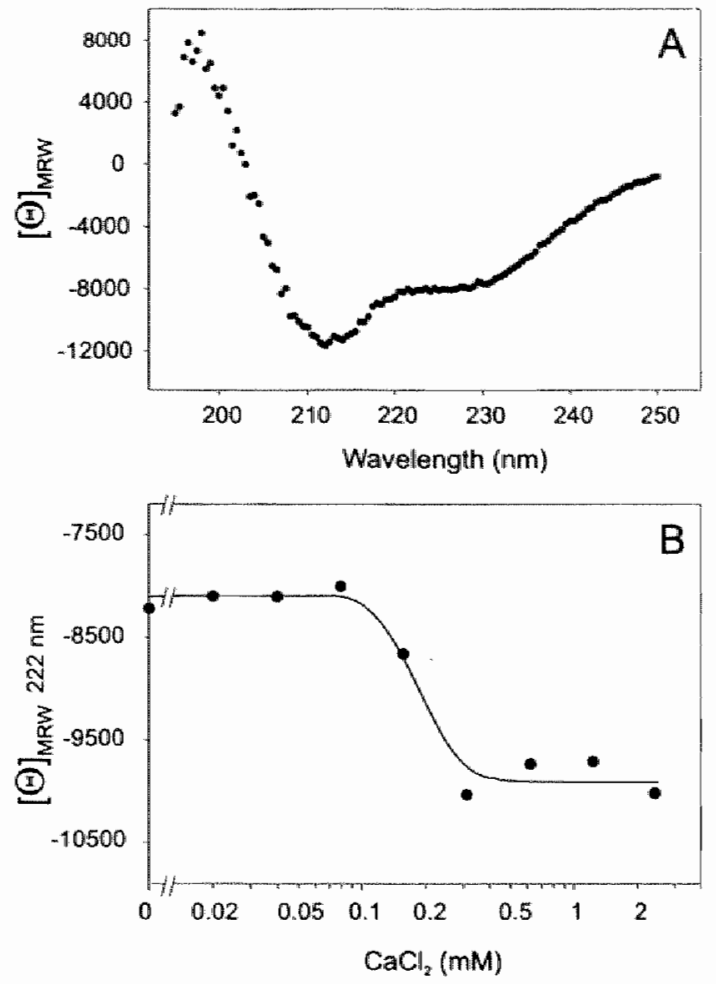

Fîgure 5

Circular dichroism spectum of synthetic matrix Gla protein. (A) The spectrum for matrix Gila protein at $25^{\circ} \mathrm{C}$ in boric acid shows $21 \%$ o-helical structure as can be estimated from the mean residual weight (MRW) ellipticity at $222 \mathrm{~nm}$. (B) The increase (25\%) of mean residual weight ellipticity of MGP at $222 \mathrm{~nm}$ as a function of $\mathrm{CaCl}_{2}$ concentration.

free cysteine in MGP $1-53$, a dimer of MGP $1-53$ is visible at $\approx 15 \mathrm{kDa}$. MGP fragment $5.4-84$ could not be detected with the monoclonal antibody. This SDS-PAGE observation provides additional proof for the native-like condition of chemically synthesised MGP.

\section{Discussion}

Matrix Gla protein, an essential $\mathrm{Ca}^{2+}$ chelator that prevents vascular calcification, was successfully synthesised using solid-phase synthesis and native chemical ligation. The 84-residue polypeptide was folded to obtain the native-like (low-solubility) conformation containing one disulfide bond. Synthetic MGP comigrated with MGP derived from human bone on SDSPAGE under denaturing conditions. The mass of the folded matrix. Gla protein as measured using electrospray ionisation mass spectrometry was identical to the theoretical average isotopic mass. The ability of MGP to form its internal disulfide shows that the initial thioester bond between Ala ${ }^{53}$ and 


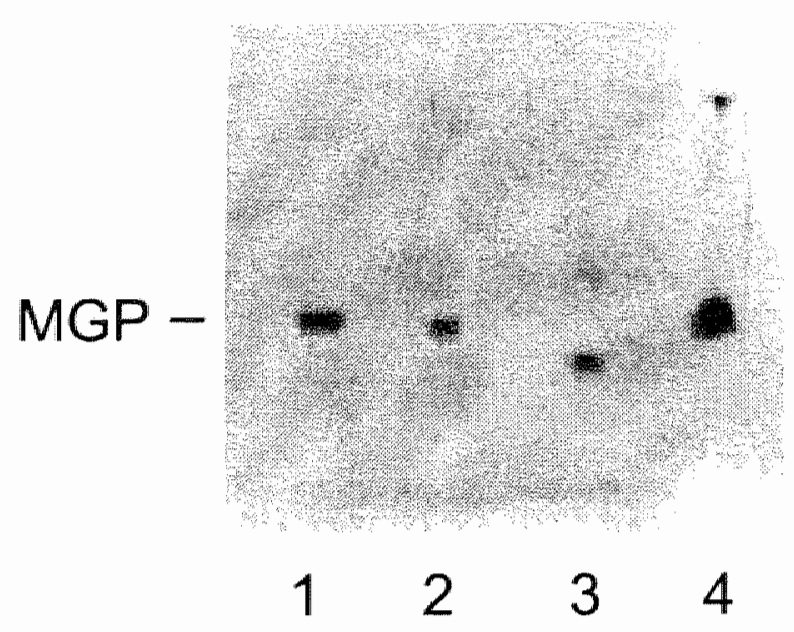

Fígure 6

SDS-PACE of MGP. Symthetic MGP (lane 1), purified MGP from human bone (lane 2), MGP peptide 1.53- COSR (tame 3), and crude MC Prom human bone (lane 4) were applied to $12.5 \%$ SDS.PACE, Western blotting, and detection with a monoclonal antibody algainst peptide 3-15 from human MGP.

$\mathrm{Cy}^{55^{54}}$ has rearranged into a peptide bond as depicted in Figure 2, resulting in the regeneration of the functional Cys $s^{\text {sit }}$ sulfhydryl side chain. When proteins fold, ESI-MS shows a characteristic shift of maximal intensity from the higher $\mathrm{m} / \mathrm{z}$ states in the reduced protein to the lower $\mathrm{m} / \mathrm{z}$ states in the folded protein. This is because the native, folded conformation of proteins typically can carry fewer charges under ESI-MS ionisation conditions than the unfolded, extended polypeptides [36]. The minor shift from the twelfth charged state for the reduced MGP to the eleventh charged state for the folded, oxidized MGP (Figure $3 \mathrm{E}, \mathrm{G}$ ) is most likely a result of the relatively high amount of positively chargeable residues arginine (14) and asparagine (7) in MGP. This means that these residues stay exposed to the bulk solvent in the folded MGP, and this might play a role in the observed low solubility of MGP.

Using HPLC and CD spectroscopy, it was shown that synthetic MGP could bind $\mathrm{Ca}^{2 *}$, inducing a shift in the HPLC retention time of MGP and an increase in $\alpha$-helicity as measured as a change in mean residual weight ellipticity at $222 \mathrm{~nm}$. From the increase in mean residual rotation at $222 \mathrm{~nm}$, it was calculated that the content of $\alpha$-helix increased by $25 \%$ in the presence of $\mathrm{CaCl}_{2}$. Therefore, the shift in retention time of synthetic MGP on HPLC in the presence of $\mathrm{CaCl}_{2}$ can be explained by an increase in $\alpha$-helicity of MGP on binding of $\mathrm{Ca}^{2+}$-ions.

Similar behaviour was shown for bone Gla protein (osteocalcin), in which $\alpha$-helicity was observed to increase from $8 \%-38 \%$ as a result of $\mathrm{Ca}^{2+}$-binding 
[84]. Although no homology between the proteins is obvious, some similar functional properties during bone metabolism can be anticipated, and it is therefore interesting that in both proteins, $=20$ residues are in $\alpha$-helical conformation in the presence of $\mathrm{CaCl}_{2}$. The synthetic, native-like MGP generated in our study will be used for structural studles and as an antigen to raise antibodies required for the development of immunoassays. Determination of MGP in plasmas from patients with cardiovascular disease and healthy individuals will give the necessary insight into a possible role of MGP in the development of atherosclerosis.

\section{Acknowledgments}

We thank Philip E. Dawson for providing access to his chemical protein synthesis facility, Kevin Judice for his excellent advice during synthesis of $\mathrm{N}^{\alpha}$-tBoc- $\gamma, \gamma$-dicyclohexyl-L- $\gamma$-carboxy glutamic acid, and Reidar Wallin for providing us with purified human matrix Gla protein. 



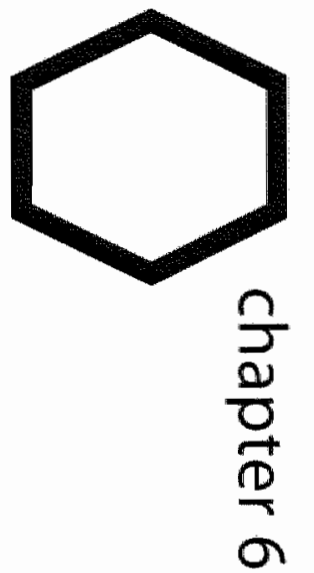

tissue-specific utilization of menaquinone-4 results in prevention of arterial calcification in warfarin-treated rats

h.m.h.spronk $\bigcirc$ b.a.m.soute $\bigcirc$ l.j.schürgers $\bigcirc$ h.h.w. thijssen j.g.r.de mey $\bigcirc$ c.vermeer submitted 


\section{Summary}

The effects of vitamin $K$ (phylloquinone: $K 1$ and menaquinone-4: MK-4) on vascular calcification and their utilization in the arterial vessel wall were compared in the warfarin-treated rat model for arterial calcification. Warfarintreated rats were fed diets containing $K{ }_{1}, M K-4$, or both. Both $K 1$ and $M K-4$ are cofactors for the endoplasmic reticulum enzyme wglutamyl carboxyllase but have a structurally different aliphatic side chain. Despite their similar in vitro cofactor activity we show that MK-4 and not K1 inhibits warfarin-induced arterial calcification. The total hepatic $K 1$ accumulation was three fold higher than that of MK-4, whereas aortic MK-4 was three times that of K1. The utilization of $K 1$ and $M K-4$ in various tilssues was estimated by calculating the ratios between accumulated quinone and epoxide species. K1 and MK-4 were both equally utilised in the liver, but the aorta showed a more efficient utilization of MK-4. Therefore, the observed differences between KI and MK-4 with respect to inhibition of arterial calcification may be explained by both differences in their tissue bioavailability and cofactor utilization in the reductase/carboxylase reaction. An alternative explanation may come from an as yet hypothetical function of the geranylgeranyl side chain of MK -4 , which is a structural analogue of geranylgeranyl pyrophosphate and could interfere with a critical step in the mevalonate pathway. 


\section{Introduction}

Vitamin $K$ is a group name for a number of related compounds, which all have a methylated naphthoquinone ring structure, but differ from each other by the length and degree of saturation of their aliphatic side chain at the 3-position [204]. Two K-vitamers were studied in this paper: phylloquinone (K1) and menaquinone-4 (MK-4). The only known function of vitamin $K$ in mammals is to act as a cofactor for $\gamma$ glutamyl carboxylase. This endoplasmic reticulum enzyme catalyses the posttranslational conversion of specific glutamic acid residues into $\gamma$-carboxyglutamic acid residues (Gla) in a limited number of proteins $[224,240]$. Reduced vitamin $\mathrm{K}\left(\mathrm{KH}_{2}\right)$ is used as the active cofactor in this reaction. During the carboxylation reaction, $\mathrm{KH}_{2}$ is converted into vitamin $\mathrm{K}$-epoxide ( $\mathrm{KO}$ ) and one or two dithiol-dependent reductases mediate the efficient recycling of the epoxide formed. The dithioll-dependent pathway is inhibited by coumarin derivates such as warfarin [58]. Mainly in the liver a second pathway for $\mathrm{KH}_{2}$ formation is formed by an NAD(P)Hdependent dehydrogenase (DT-diaphorase), which uses $K$ and not $K O$ as a substrate. Relatively high intakes of vitamin $K$ are required to generate adequate amounts of $\mathrm{KH}_{2}$ via the latter pathway because the KO formed cannot be re-used. In extrahepatic tissues such as arterial blood vessels and cartilage, the DT-diaphorase is less active than in liver [246], which explains why vitamin $\mathrm{K} 1$ effectively counteracts the effect of warfarin in the liver, but not in bone [170] and the arterial vessel wall [161]. Thus, the synthesis of Glaproteins can be blocked in extrahepatic tissues by a combination of warfarin and vitamin K1, without affecting the (hepatic) synthesis of coagulation factors and thereby avoiding the risk of bleeding [164]. Using this regimen Price et. al. showed that warfarin induced calcifications of the elastic lamellae in arteries and heart valves of rats within 3-5 weeks through inhibition of the $\gamma$-glutamyl carboxylation of matrix Gla protein $[161,162)$

Three observations suggest that in the arterial vessel wall MK-4 is preferentially absorbed and used as a cofactor in the $\gamma$-glutamyl carboxylation reaction. First, it has been reported that in rats after equal intakes of $K 1$ and $M K-4$ hepatic accumulation of $K 1$ is higher than that of MK-4 whereas higher MK-4 tissue concentrations were found the arterial vessel wall [188]. Second, it has been shown (also in rats) that even if $k 1$ is the sole source of vitamin $\mathrm{K}, \mathrm{MK}-4$ accumulates in a limited number of tissues including the aorta; this is suggestive for a conversion of $K 1$ into $M K-4$ in these tissues [188]. Third, in humans a strong and inverse correlation was found between $\mathrm{K} 2$ intake and the risk of cardiac events and aortic arteriosclerosis, whereas no protective effect was observed for dietary $K 1$ [67]. The (warfarin + k1)-treated rat provides an excellent model in which the effects of calcification-inhibiting drugs can be compared [1631. Here we report an improvement of the model in such a way that both warfarin and K-vitamins 
are administered orally. With this protocol we compared the effects of $\mathrm{KI}$ and MK-4 on vascular calcification. Moreover, the utilization of both vitamers in liver and aorta was estimated from the tissue concentrations of the respective epoxides formed.

\section{Materials and Methods}

\section{Chemicals}

All reagents were of analytical grade or better and were from commercial suppliers. Phylloquinone was obtained from Sigma (St.Louis, MO) and menaquinone-4 was a kind gift from EISAI (Tokyo, Japan). Tromborel $\$$ (a commercial human thromboplastin supplemented with calcium) and human clotting factor II-deficient plasma were from Behringwerke AG (Marburg, Germany).

\section{Animals and diets}

All studies were performed in male rats of the WKY strain (University of Maastricht), which were 8 weeks old at the start of the experiment. The animals were housed in normal cages in an environment with a 12 hour lightdark cycle, controlled temperature $\left(20 \pm 2{ }^{\circ} \mathrm{C}\right.$ ) and humidity (50 $\left.\pm 10 \%\right)$. Amimals had free access to water and the various diets, which were prepared with an irradiated (0.9 Mrad) vitamin K-deficient diet (Hope Farms, Woerden,

The Netherlands). Solutions of vitamin K1 and MK-4 were prepared in corn oil (CPC Bestfoods, Heilbronn, Germany), whereas warfarin was dissolved in phosphate-buffered saline (PBS: $150 \mathrm{mmol} / \mathrm{L} \mathrm{NaCl}, 10 \mathrm{mmol} / \mathrm{L}$ sodium phosphate, $\mathrm{pH} 7$.4). In all cases the amount of vitamin $\mathrm{K}$ and warfarin to be administered per rat per day was mixed in the vitamin K-deficient food in a professional food processor. The following abbreviations for the diets are used: diet $K 1 \& M K-4 \& W$ containing $1.5 \mathrm{mg}$ vitamin $K 1,1.5 \mathrm{mg}$ vitamin $M K-4$. and $3 \mathrm{mg}$ warfarin per gram diet; diet $\mathrm{K} 1 \mathrm{BW}$ containing $1.5 \mathrm{mg}$ witamin $\mathrm{K} 1$ and $3 \mathrm{mg}$ warfarin per gram diet; diet MK-4\&W containing $1.5 \mathrm{mg}$ vitamin MK-4 and $3 \mathrm{mg}$ warfarin per gram diet. During all experiments, the food intake was checked to be regular (see below). The Experimental Animal Ethics Committee of the University Maastricht approved all experimental protocols.

\section{Experimental procedures}

Blood was collected either by puncture of the tail vein $(150 \mu \mathrm{L}$ blood in $15 \mu \mathrm{L}$ of $100 \mathrm{mM}$ trisodium citrate) or from the abdominal aorta at the end of the experiment $(4.5 \mathrm{~mL}$ blood in $500 \mu \mathrm{L}$ of $100 \mathrm{mM}$ trisodium citrate). The samples were centrifuged for $15 \mathrm{~min}$ at $3000 \times \mathrm{g}$ and the supernatant plasma was frozen at $-80^{\circ} \mathrm{C}$ untill use. Rats were killed by exsanguination while they were under Na-nembutal (Ceva Santa Animle, Libourne, France; $100 \mathrm{\mu L} / \mathrm{g}$ body weight; $60 \mathrm{mg} / \mathrm{mL}$ ) anesthesia, and organs were perfused with saline (150 $\mathrm{mM} \mathrm{NaCl}$, sodium nitropruside) wia the portal vein. Liver, abdominal 
aorta, testis, kidney and heart were frozen at $-80^{\circ} \mathrm{C}$ until serial vitamin $K$ analysis Carotid artery, aortic arch, and abdominal aorta (from $1 \mathrm{~cm}$ above and just below the femoral bifurcation) were first placed in $4 \%(w / v)$ phosphate buffered formaldehyde within 30 minutes of death and fixed for 24 hours at room temperature. Embedding, sectioning, and histalogical analysis were carried out at the Department of Pathology, University Maastricht, The Netherlands. Arterial tissues (carotid artery and aorta) were completely sectioned in 4 um sections and every fifth section was screened for callification by Von Kossia staining. The presence of calcification was. assessed by 2 obserwers blinded as to treatment.

\section{Plasma prothrombin assay}

Prothrombin concentrations were determined in the one-stage assay using a coagulometer (KC-4, Amelung, Germany), a commercial thromboplastin preparation (Thromborel 5) and clotting factor II-deficient plasma. Prothrombin concentrations were calcullated with the aid of a reference curve from pooled normal rat plasma (same strain, sex and age as rats used in the experiment).

\section{Vitamin Kand KO determination}

Concentrations of vitamin $K 1, K 1-\mathrm{O}, M K-4$, and $M K \sim 4-O$ were analysed simultaneously in one HPLC-run. After thawing, tissues were weighed and homogenised in 1 volume ethanol and 2 volumes of water using a blender (Ultra Turrax, Janke and Kunkel, Staufen, Germany). At this stage samples were supplemented with $100 \mathrm{ng}$ vitamin MK6 as intermal standard, extracted with 4 volumes of n-hexane, and pre-purified on sillica columns as described previously [227]. Quantification of vitamin $K$ was performed by HPLC with fluarescence detection (excitation at $244 \mathrm{~nm}$, emission at $430 \mathrm{~nm}$ ) after postcolumn reduction on a $10 \times 0.2 \mathrm{~cm}$ column filled with zinc powder (RiedelDeHaèn. Seelze, Germany) at $40^{\circ} \mathrm{C}$ (82l. The mobile phase consisted of methanol/acetonitril/Reduction Buffer/water at a ratio (w/v) of 360:90:4:3 and was degassed continuously with helium. Reduction buffer contained: $1 \mathrm{MZnCl}_{2}, 1 \mathrm{M} \mathrm{NaOAC}$, M AcOH in MeOH.

\section{Data and statistical analysis}

Plasma prothrombin values and tissue vitamin $K$ concentrations are presented as means 4 5.D. for 4 rats. Comparisons between groups were performed with a nomparametric test for two-independent-samples using SPSS for Windows Release 10.0.7. Differences were considered to be significant at a level of $p<0.05$. 

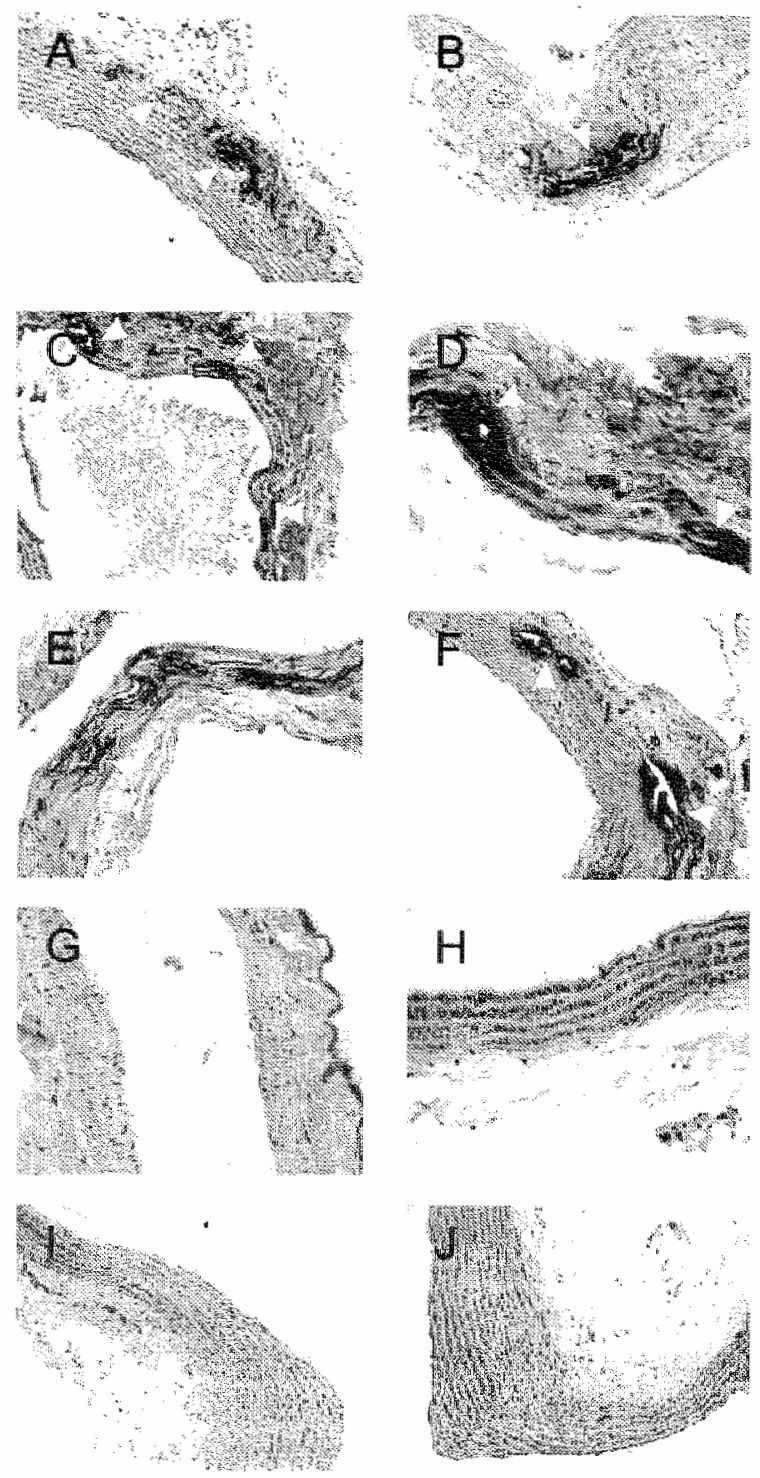

Figure 1

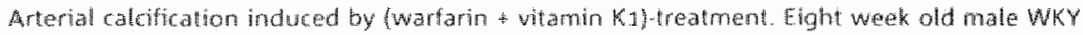

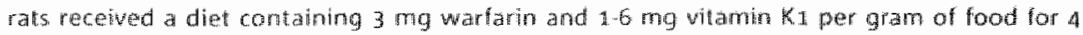

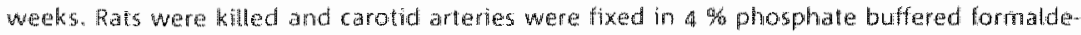
hyde. Tissues were completely sectomed and every fith section was screaned for calcificallon by Von Kossa staning (positwe staning in black and indicated with arrows). The figure shows

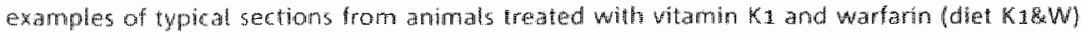

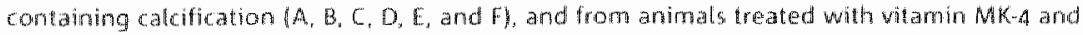

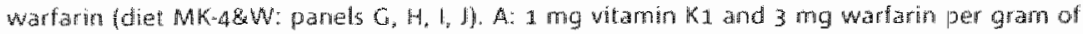

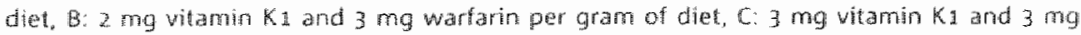
warlarin per gram of diet. D: $4 \mathrm{mg}$ whamin k1 and 3 mg warlath per gram of diet, E: 5 mg vitamin $k 1$ and $3 \mathrm{mg}$ watarin per gram of chet. F. 6 mg whamin ki and $3 \mathrm{ma}$ wartarin per gram of giet. $C_{*}, 4,1,1: 1.5 \mathrm{mg}$ menaquinone-4 and $3 \mathrm{mg}$ wartarin per gram of 1000 . 


\section{Results}

Medial calcification of arteries by dietary (warfarin $+k 1)$ regimens

In a dose-finding study arterial media calcification was induced by feeding 6 groups of four rats a diet containing warfarin and increasing doses of vitamin K1. All animals received $3 \mathrm{mg}$ of warfarin per $\mathrm{g}$ food whereas the concentration of $K 1$ increased from 1 to $6 \mathrm{mg} / \mathrm{g}$ of food with $1 \mathrm{mg}$ increments per group. The warfarin dose is based on the warfarin injection protocol used by Price et al. [161]. After four weeks, citrated blood was taken from the tail vein and subsequently the animals were killed. Sections of the aortic arch and carotid artery were prepared and stained for calcium deposits. Examples are shown in Figure 1. It turned out that all diets had induced vascular media calcification. Although there were individual variations in the extent of calcification, no trend was observed towards decreased calcification at higher vitamin $K$ intakes and even the highest intake of $K 1$ did not prevent or notably diminish calcification. The plasma prothrombin concentration was measured and compared to normal pooled rat plasma. Even in the lowest $K 1$ intake group the circulating prothrombin concentrations were comparable to those in the reference plasma, showing that on a hepatic level vitamin $\mathbb{K}$ had effectively counteracted the warfarin treatment. In a separate experiment (data not shown') we tried to decrease the treatment period, but it turned out that calcification could not be detected in all animals. For further experiments we have chosen to work with calcifying diets containing $3 \mathrm{mg}$ of warfarin and $1.5 \mathrm{mg}$ of $\mathrm{K} 1$ per $\mathrm{g}$ of food, and with a treatment period of 4 weeks.

\section{Differential effects of $K 1$ and $M K-4$}

Four groups of four rats each were compared. One group served as a control and received standard food. In the three experimental groups, all animals received $3 \mathrm{mg}$ of warfarin per $\mathrm{g}$ food. These groups differed in that their diets were supplemented with either $1.5 \mathrm{mg} \mathrm{K} 1,1.5 \mathrm{mg} \mathrm{MK}-4$, or $1.5 \mathrm{mg} \mathrm{K1}+1.5$ mg MK-4 per $g$ of food. After four weeks of treatment the animals were killed and longitudinal sections were made of the aorta and carotid arteries. As is shown in Table 1, only in the K1\&W-group the tissues were calcified. Neither the MK-4\&W nor the $K \| \& M K-4 \& W$ treatment resulted in detectable arterial calcifications (Figure 1). Total food intake was compared in the experimental and control animals, and no significant differences were found between the different groups. Also the weight gain after four weeks of treatment was equal between the four groups. 


\begin{tabular}{|c|c|c|c|c|c|}
\hline Treatiment & $\begin{array}{r}\text { Humber of } \\
\text { rats }\end{array}$ & $\begin{array}{l}\text { Tolal Food } \\
\text { Intake }\end{array}$ & Weight Guins & & Rats willy Catcitication \\
\hline & & grday & 9 & Aorta & $\begin{array}{l}\text { Carotid } \\
\text { Anterary }\end{array}$ \\
\hline Contro: & 4 & $19.7 \pm 2,16$ & $226 \pm 3.82$ & 0 & 10 \\
\hline $1 \times 180$ & 4 & $19.2 \pm 3.67$ & $24.1 \pm 1.64$ & 4 & 4 \\
\hline WHAW & 4 & $20.6 \pm 3.43$ & $19.3 \pm 5.61$ & 0 & 0 \\
\hline KIDMK48W & 4 & $21.3 \pm 4.18$ & $25.9 \pm 46$ & 0 & 0 \\
\hline
\end{tabular}

Table 1

Effect of vitamin $\mathrm{K} 2$ and vitamin $M K-4$ on food intake, weight gain, and arterial calcification

Food intake was calculated from four rats per group and 24 hours differences between two food supplies on nine randomly selected days (average \pm SD). No significant differences between groups $(p>0.05)$

$\$$ Weight gain is expressed as the average ( $n=4: \pm$ SD) percentage increase in body weight after 4 weeks of treatment. No significant differences between graups $(p>0.05)$.

\section{Tissue accumulation of $K$ vitamins and epoxides}

To estimate the utilization of $\mathrm{K} 1$ and MK-4 in different tissues the ratios between the accumulated quinone and epoxide forms were assessed (Table 2). The observed $\mathrm{K} 1$ and MK-4 tissue concentrations varied in a broad range, whereas the calculated quinone and epoxide percentages of the sum of vitamin $\mathrm{K}$ metabolites showed less inter-animal variation. Epoxides were abundantly present in the livers of all rats on a warfarin-containing diet. In the K1\&MK-4\&W group, the total liver K1 concentration (quinone + epoxide) was about 3 -fold $(p<0.05)$ that of MK-4, and comparable to that in the $\mathrm{K} 1 \& \mathrm{~W}$ group. Similarly, the total liver MK-4 concentration in the K1\&MK-4\&W group was comparable to that in the MK- $4 \& W$-treated animals, indicating that uptake of one vitamer was not influenced by the other. In all cases, half of the total hepatic $\mathrm{K} 1$ or MK-4 occurred in the epoxide form, indicating a difference in hepatic uptake rather than in utilization of both forms of vitamin K. As compared to the liver, the aortas in the K1\&MK-4\&W group contained substantially less vitamin K (MK-4: $30 \%$ of liver, $K 1: 3 \%$ of liver, see Table 2), but - like in the liver - the accumulated amounts of K1 and MK-4 in the single vitamin diets were comparable to those in the K1\&MK-4\&W diet.In the latter group the total aortic MK-4 was 3 times that of $K 1 \quad(p<0.05)$. suggesting a preference for MK-4 uptake by the arterial vessel wall. Up to 96 $\%$ of all vascular MK-4 had accumulated in its epoxide form (Table 2), whereas for $k 1$ this was $73 \%(p<0.05)$. Although total vitamin $K$ uptake in testis, kidney, or heart was lower than in the aorta, these extra-hepatic tissues showed similar patterns of vitamin $\mathrm{K}$ accumulation and utilization.

It is well known that in certain extra-hepatic tissues $\mathrm{K} 1$ may be converted into MK-4 [228]. No MK-4, either in its quinone or its epoxide form, was detected in the extra-hepatic tissues of animals treated with warfarin and vitamin $\mathrm{K} 1$. thus confirming the reported inhibition of its conversion by coumarins [228]. 


\begin{tabular}{|c|c|c|c|c|c|}
\hline Treatungal & 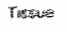 & 路 & $x: c^{2}$ & 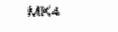 & 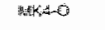 \\
\hline & & LEx & 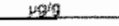 & $\mathrm{HP}$ & ing \\
\hline \multirow[t]{5}{*}{ Kis } & Eriugr & 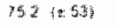 & 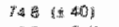 & & \\
\hline & 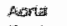 & $001 \mathrm{i} 02 \%$ & 05 徆 64 & & \\
\hline & Tesias & $6033(4004)$ & o. & & \\
\hline & Wiataloy & 9050.1 & 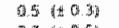 & & \\
\hline & Freand & 14 低田 & $07 \quad 105$ & & \\
\hline \multirow[t]{5}{*}{ MA世政W } & Lister & & & 30049 & $223(12)$ \\
\hline & ALPS: & & & $0.7(40.3)$ & $10.5(21)$ \\
\hline & Teipt. Hes. & & & $004(20004)$ & 1) 8 (2) 38 \\
\hline & Karginger & & & 01 (a) 04 & $\pi 8$ 糔等 \\
\hline & Higing & & & 0.5 (t) & $42\{\varepsilon \mid 2\}$ \\
\hline \multirow[t]{5}{*}{ 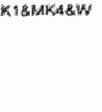 } & Litwar & $34.3(5,5)$ & 94.9504 & 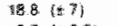 & 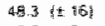 \\
\hline & Aaro:粶: & 15 (2) & 4 社 2 & $0.7\{0.5\}$ & 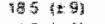 \\
\hline & Te:stis & $004\left(\frac{x}{x}(9) 2\right)$ & 0000001 & $001(2001)$ & $1.3\{\leq \| 1\}$ \\
\hline & Kintiseny & $02(40 \times 1)$ & 0400013 & $0.1\{004\}$ & 2.6 to 7 \\
\hline & Hixyik & $8(103)$ & 0.500013 & 0. $3(x) 002)$ & 3 \\
\hline \multirow[t]{2}{*}{ Tresthatent } & Tite & $\mathrm{k}^{\prime}$ & $x+0$ & MNA & BAK: \\
\hline & & $\phi_{0}$ & on & $\%$ & 48 \\
\hline \multirow[t]{5}{*}{ K1总济 } & Wiras & $\Delta 7 \quad 0 \mathrm{j}$ & 53 ( & & \\
\hline & Adrtio & 42 所 & 张: $\quad$ : & & \\
\hline & $T_{\text {Gryt: }}$ & 50126 & $70+26$ & & \\
\hline & Kundray & $32+7$ & (8. $\{2\}$ & & \\
\hline & pilarin & 72 : & 28. $(2: 7)$ & & \\
\hline \multirow[t]{5}{*}{ HH $48 \mathrm{~W}$} & Liswer & & & $55\{ \pm\}$ & 45 (t.9) \\
\hline & Aorthit & & & $9(\mathbb{Z})$ & 91 (1 2 \& \\
\hline & Devatis & & & $3( \pm 1)$ & $97(41)$ \\
\hline & Kitney & & & $6\left[\begin{array}{ll}6 & 3\end{array}\right.$ & $94(23)$ \\
\hline & Hentixt & & & $11\{t 2\}$ & $89\lfloor 27$ \\
\hline \multirow[t]{5}{*}{ K 18 } & Lijwer & 51 a d a & $49\langle i 4\}$ & $28<t$ & 72 拉时 \\
\hline & Anorta & $27( \pm 34$ & $73\langle i\}$ & $4(t) 0.4)$ & (5) $(x, 0.4)$ \\
\hline & Texsilis & $32( \pm 3)$ & 15日 (is 3 ) & $1<t 2\rangle$ & 20 \\
\hline & Kiddaey & 3国 & 70 (a) & $2(20.45$ & $88(201)$ \\
\hline & Hoख. & $70\{x ; 7\}$ & $3 \mathrm{~L}\{1 \pi$ & $10<11$ & $90<(x)$ \\
\hline
\end{tabular}

Table 2

Tissue concentrations of vitamin $K$ (total of quinone and epoxidle) and percentage of quinones. and epoxiders after four weeks of treatment.

Rats received diets supplemented with $1.5 \mathrm{mg}$ vitamin $K_{1}+3 \mathrm{mg}$ warfarin $(K 1 \& W$ ), $1.5 \mathrm{mg}$ vitamin $M K-4+3$ mgl warfarin (MK-4\&W), or $1.5 \mathrm{mg}$ vitamin $K 1+1.5 \mathrm{mg}$ vitamin $M K-4+3 \mathrm{mg}$ warfarin (K18MK-4\&W) per gram of food.

\section{Discussion}

K1 and MK-4 have a 2-methyl-naphthoquinone group in common, and differ in the side chain attached to the 3-position. In K1 this side chain consists of 4 isoprenoid residues one of which is unsaturated, whereas $M K-4$ has a geranylgeranyl side chain containing 4 isoprenoid residues, which are all unsaturated. Although both $\mathrm{K} 1$ and MK-4 function as a cofactor for $\gamma$-glutamyl carboxylase [240] the data in this paper demonstrate a marked difference between both vitamers: in contrast to vitamin $K 1$, MK-4 prevents warfarin-induced vascular media calcification. Feeding rats a diet concaining warfarin and $k 1$ induced vascular media calcification within 4 weeks. The dose of $K 1$ used exceeded the minimal daily $K 1$ requirement for conventional male rats $(0.5 \mu \mathrm{g} / \mathrm{g}$ diet) $[103]$ by 3,000 fold, and even at still higher doses calcification could not be prevented by $\mathrm{K1}$. However, no calcification was observed when MK-4 was added to the diet. Although it is unclear whether data from our animal model may be extrapolated to humans, these results are in line with a recently reported reduced risk for myocardial infarction, 
cardiac death, and atherosclerotic calcifications in subjects with a high menaquinone intake [67]. No relation between dietary $\mathrm{K} 1$ intake and cardiac events or aortic atherosclerosis was shown in the same study. In our studies we have used MK-4 as a representative of the group of menaquinones, and we demonstrate that the differences between $K 1$ and $M K-4$ with respect to inhibition of arterial calcification may be explained by both a better bioavailability and a more effective utilization of MK-4 in the vessel wall. Several mechanisms may underlie these observations.

In wiwo studies in vitamin K-deficient rats suggested a 8 fold higher activity of $K 1$ in counteracting hypoprothrombinaemia (73). These data are consistent with previous data from our group, in which we demonstrated a 10-fold higher hepatic accumulation of $K 1$ than of MK-4 whereas MK-4 was preferentially taken up by a number of extrawhepatic tissues [189]. This might be caused by the different distribution over the plasma lipoproteins of these vitamers, and by the resulting different transport to the various tissues [200]. The higher amount of vitamin $K 1$ compared to that of $M K-4$ which results in equal amounts of the epoxides of both vitamers can be explained by the 4-fold lower KM of MK-4 compared with K1 [26].

An in vivo method to estimate the in vivo utilization of different K-vitamers was first worked out by Reedstrom and Suttie [181], who blocked the recycling of K-epoxides by treating rats with warfarin and measuring the accumulated epoxides. Based on the assumption that the clearance rate of both epoxides is simillar, the ratio between $K 1$ epoxide and $M K-4$ epoxide reflects the relative utilization of both vitamins. We observed that in liver the utilization of K1 and MK-4 was similar, but that in extra-hepatic tissues such as the aorta MK-4 was preferentially converted into its corresponding epoxide, suggesting a more efficient use by extrathepatic carboxylase. In addition, these data suggest that in the vessel wall sufficient amounts of $M K-4$ hydroquinone are generated to be used as cofactor in the posttranslational $\gamma$ glutamyl carboxylation reaction. The utilization of $M K-4$ by $\gamma$-glutamyl carboxylase implies synthesis of carboxylated and thus biologically active Gla-proteins, most probably including MGP. Price et al. showed already the vital importance of MGP carboxylation in preventing arterial calcification 11621. Recently, a strong link between bone loss and arterial calcification was suggested by Price et al. [163], although the underlying mechanism remains to be elucidated.

An aiternative explanation for the differences between $\mathrm{K} 1$ and $\mathrm{MK}-4 \mathrm{might}$ be given by an as yet hypothetical function for the geranylgeranyl side chain of MK-4. Various Japanese studies have demonstrated a strong decrease of bone lass and even an increased bone mineral density by a high-dose MK-4 treatment (45 mg/day) [1. 151]. The reported effects are comparable to those 
obtained with bisphosphonate treatment. Remarkably, the optimal dose of MK-4 is much higher than can be understood from the regular function of vitamin K. Like bone loss, also vascular media calcification can be completely abolished by both $\mathrm{N}$-containing bisphosphonate treatment [163] and by high-dose MK-4 treatment (this study), but not by treatment with $\mathrm{KI} . \mathrm{N}$ containing bisphosphonates act as competitive inhibitors in the mevalonate pathway, where they inhibit the pyrophosphorylation of farnesol and gernaylgeraniol. One might speculate that the effect of $M K-4$ is partly related to its side chain, which might - like bisphosphonates - inhibit the pyrophosphorylation of geranylogeraniol, and thus interfere with the prenylation of signaltransduction proteins. However, this remains to be established.

In conclusion: our study indicates that in a rat model arterial calcification is prevented by a high dose of MK-4. Further studies are needed to unravel the underlying mechanism and to demonstrate the potential role of $M K-4$ in prevention of vascular calcification in humans. 




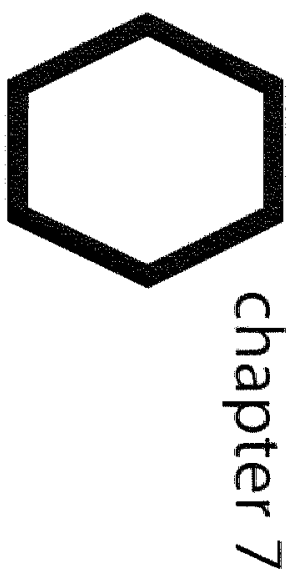

regulation of human VSMC calcification

by matrix Gla protein 


\section{Summary}

The effects of $\gamma$-glutamyl carboxylation and the vitamin $\mathrm{K}$-dependent matrix Gla protein (MGP) on VSMC calcification were measured using two in vitro models. In the first model, confluent human VSMCs spontaneously retract and form multicellular nodules which calcify within 28 days of culture. In the second model calcium ions were added to human VSMC cultures which then calcify rapidly, within 48 hours.

The formation of VSMC nodules was completely blocked by inhibition of $\gamma$-glutamyl carboxylation with the vitamin $K$ antagonist warfarin. Vitamin $\mathrm{K} 1$ counteracted the effect of warfarin, suggesting a Gla-protein dependent pathway. In contrast to vitamin $\mathrm{K} 1$, which had no effect on nodule formation, menaquinone-4 (vitamin K2, MK-4) inhibited nodule formation by $50 \%$. However, if warfarin and vitamin $\mathrm{K} 1$ were added after nodule formation had already occurred, calcification was stimulated by warfarin and inhibited by vitamin $\mathrm{K} 1$, indicating a role for Gla-proteins in prevention of vascular calcification. In the second model in which calcification was induced rapidly with $3.6 \mathrm{mM}$ ionic calcium, both synthetic full length MGP (1-84) and the $\mathrm{N}$-terminal Gla domain (1-53) prevented calcification of VSMCs, whereas the C-terminal domain of MGP (54-84) did not.

These results indicate that (1.) Gla proteins are involved in human VSMC nodule formation and calcification, (2.) MGP inhibits VSMC calcification and Gla-residues are necessary for this activity, and (3.) MK-4 not only acts as a cofactor for $\gamma$-glutamyl carboxylation, but has a second yet unknown function. 


\section{Introduction}

The postranslational conversion of specific glutamate residues into Ycarboxy glutamic acid (Gla) residues is catalysed by the endoplasmic reticulum enzyme $\gamma$ glutamyl carboxylase. Reduced vitamin $\mathrm{K}\left(\mathrm{KH}_{2}\right)$ is used as the active cofactor in this reaction and is converted into vitamin K epoxide (KO) during the carboxylation reaction. One or two dithiol-dependent reductases mediate the efficient recycling of vitamin $\mathrm{kO}$ back into $\mathrm{KH}_{2}$. Coumarin anticoagulants such as warfarin inhibit the dithiol-dependent reductases and thus the synthesis of Gla-residures [58]. Matrix Gla protein (MGP) is a vitamin $K$-dependent protein that is highly expressed by proliferating WSMCs and is thought to play a role in the inhibition of vascular calcification 1203]. The evidence for this inhibitory effect stems from its theoretical calcium-binding Gla domain [167] and from MGP deficient mice. which develop excessive wascular calcification as well as increased cartilage calcification (123) Furthermore, rats treated with both warfarin and vitamin $k$ develop vascular media calcification within 4 weeks, probably as a consequence of undercarboxylated MGP $116 \%, 162\}$. However, the mechanism underlying the calcification inhibitory activity of carboxylated MGP is not clear since the type of cells present in the vascular media from the MGP null mice resemble chondrocytes, rather than the expected vascular smooth muscle cells (VSMCs). Therefore, it is not known whether MGP can inthibit human VSMC calcification.

Isolated human aortic VSMCs maintained in confluent culture form a distinct "hill-and-valley" morphology, with cell retraction in some areas and cell accurnulation into multicellular foci (nodules) in other areas [174]. These multicellular VSMC nodules start to form within 14 days and start calcifying after 21 days in cell culture. The formation of nodules appears to be a prerequisite for spontaneous calcification [174] Proudfoot ef al. previously found that MGP MRNA expression was upregulated in nodular calcifying. human VSMCs in witro 1174 . To elucidate the role of carboxylated MGP in in witro calcification, we modulated MGP activity using warfarin, vitamin $K$ or synthetic MGP 176

\section{Materials and Methods}

\section{Cell culture}

The culture medium used was M199 (GIBCO. Breda. The Netherlands) buffered with $3.7 \mathrm{~g} / \mathrm{L} \mathrm{NaHCO}$ and $5 \% \mathrm{CO}_{2}$ and supplemented with $1001 \mathrm{U} / \mathrm{mL}$ penicillin (Sigma), $100 \mathrm{mg} / \mathrm{mL}$ streptomycin (Sigma), $250 \mathrm{ng} / \mathrm{mL}$ amphotericin B (Sigma), and 4 mmol/L of L-glutamine (Sigma). Heat-. inactivated foetal calf serum (FCS) was purchased from Sigma. Human VSMCs were obtained from nonatherosclerotic areas of aortas from organ donors of 
various ages (males and females from 3 to 65 years of age). The cells were prepared from explants of aortic tissue and were identified as smooth muscle cells (SMCs) by positive staining with monoclonal antibodies against a-SM actin (A2547, Sigma). Cells were maintained in M199 medium containing $20 \%$ FCS and were used between passages 3 and 15. At least three different isolates from individuals of different ages were used in the experiments.

\section{Nodule formation}

Day 1 (1 day after passaging) VSMC cultures were incubated in M199 medium containing $20 \% \mathrm{FSC}$ in the presence of $10 \mu \mathrm{M}$ vitamin $\mathrm{K} 1,10 \mu \mathrm{M}$ MK-4, $10 \mu \mathrm{M}$ warfarin, or $500 \mathrm{ng} / \mathrm{mL}$ full length synthetic MGP (sMGP1.84) [76]. The medium was changed every 2 days. Vitamin $k 1$ and warfarin were obtained from Sigma (St.Louis, MO) and vitamin K2, menaquinone-4 (MK-4), was a kind gift from EISAll (Tokyo, lapan).

\section{VSMC calcification}

Day 14 VSMC cultures were incubated in M199 medium containing $20 \%$ FCS in the presence of $10 \mu \mathrm{M}$ vitamin $\mathrm{K} 1$, or $10 \mu \mathrm{M}$ warfarin. The medium was changed every 2 days. After confluence, VSMCs were cultured in the presence of $s M G P^{1-84}$, sMGP ${ }^{153}$, or $s M G P^{54.84}$ with or without extra calcium $(3.6$ $\mathrm{mM}\left(\mathrm{a}^{2+}\right)$ for 48 hours. The ${ }^{\mathrm{N}} \mathrm{MGP}^{1.4}$ used in these experiments was

synthesised in the Gla form as two synthetic peptides "the Gla domain: sMGP'.53, and the carboxy-terminal part: $5 M \mathrm{GP}^{54: 54}$ ), which had been linked by native chemical ligation [76]

\section{Detection of Calcification}

Von Kossa staining: Cells were grown in 12-well plates, washed with PBS three times, and then fixed in $4 \%(v / v)$ formaldehyde in PBS for 45 minutes at $4{ }^{\circ} \mathrm{C}$. The cells were washed with distilled water and exposed to $5 \%(w / w)$ aqueous $\mathrm{AgNO}_{3}$ and an intensive light source for 60 minutes at RT. The cells were then exposed to $2.5 \%(\mathrm{w} / \mathrm{w})$ sodium thiosulfate for 5 minutes (black = positive staining).

Alizarin Red S staining: Cells were prepared and fixed as described above. The cells were washed in distilled water and then exposed to $2 \%(w / v)$ Alizarin red 5 (Sigma) for 5 minutes (red/orange = positive staining).

Calcium concentration: Cells were washed with Hank's Balanced Salt Solution without $\mathrm{CaCl}_{2}$ and $\mathrm{MgCl}_{2}$ (Sigma) and incubated in $100 \mathrm{mM} \mathrm{HCl}$ at RT overnight. Samples were collected and centrifuged at 13,000 rpm for 1 minute. $50 \mu \mathrm{L}$ of sample was mixed with $30 \mu \mathrm{L} \mathrm{H} \mathrm{H}_{2} \mathrm{O}, 10 \mu \mathrm{L}$ cresolphtalein solution $10.1 \%(w / v)$ Phtalein purple, $28 \%(v / v)$ ammonia buffer), $200 \mu \mathrm{L}$ ammonia buffer $\left(0.24 \%(w / v) \quad \mathrm{NH}_{4} \mathrm{Cl}, 5 \%(\mathrm{v} / \mathrm{v}) \mathrm{NH}_{4} \mathrm{OH}, \mathrm{pH} 10.5\right)$ and the 


\section{Western Blotting}

sMGP ( $500 \mathrm{ng} / \mathrm{mL}$ ) samples for protein analysis were prepared by dissolving them either in medium or $8 \mathrm{M}$ urea. Solutions were incubated for 15 minutes at RT and then centrifuged at $13,000 \mathrm{rpm}$ for 5 minutes. Supernatants and precipitates were dissolved in sample buffer containing $100 \mathrm{mmol} / \mathrm{L} \beta$-mercaptoethanol, boiled, and applied to a $14 \%$ polyacrylamide gel containing $8 \mathrm{M}$ urea. Gels were transferred to Immobilon-P (Millipore, Bedford, MA) by using an electroblotting system (Bio-Rad, Veenendaal, The Netherlands). Western blat analysis was performed using the monoclonal antibody $\alpha 3-15$ MGP 2111 .This antibody was detected with an anti-mouse horseradish peroxidase - conjugated antibody and stained by chemiluminescence (Amersham Pharmacia, Uppsala, Sweden).
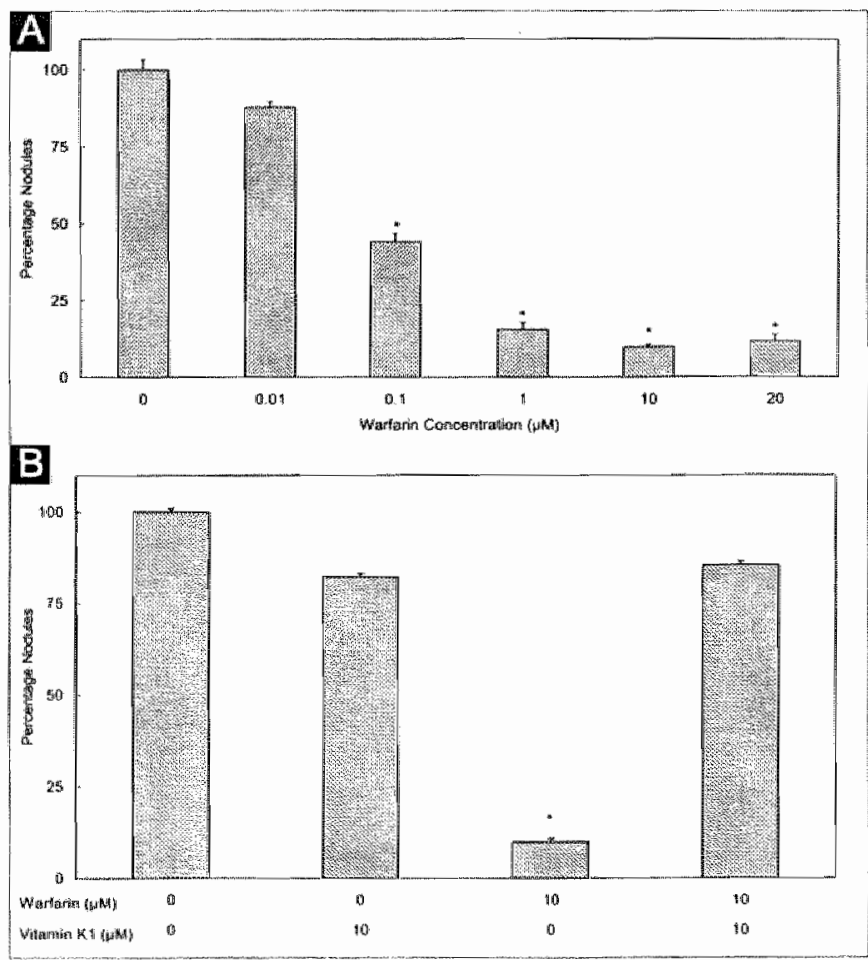

Figure 1

Effects of warfarin and vitamin K1 on in witro nodule formation by human VSMC. Panel A: Dose dependent inhibition of nodule formation by warfarin. The total number of nodules formed in control medium was set to 100\%. Panel B: $10 \mu \mathrm{M}$ witamin $\mathrm{K} 1$ and no warfarin, $10 \mu \mathrm{M}$ witamin $K 1$ and $10,1 M$ warfarin, untreated control culture. Fesults are expressed as mean $\pm S E(n=3)$. and $p$ value determined using a Student's $t$ test. *indicates significant difference from the control $(p<0.05)$. 


\section{Results}

Two approaches were used to study the influences of $\gamma$-glutamyl carboxylation and MGP on VSMC cultures. In the first setup the effect on module formation was measured. In the second approach VSMC calcification was measured.

\section{Nodule Formation}

Effects of $\gamma$-glutamyl carboxylation on human VSMC nodule formation

To examine the role of $\gamma$-glutamyl carboxylation on human VSMC nodule formation, either warfarin or vitamin K1 were added to VSMC cultures 1 day after the start of cell culture (before nodules formed). Total numbers of nodules were counted after 28 days and expressed as percentage of the total number of nodules in an untreated control culture. Nodule formation was almost completely inhibited in the presence of warfarin, whereas vitamin K1 treatment had no effect (Table 1).

To investigate whether the effect of warfarin on nodule formation is brought about via its well-known specific inhibitory activity of the dithiol-dependent vitamin K-reductase, non-nodular human VSMC day 1 cultures were cultured for 7 days in the presence of different warfarin concentrations. As can be seen in Figure 1A, the nodule formation inhibiting activity of warfarin is a dose dependent effect. Vitamin $\mathrm{K} 1$ had no effect on nodule formation but completely counteracted the inhibitory effect of warfarin (Figure 1B).

\begin{tabular}{lrc}
\hline & Number of Nodules & Percentage \\
\hline & $17.3 \pm 1.5$ & $100 \pm 8.8$ \\
Control & $0.3 \pm 0.6$ & $2 \pm 3.3$ \\
Warfarin & $20.5 \pm 2.1$ & $118 \pm 12.2$ \\
Vitamin K1 & & \\
\hline
\end{tabular}

\section{Table 1}

Modulation of VSMC nodule formation.

Human aortic V5MCS were cultured in the presence of either $10 \mu \mathrm{M}$ warfarin or $10 \mu \mathrm{M}$ witamin K1. After 28 days the total numbers of nodules were counted (average of $n=3$ ) and expressed as percentage of untreated cultures (control). 
Effects of synthetic MGP on human VSMC nodule formation

Day 1 VSMC cultures were grown in the presence of $500 \mathrm{ng} / \mathrm{mL}$ full length synthetic MGP (SMGPiss) to examine its role in human VSMC nodule formation. MGP is known to be poorly soluble. At a concentration of 500 $\mathrm{ng} / \mathrm{mL}$, however, sMGP retained solubility in the culture medium, as demonstrated by centrifugation of the medium and subsequent Western blot analysis (Figure 2). After 7, 14, 21, and 28 days the numbers of nodules were counted. The number of nodules formed in the presence of $500 \mathrm{ng} / \mathrm{mL}$ of MGP is about $50 \%$ of that found in the control medium (Figure 3 ).

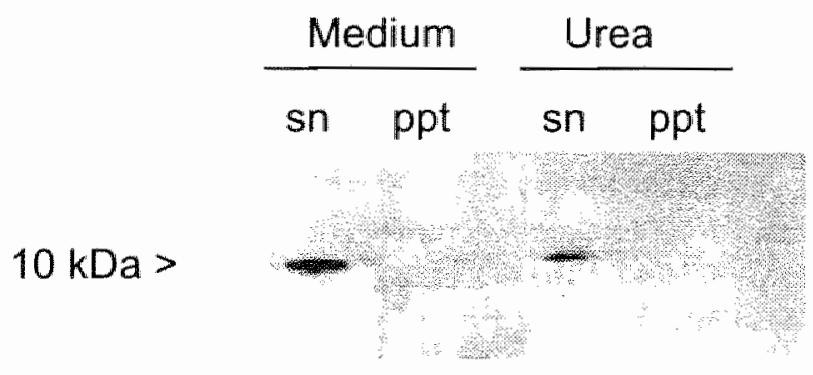

Figure 2

MGP solubility in culture medium

Synthetic MCP (sMGP: ${ }^{1}, 500 \mathrm{ng} / \mathrm{mL}$ ) was dissolved in medium or $8 \mathrm{M}$ urea. The solution was incubated for 15 minutes and then centrifuged at $13.000 \mathrm{rpm}$ for 5 minutes. The supernatant (sn) and precipitate (ppt) were separated on SDS-PAGE, blotted, and probed with $\alpha 3$-15 MGP $\mathrm{mAb}$. This blat shows that $500 \mathrm{ng} / \mathrm{mL}$ MGP remained soluble in the supernatant when added to culture medium.

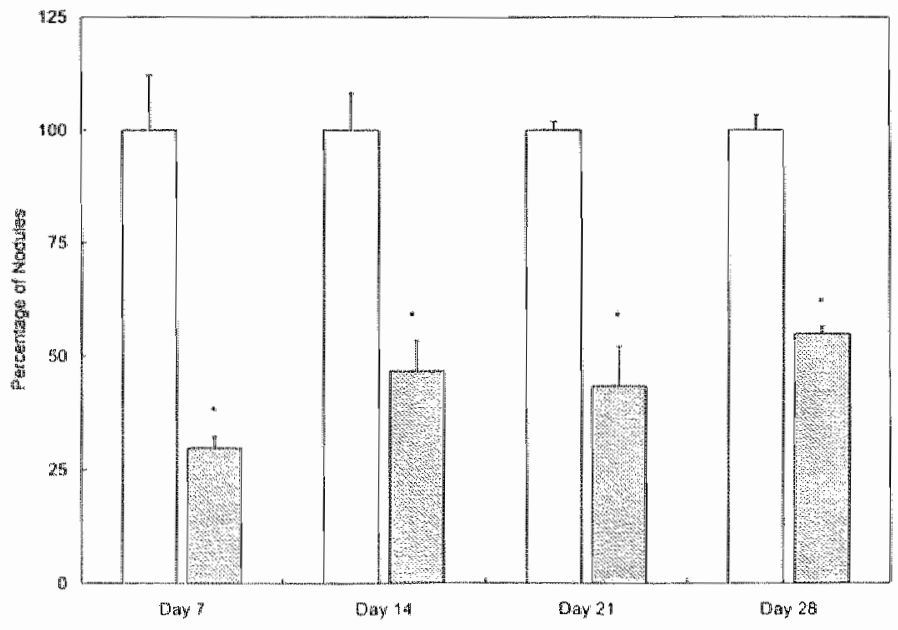

Fingure 3

Effect of synthetic MGP (sMCP:*s) on human VSMC nodule formation. Day 1 cultures were grown for up to 28 days in the presence of $500 \mathrm{ng} / \mathrm{m}$ L 5 MGP as (hatched bars) and the total number of nodules was compared to control culnures fopen bars set lo 100\% nodute formation). Results are expressed as mean 4 SE $(n=3)$, and p value determined using a Student's thest $; p<0.05$ 
Different effects of vitamin $K 1$ and $M K-4$ on human VSMC nodule formation To compare the effects of vitamin $K 1$ and MK-4 (vitamin $K 2$, menaquinone-4) on VSMC nodule formation, non-nodular human VSMC day 1 cultures were cultured for 7 days in the presence of vitamins with or without warfarin (Figure 4). Vitamin $\mathrm{K} 1$ had no effect on nodule formation and completely counteracted the inhibitory effect of warfarin (Figure 1B). On the other hand, MK-4 alone inhibited nodule formation by approximately $50 \%$ compared to the control culture. Also in the presence of both warfarin and MK-4 nodule formation was $50 \%$ compared to the control culture. The same results were obtained by adding a mixture of $5 \mu \mathrm{M}$ vitamin $\mathrm{K} 1$ and $5 \mu \mathrm{MMK}-4$ (Figure 4). These data suggest that inhibition of nodule formation by MK-4 occurs via a yet unknown pathway distinct from the Gla-protein(s) dependent pathway.

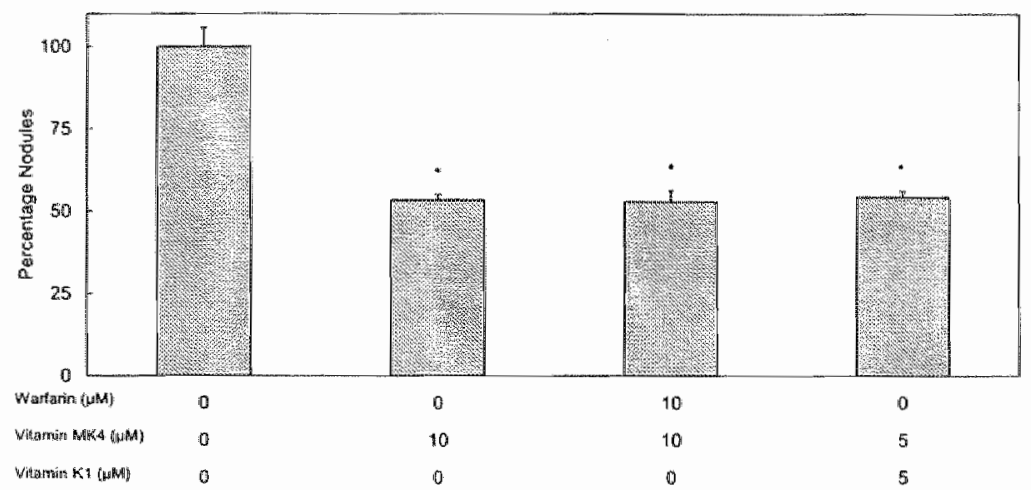

\section{Figure 4}

Effect of MK-4 on human VSMC in vitro nodule formation. The total number of nodules formed in control medium was set to $100 \%$. Results are expressed as mean $\pm S E(n=3)$, and $p$ value determined using a student's t test. * $p<0.05$.

\section{VSMC Calcification}

Effects of $\gamma$-glutamyl carboxylation on human VSMC calcification

To examine the role of $\gamma$-glutamyl carboxylation in human VSMC calcification, either warfarin or vitamin K1, were added to nodular WSMC cultures at day 14. After 14 days of treatment, the presence of calcified material was determined by Von Kossa staining and the total amount of acid-extractable calcium was. quantitated by the cresolphtalein method. Calcification was stimulated by warfarin $(p=0.02)$ whereas vitamin $k 1$ inhibited calcification $(p=0.01)$ in VSMC nodular cultures. (Figure 5). This suggests that vitamin K-dependent proteins are involved in the inhibition of VSMC nodule calcification. 

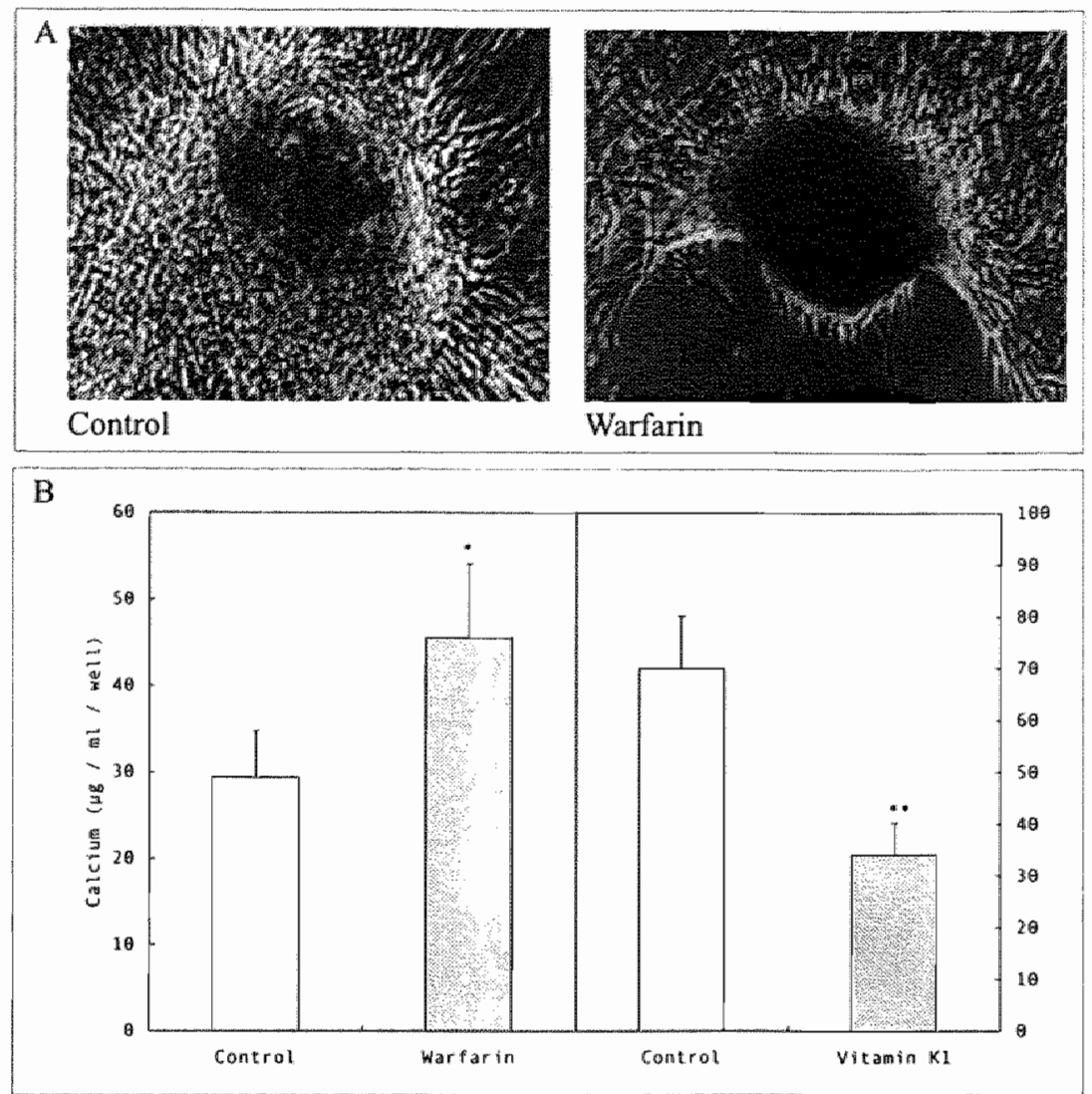

Fingure 5

Effects of warfarin and vitamin $\mathrm{K} 1$ on human VSMC calcification.

Warfarin (10 $1 \mathrm{M}$ ) or vitamin $\mathrm{K} 1$ (10 $\mu \mathrm{M}$ ), were added to nodular VSMC cultures (day 14). At day 28, cells were stained with Von Kossa (upper panel, positive staining in black). Tottal acid-extractable calcium was quantitated by the cresolphtalein method (lower panel). Warfarin stimulated calcification (" $p=0.02)$ while vitamin $k 1$ inhibited calcification (** $p=0.01)$.

\section{Effect of MGP on human VSMC calcification}

To find out whether MGP could inhibit calcification, synthetic MGP was added to human VSMC cultures in which calcium apatite formation was induced within 48 hours by incubating with twice the physiological concentration of calcium ions $\left(3.6 \mathrm{mM} \mathrm{Ca}{ }^{2+}\right)($ this model is demonstrated in Figure 6). Either sMGP1.44, the Gla domain $5 M^{1} G^{1.53}$, or the carboxy-terminal part SMGP ${ }^{\text {stim }}$ were added to human VSMC cultures with or without $3.6 \mathrm{mM}$ $\mathrm{Ca}^{2 *}$ for 48 hours and calcification was measured by the cresolphtalein method. At $500 \mathrm{ng} / \mathrm{mL}$, sMGP $\mathrm{P}^{-84}$ significantly $(\mathrm{p}=0.01)$ inhibited VSMC calcification by approximately $60 \%$ compared to controls (Figure 7A), whereas no inhibition was observed at 50 and $100 \mathrm{ng} / \mathrm{mL}^{5} \mathrm{MGP} \mathrm{P}^{1.84}$. Furthermore, the N-terminal part of MGP (1-53, Gla) inhibited calcification at a concentration of $500 \mathrm{ng} / \mathrm{mL}$, while the C-terminal part (54-84) did not (Figure 7B). 


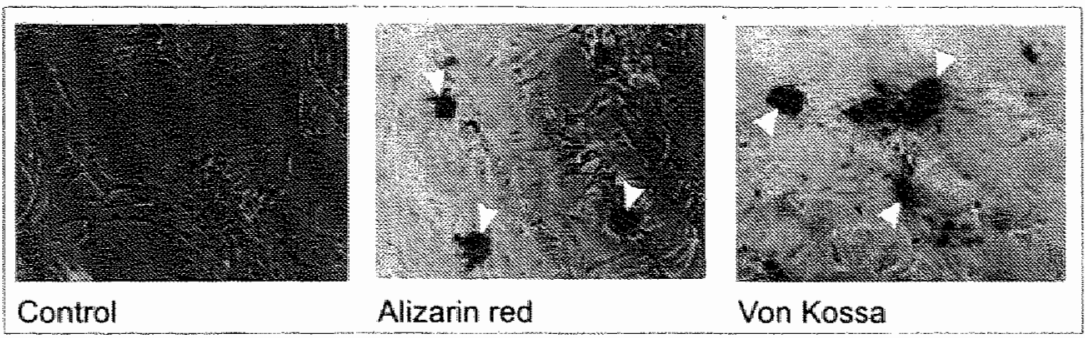

Figure 6

Calcification in VSMC monolayers. Human VSMC monolayers were incubated in either control medium containing $1.8 \mathrm{mM} \mathrm{Ca}{ }^{* *}$ or medium containing $3.6 \mathrm{mM} \mathrm{Ca}$ for 48 hours subsequently cultures were stamed for calcification using Alizarin red or Von Kossa. Unlike VSMCs exposed to $1.8 \mathrm{mM} \mathrm{Ca}^{2 *}$ (control), human VSMC cultures exposed to wice the physiological Ca concentration calcified within 48 hours.

\section{Discussion}

Human aortic VSMC nodule formation and calcification occur spontaneously in vitro, without the addition of exogenous factors [174]. The mechanisms involved in these two processes are not known. In this article, we show that a complete inhibition of $\gamma$ glutamyl carboxyllation blocks nodule formation but stimulates nodule calcification. Furthermore, exogenously added fully carboxylated synthetic MGP inhibited VSMC calcification.

\section{Nodule Formation}

The complete inhibition of VSMC nodule formation by warfarin and reversal with vitamin $\mathrm{K} 1$, suggests the involvement of Gla-protein(s) in this process. Three vitamin $K$-dependent proteins are known to be expressed by the arterial vessel wall: protein S, MGP, and growth-arrest-specific gene-6 protein (Gas6). Protein $S$ is expressed by VSMCs and endothelial cells and possibly involved in the local inthibition of thrombosis $[8,52]$. Gas6 prevents serum starvation-induced death of fibroblasts and VSMCs, and may act as a growth-potentiating factor $[72,141,239]$. Gla-residues were shown to be essential for the functions of Gas.6 in cell culture [141. Also, the calcification inh ibitory function of MGP requires the presence of Gla-residues 1161.1621. The paradoxical effects of warfarin and $5 M G P^{1-44}$ on nodule formation can be explained by two hypotheses. First, a yet unknown Glawprotein may stimulate VSMC nodule formation in its carboxylated form. Second, the Glaw residues of MGP are not involved in the inhibition of VSMC nodule formation. Whether higher concentrations of SMGP result in an even greater degree of inhibition, could not be tested because of the insolubility properties of MGP.

\section{Different effects of vitamin $K 1$ and $M K-4$ on human V $5 M C$ nodule formation}

Although both vitamin $K \mathbb{1}$ and $M K-4$ serve as a cofactor in $\gamma$-glutamyl carboxylation, several data suggest a second function for MK-4. Wang et al. reported the growth inhibition of hepatocellular carcinoma cells by MK-4 
(250) and several studies showed apoptosis inducing activity for MK-4 197, 136, 147. 2671. Also, a nuclear vitamin $\mathrm{K2}$ binding protein homologues to glyceraldehyde 3 -phosphate dehydrogenase (GAPDH) has been detected in human osteoblasts 187 ]. Taken together, these data suggest a new role for vitamin $\mathrm{K} 2$ outside the field of $\gamma$ glutamyl carboxylation.

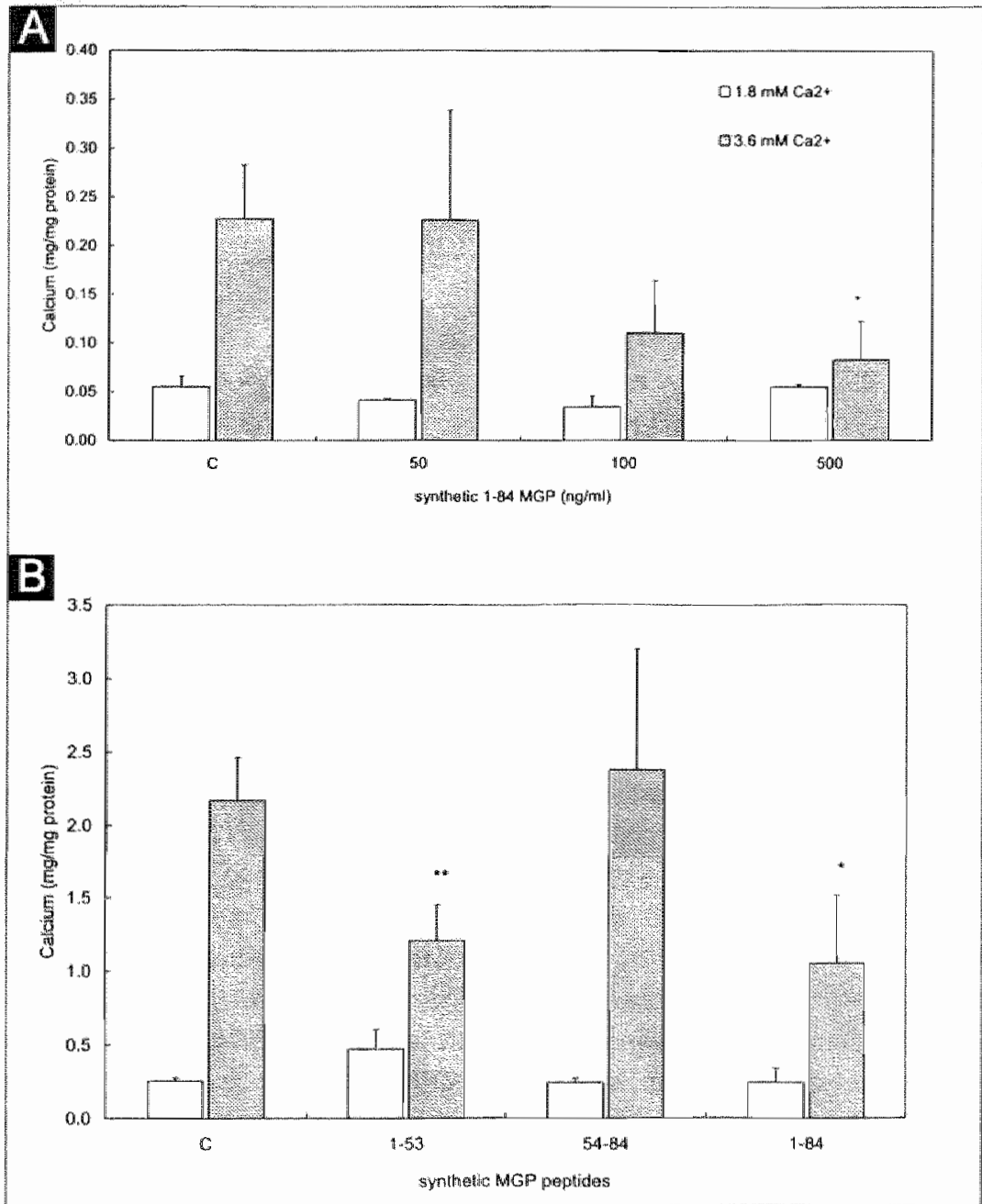

Figure 7

Effect of full-tength MCP (Panel A) and MGP fragments. (panel B) on calcification. 5 MGPi was added to cultures with or without extra calcium ions for 48 hours and calcification was measured by the cresolphtalein method. At 500 ng/mL. MGP and the 1-53 portion of MGP significantly inhibited calcification compared with contrals $\quad P=0.01$ and * $P<0.02$ respectivelyy. 


\section{VSMC Calcification}

Using full length synthetic MGP, we demonstrated that exogenous addition of MGP inhibited calcification of human VSMCs in vitro and that this activity required the $N$-terminal (Gla-containing) moiety of MGP. Based on the phenotype of the MGP null mouse 123 and results from the warfarin-treated rats 1161 it seems reasonable to propose a direct role for $M G P$ in the inhibition of VSMC calcification. It is unclear whether descarboxy-SMGP ${ }^{\text {.an }}$ has the same calcification inhibitory activity as SMGP. since this peptide is not yet available. Other peptides which are interesting for in vitro calcification inhibition studies are for example the full length MGP with or without serinephosphorylation at positions 3,6 and 9. Future use of peptides in the VSMC in vitro model might contribute to understanding the molecular mechanism of MGP in arterial calcification. The mechanism by which MGP may inhibit calcification remains a matter of speculation. Full-length synthetic MGP binds calcium ions, which induces an increase in $\alpha$-helicity I7G). Furthermore, MGP bind's to hydroxyapatite with a relative high association constant compared to other hydroxyapatite-binding proteins 1190 . The binding of MGP to hydroxyapatite, however, is increased in the presence of calcium ions 11901 . Similar hydroxyapatite binding behaviour has been reported for osteocalcin [84], suggesting that MGP binds to hydroxyapatite wial calcium ions which induce an increase in o-helical structure of the Gla domain. By binding to calcium ions or crystals, MGP is expected to prevent crystal growth.

In conclusion, these in vitro studies have shown that Gla-containing proteins play an important role in nodule formation and calcification. The dramatic blockade of nodule formation by warfarin was a surprising observation, given that it is a stimulator of calcification. This finding revealed that although nodule formation is a prerequisite for calcification [isul, nodule formation and calcification should be studied separately to elucidate the processes leading to VSMC calcification. The mechanisms regulating nodule formation are not known and it is therefore difficult to speculate on the mechanism of action of Gla-proteins in this process. In addition, these in vitro experiments have highlighted that MGP is an inhibitor of human VSMC calcification and that the Gla domain is important for this function. 



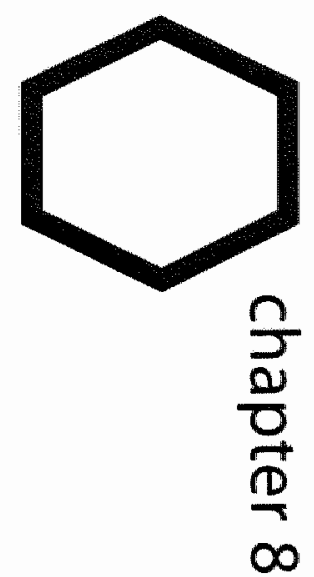

possible role for apoptotic bodies in the cellular release of matrix gla protein 



\section{Summary}

Matrix Gla protein (MGP) is a vitamin K-dependent protein expressed by various tissues, including the arterial vessel wall, where it is synthesised by vascular smooth muscle cells (VSMCs). MGP is thought to play a role in the inhibition of soft-tissue calcification. Its association with the extracellular matrix, the presence of a predicted signal-peptide, and Gla-residues within its $\mathrm{N}$-terminal domain suggest it to be an extracellular protein.

Here we report the intracellular localisation of MGP in cultured human aortic vascular smooth muscle cells (VSMCs), human breast cancer epithelial cells (T47D), and human osteoblastic osteosarcoma cells (MG-63). Using Western blot, ELISA or immunoprecipitation techniques and a monoclonal antibody raised against amino acids 3-15 of human MGP, MGP was detected in cell lysates but not in the conditioned medium of these three cell types. Stimulating or inhibiting $\gamma$-glutamyl carboxylation with vitamin $k 1$ and warfarin respectively, had no effect on the localisation or secretion of MGP. The intracellular localisation of MGP was investigated using confocal analysis and MGP was found diffusely throughout the cytoplasm but was highest at the nuclear periphery. Although MGP was not detected in conditioned media $_{\text {it }}$ it was present in VSMC-derived apoptotic bodies and small vesicular membrane structures. The presence of MGP in these membrane structures suggests that this may be the mechanism by which MGP is released by cells. Since apoptotic bodies and vesicles are prone to calcification, MGP may regulate mineralization at these sites. 


\section{Introduction}

Mammalian Gla-proteins are involved in at least three physiological processes: haemostasis, bone metabolism, and vascular biology. $y$-Carboxy glutamate residues (Gla) are the result of a posttranslational modification of glutamate residues (Glu). This reaction is catalysed by the endoplasmic reticulum enzyme $\gamma$ glutamyl carboxylase, which uses vitamin $K$ as a cofactor. In all known Gla-containing proteins, the Gla-residues are essential for stabilizing the tertiary structure and for the function of these proteins.

Matrix Gla protein (MGP) was first described by Price et al. in 1983 and since then its symthesis has been shown in bone, cartilage, lung heart, kidney. arterial smooth muscle cells (VSMCs) and in calcified atherosclerotic plaques. \$61,167,2011. Although the precise molecular mechanism of MGP function is not known, recent data demonstrate that it play's a major role in the inhibition of soft-tissue calcification. Targeted deletion of the MGP gene in mice resulted in extensive medial calcification of the aorta, leading to death within eight weeks after birth due to ruptures of the thoracic or abdominal aorta [123]. In these MGP-dleficient mice, cartilagemproducing chondrocytes were detected in the tunica media of the calcified arteries. A relation between MGP and chondrocyte function was recently suggested by Yagami et al., who showed that in vitro calcification in hypertrophic chondrocyte cultures was triggered by treatment with the vitamin K-antagonist warfarin, whereas calcification was counteracted by MGP overexpression in the presence of vitamin K [266]. In the same study, constitutive MGP overexpression in chicken limb resulted in in vivo inhibition of cartilage mineralization, delayed chondrocyte maturation and termination of endochondral and intramembranous ossification. The importance of MGP Gla-residues in the prevention of vascular calcification was shown by inhibition of $\gamma$-glutamyl carboxylation in rats with warfarin $[161,162]$. Within 3 to 4 weeks of treatment, arterial calcification was found around the elastic lamellae of the media. Furthermore, in humans, mutations in MGP that predict a non-functional protein have been shown to cause Keutel syndrome, a rare disorder characterised by abnormal cartilage calcification and pulmonary stenoses [139]. Post mortem examination of a young Keutel patient also revealed extensive vascular calcification (134). It is currently thought that for MGP to prevent calcification it must be secreted and be associated with the extracellular matrix $[161,2661$. Prevention of calcification is likely to inwolve binding of calcium ions or crystals 1166,1901 and/or binding of calcification-inducing proteins [14.245]. MGP related antigen is also found in plasma and, like osteocalcin, is thought to be released into the circulation wia its tissue of synthesis. Whether MGP circulates as a free protein or in a complex is not known, although MGP can occur as a plasma complex with calcium, phosphate and fetuin in rats treated with etidronate [166]. 
Since secretion of MGP is thought to be pivotal to its calcification-inhibitory activity, we have investigated its release from cultured cells. Surprisingly, we found that in human VSMCs and in cell lines constitutively expressing high levels of MGP, the protein remained intracellularly and was not secreted. The intracellular location of MGP persisted even when the cells were incubated with excess vitamin $\mathrm{K} 1$ or MK-4. Further experiments suggested that MGP may only be released by VSMCs in association with apoptotic bodies or vesicles.

\section{Materials and Methods}

\section{Chemicals and Reagents}

All solutions were prepared using reagents of analytical or HPLC grade. Vitamin K1, warfarin, and Dulbecco's modified Eagle"s medium (DMEM) and M199 medium were purchased from Sigma (St.Louis, MO). Vitamin K2 (menaquinone-4) was a kind gift from EISAI (Tokyo, Japan). Eagle's minimum essential medium (EMEM) with Earle's balanced salt solution without L-glutamine was obtained from Bio-Whittaker (Verviers, Belgium).

\section{Selection of cell-types}

In previous studies it was shown that MGP mRNA is expressed by various human cell types such as VSMCs [203], epithelial cells [206], and osteosarcoma cells [30]. Therefore, a range of cells was tested for MGP expression and these cells (T47D, MG-63, HEK 293, VSMCs, and SAH) were used in this study.

\section{Cell Cultures}

VSMCs were prepared from medial explants of human aortic tissue and cultured in 20\% FCS in M199 medium, as described previously [176]. T47D is a human breast cancer epithelial cell line, HEK-293 is a human embryonic kidney cell line, MG-63 is a human osteoblastic osteosarcoma cell line, and SAH is a human hepatocyte cell line and was a kind gift from Dr. R. Kuijer (University Maastricht, The Netherlands). T47D, HEK-293 and MG-63 were obtained from the European Collection of Cell Cultures (ECACC). T47D and HEK-293 were cultured in DMEM supplemented with 10\% FCS and L-glutamine. MG-63 and SAH were cultured in EMEM supplemented with 10\% FCS and L-glutamine. To examine the effect of $y$-glutamyl carboxylation on the MGP localisation, cells were treated with $10 \mu \mathrm{M}$ vitamin $\mathrm{K} 1,10 \mu \mathrm{M}$ vitamin $K 2$, or 10 uM warfarin for seven days. Medium was changed every 2-3 days and conditioned medium was collected without further treatment.

\section{Immunoprecipitation of $M G P$}

A commercially available immunoprecipitation kit (Roche Diagnostics, Almere, The Netherlands) was used for the immunoprecipitation of MGP from cellular extracts and conditioned medium. In brief, cells were washed twice 
with ice-cold PBS after removal of the conditioned medium and suspended in lysis buffer $\left(50 \mathrm{mM}\right.$ Tris-HCl, $\mathrm{pH} 7.5,150 \mathrm{mM} \mathrm{NaCl}, 1 \%(w / v)$ Nonident $\mathrm{P} 40_{\text {, }}$ $0.5 \%(w / w)$ sodium deoxycholate). To each cellullar extract or conditioned medium sample 5 Hg monoclonal $\alpha 3-15$ MGP IgG (1) was added and incubated at $4{ }^{\circ} \mathrm{C}$ for 3 hours. Protein G-agarose was addled and after overnight incubation at $4^{\circ} \mathrm{C}$ the complexes were collected by centrifuglation. Complexes were washed twice in lysis buffer, twice in a high salt washing buffer $(50 \mathrm{mM}$ Tris-HCl, pH 7.5,500 $\mathrm{mM} \mathrm{NaCl}, 0.1 \%(\mathrm{v} / \mathrm{v})$ Nonident P40, 0.05 $\%(w / v)$ sodium deoxycholate) and finally once in a low salt washing buffer $(50 \mathrm{mM}$ Tris-HCl, $\mathrm{pH} 7.5,0.1 \%(\mathrm{w} / \mathrm{v})$ Nonident P40, $0.05 \%(\mathrm{w} / \mathrm{v})$ sodium deoxycholate). The immunoprecipitated proteins were analysed on SDSpolyacrylamide gel electrophoresis (-PAGE) and subsequent Western blot analysis.

\section{SDS-PAGE and Western blot analysis}

Protein samples in SDS sample buffer $(40 \mathrm{mM}$ Tris $H \mathrm{HCl} \mathrm{pH} 6.7,4 \%(\mathrm{w} / \mathrm{v})$ SDS, $10 \%(\mathrm{v} / \mathrm{v})$ glycerol, $2 \%(\mathrm{v} / \mathrm{v}) 2$-mercaptoethanol, $0.01 \%(\mathrm{w} / \mathrm{v})$ bromophenol blue) were boiled for 5 min. Polyacrylamide gels $12.5 \%(\mathrm{w} / \mathrm{v})$ in SDS were run under denaturing conditions $[113]$ in $8 \mathrm{M}$ urea. After electrophoresis, the gels were transferred to an Immobilon-P PVDF membrane (Millipore, Bedford, MA) [2331. After washing the membranes in PBS for 15 min, non specific binding sites were blocked with blocking buffer $(3 \%(w / v)$ non-fat dry milk powder in PBS) for $1 \mathrm{~h}$ at RT and incubated at $4{ }^{\circ} \mathrm{C}$ overnight with biotin-conjugated Q3-15 MGP IgG in blocking buffer. After washing with PBS-Tween $10.3 \%(\mathrm{v} / \mathrm{v})$ Tween-20 in PBS), the membrane was incubated for $1 \mathrm{~h}$ at RT with streptavidin-HRP (Dako, Glostrup, Danmark) diluted in PBS-Tween. Membranes were washed three times with PBS-Tween, followed by a final wasth step of $15 \mathrm{~min}$ with PBS and development with ECL Western blotting detection reagents (Amersham Pharmacia, Uppsala, Sweden). Finally, protein bands were visualized on Hyperfilm ECL (Amersham Pharmacia).

\section{Single antibody ELISA}

Single antibody ELISA was performed by coating microtiter plates (60 Protein Immobilizer, Sanver TECH, Heerhugowaard, The Netherlands) with monoclonal $\alpha 3-15 \mathrm{MGP}$ lgG $1500 \mathrm{ng} /$ well) in carbonate buffer $10.1 \mathrm{~mol} / \mathrm{L}$ sodium

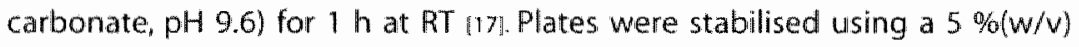
sucrose solution. Cells were washed twice with ice-cold PBS after removal of the conditioned medium and suspended in lysis buffer. Samples "cell lysates and conditioned media) were diluted with lysis buffer as indicated and supplemented with a constant amount of tracer (biotinylated MGPa-15 peptide, $1.8 \mathrm{ng}$ per $\mathrm{mL}$ of sample). Next, $100 \mu \mathrm{L}$ of the mixtures were transferred to the microtiter plate wells and incubated for $2 \mathrm{~h}$ at RT. After three washing cycles with PBS-Tween, the amount of tracer bound was quantified by incubation with avidin-labelled horse radish peroxidase (Dako, 
$10 \mathrm{fg} /$ well) and subsequent staining with $3,3,5,5$ tetramethylbenzidine reagent 1 Pierce, Rockford, IL). After 15 minutes the staining process was stopped by adding $2 \mathrm{~mol} / \mathrm{L} \mathrm{H}_{2} \mathrm{SO}_{4}$ and plates were read at $450 \mathrm{~nm}$. Reference curves were prepared by serial dilution of $\mathrm{MGP}^{3 \cdot 15}$ peptide. Experimental samples were tested in duplicate in 2-fold dilutions and read from the reference curve.

\section{Immunofiuorescence microscopy}

Cells were washed twice with PBS prior to one of the following protocols. Cells were either fixed by incubation in $4 \%(v / V)$ formaldehyde in PBS for 45 minutes at $4{ }^{\circ} \mathrm{C}$ and subsequent permeabillised with $0.5 \%(\mathrm{v} / \mathrm{w}) \mathrm{NP}-40,0.1 \%(\mathrm{w} / \mathrm{v})$ Triton $X-100$ in PBS, fixed without permeabilisation, or not fixed and not permeabilised. Primary antibody, monoclonal $\alpha 3-15$ MGP IgG, was added for 1 hour at room temperature. Coverslips were washed three times with PBS, then incubated with FITC-conjugated anti-mouse IgG (DAKO) for a further hour at room temperature. Negative controls were performed by substituting the primary antibody by either PBS, or an irrelevant antibody. After several washes in PBS, coverslips were mounted face down in Mowiol (Calbiochem) containing $1 \mu \mathrm{g} / \mathrm{ml}$ DAPI. Immunostained samples were viewed using a Zeiss axjovert 10 microscope with a plan-APOCHROMAT $63 \times / 1.40$-oil immersion lens and equipped with a Digital Pixel Instruments 12-bit CCD camera. Images were cap tured using IP Lab Scientific Imaging Software (Scanalytics). Additionally, a

Zeiss LSM 410 confocal laser scanning microscope was used $(63 \times / 1.40$ oil immersion lens) for imaging of MGP within cells.

\section{Immunohistochemistry}

Paraffin-embedded human tissues were obtained from the archives of the Department of Pathology of the University Hospital of Maastricht. Tissues were collected, fixed by immersion in $4 \%$ formaldehyde in PBS for 12 th at room temperature, and embedded in paraffin. Sections ( $4 \mu \mathrm{m}$ ) were stained with hematoxylin and eosin for general histological evaluation. Immunohistochemistry was performed by using the monoclonal a3-15 MGP IgG as a first antibody and biotinylated anti-mouse $\lg G$ (Dako) as the second antibody. Staining was performed with the avidin-biotin immuno alkaline phosphatase kit from Dako. Negative controls were performed by substituting the primary antibody by either PBS, an irrelevant antibody, and by adding competitive amounts of synthetic MGP peptides.

\section{Inducing apoptosis in VSMCs}

Apoptosis was induced in human VSMCs by addition of $\alpha F a s / g M(100 n g / m L$, clone $\mathrm{CH} 11$, Upstate Biotechnology) and cycloheximide $(10 \mu \mathrm{g} / \mathrm{mL})$ in serum free $\mathrm{M} 199$ for 24 hours. Apoptotic bodies were collected from cultures by centrifuging cell culture supernatants at $2,500 \mathrm{rpm}$, as described previously 


\begin{tabular}{|c|c|c|c|}
\hline \multirow[t]{2}{*}{ Cell Type } & Condition & Cell Lysate & Conditioned Medium \\
\hline & & $\mathrm{ng} / \mathrm{mg}$ & $\mathrm{ng} / \mathrm{mg}$ \\
\hline
\end{tabular}

T47D

$\begin{array}{lll}\text { Control } & 21.2 \pm 0.3 & \text { b.d.I. } \\ \text { Vitamin K1 } & 27.7 \pm 4.7 & \text { b.d.I. } \\ \text { Menaquinone-4 } & 28.1 \pm 1.5 & \text { b.d.l. } \\ \text { Warfarin } & 25.8 \pm 4.5 & \text { b.d.1. }\end{array}$

VSMC

$\begin{array}{lrr}\text { Control } & 9 \pm 0.4 & \text { b.d.l. } \\ \text { Vitamin K1 } & 9.5 \pm 1.5 & \text { b.d.l. } \\ \text { Menaquinone-4 } & 8.6 \pm 0.7 & \text { b.d.l. } \\ \text { Warfarin } & 4.5 \pm 1.8 & \text { b.d.l. }\end{array}$

MG-63

$\begin{array}{lrl}\text { Control } & 26.4 \pm 4.4 & \text { b.d.I. } \\ \text { Vitamin K1 } & 34 \pm 2.6 & \text { b.d.I. } \\ \text { Menaquinone-4 } & 32.9 \pm 4.3 & \text { b.d.I. } \\ \text { Warfarin } & 22.5 \pm 3.1 & \text { b.d.I. }\end{array}$

SAH

$\begin{array}{lll}\text { Control } & \text { b.d.I. } & \text { b.d.I. } \\ \text { Vitamin K1 } & \text { b.d.I. } & \text { b.d.I. } \\ \text { Menaquinone-4 } & \text { b.d.I. } & \text { b.d.I. } \\ \text { Warfarin } & \text { b.d.I. } & \text { b.d.I. }\end{array}$

Table 1

MGP concentration in cell lysates and conditioned media of T47D, VSMCs, MG-63, and SAH cells Concentrations are in mean $\pm 250(n=3)$, b.d.l. stands for below detection limit $(2 \mathrm{ng} / \mathrm{mL})$.

\section{Results}

Expression of $M G P$ in various Cell Types

To investigate secretion of MGP by VSMCs and other cell lines known to express MGP mRNA, both cell lysates and corresponding conditioned media (collected after 3 days) were subjected to Western blot amalysis. A monoclonal antibody against the 3-15 epitope of MGP ( 13 3-15 MGP IgG) was used for detection [17). MGP (13.6 kD) was present in the cell lysates of VSMCs, MG-63, HEK-293, and T47D cells but no MGP was detected in the corresponding conditioned media (data not shown). Also, no MGP was observed in the cell lysate and conditioned media of SAH cell cultures. This cell line was therefore used as a negative control in subsequent experiments. Since MGP is thought to be a secreted protein we further investigated cell conditioned media for its presence using both ELISA and immunoprecipitation. 
cells was confirmed using a single antibody competition ELISA for human MGP [17] (Table 1). However, no MGP was detected in the corresponding conditioned media. Since correct $\gamma$-glutamyl carboxylation is necessary for the biological activity of MGP [162], it may also influence the location and distribution of the protein (i.e. secretion). Therefore, cell cultures were treated with either vitamin $K 1$, menaquinone-4 or, warfarin and MGP was measured in both the cell lysate and corresponding conditioned media. However, neither vitamin $\mathrm{K}$ nor warfarin treatment influenced the secretion of MGP by VSMC, T47D, and MG-63 cell cultures: MGP was present in the cell lysate and absent in the corresponding conditioned media (Table 1).

\section{Immunoprecipitation of MGP}

An MGP concentration in the conditioned medium below the detection limit of Western analysis or ELISA could cause a false negative result. Therefore, cell lysates and conditioned media were concentrated via immunoprecipitation using the $\alpha 3-15$ MGP IgG. Subsequently the samples were subjected to Western analysis. Using this method MGP was detected in the immunoprecipitated cell lysates but not in the conditioned media of MG-63, VSMCs, T47D, or HEK-293. Again, treatment of the cells with either warfarin or vitamin $K 1$ had no effect on the distribution of MGP (Figure 1A).

These observations were confirmed using an antibody against the 63-75 epitope of MGP ( $\alpha 63-75$ MGP IgG) (Figure 1B and 1C). Firstly, samples were concentrated via immunoprecipitation using the $\alpha 3-15 \mathrm{MGP} \operatorname{IgG}$ and analysed by Western blot using the $\alpha 63-75$ MGP IgG (Figure 1B). In the second approach, the $\alpha 63-75$ MGP $\| g G$ was used for both the immunoprecipitation and Western analysis (Figure 10). With neither of both approaches, MGP was detected in the conditioned medium, which strongly suggests that MGP is not secreted by these cultured cells.

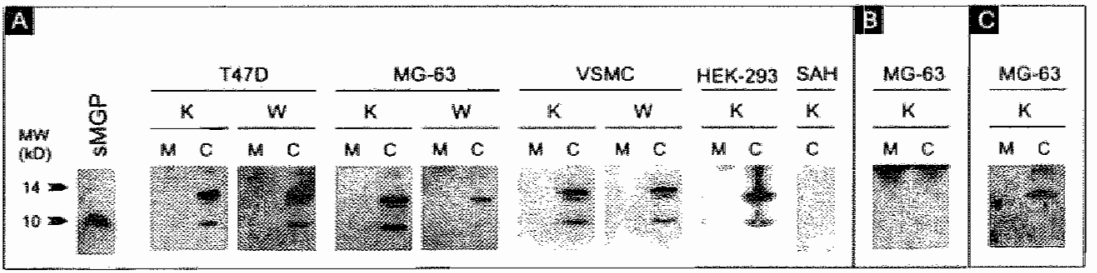

Figure 1:

Immunoprecipitation of MGP. After treatment of T47D cells, MG-63 cells, WSMC3, HEK-293, and $5 A H$ cells with either vitamin $K 1(K)$ or warfarin (W) for 72 hours, cell lysates (C) and conditioned medium (M) were incubated with a3-15 MGP mAb (panels A and B) or a63-75 MCP mAb (panel C). After precipitation using protein a agarose, samples were separated on SDS. PAGE and blotted to PWDF-inembrane. Panel A was stained with biotin conjugated o3-15 MGP MAb. panel $B$ and $C$ were sitained with a63-75 MGP mAb and rabbit antimouse peroxidase. conjugated IgG. Synthetic MGP peptide (sMGP) was used as a positive control. MGP was absent in the SAH cell lysate and conditioned media, confirming the absence of MCP expression in this cell type. 


\section{Immunofluorescence microscopy}

Given the presence of MGP in cell lysiates from various cell types, we determined whether MGP was localised at the extracellular or intracellular side of the cell membrane. Initially, this was investigated by evaluating the effect of fixation and permeabilisation of the cells, followed by subsequent immunfluorescence analysis. When non-fixed and non-permeabilised MG-63 cells were stained with the $\alpha 3-15$ MGP lgG, staining was weak or absent (Filgure 2A).Also, after fixation without permeabilisation no MGP was detected in the extracellular space (Figure 2B). These results indicate that MGP is absent in the extracellular space. On the other hand, fixation and permeabilisation of the cells prior to antibody staining showed the presence of intracellular MGP (Figure 2C). Similar observations were made with human VSMC5, and T47D (Figures, 2A, C). No staining was observed in the case of the SAH cells, again indicating absence of MGP (Figure 2). These studies suggest that MGP is located inside the cell, rather than at the cell surface. The specs of staining were not observed in all cases and might reflect antibody precipitation. $\gamma$-Glutamyl carboxylation of MGP did not change the intracellular localisation of MGP as was shown by adding vitamin $\mathrm{K} 1$, MK-4, or warfarin to the culture medium (Figures $2 \mathrm{D}_{*} \mathrm{E}_{n} \mathrm{~F}$ ).

\section{Confocal microscopy}

The intracellular location of MGP was further investigated using confocal microscopy. In MG-63 cells stained with the $\alpha 3-15$ MGP IgG, MGP was found diffusely throughout the cytoplasm, some of which was in rounded structures with more dense staining near the edges of the cells (Figure 3). There was an intense perinuclear staining, which suggests localisation of MGP in the RER. Little or no MGP was detected in the nucleus or associated with the cellular membrane. Similar results were obtained for T47D cells and VSMCs (data not shown).

\section{MGP in vivo}

MGP protein has been detected in the extracellular matrix of bone and cartilage (Figure 4) as well as in VSMCS and elastic lamellae of the artery wall $[167,174]$. MGP expression has been reported for malignant human cultured epithelial cells $[32,206$ and we have investigated epithelial cell expression of MGP within human tissues (Figure 4). Immunohistochemical staining of human gland epithelial cells showed high levels of MGP deposition within cubic shaped epithelial cells, whereas MGP staining was lower or absent in more pavement shaped cells (Figure 4). Also in this in wivo situation, MGP was localised in the cytoplasm of the cells and no MGP staining was observed in association with the extracellular matrix. 


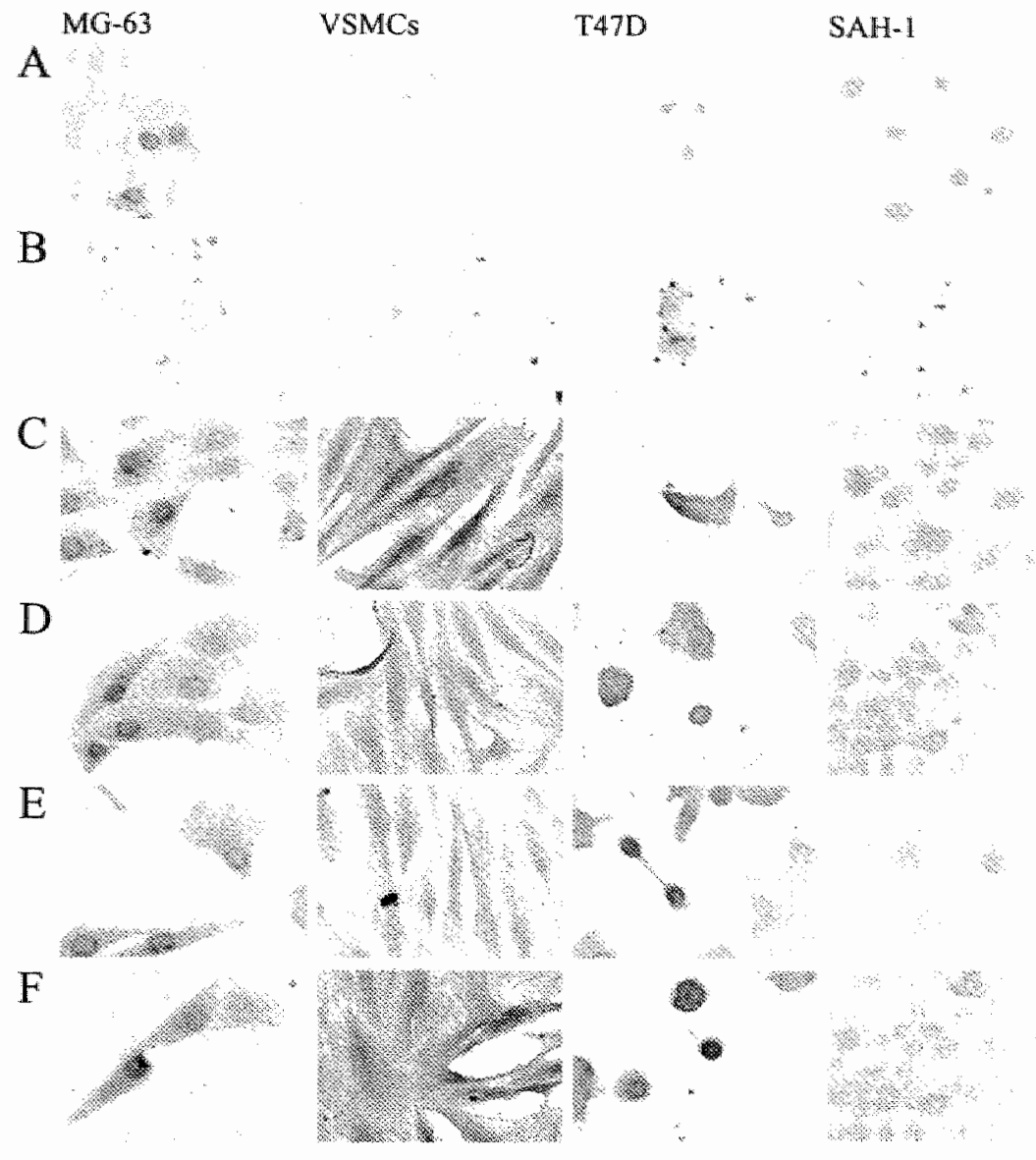

Figure 2:

Irmmunofluorescence analysis of MG.63 cellis. VSMCs. TA7D cells, and SAH cells. Cells were stained with a3-15 MCP MAb and subsequently with FlrC-conjugated anti-mou se lgC (positive signal in green). Nucleus staned in blue. Cells were stained directly (A), after fixation (B], after fixation and permeabilisation (C), and after 72 hours treatment with 10 HM vitamin K1 (D), 10 $\mu \mathrm{M}$ vitamin Ka (E), or $10 \mu \mathrm{M}$ warfarin (F) (all three with lixation and permeabilisation).

Release of MGP wia apoptotic bodies.

We previously reported that apoptosis is involved in calcification of VSMC multicellullar nodules [175]. We also found that isolated VSMC-derived apoptotic bodies could calcify in a similar manner to matrix vesicles. Since MGP is involved in both calcification [123] and apoptosis [145] and is expressed by VSMC calcifying nodular cells (176), we analysed apoptotic bodies for the presence of MGP. By Western blot analysis it was shown that apoptotic bodies released by VSMCs, upon exposure to $\alpha$ Fas IgM and cycloheximide, contained MGP (Figure 5A). In addition, extracellular vesicular structures in human VSMC cultures stained intensely using the 03 -15 MGP IgG (Figure 5B). These bodies were also observed in MG-63 cells (Figure 2C). These 
bodies/vesicles, of a size similar to apoptotic bodies, could be the mechanism by which MGP is exported from cells.

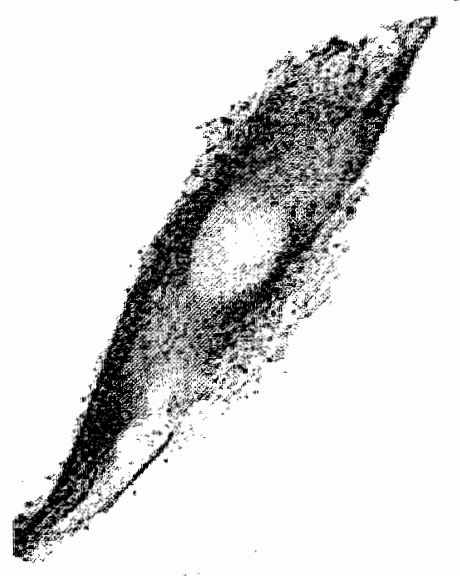

Figure 3:

Immunofluorescence confocal microscopy of human osteoblastic osteosancoma cell line (MG-63), using the a3-15 MGP lgG antibody. Positive MPG staining in black.

\section{Discussion}

The immature vitamin K-dependent matrix Gla protein contains a predicted signal peptide of 19 amino acid residues, which is necessary for translocation across the rough endoplasmic reticulum membrane and subsequent posttranslational modifications [167]. Several studies indicate that MGP plays a major role in the prevention of soft-tissue callification [123. 161, 176]. Until recently most studies on MGP were based on MRNA or genomic DNA and only a few studies focussed on the protein itself, probably because of the insolubility of purified or synthesized MGP under physiological conditions $[17,76]$ MGP mRNA is expressed by many tissues but the protein only accumul* lates at specific sites such as the extracellular matrix of bone, cartilage, and the arterial vessel wall $[77,167,176]$.

In this study, we provide experimental evidence for an intracellular localisation and secretion via apoptotic bodies of MGP in cultured cells. We primarily analysed human VSMCs and compared these to other human cells that are known to express high or low levels of MGP MRNA. ELISA and Western analysis showed the presence of MGP in cell lysates of human breast cancer epithellial cells (T47D), human osteoblastic osteosarcoma cells (MG-63), human embryonic kidney cells (HEK-293), and human aortic VSMCs. No MGP was detected in the corresponding conditioned media by immunoprecipitation and subsequent Western analysis. Two different 
antibodies raised to $\mathrm{N}$ - or C-terminal epitopes of MGP were used and both precipitated MGP in cell lysates but not from conditioned medium. Possible extracellular degradation of MGP by a protease can be excluded, since with both the $\mathrm{N}$-terminal and C-terminal MGP antibodies no MGP fragments were detected. Our observations differ from studies of MGP secretion from non-human cells in culture. In rat cells in culture, MGP has been detected in conditioned medium from lung, kidney and osteosarcoma cells [28,61, 180]. Also in mouse preosteoblastic M2 cells, MGP was detected intracellularly in newly plated cultures, but translocated to the extracellular matrix within 3 days of culture [269].
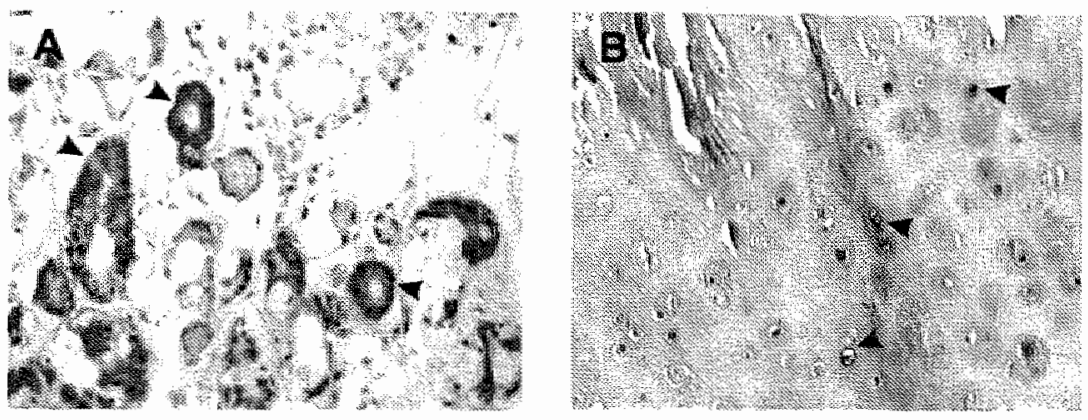

Figure 4:

Immenohistochernical staining of human gland epithelial cells (A) and chondrocytes (B) in the trachea with a3.15. MGP MAb. Positive staining is indicated with arrows.

The finding of intracellular MGP may simply reflect its storage prior to release in cultured cells but it is also possible that MGP has an intracellular role. Further analysis of MGP within cells revealed that it was abundant and diffusely distributed thiroughout the cytoplasm, with a higher concentration around the nucleus. The perinuclear staining is likely to represent the RER since $\gamma$-gilutamyl carboxylation occurs at this site. Native MGP in its Gla-form is predicted to bind calcium ions and could therefore have a role in cellular calcium homeostasis and signalling.

MGP was found not only intracellularly in cultured human cells but also in human tracheal epithelial cells and cartilage in vivo. However, as mentioned previously, MGP has been found in the extracellular matrix of bone, cartilage and the vasculature. This raises the possibility that MGP is only secreted by specific cells or that it onlly accumulates in specific extracellular matrices. MGP is therefore thought to be a secreted protein.

Release of MGP in the form of apoptotic bodies/vesicles

Our experiments suggest that MGP is an intracellular protein. However, the extracellular location of MGP in wivo indicates that it must be secreted by cells wia a presently unknown mechanism. We found that VSMCs undergoing 

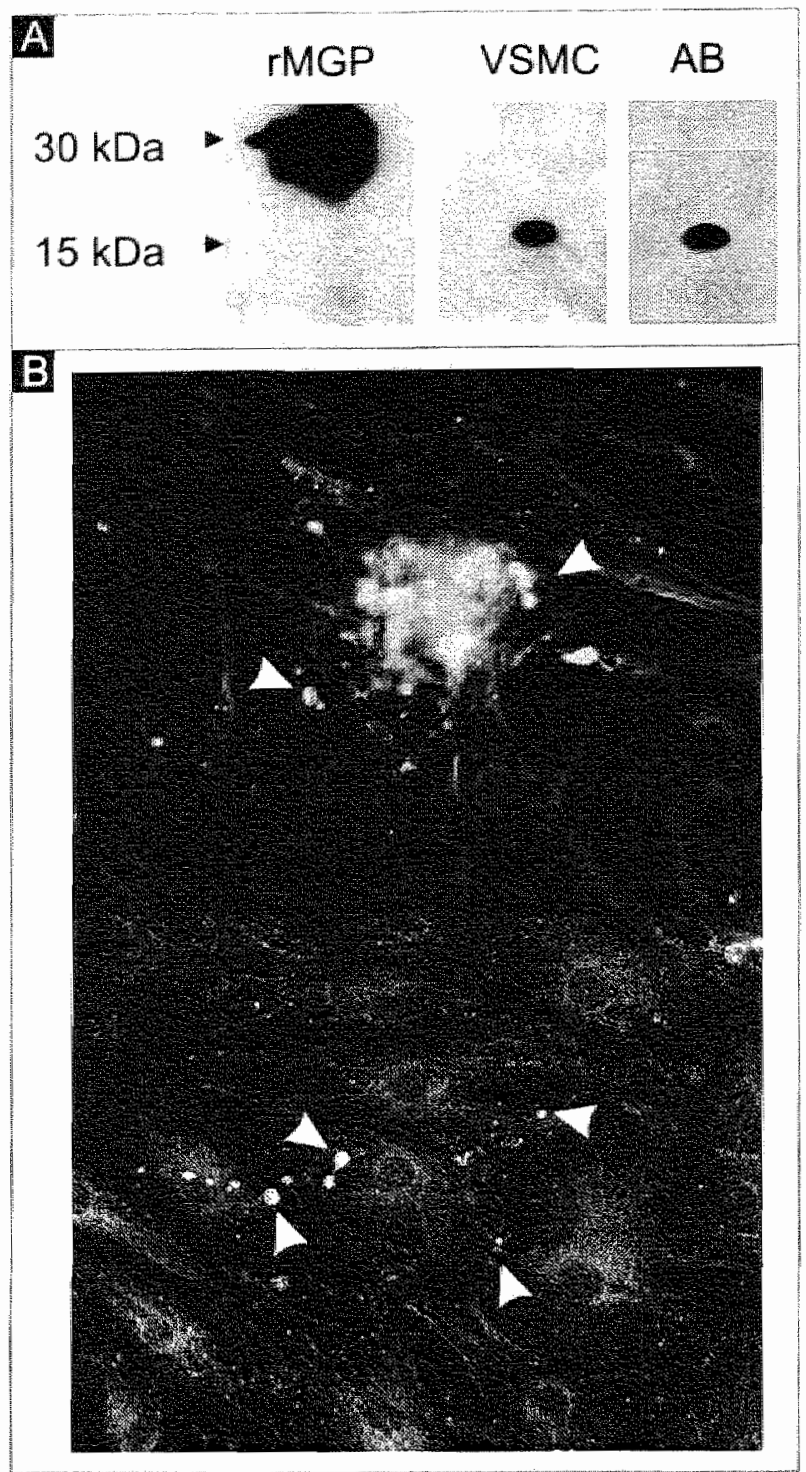

Figure $5:$

MGP' in apoptotic badies/vesicles.

A. Both VSMCs and apoptotic bodies (AB) were resuspended in $8 M$ urea, diluted 1:1 in $2 \times 505$ PAGE sample buffer and $10 \mathrm{Hg}$ was electrophoresed on a $12 \%$ polyacrylamide gel. The get was subsequently blotted and probed with the $\alpha 3-15$ MGP monoclonal antibody as described in the methods section. MCP was cletected in botin WSMCs and apoptotic bodies. The positive controt for MGP in this Western was a recombinant form of MGP (rMGP), linked to DHFR, as described pireviously.

B. Bath panels strow two different human V5MC isolates stained with the $03^{-15}$ MGP monoclonal antibody. The top panel contains monolayer cells as well as a multicellilar nodule which stains intensely for MCP. In both isolates MGP staining is seen throughout the cytoplasm and some cells have intense perinuelear staining. Vesicular structures containing MGP are indicated by arrows. 
apoptosis released apoptotic bodies which contained MGP. Therefore, apoptotic body or vesicle release could facilitate MGP export from cells. Since MGP is prone to precipitation, it is possible that apoptotic bodies 'chaperone' MGP and maintain its solubility. Our findings are supported by an electron microscopic study of adult cartilage in which MGP was detected within chondrocytes and matrix vesicles. [1221. Matrix vesicles in cartilage and bone are membrane-bound bodies, often generated in association with apoptosis, which bud-off from chondrocytes and osteoblasts $[3,1021$. Our previous studies have shown that VSMC apoptotic bodies have similarities with matrix vesicies in that they can accumulate calcium ions and calcify in vitro [175], suggesting that they may be key sites for calcium crystal nucleation in vascular calcification. The presence of MGP in both VSMC apoptotic bodies and matrix vesicles indicates that calcification of these vesicles may be regulated by MGP. Although apoptotic cells are normally rapidly phagocytosed, both apoptotic bodies and matrix vesicle-like structures have been detected in bllood vessels which indicates that phagocytosis is inhibited in the diseased vessel wall. We have recently shown that modified lipids can inhibit apoptotic body phagocytosis by VSMCs in vitro thereby enhancing calcification [172]. It is likely that MGP is present in apoptotic bodies to ensure that calcification does not occur before they are phagocytosed. It is also possible that MGP has a role in phagocytosis since Gla proteins are predicted to bind acidic phospholipids and the Gla protein Gas6 has been shown to promote uptake of apoptotic bodies via binding to phosphatidy/serine [141]. Furthermore, it has recently been shown that MGP has a role in preventing apoptotsis at specific stages of chomdrocyte differentiation [145] and has also been linked with apoptosis in other cell types 15,21 . It is therefore tempting to speculate that one of the mechanisms by which MGP might inhibit vascular calcification is via inhibition of VSMC apoptosis.

Non-phagocytosed apoptotic bodies are expected to either calcify or undergo secondary necrosis, releasing MGP. This may be particularly important in atherosclerositc plaques since MGP is deposited in calcified lesions 12011. Therefore, the accumulation of MGP in plaques could be due to apoptosis and a lack of phagocytosis. MGP may then be trapped due to the awascular, lipid-rich nature of the plaque. Alternatively, MGP may remain in plaques because it is modified or undercarboxylated [197].

Amother potential fate of non-phagocytosed apoptotic bodies is migration to the blood vessel lumen. Vascular cell-derived apoptotic microparticles have been detected in circulating blood from normal individuals and are more abundant in patients with complicated atherosclerosis 128 . MGP levels are also elevated in serum from patients with severe atherosclerosis 117 . From these observations we can speculate that in the blood ves sel or tissue where MGP MRNA is expressed, the protein is released from cells in the form of 
apoptotic vesicles that travel through the matrix to the lumen. In calcified blood vessels, the vesicles may contain more MGP and/or there is an increase in production of these vesicles, either retained in the diseased tissue or relleased into the circulation. However, it remains to be investigated whether MGP is associated with apoptotic vesicles in vivo. At present, tissue factor is the onlly other protein known to be relleased from VSMCs in the form of apoptotic vesicles [129].

In conclusion, we have shown that MGP is an intracellular protein which is released via apoptotic bodies. MGP is a potent inhibitor of calcification in vivo but its mechanism of action remains unknown. Our study now highlights that MGP could have an intracellular function as well as an extracellular role associated with apoptotic vesicles. 




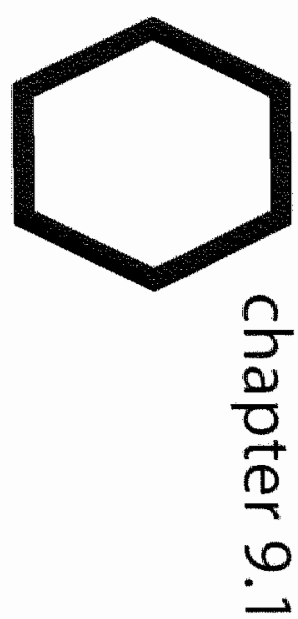

discussion and summary 
The posttranslational process of $\gamma$-glutamyl carboxylation is found in various species including drosophila $[120,243$. suggesting early development of this process during evolution. After translocation of the precursar protein across the rough endoplasmic membrane, specific glutamic acid residues (Glu) are converted into $\gamma$-carboxy glutamic acid residues (Gla). In this process are involved: the transmembrane enzyme Y-glutamyl carboxylase which catalyses the reaction, vitamin $K$ as a cofactor, and at least two known reductases for the recycling of vitamin $K$ (Chapter 1, Figure 3.2). The resulting protein is called a Gla-protein or vitamin Kmdependent protein.

Gla-proteins may be classified in three groups: I. Glamproteins involved in blood haemostasis: prothrombin, coagulation factors $V_{I}, X_{*}$ and $X_{s}$ protein $C_{\text {. }}$ protein S, and protein Z. Il: Gla-proteins involved in tissue calcification: matrix Gla protein (MGP) and osteocalcin (OC). And II: other Gla-containing proteins such as praline-rich Gla-proteins and Gas6. In all these proteins the presence of Gla-residues is a prerequisite in the $\mathrm{Ca}^{2 *}$-binding and/or $\mathrm{Ca}^{2 *}$-dependent interaction with negatively charged surfaces.

In 1929 the Danish scientist Henrik Dam described the first disorder due to a malfunction of the $\gamma$-glutamyl carboxylation process. Since then, several pathological symptoms resulting from inhibition or malfunction of one of the components involved in the $\gamma$-glutamyl carboxylation process have been described. Taking a close look at the carboxylation process (Chapter 1, Figure 3.2) several reasons may underlie the accurrence of non-carboxylated Glaproteins and the subsequent (pathologicall) phenotype displayed. First, a blockade of vitamin $K$-reductase as a result of coumarin ingestion or a mutation may lead to impaired recycling of vitamin $K$ and finally to an exhaustion of the available vitamin K stores. Second ${ }_{s}$ a mutation in the Glaprotein may result in either poor substrate recognition by carboxylase i 79 ) or in impairment of propeptide cleavage from the mature protein [251]. Thind, the rare disorder of a mutation in the $\gamma$-glutamyl carboxylase gene leading to a defective enzyme. Two Lebanese patients with the same mutation in the $\gamma$ glutamyl carboxyllase gene are described in Chapters 2.1 and 2.2 . Both patients are the first offspring of consanguineous parents and are homozygous for a point mutation in exon 11 of the $\gamma$-glutamyl carboxylase gene. The mutation causes the conversion of a tryptophan codon (TGG) to a serine codon (TCG) at amino acid residue 501 of $\gamma$-glutamyl carboxylase (W5015). As a result of the mutation both hepatic and extra-hepatic Glawproteins are affected (non-carboxylated) leading to a hereditary combined deficiency of all vitamin K-dependent procoagulants and anticoagulants. For rapid detection of the mutation a RFLP technique based on the presence of 3 BstNI sites in the unaffected allele and 2 BstN\| sites in the affected allele was developed (Chapter 2.1). Using this screening technique the autosomal recessive pattern of inheritance of this disease was shown. 
Hereditary combined deficiency of all vitamin K-dependent procoagulants and anticoagulants is a rare bleeding disorder reported only by a few authors 112. 19,37.95, 1541. Until now, only in two other cases mutations leading to a defective $\gamma$-glutamyl carboxylase enzyme have been reported 119.209. This suggests that most mutations in the $\gamma$ glutamyl carboxylase enzyme are not compatible with embryonic development and therefore are not detected. In other words, only mutations leading to a rather mild dysfunction of $y$ glutamyl carboxylase are not lethal for the embryo. This is supported by the fact that in the two patients which we investigated oral vitamin Kl administration resulted in resolution of the clinical symptoms. Before birth, the vitamin Kodependent blood coagulation factors are synthesised at levels (ca. 20\%) far below adult levels (1581. After birth, synthesis is increased and from then on higher vitamin $K 1$ amounts are needed for complete $\gamma$-glutamyl carboxylation.

A second explanation for the effect of oral vitamin $\mathrm{K} 1$ administration is given by the molecular nature of the W5015 mutation (Chapter 3). The impact of the W5015 mutation on the activity of $\gamma$-glutamyl carboxylase was characterised using recombinant $\gamma$-glutamyl carboxylase expressed in insect cells. It was demonstrated that the mutation is most likely localised in the propeptide binding domain of carboxylase. The conversion of tryptophan residue 501 to serine results in a decreased affinity for substrate (propeptide) binding to $\gamma^{\prime}$ glutamyl carboxylase. For example, the blood coagulation factor IX derived substrate FIXproGla binds with an 80 fold higher $K_{m}$ value to W5015-carboxylase than to wild type enzyme. Binding of a propeptide covalently linked to the Gla domain induces a substantial decrease in the $K_{\text {s. }}$ for vitamin $\mathrm{KH}_{2}[88,209]$.It is possible that the decreased propeptide affinity of W5015-carboxylase negatively affects the $\mathrm{K}_{\mathrm{m}}$ for the cofactor $\mathrm{KH}_{2}$. Given the low vitamin $K 1$ levels in newborns, additional vitamin $K 1$ supplementation leads to a $\mathrm{KH}_{2}$ concentration above the $K_{\mathrm{M}}{ }^{*}$ value and thus to partial improvement of carboxylation.

In order to gain more insight in the role of MGP in vascular calcification, monoclonal antibodies (Chapter 4) and synthetic full length MGP (Chapter 5) were prepared. The two monoclonal antibodies described were raised against synthetic peptides homologous to the sequences 3-15 and 63-75 of human MGP and both antibodies recognize recombinant and synthetic human MGP. The wo antibodies were used for immunohistochemical localisation of MGP in human calcified areas. MGP was associated with the extracellular matrix of non-calcified bone and with chondrocytes in cartilage. In the healthy human arterial vessel wall, MGP antigen was demonstrated in association with smooth muscle cells and elastic laminae of the tunica media, and with the extracellular matrix of the adventitia. The co-localization with the elastic laminae was lost at sites of medial calcification: in both human and 
rat arteries, high amounts of MGP were found in the extracelluhar matrix at borders of intimal and medial calcification. Native MGP is difficult to isolate from human bones and due to solubility problems, processing of a recombinant MGP-fusion protein chimera to obtain MGP was unsuccessful. Therefore, in Chapter 5 we describe the total chemical synthesis of MGP by tBoc solid-phase peptide synthesis (SPPS) and native chemical ligation. Two peptides. Tyr'-Ala ${ }^{53}$ and Cys ${ }^{54}-\mathrm{Lys}^{54}$, were separately synthesised and subsequently coupled with native chemical ligation.

As described above, a blockade of vitamin $K$-reductase by coumarin inhibits $\gamma$-glutamyl carboxylation leading to undercarboxylated Gla-proteins. In Chapter 6 we describe an animal model in which the extra-hepatic y-glutamyl carboxylase was inhibited using warfarin, whereas the hepatic enzyme remained unaffected. Using this model we demonstrated that, in contrast to vitamin $\mathrm{K} \|$, menaquinone-4 (MK-4) prevents warfarin-induced arterial calcification. Furthermore, we demonstrated both a better bioavailability and a more effective utilisation of MK-4 in the arterial vessel wal. Although both vitamin $K 1$ and $M K-4$ have a 2 -methyl-naphthoquinone group in common, and both function as a cofactor for $\gamma$-glutamyl carboxylase, our observations demonstrate a marked difference between both vitamers. These results are consistent with the strong inverse correlation found between vitamin $K 2$ intake and artery calcification, myocardial infarction and total cardiac death [67]. Kawashima et al. showed that high menaquinone intake suppressed the progression of atherosclerotic plaques, intimal thickening and pulmonary atherosclerosis in hypercholesteralemic rabbits [99].

MGP is expressed by vascular smooth muscle cells (VSMCs) in the arterial vessel wall and thought to play a role in the inhibition of soft-tissue calcification. In Chapter 7 we added the synthetic full length MGP to calcifying human aortic VSMCs cultures. We showed that in witro at a concentration of $500 \mathrm{ng} / \mathrm{mL}$ synthetic full length MGP inhibited VSMCs calcification. In this Chapter we also demonstrate a difference between vitamin K1 and menaquinone-4 on VSMCs nodule formation. Vitamin K1 had no effect, whereas MK-4 inhibited nodule formation by $50 \%$. This inhibitory activity of MK-4 was not $\gamma$-glutamyl carboxylase dependent and therefore suggests a second, yet unknown, function for vitamin $k 2$.

Various Japanese studies have demonstrated a strong decrease of bone loss and even an increase of bone mineral density by a high-dose MK-4 treatment (45 mg/day) (1. 151. Remarkably, the used dose is much higher than can be

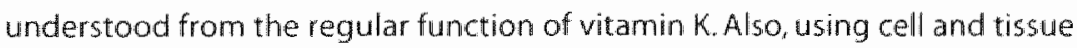
culture experiments it was shown that: (a) among all the poly-isoprenoids known as witamin $K$ side chains, only geranylgeraniol was capable of 
inhibiting osteoclast activity 1811 . and (b) MK-4 specifically induced apoptosis of osteoclasts in experimental model systems [97]. Together with the observed differences between vitamin $\mathrm{K} 1$ and $\mathrm{K} 2$ described in Chapter 6 , this has lead to a new hypothetical function for the geranylgeranyl side chain of $M K-4$. The reported inhibitory effect of $M K-4$ on bone loss is comparable to those obtained with bisphosphonate treatment. Like bone loss, also vascular media calcification can be completely abolished by both bisphosphonate treatment (1633), and by high-dose MK-4 treatment (Chapter 6), but not by treatment with K1. Bisphosphonates are well known inhibitors of osteoclastic bone resorption. Nitrogen-containing bisphosphonates are specific inhibitors of the enzyme farnesyl-pyrophosphate synthase and in bone this leads to reduced production of the compounds farnesyl-pyrophosphate and gieranylgerany/ pyrophosphate [186]. The latter compounds are needed for the prenylation of signal-transducing proteins such as rho, rac, and ras, which stimulate osteoclast activity and bone resorption [238]. In this way it can be understood that bisphosphonates lead to disturbed signal transduction, followed by loss of cellular onganization and leading to inactivation of the osteoclasts and their subsequent apoptosis. The function of the geranylgeranyl side chain in MK-4 would thus be that it serves as a competitive inhibitor in the prenylation of signal transduction proteins, in such a way that the naphthoquinone group in $\mathrm{MK}-4$ could block either the phosphorylation of farnesyl and geranylgeranyl or the protein coupling to farnesyl- and geranylgeranyl-pyrophosphate. As a consequence, high doses of MK-4 may bind to and thus saturate the geranylgeranyl-binding sites in the prenylating enzyme system, which makes clear why high doses of MK-4 are required for in vivo effects comparable with those obtained with bisphosphonates.

The association of MGP with the extracellular matrix, the presence of a predicted signal-peptide, and Gla-residues within its $\mathrm{N}$-terminal domain suggests it to be an extracellular protein. In Chapter 8 we show an intracellular localization of MGP in cultured human aortic VSMCs, human breast cancer epithelial cells (T47D), and human osteoblastic osteosarcoma cells (MG-63). These data are in contrast with the extracellular location of MGP in vivo and indicates that the protein must be secreted wia a presently unknown mechanism by cells. We found that VSMCs undergoing apoptosis released apoptotic bodies which contained MGP. In addition, in normal cell cultures which expressed MGP, numerous small MGP containing vesicular structures could be detected. Therefore, apoptotic body or vesicle release could facilitate MGP export from cells.

During the past decade it became clear that vitamin K-dependent proteins are not only involved in the blood coagulation process. An example of such a protein is the matrix Gla protein, which has an important role in the prevention of soft tissue calcification. Together with the proposed second, yet 
unknown, function of menaquinone-4 this makes the scientific field of $\gamma$-glutamyl carboxylation, vitamin $\mathrm{K}$, and matrix Gla protein of potential relevance in cardiovascular research. 


$$
\text { . }
$$




$$
\begin{aligned}
& \frac{1}{2} \\
& \frac{0}{0} \\
& \stackrel{+}{D} \\
& \stackrel{N}{N}
\end{aligned}
$$

discussie en samenvatting 

De y-glutamylcarboxylering van specifieke glutaminezuurresiduen is een posttranslationele madificatie die plaats vindt bij verschillende diersoorten. De aanwezigheid van het enzym rglutamyl carboxylase in de fruitvlieg suggereert een vroege ontwikkeling van het proces gedurende de evolutie $1120,243]$. Nadat een immatuur eiwit over de membraan van het ruw endoplasmatische reticulum is getransporteerd, worden specifieke glutaminezuurresiduen omgezet in $\gamma$-carboxyglutaminezuren (Gla). Bij deze omzetting zijn de volgende componenten betrokken: het transmembraan enzym $\gamma$-glutamyl carboxylase welk zorgt woor katalysatie van de reactie, vitamine $K$ als co-factor, ten minste twee reductases voor de recycling van vitamine $K$, en het te carboxyleren eiwit (Hoofdstuk 1. Figuur 3.2). Dit substraat eiwit wordt een Glar-eiwit of een vitamine $\mathrm{K}$-afhankelijk eiwit genoemd.

Gla-eiwitten kunnen in drie groepen worden onderverdeeld: I. Gla-eiwitten betrokken bij bloedstolling: prothrombine, factoren VII, IX en $X$, proteine $C$, proteine 5 en proteine Z. II: Gla-eiwitten betrokken bij verkalking van weefsels: matrix Gla proteine (MGP) en osteocalcine (OC). En Ill: andere Glaeiwitten zoals de proline-rijke Gla-eiwitten en Gas6. Bij al deze eiwitten is de aanwezigheid van Gla-residuen een vereiste voor de binding van calciumionen $\left(\mathrm{Ca}^{24}\right)$ en/of de calcium-afhankelijke interactie met negatief geladen oppervlakken.

De Deense wetenschapper Henrik Dam beschreef in 1929 als eerste een aandoening die werd weroorzaakt door een slecht werkend carboxylase proces. Sindsdien zijn verscheidene pathologische symptomen beschreven welke het gevollg zijn van remming of slecht functioneren van componenten betrokken bij de $\gamma$-glutamyl carboxylase reactie. Kijken we naar het carboxylerings proces (Hoofdstuk 1, Figuur 3.2) dan wordt duidelijk dat diverse oorzaken kunnen leiden tot de aanmaak van niet gecarboxyleerde Gla-eiwitten en het daaropvolgende (pathologische) fenotype. Als eerste, remming van het vitamime Kureductase als gevolg van coumarine inname of een mutatie kan resulteren in een slecht hergebruik van vitamine $K$ en uiteindelijk tot uitputting van de beschikbare vitamine $k$ voorraad. Als tweede, een mutatie in het Gla-eiwit kan leiden tot een slechte herkenning van het substraat door het enzym $\gamma$ glutamyll carboxylase [79] of tot het niet verwijderen wan het propeptide van het uiteindelijke eiwit [251]. Als derde, een mutatie in het $\gamma$-glutamyl carboxylase gen kan leiden tot een slecht werkzaam enzym. Dit laatste is echter een zeldzame aandoening. In de hoofdstukken 2.1 en 2.2 worden twee patienten beschreven met dezelfde mutatie in het $\gamma$-glutamyl carboxylase gen. Beide patienten zijn de eerste nakomelingen van bloedverwante ouders en zijn homozygoot voor een punt mutatie in exon 11 wan het $y$-glutamyl carboxylase gen. De mutatie veroorzaakt de omzetting van een tryptofaan codon (TGG) naar een serine codon (TCG) van aminozuur residu 501 (W5015) in $\gamma$-glutamyl carboxylase. 
Als gevolg van deze mutatie zijn zowel de hepatische als extra-hepatische Gla-eiwitten niet gecarboxyleerd, hetgeen leidt tot een erfelijke gecombineerde deficientie van alle vitamine K-afhankelijke eiwitten. Voor een snelle detectie wan de mutatie werd een RFLP-techniek opgezet, op basis van drie aanwezige BistNI restrictie enzym herkenningsplaatsen in het onaangedane allel en twee BstNI plaatsen in het aangedane allel (Hoofdstuk 2.1). Met behulp van deze methode werd het autosomale recessieve overervingpatroon van deze ziekte aangetoond.

Erfelijke gecombineerde deficientie van alle witamine K-afhankelijke eiwitten is een zeldzaam voorkomende bloedingaandoening, waarvan maar door enkele auteurs melding wordt gemaakt $[12,19,37,95,154]$. Tot nu toe zijn maar twee patiënten bekend waarbij een mutatie resulteert in een defect q-glutamyl carboxylase enzym [19, 209]. Dit suggereert dat de meeste mutaties in het $\gamma$ glutamyl carboxylase enzym reeds in de embryonale fase tot de dood leiden en dien ten gevolge niet gevonden worden. Met andere woorden, alleen mutaties welke leiden tot een mille disfunctie van y-glutamyl carboxylase zijn niet lethaal woor het embryo. De bevinding dat orale vitamine $\mathrm{K}$ toediening in de hier onderzochte patiénten resulteerde in herstel van de klinische symptomen, ondersteunt dit. Voor de geboorte worden de vitamine K-afhankelijke stollingseiwitten aangemaakt op een niveau (ca. $20 \%$ ) ver beneden het niveau gevonden bij volwassenen I1581. Na de geboorte neemt de synthese toe en is een hogere vitamine $K$ inname nodig voor een volledige $\gamma$-glutamyl carboxylering.

Een tweede oorzaak voor het effect van orale vitamine $K$ toediening werd gevonden in de moleculaire achtergrond van de W5015 mutatie "Hoofdstuk 3). Recombinant $\gamma$ glutamyl carboxylase werd tot expressie gebracht in insect cellen om het effect van de W5015 mutatie op de enzymatische functie te onderzoeken. El werd aangetoond dat de mutatie waarschijnlijk in het propeptide bindende gedeelte van $\gamma$ glutamyl carboxylase zit. De conversie van tryptopfaan residu 501 tot een serine leidt tot een afgenomen herkenning en binding van het substraat (propeptide) aan $\gamma$-glutamyl carboxylase. Bijvoorbeeld, het van bloedstollingsfactor $I X$ afgeleidde substraat FlXproGla bindt 80 maal slechter aan W5015 $\gamma$-glutamyl carboxylase dan aan het wildtype enzym. Het is aangetoond dat een propetide welk cowalent gekoppeld is aan een Gla-domein een substantiele afname in de $\mathrm{K}_{\mathrm{s}}$ voor $\mathrm{KH}_{2}$ induceert $[8 \mathrm{~s}, 209]$. Het is daarom ongekeerd ook mogelijk dat de verlaagde affiniteit woor een propeptide, veroorzaakt door de W501S mutatie, de $K_{\mathrm{m}}$ voor cofactor $\mathrm{KH}_{2}$ negatief beînvloed. Om meer inzicht te verkrijgen in de rol wan MGP in vascullaire verkalking, werden monoklonale antilichamen (Hoofdstuk 4) en synthetisch MGP (Hoofdstuk 5) gemaakt. De twee monoklonale antilichamen die hier worden beschreven werden opgewekt tegen symthetische peptiden homoloog aan de 
sequenties 3-15 en 63-75 wan humaan MGP en herkennen beiden zowel recombinant als synthetisch MGP. De twee antilichamen werden giebruikt voor immunohistochemische lokalisering van MGP in humane verkalkte gebieden. MGP is geassocieerd met de extracellulaire matrix van niet verkalkt bot en met chondrocyten in kraakbeen. In de gezonde humane arteriële vaatwand werd MGP antigeen aangetoond in associatie met gladde spier cellen en de elastische laminea van de tunica media en met de extracellulaire matrix van de adventitia. De co-lokalisatie met de elastische laminea ging verloren in gebieden van mediale verkalking. In zowel humane als rat arteriën werden grote hoeveelheden MGP gevonden in de extracellulaire matrix aan de grensvlakken van intimale en mediale verkalking. Natuurlijk voorkomend MGP is moeilijk te isoleren uit humaan bot en door oplosbaarheils problemen was de verwerking wan recombinant chimeer MGP niet succesvol. Daarom wordt in Hoofdstuk 5 de totale chemische synthese van MGP door middel van tBoc solid-phase peptide synthesis (SPPSy en native chemical ligation beschreven. De twee peptiden, Tyr ${ }^{3}-\mathrm{Al}^{\mathrm{s}}{ }^{\mathrm{3}} \mathrm{en}$ $\mathrm{Cys}^{54}$-Lys $5^{5.4}$, werden afzonderlijk gemaakt en vervolgens gekoppeld door middel van native chemical ligation.

Zoals hierboven beschreven leidt een blokkade van het vitamine $K$ reductase door coumarine tot remming van de $y$ glutamyl carboxylering en zo tot niet gecarboxyleerde Gla-eiwitten. In hoofdistuk 6 wordt een dier model beschreven waarin het extrahepatische $\gamma$ glutamyl carboxylase werd geremd door middel van warfarine, terwijl het hepatische enzym niet werd beinvloed. Met behulp vain dit model werd aangetoond dat menaquinone-4 (MK-4), in tegenstelling tot vitamine $\mathrm{K} 1$, de warfarine geinduceerde arteriële verkalking voorkomt. Daarnaast werd een betere biologische beschikbaarheid en een meer efficiënt gebruik van MK-4 door de arteriële vaatwand aangetoond. Hoewel vitamine $K 1$ en MK-4 beiden een 2-methylnaphtoquinone groep hebben en beiden fungeren als co-factor voor Yglutamyl carboxylase, tonen deze resultaten een opmerkelijk verschil aan tussen beide vitaminen. De hier gepresenteerde resultaten zijn in overeenstemming met de gevonden sterke inverse correlatie tussen vitamine $\mathrm{K} 2$ inname en respectievelijk arteriële verkalking, het risico op een hart aanval en totale cardiale dood [67]. Deze bevindingen worden ondersteund door de resultaten van Kawashima et al. Zij hebben aangetoond dat een hoge menaquinone inname de ontwikkeling van atherosclerotische plaques onderdrukt in hypercholesterolemische konijnen [s9]

MGP wordt tot expressie gebracht door vasculaire gladde spier cellen (VSMCs) in de ar teriële vaatwand en speelt een belangrijke rol in de remming van verkalking in zachte weefsels. In hoofdstuk 7 wordt de toevoeging van synthetisch MGP aan verkalkende humane aorta VSMCs culturen beschreven. Er werd aangetoond dat in dit in vitro systeem een synthetische 
MGP concentratie van $500 \mathrm{ng} / \mathrm{ml}$ de verkalking van VSMCs remt. Met dit model werd ook aangetoond dat vitamine $K 1$ en MK-4 een verschillend effect hadden op de vorming van VSMC5 nodules. Vitamine $K 1$ had geen effect. terwijl MK-4 de vorming wan nodules met $50 \%$ remde. Deze remmende activiteit van MK-4 was niet afhankelijk van $\}$ glutamyl carboxylase en dit suggereert een tweede, tot op heden nog niet bekende, functie voor MK-4.

Verschillende Japanse studies tonen een sterk verminderd botverlies en zelfs een toename in botdichtheid aan bij inname van een hoge dosis MK-4 (45 $\mathrm{mg} /$ dag) [ 1,151 . Opmerkelijk was dat de optimale MK-4 dosis veel hoger is dan kan worden verwacht op basis van een rol als co-factor voor $\gamma$-glutamyl carboxylase. Door gebruik te maken van cel en weefsel cultuur experimenten werd aangetoond dat: (a) van alle poly-isoprenoiden bekend als vitamine $k$ zijketens alleen gerany/geraniol osteoclast activiteit remt (81), en (b) MK-4 specifiek apoptose induceert in osteoclasten [97]. Samen met de resultaten beschreven in Hoofdstuk 6 heeft dit geleid tot een nieuwe hypothetische functie voor de geranylgeranyl zijketen van MK-4.

Deze gemelde remmende effecten van MK-4 op bot verlies zijn vergelijkbaar met de resultaten verkregen uit studies met bisfofonaat behandeling. Daarnaast kan mediale verkalking evenals botverlies. worden tegengegaan door behandeling met bisfosfonaten [163] of een hoge dosis MK-4 (Hoofdstuk 6), maar niet door behandeling met vitamine $\mathrm{K} 1$. Bisfosfonaten zijn bekende remmers van asteoclastische bot resorptie. Stikstof bevattende bisfosfonaten zijn specifieke remmers van het enzym farnesyl-pyrofosfaat synthase en dit leidt in bot tot een gereduceerde productie van de componenten farnesylpyrofosfaat en geranylgeranyl-pyrofosfaat [186]. Deze laatste component is nodig voor de prenylering van signaal overbrengende eiwitten zoals rho, rac en ras welke de osteoclast activiteit en bot resorptie stimuleren [238]. Op deze manier zorgen bisfosfonaten voor een verstoorde signaal overdracht, gevolgd door inactiviteit en apoptose van de osteoclasten. In dit systeem zall de geranylgeranyl zijketen van MK-4 fungeren als een competitieve remmer van de prenylering van signaal overbrengende eiwitten. De naphthoquinone groep van MK-4 kan de fosforylering van farnesyl en geranylgeranyl blokkeren of de eiwit koppeling aan farnesyl- en geranylgeranyl-pyrofosfaat. Als een gevolg hiervan kan een hoge dosis MK-4 binden aan de geranylgleranyl-bindende plaatsen in het prenylerings enzym systeem en deze dus verzadigen. Dit maakt ook meteen duidelijk waarom een hoge dosis $M K-4$ nodig is voor in vivo effecten, vergelijkbaar met die verkregen met bisfosfomaten.

De associatie van MGP met de extracellulaire matrix, de aanwezigheid van een voorspeld signaal-peptide en de Gla-residuen in zijn N-terminus, suggereren dat MGP een extracellulair eiwit is. In Hoofdstuk 8 laten we een 
intracellulaire lokalisatie zien voor MGP in een humane aorta VSMCs cultuur, een humane borstkanker epitheel cel (T47D) cultuur en een humane osteosarcoma cel (MG-63) cultuur. Deze gegevens staan in contrast tot de extracellulaire lokalisatie van MGP in vivo en suggereren dat het eiwit via een tot nu toe onbekend mechanisme door de cellen wordt uitgescheiden. We vonden dat VSMCS in apoptose MGP bevattende apoptotische lichaampjes vrijgeven. Tevens werden in normale cel culturen, welke MGP tot expressie brengen, membraan blaasjes gedetecteerd met daarin MGP. Apoptotische lichaampjes of membraan blaasjes kunnen dus de afgifte van MGP door cellen verzorgen.

Gedurende de laatste decennia wordt het steeds duidelijker dat vitamine $K$-afhankelijke eiwitten niet alleen betrokken zijn bij de bloedstolling, maar ook een belangrijke rol spelen in andere processen. Een voorbeeld van zo een vitamine $K$-afhankelijk eiwit is het matrix Gla proteïne, dat betrokken is bij het voorkomen van zacht weefsel verkalking. Samen met de voor gestelde tweede functie van menaquinone-4 maakt dit het wetenschappelijke veld van $\gamma$-glutamyl carboxylering, vitamine $\mathrm{K}$ en matrix Gla proteïne van potentieel belang in cardiovasculair onderzoek. 



\section{Personal}

Name

Date of birth

Place of birth

\section{Education}

$1976-1982$

$1982-1986$

$1986-1990$

$1990-1994$

$1994-1997$

$1998-2002$

2002 - present
Henri M.H. Spronk

June 7.1970

Margraten, The Netherlands

Primary school (Basisschool)

Maurice Rose, Margraten

Secondary school (MAVO)

St. Petrus, Gulpen

School for Clinical Chemistry laboratory

assistant

Zuid-Limburgse Laboratorium School

Sittard

B.Sc. programme Biochemistry

Hogeschool Heerlen, Sittard

M.Sc. programme Molecular Biology

Katholik University Nijmegen

Ph.D. Student

Departments of Biochemistry and

Pharmacology and Toxicology

University Maastricht

Research Fellow

Department of Internal Medicine

University Maastricht 

Spronk, H.M.H., Soute, B.A.M., Vermeer, C. Shanahan, C.M., Weissberg. P.L., Proudfoot, P. Matrix Gla Protein is an Intracellular Protein. Submitted.

Soute, B.A.M., Jin, D.Y., Spronk, H.M.H. Mutucumarana, V.P., Lin, P.I., Vermeer, C., Stafford, D.W. Characteristics of recombinant W5015 mutated human $\gamma^{*}$ Glutamyl Carboxylase. Submitted.

Spronk, H.M.H., Soute, B.A.M., Schurgers, L.J., Thijssen, H.H.W., De Mey, I.G.R., Vermeer, Tissue-specific utilization of menaquinone-4 results in prevention of arterial calcification in warfarin-theated rats. Submitted.

Dhore, C.R., Cleutjens, I.P.M., Lutgens, E., Cleutjens, K.B.J.M., Geussens, P.M., Kitslaar, P.J.E.H.M., Tordoir, J.H., Spronk, H.M.H., Vermeer, C., Daemen. M.J.A.P. Differential expression of bone matrix regulatory proteins in human atherosclerotic plaques. Arteriosclerosis, Thrombosis and Vascular Biology, 2001 21: 19982003.

Spronk, H.M.H., Soute, B.A.M., Schurgers, L.J., Cleutjens, I.P., Thijssen, H.H.W., De Mey, I.G.R., and Vermeer, C. Matrix gla protein accumulates at the border of regions of calcification and normal tissue in the media of the arterial vessel wall. Biochemical and Biophysical Research Communications, 2001 289: 485-490.

Mousallem M., Spronk, H.M.H., Sacy, R., Hakime, N., Soute, B.A.M. Congenital Cambined Deficiencies of All Vitamin K-Dependent Coagulation Factors. Thrombosis and Haemostasis, 2001 86(5): $1334-1336$.

Farzaneh-Far, A., Davies, J.D., Braam, L.A., Spronk, H.M.H., Proudfoot, D., Chan 5.W. O'Shaughnessy, K.M., Weissberg, P.L., Vermeer, C., Shanahan, C.M. A polymorphism of the human matrix gamma-carboxyglutamic acid protein promoter alters binding of an activating protein-1 complex and is associated with altiered transcription and serum levels. Journal of Biological Chemistry, $2001276(35): 32466-32473$. 
Hackeng, T.M., Rosing, 1., Spronk, H.M.H., Vermeer, C. Total chemical synthesis of human matrix Gla protein. Protein Science, 2001 10: 864870.

Schurgers, L.I. Dissel, P.E.P., Spronk, H.M.H., Soute, B.A.M., Dhore, C.R., Cleutjens, J.P.M. Vermeer, C. Role of vitamin $K$ and vitamin $K$ dependent proteins in vascular calcification. Zeitschrift fur Kardialogie, 2001 90: 53, 111/57-63.

Spronk, H.M.H., Farah, R.A., Buchanan, G.R., Vermeer, C., Soute, B.A.M. A novel mutation in the $\gamma$-glutamyl carboxylase gene resulting in congenital combined deficiency of all vitamin K-dependent blood coagulation factors. Blood, 2000 96: 3650-3652.

Braam, L.A.J.L.M., Dissel, P.E, Gijsbers, B.L.M.G., Spronk, H.M.H., Hamulyák, K., Soute, B.A.M., Debie, W. Vermeer, C. Assay for human matrix Gla-protein in serum: potential applications in the cardiovascular field. Arteriosclerosis, Thrombosis and Vascular Biology, 200020 : 1257-1261. 
Spronk, H.M.H., Soute, B.A.M., Proudfoot, D., Shananan, C.M., De Mey, J.G.R., Vermeer, C. Arterial calcification is inhibited by matrix Gla protein, a vitamin K-dependent protein produced by smooth muscle cells. NVTH Symposium (2002).

Spronk, H.M.H., Soute, B.A.M., Schurgers, L.J., De Mey, I.G.R., Vermeer, C. Menaquinone-4 inhibits warfarin induced vascular media calcification. FASEB Summer Research Conference (2001).

Spronk, H.M.H., Braam, L.A.J.L.M., Gijsbers, B.L.M.G., vermeer, C. Improved immuno assay for matrix Gla protein in human serum and plasma. FASEB Summer Research Conference (2001).

Proudfoot, D., Spronk, H.M.H., Vermeer, C., Shanahan, C.M., Weissberg, P.L. Regulation of calcification by matrix Gla protein. FASEB Summer Research Conference (2001).

Dhore, C., Cleutjens, J., Kitslaar, P., Spronk, H.M.H., Vermeer, C., Daemen, M. Differential expression of bone matrix regullatory proteins in human atherosclerotic plaques. Iournal of Submicroscopic Cytology and Pathology (2000) 32; 442.

Dhore, C., Cleutjens, I., Kislaar, P., Spronk, H.M.H., Vermeer, C. Daemen, M.Enhanced Expression of Proteins Involved in Bone Formation in Advanced Human Atherosclerotic Plaques. First Conference on Arteriosclerosis, Thrombosis, and Vascular Biology (2000).

Soute, B.A.M., Braam, L.A.J.L.M., Spronk, H.M.H., Vermeer C. Matrix Gla Protein as a marker for atherosclerosis. 11 th Europeam Fat-Soluble Vitamins Group Meeting (2000).

Braam, L.A.J.L.M., Dissel, P.E.P., Spronk, H.M.H., R. Houben, B.A.M. Soute, B.L.M.G. Gijsbers, M.J.A.P. Daemen, I.P.M. Cleutjens, C.R. Dhore, K. Hamulyák, C. Vermeer. Development And Evaluation of An Enzyme-Linked Immumo Sorbent Assay (Elisa) For Circulating Matrix Gla-Protein. Thromb. Hameostas. Suppl (1999).

Craciun, A., Spronk, H.M.H., Jebeleanu, G., Bolosiu, H.D., Miu, N., Vermeer, C. Apolipoprotein E Gene Polymorphisms in Romanian Individuals: Implications of Apo E Genotype in Vitamin $K$ and D Deficiencies. Thromb. Hameostas. Suppl (1999). 

"Sommige mensen wachten hun hele leven op applaus van de wereld en pas vlak voor hun dood komen ze tot de ontdekking dat ze voor een lege zaal hebben staan spelen"

Marek van der Jagt

Als ik iets heb geleerd in vier jaar aiouschap is het wel dat weten-

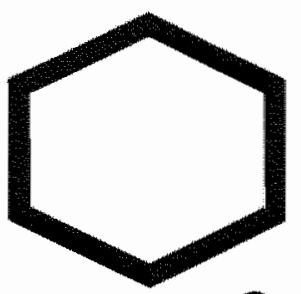
schap geen soloschap is. Op dit dankwoord na zijn alle teksten in dit boekje (en de onderliggende experimenten) tot stand gekomen dankzij de steun en hulp van een groot aantal personen. Daarom mijn applaus voor iedereen die, op welke manier dan ook, een bijdrage heeft geleverd aan dit proefschrift:

Promotie Team:

Jo De Mey

Kees Vermeer

Henk Thijssen

De patholoogjes:

Birgit Faber

Cherida Dhoré

Jack Cleutjens

Wendy Boon

Aniek Janssen - Vrehen

Petra Aarts
De Beoordelingscommissie:

Jos Smits

Math Daemen

Frans Ramaekers

Hugo ten Cate

Jan Rosing

Praktische ondersteuning:

Berry Soute

Leon Schürgers

Kirsten Teunissen

Marjo Knapen

Birgit Gijsbers

Paul Dissel

Roger Houben

Kitty Linssen

Namens de proefdieren:

Peter Leenders

lacques Debets

Nicole Bitch

Agneska Brouns

Harry Zeegers

Monique Passage

Olaf van Heur

John Mullins 
MCB:

Guillaume van Eys

Victor Thijssen

Sander Rensen

Wiel DeBie

Jos Broers

De Vrijdagavond club

Jessica

of gewoon iedereen die het verdient
Cambridge (UK):

Peter Weissberg

Cathy Shanahan

Diane Proudfoot
Paranimfen:

Lavienja Braam

Tanja Spronk

Pap en Mam 
1. Akiba, T. Kurihara, S., Tachibara, K., Kuwahara, M., Sakamoto, H., Yoneshima, H. and Marumo, F. Vitamin $K(K)$ increased bone mass (BM) in themodialysis patients (Pis) with low turnover bone disease (LTOBD). I Am Soc Mephrol (1991) 2: 608.

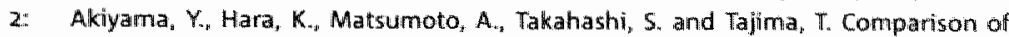
intestinal absorption of vitamin $\mathrm{K} 2$ (menaquinone) homologues and their effects. on blood coagulation in rats. with hypoprothrombinaemia. Biochem pharphacol (1995) 49: 1801-1807.

3: Anderson, H.C. Molecular biology of matrix vesicles. Clin Orthop (1995) 265-280.

4: Barone, L.M., Owen, T.A., Tassinari, M.S. Bortell, R., Stein Developmental expression and hormonal regulation of the rat matrix Gla protein (MGP) gene in chondrogenesis and osteogenesis. J Cell Biochem (1991) 46: 351-365.

5: Baudet, C., Perret, E., Delpech, B., Kaghad, M., Brachet, P., Wion, D. and Caput, D. Differentially expressed genes in 6.9 glioma cells during vitamin D-induced cell death program. Cell Death Differ (1998) 5: 116-125.

6: Begley, G.S. Furie, B.C., Czerwiec, E., Taylor K.L., Furie, G.L., Bronstein, L., Stenflo, ,. and Furie, B. A Conserved Motif within the Vitamin K-dependent Carboxylase Gene Is Widely Distributed across Animal Phyla. I Biol Chem (2000) 275: 36245-36249.

7: Benton, M.E., Price, P.A. and Suttie, I.W. Multi-site-specificity of the vitamin Kdependent carboxylase: in witro carboxylation of des-gamma-carboxylated bone Gla protein and Des-gamma-carboxylated pro bone Gla protein. Biochemistry (1995) 34: $9541-9551$.

8: Benzakour, 0 . and Kanthou, $C$. The anticoagutant factor, protein 5 , is produced by cultured thuman wascular smooth muscle cells and its expression is up-regulated by thrombini. Blood (2000) 95: 2008-2014.

9: Berkner, K.L. and Pudota, B.N. Vitamin K-dependent carboxylation of the carboxylase. Proc Nall Acad Sci USA (1998) 95: 466-471.

10: Blacher, I., Guerin, A.P., Pannier, B., Marchais, S.J. and London, G.M. Arterial calcifications, arterial stiffness, and cardiowascular risk in end-stage renail disease. Hypertension (2001) 38: 938-942.

11: Bolton-5mith, C., Price, R.l., Fenton, S.T., Harrington, D.J. and Shearer, M.J. Compilation of a provisional UK database for the phylloquinone (vitamin Ka) content of foods. Br I Mutr (2000) 83: 389-399.

12: Boneh, A. and Bar-ZiW, J. Hereditary deficiency of witamin Kidependent coagulation factors with skeletal abnormalities. Am / Med Genet (1996) 65: 241-243.

13:" Booth, S.L., Sadowski, J.A., Weihrauch, J.L. and Ferland, G. Vitamin K1 (phylloquino mel content of foods: a provisional table. I Food Comp Anol (1993) 6: 109-120.

14: Bostrom, K., Tsao, D., Shen, S, Wang, Y. and Demer, LL. Matri GLA proteir modulates differentiation induced by bone morphogenetic protein-2 in $\mathrm{C} 3 \mathrm{H} 10 \mathrm{Tl} / 2 \mathrm{z}$ cells. I Biol Chem [2001| 276: 14044-14052.

15: Bostrom, $K_{2}$, Watson, K.E., Horm, $S_{a_{v}}$ Wortham, C. Herman. I.M. and Demer, L.L. Bone morphogenetic protein expression in human atherosclerotic lasions. Clin Invest (1993) 91: 1800-1809.

16: Bostrom, K.1. Cell differentiation in vascular calcification. Z Kardiof (2000) B9:69-74.

17: Braam, L.A., Dissel, P. Gijsbers, B.L., Spronk, H.M., Hamulyak, K., Soute, B.A., Debie, W. and Vermeer, C. Assay for Human Matrix Gla Protein in Serum : Potential Applications in the Cardiovascular Field. Arterioscler Thromb Wasc Biol (2000) 20: $1257 \times 2261$.

18: Brenner. B. Hereditary deficiency of vitamin K-dependent coagulation factors. Thromb Hoemost (2000) 84: $935-936$.

19: Brenner, B., Sanchez.Vega, B., Wu, S.M., Lanir, N., Stafford, D.W. and Solera, J. A mis sense imutation in gamma-glutamyl carboxylase gene causes combined deficiency of all witamin K-dependent bilood coagulation factors. Blood (1998) 92: 4554-4559.

20: Brenner, B., Tavori, S, Zivelin, A., Keller, C.B. Suttie, I.W., Tatarsky, I. and Sellgsohm, U. Hereditary deficiency of all vitamin k-dependent procoagularits and anticoagu-lants. Br J Haematol (1990) 75: $537-542$.

21: Brieht, M.M. and Miesfeld, R.L. Isolation and characterization of transcripts Induced by androgen withdrawal and apoptotic cell death in the rat ventral prostate. Mol 
Endocrinol $(1991)$ 5: 1381-1388.

22: Brighton, C.T Lorich, DG., Kupcha, R., Retlly, J.M., Jones, A.R. and Woodbury, R.A., and The pericyte as a possible osteoblast progeritor cell Clin Orthop (1992) 287-299.

23: Bristot, H.A., Furie, B.C. and Furie, B. Propeptide processing during factor BX biosynthesis. Effect of point millations adjacent to the propeptide cleavage site. 1 Brol Chem (1993) 268: $7577-7584$

24: Bristal, A.A., Ratcliffe, IN. Roth, O.A., Jacobs, M.A. Furie, B.C. and Furie, B. Biosynthesis of prothrombin: intracellutar localization of the witamin K-dependent carboxylase and the sites of gamma-carboxylation. Blood (1996) 88: 2585-2593.

25: Buchthal, S.D. and Bell, R. G. Vitamin K dependent carboxylation of glutamate residues to gamma-carboxyglutamate in microsomes from spleen and testes: comparison withi liwer. Lung. and kidney. Biochemistry (1983) 22: $1077 \times 1082$.

26: Buitemthuis, H.C., South B.A. and vermeer, C. Comparison of the vitamins $K_{1}, K_{2}$ and $K_{3}$ as cofactors for the hepatic vitamin K-dependent carboxylase. Biochim Biophys Acta (1990) 1034: $170-175$.

27: Cancela, $L$, Hsieh, C.L, Francke, U and Price, P.A. Molecular structure, chromosome assignment, and promoter organization of the human matrix Gla protein gene. I Eiol Chem (1990) 265: 15040-15048.

28: Cancela. ML, HU, B. and Price, P.A. Effect of cell density and growth factors on matrix GLA protein expression by normat rat kidney cells. / Cell Physiol (1997) 171: 125-134.

29: Cancela, M.L., Ohresser, M.C., Relia, J.P., Viegas, C.S., Williamson, M.K. and Price, P.A. Matrix Gla protein in Xenopus laewis: molecular cloning, tisswe distribution, and evolutionary considerations. I Bone Miner Res (2001) 16: 1611-16:21.

30: Cancela, M.L. and Price, P.A. Retinoic acid induces matrix Gla protein gene expression in thumar cells. Endocrinology (1992) 130: 102-108.

3i: Cancela, M.L., Williamson, M.K. and Price, P.A. Amino-acid sequence of bone Gla protein from the African clawed toad Xenopus laevis and the fish Sparus aurata. Int $J$ Pept Protein Fes $(1995)$ 46: 419-423.

32. Chen, L., IP, O.8., Smith, H.S. and Liu, E. Overexpression of matrix Gla protein mRNA in malignant human breast cells: solation by differential CDNA hybridization. Oncogene (1990) 5 : 1391-1395.

33: Chem, Y.H., Yang, JiT. and Chau, K.H. Determination of the helix and beta form of proteins in aqueous solution by circular dichroism. Biochemistry (1974) 13: 3350-3359.

34: Cheng, G.C., Loree, H.M., Kamm. R.D., Fishbein, M.C. and Lee, R.T. Distribution of circumferential stress in ruptured and stable atherosclerotic lesions. A structural analysis with histopathological correlation. Circulotion (1993) 87: 1179-1187.

35: Cheung, A, Engelke, J.A., Sanders, C. and Suttie, J.W. Vitamin K-dependent carboxylase: influence of the "propeptide" region on enzyme activity. Arch Biochem Biophys (1989) 274: $5744-581$.

36: Chowdhury, S.K., Katta, V. and Chait, B.T. Probing conformationat changes in proteins by mass spectrometry. I Am Chem Soc (1990) 112: 9012*9013*

37: Chung, K.S., Bezeaud, A., Goldsmith, J.C. McMillan, C.W., Menache, D. and Roberts, H.R. Congenitat deficiency of blood cllotting factors $1, V\left(H_{1}, \| X\right.$, and $X, B l o o d(1979)$ 53: 776-787.

38: Concoff, A.L. and Kalunian, K.C. What is the relation between crystals and osteoarthritis? Curr Opin Rheumatol (1999) 11: 436-440.

39. Dahiback, 18. Blood coagulation. Lancet (2000) 355: 1627-1632.

40: Dawies, M.J. and Thomas, A.C. Plaque fissuring- the cause of acute myocardiat infarction, sudden ischaemic death, and crescendo anginia. Br Heart /(1985) 53: 363-373.

4.1: Dawson, P.E., Muir, T.W., Clark-Lewis, I. and Kent, S.B. Synthesis of proteins by matiwe chemical ligation. Science (1994) 266: $776 \% 779$.

42: de Boer van den Berg, M.A., Uitendaal "M.P. and Vermeer ${ }^{\text {C. }}$. Direct measurement of vitamin k-dependent enzymes in various isolated and cultured tumor and non cells. Mol Cell Biochem (1987) 75: 71-76.

43. de Boer wan den Berg, M.A., Verstijnen, C.P. and Vermeer, C. Witamin K-dependent carboxylase in skin. I thwest Dermatol (1986) 87: 377-380.

44: de Boer-wan den Berg, M.A., Ulich, M.M. Hemker, H.C., Soute, B.A. and Vermeer, C. Vitamin K-dependent carboxyllase: the carboxylation of exogenous substrates in different 
systems. Biochim Biophys Acta (1985) 831: 94-98.

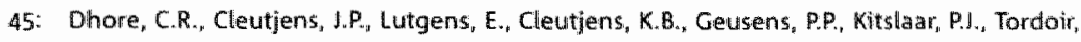
1.H. Spronk, H.M., Vermeer, C. and Daemen, M.J. Differential expression of bone matrix regulatory proteins in human atherosclerotic plaques. Arterioscler Thromb Vasc Brol (2001) 21: 1998-2003.

46: Doherty, T.M. and Detrano, R.C. Coronary arterial calcification as an active process: a new perspective on an old problem. Colcif Tissue int (1994) 54: 224-230.

47: Dowd, P, Hershtine, R., Ham, S.W. and Naganathan, S. Vitamin $K$ and energy transduction: a base strength amplification mechanism. Science (1995) 269: 1684-1691.

48: Edmonds, M.E., Marrison. N., Law5, J.W. and Watkins, P.1. Medial arterial callification and diabetic neuropathy. Br Med I (Clin Res Ed) (1982) 284: 928-930.

49: Engelke, J.A., Hale, I.E., Suttie, I.W. and Price, P.A. Vitamin K-dependent carboxylase: Litilization of decarboxylated bone Gla protein and matrix Gla protein as substrates. Biochim Biophys Acta (1991) 1078: 31-34.

50: Esmon, C.T. Stenflo, J. and Suttie, J.W. A new vitamin K-dependent protein. A phospholipidabinding zymogen of a serine esterase. / Biol Chem (1976) 251: 3052 3056.

51: Everhart, I.E., Pettitt, D.), Knowler, W.C., Rose, F.A. and Bennett, P.H. Medial arterial calcification and its association with mortality and complications of diabetes. Diabetologio (1988) 31: 16-23.

52: Fair, D.S., Marlar, R.A. and Levin, E.G. Human endothelial cells synthesize protein 5 . Blood (1986) 67: 1168-171.

53: Falk, E. Coronary thrombosis: pathogenesis and climical manifestations. Am / Cardiol (1991) 68: 28B-35B.

54: Farb, A., Burke, A.P., Tang, A.L. "Liang, T.Y, Manman, P., 5 mialek, I. and Wirmani, R. Caronary plaque erosion without rupture into a lipid core. A frequent cause of coronary thrombosis in sudden coronary death. Circulation (1996) 93: 1354-1353.

55: Farzaneh-Far, A., Davie5, J.D., Braam, L.A., Spronk, H.M., Proudfoot, D., Chan, 5.W., O'Shaughnessy, K.M., Weissberg, P.L., Vermeer, C. and Shanahan, C.M. A polymorphism of the human matrix gamma-carboxyglutamic acid protein promoter alters binding of an activating protein-1 complex and is associated with altered transcription and serum levels. I Biol Chem (2001) 276:32466-32473.

56: Farzaneh-Far, A., Proudfoot, D., Weissberg, P. L, and Shanahan, C.M. Matrix Gla Protein is Regulated by a Mechanism Functionally Related to the Calcium-Sensing Receptor. Biochem Biophys Res Commun (2000) 277: 736-740.

57: Farzaneh-Far, A., Weissberg, P.L., Proudfoot, D. and Shanahan, C.M. Transcriptional regulation of matrix gla protein. 2 Kardiol (2001) 90 Suppl 3: 38:42.

58: Fatsco, M.1, Hildebrandt, E.F. and Suttie, J.W. Evidience that warfarin anticoagulant action involves two distinct reductase activities. I Biol Chem (1982) 257: 11210-11212.

59: Fasco, M.J. and Principe, L.M. R- and S-Warfarin intibition of vitamin $K$ and vitamin $K 2,3$ epoxide reductase activities in the rat. $/$ Brol Chem (1982) 257: 4894-4901.

60: Fraser J.D., Otawara, Y. and Pirice, P.A. 1,25 Ditydroxyvitamin D3 stimulates the synthesis of matrix gammia-carboxyglutamic acid protein by osteosarcoma cells. Mutually exclusive expression of vitamin K-dependent bone proteins by clonal osteoblastic cell ilines. $J$ Biol Chem (1988) 263: 911-916.

61: Fraser, 1.D. and Price, P.A. Lung, heart, and kidney express high levels of mRNA for the witamin K-dependent matrix Cla protein. Implications for the possible functions of matrix Gla protein and for the tissue distribution of the gamma-carboxylase. I Biol Chem (1988) 263: 11033-11036.

62: Fraser, 1.D. and Price, P.A. Induction of matrix Gla protein synthesis during prolonged 1,25-dihydroxywitamin $0_{3}$ treatment of osteosarcoma cells. Colcif Tissue int (1990) 46 : 270-279.

63: Furie, B., Bouchard, B.A. and Furie, B.C. Witamin K-dependent biosynthesis of gammacarboxyglutamic acid. Blood (1999) 93: 1798-1808.

64: Furie, B. and Furie, B.C. Molecular basis of vitamin K-dependent gamma-carboxylation. Blood (1990) 75: 1753-1762,

65: Furie, B.C. Ratcliffe, II. ., Tward, I., Jorgensen, M.I., Blalszkowsky, L.S., DiMichele, D. and Furne, B. The gamma-carboxylation recognition site is sufficient to direct vitamin K- 
dependent carboxylation on an adjacent gtutamaterich region of thrombin in a propeptide-thrombin chimera. A Biol Chem (2997) 272: 28258-28.262.

66: Fuster, $V_{\text {, }}$ Badimon, $L$, Badimon, 1 . and Chesebro, J.H. The pathogenesis off coronary artery disease and the acute coronary syndromes (1). N Engl Hed (1992) 326: 242-250

67: Gelejinse, J.M., Vermeer, $C_{n,}$ Shurgers, L.V., Grobbee, D.E, Pols, H.A.P. and Witteman, I.C.M. Inwerse association of dietary vitamin $k-2$ intake with cardiac events and aortic atherasclerosis: the rotterdaim study. Thromb Hoemost (2001) Abstracts of XVIIIth ISTH Congress: 473 .

68: Giachelli, C.M., Bae, N, Almeida, M Denthardit, D.T, Alpers, C.E and $5 \mathrm{chw}$, Dartz, S.M. Osteopontin is elevated during neointima formation in rat arteries and is a novel component of human atherosclerotic plaques. / Clin Invest (1993) 92: 1686-1696.

69: Gijsbers, B.L., Jie, K.S. and Vermeer, C. Effect of food composition on vitamin K absorption in human volunteers. Br J Nutr (1996) 76: 223-229.

70: Gitelman, H.J. An improved automated procedure for the determination of calcium in biological specimens. Anat Biochem (1967) 18:521-531.

71: Coldsmith, G.MH, Ir.. Pence, R.E., Ratnoff, O.D. Adelstein, D.I. and Furie, B. Studies on a family with combined finctional defictencies of vitamin $K$ - dependent coagulation factors. / Cin Invest (1982) 69: 1.253-1260.

72: Goruppi, 5., Ruaro, E. and Schneider, C. Gas6, the ligand of Axl tyrosine kinase receptor. has mitogenic and survival activities for serum starved $\mathrm{NH}_{3} \mathrm{~T} 3$ fibroblasts. Oncogene (1996) 12: 471-480.

73: Groenen-van Dooren, M.M., Soute, B.A., lie, K.S., Thijssen, H.H. and Vermeer, C. The relative effects of phylloquinone and menaquinone-4 on the blood coagulation fiactor symthesis in witamin K-deficient rats. Biochem Pharmacol (1993) 46: 433-437.

74: Cundberg, C.M." Hauschka, P.W. Lian, I.B. and Gallop, P.M. Osteocalcin: isolation, characterization, and detection. Methods Enzymol (1984) 107: 516-544.

75: Hackeng, T.M., Griffin, J.H. and Dawson, P.E. Protein synthesis by native chemical ligation: expanded scope by using straightforwand methodology. Proc Narl Acod SG USA (1999) 96: $10068-10073$

76: Hackeng, T.M., Rosing, I., Spronk, H.M. and Vermeer, C. Total chemical synthesis of human matrix Gla protein. Protein Sci (2001) 10: 864:870.

77: Hale, J.E. Fraser, J.D. and Price, P.A. The identification of matrix Gila protein in cartilage. Biol Chem (1988) 263: 582015824 .

78: Hale, J.E, Williamson, M.K. and Price, P.A. Carboxyl-terminall proteolytic processing of matrix Gla protein. J Biol Chem (1991) 266: 21145-21149.

79: Hamaguchi, N., Roberts, H. and Stafford, D.W. Mutations in the catalytic domain of factor IX that are related to the subclass hemophilia Bm. Biochemistry (1993) 32: 6324-6329.

Bo: Handford, P.A., Winstip, P.R. and Brownlee, G.G. Protein engineering of the propeptide of human factor IX. Protein Eng (1991) 4: 319-323.

81: Harg, $K_{2}$ Akiyama, "Y, Nakamura, T. Murota, S. and Morita, 1. The inthibitory effect of vita min $\mathrm{K}_{2}$ (menatetrenone) on bone resorption may be related to its side chain. Bone (1995) 16: $179-184$

82: Haroon, Y., Bacon, D.S. and Sadowski, I.A. Chemical reduction system for the detection of phylloquinome (vitamin $\mathrm{K}_{1}$ ) and meniaquinones (vitamin K2). I Chromatogr (1987) 384: $383-389$.

83: Hashimoto, S., Ochs, R.L., Rosen, F, Quach, J., McCabe, Gi, Solan, J., Seegmiller, J.E. Terkeltaub, R. and Lotz, M. Chondrocyte-derived apoptotic bodies and calcification of articular cartilage. Proc Notl Acad Sci USA (1998) 95: 3094-3099.

84: Hauschia, P.V. and Carr, 5.A. Calciumodependent alphawhelical structure in osteocalcin. Biochemistry (1982) 21: 2538-2547.

85: Hermann, S.M., Whathing, C., Brand, E., Nicaud, V., Gariepy. 1., Simon, A., Evans, A., Rudidavets, I.B. Arveller, D. LuC, G. Tiret, L., Henney, A. and Cambien F, Polymorphisms of the Human Matrix Gla Protein (MGP) Gene, Vascular Calcification, and Myocardial Infarction. Arterioseler Thromb Vasc Biol (2000) 20: $2386-2393$.

86. Hogg. P.l. and Stenflo, J. Interaction of vitamin K-dependent protein $Z$ with thrombin. Consequences for the amidolytic activity of thrombin and the interaction of thrombin with phospholipid wesicles. 1 Biol Chem (1991) 266: $10953-10958$. 
87. Hoshi, Ko Nomura, K., Samo, $Y$, and Koshihara, $Y$. Nuctear vitamin $K 2$ binding protein in human osteoblasts: homologue to glyceraldehyde-3phosphate dehydrogenase. Brochem Pharmacol (1999) 58: 1631-1638.

88: Houben, R.I., Jin, D., Stafford, D.W., Proost, P., Ebberink, R.H., Vermeer C. and Soute, B.A. Osteocalcin binds tightly to the gammatglutamylcaboxylase at a site distinct from that of the other known vitamin Krdependent proteins. Borthem / (1999) 341: 265-259.

89: Howben, R.J., Rijkers, D.T., Stanley, T.B., Acher, F., Azerad, R., Kakonen, 5 M., Vermeer, C. and Soute, B.A. Characteristics and composition of the vitamin K-dependent gammaglutamyl carboxylase-binding domain on osteocalcin. Biochem / (2002) 364:323-328.

90: Howben, R.I., Soute, B.A. and Vermeer, C. Assay of vitamin Kodependent carboxylase activity in hepatic and extrahepatic tissues. Methods Enzymol (1997) 282: 358 368.

91: Huang, H., Virmani, R., Younis, H.* Burke, A.P., Kamm, R.D. and Lee, R.T. The impact of calcification on the biomechancal stabitity of atherosclerotic plaques. Circulation (2001) 103: 1051 1056.

92: Huber, P., Schmitz, T., Griffin, I., Jacobs, M., Walsh, C, Furie, B. and Furie, B.C. Identification of amino acids in the gamma-carboxylation recognition ste on the propeptide of prothrombin. Biol Chem (1990) 265: 12467-12473.

93: Ikeda, T., Yamaguchi, A., Icho, T., Tsuchida, N. and Yoshiki, S. cDNA and deduced amino acid sequence of mouse matrix gla protein: one of five glutamic acid residues potentially modified to gla is not conserved in the mouse sequence. I Bone Mirier Res (1991) 6:1013-1017.

94: Jie, K.S., Bots, M.L., Vermeer, C., Witteman, J.C and Grobbee, D.E Vitamin K intake and osteocalcin levels in women with and without aortic atherosclerosis: a population-based study. Atherosclerosis (1995) 116: 117.123.

95: Jahnson, C.A., Chung, K.S., McGrath, K.M., Bean, P.E. and Roberts, H.R. Characterization of a variant prothrombin in a patient congenitally deficient in factors. 11 , WII $I X$ and $X$. Br I Hoematol (1980) 44: 461-469.

96: Jorgensen, M.1. Cantor, A.B., Furie, B.C., Brown, C.L., Shoemaker, C.B. and Furie, B. Recognition site directing vitamin K-dependent gamma-carboxylation resides on the propeptide of factor $\mid X$. Cell (1987) 48: 185,191.

97: Kameda, T., Miyazawa, K., Mori, Y., Yuasa, T, Shiokawa, M., Nakamaru, Y., Mano, H., Hakeda, Y., Kameda, A. and Kumegawa, M. Vitamin Ka inhibits osteoclastic bone resorp tion by inducing osteaclast apoptosis. Blochem Blophys Res Commun (1996) 220: 515-519.

98: Katsudia, 5. Okada, Y., Minamoto, T., Oda, Y., Matsui, Y. and Nakanishi, I. Collagens in human atheroscterosis. Immunohistochemical analysis using collagen type-specific antibodies. Arterioscler Thromb [1992) 1.2: 494-502.

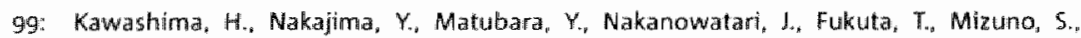
Takahashi, S., Tajima, T and Nakamura, T. Effects of vitamin $K_{2}$ (rrenatetrenone) on atherositerosis and blood coagulation in hypercholesterolemic rabbits. Jpm / Pharmocol (1997) 75: 135-1.43.

100: Kiefer, M.C., Bauter, D.M., Young, D. Hermsen, K.M., Masiarz, F.R. and Batro P., The CDNA and derived amino acid sequences for human and bovine matrix Gla protein. Nucleic Acids Res (1988) 16: 5213 .

101: Kim, K.M. Calcification of matrix wesicles in human arortic valve and aortic media. Fed Proc (1976) 35: 156-162.

102: Kim, K.M. Apoptosis and calcification. Scanning Microsc (1995) 9: 11.37.1175.

103: Kindberg, C.G. and Suttie, I.W. Effect of various intakes of phylloquinome on signs of vitamin $K$ deficiency and seruin and Hizer phylloquimane concentrations in the rat. I Nutr (1989) 119: 175-180.

104: Kirfel, 1. Kelter, M. Cancela. L.M., Price, P.A. and Schule, R. Identification of a novel negative retinoic acid responsive element in the promoter of the human matrix ola protein gene. Proc Natl Acod 5Ci USA (1997) 94: 2227)-2232.

105: Knobloch, I.E. and Suttie, IW. Vitamin Kudependent carboxylase. Control of enzyme activity by the "propeptide" region of factor $X$ I Bjol Chem (1987) 262: 15334-15337.

106: Kockx, M.M., De Meyer, G.R., Muhning, I., Jacob, W., Bult, H. and Herman, A. G. Apoptosis and related proteins in differenti stages of human atherosclerotic plaques. Circulation (1998) $97: 2307-2315$. 
107: Kohlmeter, M. Salomon, M., Sauphe, J. and Shearer, M.J. Transport of vitamin K to bone in humans. Nutr (1996) 126: 11925-1196s.

108: Kullopulas, A, Nelson, M.P., Yamada, M., Walsh, C.T, Furie, B. Furie, B.C. and Roth, D.A. Localization of the affinity peptide-substrate inactivator site on recombinant vitamin $K-$ dependent carboxylase. I Biol Chem (1994\$269: 21364-21370.

109: Kulman, 1.D. Harris, J.E., Haldernan, 8.A. and Davie, E.W. Primary structure and tissue distribution of two novel proline-fich gamma-carboxyglutamic acid proteins. Proc Notl Acad SCI US,A (1997) 94: 9058-9062.

110. Kulman, J.D. Harris, I.E. Xie, 1. and Dawie, E.W. Identification of two novel transmembriane gammararboxyglutamic acid proteins expressed broadly in fetal and adult tíssues. Proc Nall Acad Sci USA (2001) 98: 370-1375.

111: Kurkel, T.A. Rapid and efficient sitte-specific mutagenesis without phenotypic selection. Proc Natl ACad Scĩ USA (1985) 82: 488-492.

112: Kuo, W.L., Stafford, D.W., Gruces, 1., Gray, J. and Solera, 1. Chromosomal localization of the gamma"glutamyl carboxylase gene at 2p12. Genomics (1995) 25: 746-748.

113: Laemmli, U.K. Cleavage of structural proteins during the assembly of the head of bacteriophage T4. Nature (1970) $227: 680-685$.

114. Lamon-Fava, 5., Sadowski, I.A. Davidison, K.W., O'Brien, M.E, McNamara, J.R. and Schater, Es. Plasma lipoproteins as carriers of phylloquinone (vitamin K1) in humans. Am f Clin Nutr (1998) 67: 12261-1231.

115: Larson, A,E. Friedman, P.A. and Suttie, I.W. Witamin K-dependent carboxylase. Stoichiometry of carboxylation and witamin K 2,3-epoxide formation. J Biol Chem (1981) 256: 11032-11035.

116: Lee, R.T. The lower incisor bonded retainer in clinicall practice: a three year study. Br I Orthod [1981]8: 15, 18 .

11\%: Lee, R.T., Grodzinsky, A.I, Frank, E.H., Kainm, R.D. and Schoen, FJ. Structure-dependent dynamic mechanical behavor of fibrous caps from human atherosclerotic plaques. Circulation (1991) 83:1764-17770.

118: Lehto, Sn, Niskanen, L., Suhonen, M., Ronnemaa, T. and Laakso, M. Medial artery calcification. A neglected harbinger of cardiovascular complications in nominsulin-dependent diabetes mellitus. Arterioscler Thromb Vasc Biol (1996) 16: 978-983.

119: Levy, R. 1. , Gundberg. C. and Scheinman, R. The identification of the vitamin K-dependent bone protein osteocalcin as one of the gamma-carboxyglutamic acid containing proteins present in calcified atherosclerotic plaque and mineralized heart valwes. Atherosclerosis (1983) 46: 49-56.

120: Li, T. Yang, C.T., Jin, D, and Stafford, D.W. Identification of a Drosophila vitamin $K$ dependent gamma-glutamyl carboxylase. I Biol Chem (2000) 275: 18291-18296.

121: Lin, PJ, لlin, D.Y, Tie, I.K., Presnetl, S.R., Straight, D.L. and Stafford, D.W. The Putative Vitamin K-dependent garnma Cllutamyl Carboxylasie Internal Fropeptide Appears to Be the Propeptide Binding Sitte. Btol Chem (2002) 277: 28584-28591.

122: Loeser, R., Carlsom, C.S., Tulli, H., Verome, W.G., Mille, L. and Wallin, R. Articular-cartilage matrix gamma-carboxyglutamic acid-containing protein. Characterization and immunoLocalization. Elochem / (1992) 282:1.6.

123: Luo, G., Ducy, P. Mckee, M.D., Pinero, G.J., Loyer, E., Behringer, R.R. and Karsenty, G. Spontaneous calcification of arteries and cartilage in mice lacking matrix GLA protelin. Nature (1997) 385: 78-81.

124: Lua, G. Souza, R., Hogue, D. and Karsenty, G. The matrix Gla protein gene is a marker of the chondrogenesis cell lineage dung mouse dewelopment. / Bone Miner Res (1995) 10: $325-334$.

125. Madhavan, S., Oof, W.L., Cohen, H. and Alderman, M.H. Relation of pulse pressure and blood pressure reduction to the incidence of myocardial infarction. Hypertension (1994) 23: 395-401.

126: Mahley, R.W., Hui, D.Y, Innerarity, TL. and Beisiegel, U. Chylomicron remnant metabolism. Role of hepatic lipoprotein receptors in mediating uptake. Arteriosclerosis (1989) 9: 114118.

127: Maillet, M. Morris, D. Gaudry, M. and Marquet, A. The active site region of the vitamin Kependent carboxylase includes both the amino-terminal hydrophobic and carboxy 
terminal hydrophilic domains of the protein. FEBS Lett (1997) 413: 1-6.

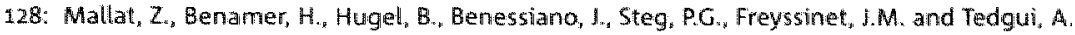
Elevated levels of shed membrane microparticles with procoagulant potential in the peripheral circulating blood of patients with acute coronary symdromes. Circulation(2000) 101: 841-843.

129: Mallat, 2., Hugel, B., Ohan, J., Leseche, G. Freyssinet, I. and Tedgui, A. Shed membrane microparticles with procoaigulant potential in human atherosclerotic plaques: a role for apoptosis in plaque thrombogenicity. Girculotion (1999) 99: 348-353.

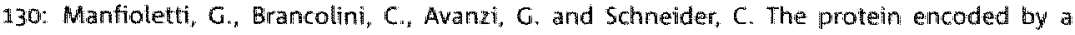
growth arrest-specific gene (gas6) is a new member of the vitamin Kependent proteins. related to protein 5 , a negative coregultator in the blood coagulation cascade. Mol Cell Biol (1993) 13: 4976-4985.

131. Matschiner, 1.T. and Taggart, W. Bioassay of witamin $K$ by intracardial injection in deficient adult male rats. I Nutr (1968) 94: 57-59.

132" McCue, J.M., Gordy, P.W., Cantlon, J.D. Baker, D.C. and Bowem, R.A. The Sequence of the Owine Gamma-Carboxylase CDNA. Genbank, Accession number: AAG30935. (2000)

133: McMillan, C.W. and Roberts, H.R. Congenital combined deficiency of coaguilation factors II, VII, IX and X. Report of a case. N Engl/ Med (1966) 274: 1313-1315.

134: Meier, M., Weng. L.P., Alexandrakis, E., Ruschoff, 1. and Goeckenjan, G. Tracheobronchial stenosis in Keutel syndrome. Eur Respoir J (2001) 17: 566-569.

135: Melaragno, M.G., Fridell, Y.W. and Berk, B.C. The Gas6/Axl system: a novel regulator of wascular cell. function. Trends Cordiowase Med (1999) 9: 250-253.

136: Miyazawa, K., Yaguchi, M., Funato, K., Gotoh, A., Kawanishi, Y., Nishizawa, Y., Yuo, A. and Ohyashiki, $K$. Apoptosis/differentiation-inducing effects of vitamin $K 2$ on HL-60 cells: dichotomous nature of vitamin $K z$ in leukemia cells. Leukemía (2001) 15: 1111-1117.

137: Morris. D.P. Soute, B.A., Vermeer, C. and Staffiond, D.W. Characterization of the purified vitamin K-dependent gamma-glutamyl carboxylase. I Biol Chem (1993) 268: 8735-8742.

138: Mousallem, M., Spronk, H.M., Sacy, R., Hakime, N. and Soute, B.A. Congenital cambined deficiencies of all witamin K-dependent coagulation factors, Thromb Haemost (2001) 86: 1236-1238.

139: Munroe, P.B. Olgunturk, R.O., Fryns, I.P., Van Maldergem, L., Ziereisen, F., Yuksel, B., Gardiner. R.M. and Chung, E. Mutations in the gene encoding the human matrix Gla protein cause Keutel syndrome. Not Genet (1999) 21: 142-144.

140: Mutucumarana, V.P., Stafford, D.W., Stanley, T.B., Jin, D.Y, Solera, 1., Brenner, B., Azerad, R. and Wu, S.M. Expression and characterization of the naturally occurring mutation L.394R in human gamma -glutamyl carboxylase. \& Biol Chem (2000) 275: 32572-32577.

1.41: Nakano, $T_{\text {, }}$ Kawamoto, K., Kishmo, I., Nomura, K., Higashino, K. and Arita "H. Requirement of gamma-carboxyglutamic acid residues for the biological actiwity of Gasts: contribution of endogenous Gas6 to the proliferation of wascular smooth muscle cells. aliochems $(1997) 323: 387-392$

142: Nelsestuen, G.L. Role of gamma-carboxyglutamic acid. An unusual protein trangition required for the calcium dependent binding of prothrombin lto phospholipid. / Biol chem (1976) 251: $5648-5656$.

143: Nelsestuen, G.L, Shah, A.M. and Harvey, S.B. Vitamin K-dependent proteins, Vitam Horm $12000) 58: 355 * 389$.

144: Nelsestuen, G.L., Zytkovicz, T.H. and Howard, J.B. The mode of action of witamin K Identification of gamma-carboxyglutamic acid as a component of prothrombin. A Brol Chem (1974) 249: 6347-6350.

145: Newman, B., Gigout. L.I., Sudre, L, Grant, M.E. and Wallis, G.A. Coordinated expression of matrix Gla protein is required during endochondral ossification for chondrocyte survival. $J$ Cell Bial (2001) 154: 659-666.

146: Newman, P, Bonello, F., Wherzbicki, A.5., Lumb, P., Savidge, C.F. and shearer, M.J. The uptake of lipoprotein-borne phylloquinone (vitamin $K 1$ ) by osteoblasts and osteoblastlike cells: role of heparan sulfate proteoglycans and apolipoprotein E. I Bone Miner Res (2002) 17: 426-433.

147: Nishimaki, I., Miyazawa, K., Yaguchi, M., Katagiri, T., Kawanishi, Y., Toyarria, K., Otayastiki, K.. Hashimoto, 5., Nakaya, K. and Takiguchi, T. Vitamin Ka induces apoptosis of a novel 
cell tine estabished from a pattent with myelodysplastic syndrome in blastic transformation. Leukemio (1999) 13 : 399 -1405.

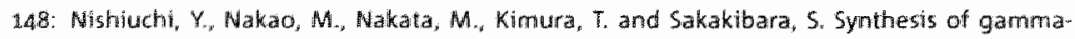
carboxyglutarric acid-containing peptides by the boc strategy in / Pept Protein pes (1993) $42: 533-538$.

49: Oldenburg, 1, von Braderlow, B. Fregin, A., Rost, S., Wolz. W. Eberl, W., Eber, \$., Lenz, E., Schwaab, Br, Brackmann, H.H. Effenberger, W., Harbrech, U., Schurgers, L., Vermeer, $C$. and Muller, KR. Congental teficiency of witamin K dependent coaqulation factors in two familes presents as a genetic defect of the vitamin K-epoxidereductasencomplex. Thromb Haemost (2000) 8.4: $937-941$.

150: Olson, I.A. Recommended dietary intakes (ROH) of witamin $K$ in humans. Am I Clin Nutr (1987) 45: 687-692.

152: Orimo, H., Shiraki, M., Tomita, A., Morii, H., Fujita, T. and Ohata, M. Effects of menatetrenone on the bone and calcium metabolism in asteoporosis: $A$ double-blind placebo contralled study. Bone Miner Metab (1998) 16: 106-112.

152: Otawara, $Y$ and Price, P.A. Dewelopmental appearance of matrix GLA protein during calcification in the rat. I Biol Chem (1986) 26:1: $10828-10832$.

153: Parfitt, A.M. Soft-issue calcification in uremia. Arch intern Med (1969) 124: 544-556.

15.4: Pauli, R.M. Lian, J,B. Mosher, D.F. and Suttie, J.W. Association of congenital deficiency of multiple vitamin K-dependent coagulation factors and the phenatype of the warfarin embryopathy: clues to the mechanism of teratogenicity of coumarin derivatives. Am I Hum Cenet (1987) 41: $566-583$.

155: Pachlaner, C, Vogel, W., Erhart, R., Pumpel, E. and Kunz, IF A new case of combined deficiency of vitamin $K$ dependent coagulation factors [letter]. Thromb Haemost (1992) $68: 617$.

156: Petersen, T.E., Thlgersen, H.C., Sottrup-lensen, L., Magnussion, 5. and Jornvall, H. Isolation and M-terminal amino acid sequence of protein $Z$, a gamma carboxyglutamic acid containing protein from bovine plasma. FEBS Lett (1980) 114: 278-282.

157: Pettifor, J.M. and Benson, R. Congenital matformations associated with the administration of oral anticoagulants during pregnancy. I Pediatr (1975) 86: 459-462.

158: Pietersma-de Bruyn, A.L., van der Straaten, P.J., van Haard, P.M., Kuijpers, I.C., Hamulyak, $K$. and Ruys, J.H. Vitamin $K_{1}$ levels and K1-dependent coagulation factors II and $\mathrm{X}$ in pre term and small-for-date neonates. Eur $J$ Pediotr (1990) 149: 64-644.

159: Pinto, 1.P., Ohresser, M.C. and Cancela, M.L. Cloning of the bone Gla protein gene from the teleost fish Sparws aurata. Evidence for overall conservation in gene organization and bone- specific expression from fish to man. Gene (2001) 270: 77-91.

160: Presnell, S.R., Tripathy, A.o Lentz, B.R., Jin, D.Y. and Stafford, D.W. A novel fluorescence assay to study propeptide interaction with gamma-glutamyl carboxylase. Biochemistry (2001) 40: 1172311733.

161: Price, P.A., Faus, 5.A. and Williamson, M.K. Warfarin causes rapid calcification of the elastic lamellae in rat arteries and heart valves. Arterioscler Thromb Vosc Biol (1998) 18: 14900-1407.

162: Price, P.A., Faus, S.A. and Wiltiamson. M.K. Warfarin-induced artery calcification is accelerated by growth and vitamin D. Arterioscler Thromb vase Biol (2000) 20: 317-327.

163: Price, P.A., Faus, S.A. and Williamson, M.K. Bisphosphonates allendronate and ibandronathe inhibit artery calcification at doses comparable to those that inhibit bone resorption. Arterioscter Thromb Vasc Biol (2001) 21: 817-824.

154: Price, P.A. Fraser, J.D, and Metz Virca, G. Molecular clloning of matrix Gla protein: implications for substrate recognition by the vitamin $K$-dependient gamma-carboxylase. Proc Nat Acad Sci USA (1987) 84:8335-8339.

165: Price, P.A., Rice, J.S. and Williamson, M.K. Conserved phosphorylation of serines in the Ser-X-Glu/Ser( $\boldsymbol{\rho})$ sequences of the vitamin K-dependent matrix Gla protein from shark, lamb, rat, cow, and human. Protein Sci (1994) 3: 822-830.

166: Price, P.A., Thomas, G.R., Pardini, A.W., Figueira, W.F., Caputo, J.M. and Williamson, M.K. Discovery of a high molecular weight complex of calcium, phosphate, fetuin, and matrix gamma-carboxyglutamic acid protein in the serum of etidronate-treated rats. 1 Biol chem (2002) 277: 3926-3934. 
167: Prite, PA., Urist, MR. and Otawara, Y. Matrix Gla protiein, a new gambrra-Gaboxy glutamic acid-containing protein which is associated with the organic matrix of bone ghochem Biophys Res Commun (1983) 117: 7654771.

168: Price, P.A. and Williamson, M.K. Primary structure of bowne matrix Gla protein, new vitamin Kependent bone protein. Hiol Chem (1985) 260: 14971-14975.

169: Price, P.A and Willamson, M.K. Subtrate recognition by the vitarnin Kdependent gamma-glutamyl carboxylase: identification of a sequence homology between the carboxylase and the carboxylase recognition site in the substrate. Protein Sci (1993) 2: $1987-1988$.

170: Price, P.A., Willitamson, M.K. Haba, T. Dell, R.B. and Jee, W.S. Excessive nineralization with growth plate closure in rats on chronic wartiarn treatment. Proc Noll Acod SCI USA (1982) 79: 7734-7738.

171: Proudfoot, D. Personal communication.

172: Proudfoot, D. Davies, J.D., Skepper, IM. Weissberg, P. L, and Shanaham, C.M. Acetyated low-density lipoprotein stimulates human vascular smooth muscle cell callefication by promoting osteoblastic differentiation and inhibiting phagocytosis. Circulation (2002) 106: $3044 \cdot 3050$.

173: Proudfoot, D. and Shanahan, C.M. Biology of calcification in vasculair ralls: intimat wersus media. Herz (2001) 26: 245-251.

174: Froudfoot, D., Shanahan, C.M. and Weissberg, P. L. Vascular calcification: new insights into an old problem leditorial; comment) Pathol (1998) 185: 1-3.

175: Proudfoot, D., 5kepper, J.N. Hegyi, L., Bennett, M.R., Shanahan, C.M. and Weissberg, P.L. Apoptosis regulates thuman vascular calcification in vitro : evidence, for initiation of vascular calcification by apoptotic bodies. Circ Res (2000) 87: 1055-1062.

176: Proudfoot, D., Skepper, IN., Shanahan, C.M. and Weiss.berg, P.L. Calcification of human vascular cells in vitro is correlated with high levels of matrix Gla protein and low levels of osteoportin expression. Arterioscter Thromb Vasc Biol (1998) 18: 379-388.

177: Pudota, B.N., Hommema, E.L., Hallgren, K.W. MCNally, B. A, hee, S. and Berkner, Kolw. Idientification of sequences within the gamma-carboxylase that represent a novel contact site with vitamin K-dependent proteins and that are required for activity. 1 Biol Chem (2001) 276: 45878-46886.

178: Pudota, B.N., Miyagi, M., Hallgren, K.W., West, K.A., Crabb, J.W., Misono, K.S. and Berkner, K.L. Identification of the vitamin K-dependent carboxylase active site: cys-99 and cys-450 are required for both epoxidation and carboxylation. ProC Natl ACad SCI USA (2000) 97 : $13033-13038$.

179: Raines, E.W., Lane, T.F., lruela-Arispe, M.L, Ross, R. and Sage, E.H. The extracellular glycoprotein SPARC interacts with platelet-dierived growth factor (PDCF) AB and $B B$ and inthibits the binding of PDCF to lits receptors. Proc Natl Acod SCi USA (1992) 89: 1281-1285.

480: Rannels, 5.R., Cancela, M.L., Wolpert, E.B. and Price, P.A. Matrix Gla protein minA expression in cuttured type li pneumocytes. Am / Physhol (1993) 265: 2770-278.

181: Reedstrom, C.K. and Suttie, I.W. Comparative distribution, metabolism, and utilization of phylloquinone and menaquinome-9 in rat tiver. Proc Soc Exp Biol Med (1995) 209: 403 anog.

182: Rehemtulla, A., Roth, D.A., Wasley, L.C., Kuliopuloz, A., Walsh, C.T, Furie, B., Furie, B.C and Kaufman, $\mathbb{R}$.J. In vitro and in vivo functional characterization of bovine vitamin $K-$ dependert gamma carboxylase expressed in Chinese hamster ovary cells. Proc Nad Acad Sci USA [1993) 90: $4611-4615$.

183: Rice, 1.S., Wiltianson, MK. and Price, P.A. Isolation and sequence of the vitamin Kdependent matrix cha protein from the calcified cartilage of the soupfin shark, Bone Miner Res (1994) 9: 567-5,76.

184: Richardson, P.D. Dawies, M.J. and Born, G.V. Influence of piaque configuration and stress distribution on fissuing of coronary atheroscieratic plaques. Lancet (1989) 2 : $941-944$.

185: Ritey, E.H., Lane, J.M. Urist, M.R., Lyons, K.M. and Lieberman, I.R. Bone morphogenetic protein-2: biology and applications. Chin Orthop $(1996) 39-46$.

186: Rodan, G.A. Mechanïsms of action of bisphosphonates. Annu Rew Phamacol Toxical $(1998) 38: 375-388$ 
187: Romero, E.E., Velazquez-Estades, L.h, Deo, R. Schapiro, B. and Roth, D.A. Cloning of r a: vitamin Kependent gamma glutamyl carboxylase and developmentally regulated gene expression in postimplantation emibryos. Exp Cell Res (1998) 243: 334-346.

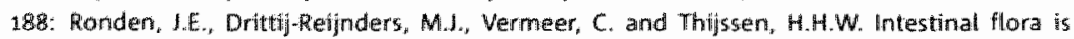
not an intermediate in the phylloqumone-menaquinone-4 conversion in the rat. Biochim Biophys Acta (1998) 1379: 69-75.

189: Ronden, I.E., Thijssen, H.H. and Vermeer, C. Tissue distribution of K-vitamers under different nutritional regimens in the rat. Biochim Biophys Acta (2998) 1379: 16-22.

190: Roy, M.E. and Nishimoto, S.K. Matrix Gla protein binding to hydroxyapatite is dependent on the fonic environment: calcium enhances binding affinity but phosphate and magnesium decrease affinity. Bone (2002) 31: 296-302.

191: Sambrook, 1., Frittsch, E.F. and Maniatiis, T. Molecular Cloning, A Laboratory Manual. (1989) Cold Spring Harbor Laboratory Press Cold Spring Harbor, N.Y.

192: Sartin, V.K. Kent, S.B., Tam, J.P. and Merrifield, R.B. Quantitative monitoring of solid-phase peptide synthesis by the ninhydrin reaction. Anol Brochem (1981) 117: 147-157.

193: Schinke. T. and Karsenty, G. Vascular calcification-a passive process in need of inthibitors. Nephrol Dial Tramsplant (2000) $15: 1272-1274$.

194: Schmid, FX. Protein sitructure, a practical approach. (1989) IRL Press Oxfard.

195: Schmid, K. McSharry, W.O., Pameijer, C.H. and Binette, I.P. Chemical and physicochemical studies on the mineral deposits of the human atherosclerotic aorta. Atherosclerosis (1980) 37: $199-210$.

196: Schnolzer M. Alewood, P., Jones, A., Alewood, D. and Kent, 5.B. In situ neutralization in Boc-chemistry solid phase peptide synthesis. Rapid, high yield assembly of difficult sequences. Int I Pept Protein Res (1992) 40: 180-193.

197: Schurgers, L.t., Dissel, P.E., Spronk, H.M., Soute, B.A., Dhore, C.R., Cleutjens, J.P. and Vermeer, $C$. Role of witamin $K$ and vitamin $K$-dependent proteins tin vascular calcification. Z Kardial (2001) 90 Suppl 3: 57-63.

198: Schurgers, L.J. Geleijnse, J.M., Grobbee, D.E., Pols. H.A.P., Hofman, A., Witteman, A.C.M. and $C$, vermeer, $C_{n}$ Nutritional intake of vitamins $k-1$ (phylloquinone) and $K-2$ (menaquinonel in The Netherlands. I Nutr Environm Med (1999) 9: 115-122.

199: Schurgers, L.J. and Vermeer, C. Determination of Phylloquinone and Menaquinones in Foodl. effect of food matrix on circulating vitamin $K$ concentrations, Haemostosis (2000) 30: $298-307$.

200: Schurgers, L.J. and Vermeer, C. Differential lipoprotein transport pathways of K-vitamins in healthy subjects. Biochim Biophys Acto (2002) 1570: 27-32.

201: Shanahan, C.M., Cary. N.R., Metcalfe, J.C. and Weisisberg, P.L. High expression of genes for calcification-regulating proteins in human atherosclerotic plaques. J Clin lnvest (1994) 93: $2393 \div 2402$.

202: Shanahan, C.M. Cary, N.R., Salisbury, J.R., Proudfoot, D., Weissberg, P.L. and Edmonds, M.E. Medial Localization of Mineralization-Regulating Proteins in Association With Monckeberg's Sclerasis : Evidence for Smooth Muscle Cell- Mediated Vascular Calcifteatiom. Cifculation (1999) 100: 2168-2176.

203: Shanahan, C.M., Weissberg. P.th. and Metcalfe, I.C. Isolation of gene markers of differentiated and proliferating vascular smooth muscle cells. Circ Res (1993) 73: 193-204.

204: Shearer, M.I. Vitamin K, Lancet (1995) 345:229-234.

205: Shearer, M.I. McBurney, A. and Barkhan, P. Studies on the absorption and metabotism of phylloquinone (vitamin K1) in man. Witam Horm (1974) 32: 5.13-542.

206: Sheikh, M.S., Shao, .2.M., Chen, H.C. and Fontana, J.A. Differential regulation of matrix Gla prote in (MGP) gene expression by retinoic acid and estrogen in human $b \quad r$ a $s t$ carcinoma cells. Mol Cell Endocrinol (1993) 92: 153-160.

207: Shioi, A., Nishizawa, Y., Jono, S. Koyama, H., Hosoi, M. and Morii, H. Beta-glycerop hosphate accelerates calcification in cultured bowine vascular smooth muscle cells. Arterioscler Thromb Vasc Biol (2995) 15: 2003-2009.

208: Simons, D.B., Sichwartz, R.S., Edwards, W.D., Sheedy, P.F, Breen, J.F. and Rumberger, ע.A Nonimvasive definition of anatomic cononary artery disease by ultrafast computed toma graphic scanning: a quantitative pathologic comparison study. I Am Coll Cardiol $(1992)$ 20: $1118-1126$. 
209: Soute, B.A. Ulrich, M.M., Watson, A.D., Maditison, H.E., Ebberink, R.H. and Vermeer, C. Congenital deficiency of all vitamin K-dependent blood coagulation factors due to a defective vitamin $k$-dependent carboxylase in Devon Rex cats. Thromb Hoemost (1992) 68: $521-525$.

210: Spronk, H.M., Farah, R.A., Buchanan, G.R., Vermeer, C. and Soute, B.A. Nowal mutation in the gamma-glutamyl carboxylase gene resulting in congenital combined deficiency of all witamin K-dependent blood coagulation factors. Blood (2000) $96: 3650-3652$

211: Spronk, H.M., Soute, B.A., Schurgers, L.., Cleutjens, J.P. Thijssen, H.H., De Mey, J.G. and Vermeer ${ }_{x}$ C. Matrix gla proten accumulates at the border of regions of calcification and normal tissue in the media of the arterial wessel wall. Biochem Biophys Res Commun (2001) 289: $485 \cdot 490$.

212: Stanley, T.B., Humphries, I., High, K.A. and Stafford, D.W. Amino acids responsible for reduced affinities of vitamin $K$-dependent propeptides for the carboxylase. Biochemistry (1999) 38: 15681-15687.

213: Stanley, T.B., Jin, D.Y. Lin, P.J. and Stafford, D.W. The propeptides of the vitamin $X_{\text {* }}$ dependent protieins possess different affinities for the vitamin $K$-dependent carboxylase. 1 Biol Chem (1999) 274: 169.40-16944.

214: Stanley, T.B., Wu, S.M., Houben, R.J., Mutucumarana, V.P and Stafford, D.W. Role of the propeptide and gammanglutamic acid domain of factor IX for in vitro carboxylation by the vitamin K-dependent carboxylase. Biochemistry (1998) 37: 13262-13268.

215: Stary, H.C. The sequence of cell and matrix changes in atherosclepotic lesions of coronary arteries in the firsit forty years of life. Eur Heart / (1990) 11 Suppl E: 3-19.

216: Stearns, D.J., Kurosawa, S., Sims, P.J., Esmon, N.L. and Esmon, C.T. The interaction of a Ca2*-dependent monoclonal amtibody with the protein $\mathrm{C}$ activation peptide region. Evidence for obligatory Ca2+ binding to both antigen and antibody. I Biol Chem (1988) 263: 826-832.

217: Steitz, S.A., Speer, M.Y., Curinga, G., Yang, H.Y., Haynes, P, Aebersold, R., Schinke, T., Karsenty, G. and Giachelli, C.M. Smooth muscle cell phenotypic transition associlated with calcification: upregulation of Cbfa1 and downregulation of smooth muscle lineage markers. Circ Res (2001) 89: 1147-1154,

218: Stenflo, 1., Ferlund, P., Egan, W. and Roepstorff, P. Vitamin K dependent modifications of glutamic acid residues in prothrombin. Proc Notl Acad SCi USA (1974) 71: 2730.2733.

219: Stenflo, J. and Jonsson, M. Protein S, a new vitamin K-dependent protein from bovine plasmai. FEBS Lett (1979) 101: 377-381.

220: Stryer L. Biochemistry. (1988) W.H. Fireeman and Company New York.

221: Sugiura, I., Furie, B., Walsh, C.T. and Furie, B.C. Profactor IX propeptide and glutamate substrate binding sites on the witamin $K$-dependent carboxylase identified by site-directed mutagenesis. I Blat Chem (1996) $271: 17837 \times 17844$.

222: Sugiura, 1. Furie, B., Walsh, C.T. and Furie, B.C. Propeptide and glutamate-containing sub strates bound to the vitamin K-dependent carboxylase convert hits vitamin $K$ epoxidase function from an inactive to an active state. Proc Nafl Acad Sci USA (1997) 94: 9069-9074.

223: Suttie, 1.W. Mechanism of action of vitamin $K$ : synthesis of gamma-carboxyglutamic arid. CRC Crit Rev Biochem (1980) 8: 191-223.

224: Suttie, J.W. Recent adwances in hepatic vitamin $\mathrm{K}$ metabolism and function. Hepatolagy (1987) 7: 367-376.

225: Suttie, H.W. Canfield, L.M. and Shah, D.V. Microsomal vitamin K-dependent carboxylase. Methods Enzymol (1980) 67: 180-185.

226: Suttie, I.W. Mummah Schendel, L.L., Shah, D.V., Lyle, B.J. and Greger, 1L. Vitamin k deficiency from dietary vitamin $K$ restriction in humans. Am / Clin Nutr (1988) 47:475 480.

2.27: Thijssen, H.H. and Drittij Reijnders, M.J. Witamin $K$ idistribution in rat tissues: dietary phylloquinone is a source of tissue menaquinone-4. Br / Nutr (1994) 72: 415-425.

228: Thijssen, H.H.W. Drittij Reijnders, M.J. and Fisther; M.A. Phylloquinone and menaquinone-4 distribution in rats: synthesis rather than uptake determines menaquinone-4 organ concentrations. Nutr (1996) 126: 537-543.

229: Tie, I., Wul, S.M., Jin, D. Nicchitta, C.V and Stafford, D.W. A topological situdy of the human gamma-glutamyl carboxylase Blood (2000) 96: 973-978.

230: Tintul, Y., Parhami, F., Bostrom, K. Jacksom, 5.M. and Demer, L.L. CAMP stimulates 
osteoblast-ihe differentiation of calcifying vascullar cells. Potential signaling pathway for vascular calcification. I Biol Chem (1998) 273: 7547-7553.

231: Tintut, Y. Patel, 1., Parhami, F and Derner, L.L. Tumor necrosis factor-atpha promotes in vitro calcification of vascular cells via the CAMP pathway Itn Process Gitationl. Circulotion (2000) 102: 2636-264:2.

232: Tíntut, Y., Patel, A., Territo, M., Saini, T., Parhami, F. and Demer, L.L. Monocyte/macropha ge regulation of vascular calcification in vitro. Circulation (2002) 105: 650-655.

233: Towibin, H., Staehelin, T. and Gordon, 1. Electrophoretic transfer of proteins from polyacrylamide gets to nitrocellulose sheets: procedure and some applications. Proc Nat Acad SeI USA (1979) 76: 4350-4354.

234: Tsaloun, K.I. Vitamin Kudependent proteins in the developing and aging nervous system. Nutr Rev 12999) $57: 231-240$.

235: Vematsu, T., Nagashima, S., Niwa, M. Kohno, K., Sassa, T., Ishii, M., Tomono, Y, Yamato. $C$ and Kanamart, M. Effect of dietary fat content on aral bioavailability of menatetrenone in humans, / Pharm 5ci (1996) 85: 1012-1016.

236: Ulrich, M.M., Soute, B.A., de Boer-van den Berg. M.A. and Vermeer, C. Isoenzymes of vitamin-K-dependent carboxylase, Biochim Biophys Acta (1985) 830: 105-108.

2377: Urist, M.R., Huo. Y.K., Brownell, A.G., Hohl, W.M., Buyske, 1., Lietze, A., Tempst, P., Hunkapiller, M. and DeLange, R.A. Purfication of bovine bone morphogenetic protein by Ihydroxyapatite chromatography. ProC Not ACad Sci USA (1984) 81: 371-375.

238: van Beek, E., Pieterman, E., Cohen, L., Lowik, C. and Papapoulos, S. Farnesyl pyrophosphate synthase is the molecular target of nitrogen-containing bisphosphonates. Biochem Biophys Res Commun (1999) 264: 108-111.

239: Varnum, B.C. Young, C., Elliott, G., Garcia, A., Bartley, T.D., Fridell, Y.W., Hunt, R.W., Trail, $G_{\text {.. }}$ Clogston $_{n}$ C., Toso, R.J. and et al. Axl receptor tyrosine kinase stimulated by the vitamin K-dependent protein encoded by growth-arresil-specific gene 6. Nature (1995) 373: $623-626$.

240: Vermeer, C. Gamma-carboxyglutamate-containing proteins and the vitamin K-clependent carboxylase. Biochem J (1990) 266: 625-636.

241: Vermeer, $C$, Hendrix, $H$. and Daemen, $M$. Vitamin $K$-dependent carboxylases from nonhepatic tissues. FEBS Lett (1982) 148: $317-320$.

2.42: Vicente, V., Maia, R., Alberca, 1., Tamagnini, G.P. and Lopez Borrasca, A. Conglental deficiency of vitamin $K$-dependent coagulation factors and protein $C$. Thromb Hoemost (1984) 51: 343-3:46.

2.43: Walker, C.S., Shetty, R.P., Clark, K., Kazuko, 5.G., Letsou, A., Olivera, B.M. and Bandyopadinyay, P.K. On a potential global role for vitarnin $K$-dependent gammacarboxylation in animal systems. Evidence for a gamma-glutamyl carboxylase in Drosophila. J Biol Chem (2001) 276: $7769-7774$.

244: Wallin, $R$. Vitamin $K$ antagonism of coumarin anticoagulation. A dehydrogenase pathway in rat liwer is responsible for the antagonistic effect. Biochem /(1986) 236: 685-693.

245: Wallin, R., Cain, D., Hutson, S.M., Sane, D.C. and Loeser, R. Modulation of the binding of matrix Cla protein (MGP) to bone morphogenetic protein-2 (BMP.2). Thromb Haemost (2000) 84: 1039-1044.

246: Wallin, R., Cain D. and Sane, D.C. Matrix Cla protein synthesis and gamma-carboxylation in the aortic vessel wall and proliferating vascular smooth muscle cells - a cell system which resembles the system in bone cells. Thromb Haemost (1999) 82: 1764-1767.

247: Wallin, R. and Hutson, 5. Vitamin K-dependent carboxylation. Evidence that at least two microsomal dehydrogenases reduce vitamin $K_{1}$ to support carboxylation. 1 Biol chem (1982) 257: 1583-1586.

248: Wallin, R. and Martin, L.F. Vitamin K-dependent carboxylatian and vitamin K metabolism in liver. Effects of warforim. I Clin invest (1985) 76: 1879-1884.

249: Wallin, R. and Martin, L.F. Warfarin poisoning and vitamin $K$ antagonism in rat and human (iver. Design of a system in vitro that mimics the situation in wivo. Biochem J (1987) 241: 389-396.

250: Wang, 2, Wang, M., Finn, $\mathbb{F}$, and Carr, B.1. The growth inhibitory effects of vitamins $K$ and their actions on gene expression. Hepotology (1995) 22: 876-882. 
251: Ware, J., Diuguid, D.L. Liebman, H.A., Rabiet, M.J., Kasper, C.K., Furie, B.C., Furie, B. and Stafford, D.W. Factor 1 San Dimas Substitution of glutamine for Arg 4 in the propeptide leads tio incomplete gamma-carboxylation and alltered phospholipid binding properties. 1 Biol Chem (1989) 264: 11401-11406.

252: Waslley. L.C., Rehemtulla, A. Bristol, J.A. and Kaufman, Rs. PACE/furin can process the witamin K-dependent proffactor $\mathrm{X}$ precursor within the secretory pathway. $/$ Biol Chem (1993) 268: $8458 \cdot 8465$.

253: Watanabe, I. Tsukamoto, K., Shiba, T. and Emi, M. Isolation and radiatian thybrid mapping of dirucleotide repeat polymorphism at the human matrix Gla protein (MGP) locus. 1 Hum Genet (1998) 43: 75-76.

254: Watson, K.E., Bositrom, K., Ravindramath, R., Lam, T., Norton, B. and Demer, L.L. TGF-beta1 and 25 -hydroxycholestenol stimulate osteoblast-like vascular cells to calcify. 1 clin invest (1994) 93: 2106-2113.

255: Weintraub, M.S., Eisenberg, S. and Breslow, J.L. Dietary fat clearance in normal subjects is regulated by genetic wariation in apolipoprotein E. / Clin Invest (1987) 80: $1571-1577$.

256: Wiedemanm, M., Trueb, B. and Belluoccio, D. Molecular cloning of avian matrix Gla protein. Biochim Biophys Acta (1998) 1395: 47-49.

257: Wilson, P.W, Kauppila, L.I., O'Donnell, C.J., Kiel, D.P. Hannan, M, Polak, J.M. and Cupples, L.A. Abdominal Aortic Calcific Deposits Are an Important Predictor of Vascular Morbidity and Mortality. Circulation (2001) 103: 1529 1534.

258: Wong. N.D. Hsu, I.C. Detramo, R.C., Diamond, G Eisenberg, H. and Gardin, I.M. Coronary antery calcium evaluation by electron beam computed tomography and its mation to new cardiowascular events. Am I Cardiof (2000) 85: 495-498.

259: Wood, G.M. and Suttie, I.W. Vitamin K-dependent carboxylase. Stoichiometry of vitamin $K$ epoxide formation, gammal-carboxyglutamyl formation, and gamma-glutamyl-3H cleavage.) Biol Chem (1988) 263: 3234-3239.

260: Wu, S.M., Cheung, W.F., Frazier, D. and Stafford, D.W. Cloning and expression of the CDNA for human gamma-glutamyll carboxylase. Science (1991) 254: 1634-1636.

261: Wu, S.M., Morris, D.P. and Stafford, D.W. Idientification and purification to near homogeneity of the vitamin K-dependent carboyylase. Proc Notl Acad Sci USA (1991) 88:22362240 .

262: Wu, S.M., Mutucumarana, W.P., Geromanos, S. and Stafford, D.W. The propeptide binding site of the bovine gammanglutamyl carboxylase. J Biol Chem (1997) 272: 11718-11722.

263: Wu, S.M., Soute, B.A., Vermeer, C. and Stafford, D.W. In vitro gamma-carboxylation of a 59-residue recombinant peptide including the propeptide and the gammacarboxyglutamic acid domain of coagulation factor $\mid X$. Effect of mutations near the propeptide cleavage site. Alol Chem (1990) 265: 13124-13129.

264: Wu, 5.M., Stafford, D.W., Frazler, L.D. Fu, Y.Y, High, K.A. Chu, K., sanchez Vega, B. and Solera, J. Cienomic sequence and transcription start site for the human gamma-glutamyt carboxylase. Blood (1997) 89: 4058-4a62.

265: Wuyts, A., Wan Osselaer, N.. Haelens, A., Samson, 1., Herdewijn, P., Ben-Baruch, A." Oppenheim, I.l. Proost, P. and Van Damme, I. Characterization of synthetic human gramulocyte chemotactic protein 2: usage of chemokine receptors CXCR1 and CXCR2 and in wivo inflammatory properties. Biochemistry (1997) 36: 2716-2723.

266: Yagami, K., Sult, J.Y., Enomoto-lwamoto, M., Koyama, E., Abrams, W.R., Shapiro, I.M., Pacifici, M. and Iwamoto. M. Matrix GliA protein is a developmental regulator of chondrocyte mineralization and, when constitutively expressed, blocks endochondral and intramembranous ossificathon in the limb / Cell Biol (1999) 147: 1097-1108.

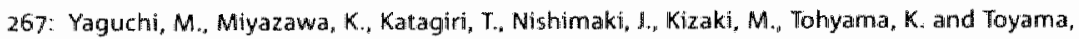
$k$. Witamin $K_{2}$ and its derivatives induce apoptosis in teukemia cells and entance the effect of all-trans retinoic acid. Leukemio (1997) 11: 779-787.

268: Yamada, M., Kutiopulos, A., Nelson, N.P., Roth, D.A., Furie, B., Furie, B.C. and Walsh, C.T. Localization of the factor $I X$ propeptide binding site on recombinant vitamin $K$ dependent carboxylase using benzoylphenylalanine photoaffinity peptide inactivators. Biochemistry (1995) 34:481-489.

269: Zebboudj. A.F. Imura, M. and Bostrom, K. Matrix GLA protein, a regulatory protein for bone morphogenetic protein-2. I Biol Chem (2002) 277:4388i-4394. 
270: Zhao, t. and Warburton, D. Mathx cla protein gene expression is induced by transforming growth factorbeta in embryonic lung culture. Am) Physiol (1997) 273: L282-287.

271: Zhu, $A$, zheng, $X$, and Cinsburg. D. Charecterization of the mouse gamma-carboxylase genomic locus and its promoter, Genbank, Accession rumber: NMo19802. (2000) 